\title{
Optimization of Two-Way Post-Tensioned Concrete
}

\section{Floor Systems}

\author{
A Thesis \\ presented to \\ the Faculty of California Polytechnic State University, \\ San Luis Obispo
}

In partial fulfillment

of the Requirements for the Degree

Master of Science in Architecture with a Specialization in Architectural Engineering

by

Gaelyn Krauser

October 2009 
(C) 2009

Gaelyn Krauser

ALL RIGHTS RESERVED 


\section{COMMITTEE MEMBERSHIP}

TITLE:

OPTIMIZATION OF TWO-WAY POST-TENSIONED CONCRETE FLOOR SYSTEMS

AUTHOR: Gaelyn Krauser

DATE SUBMITTED: October 2009

COMMITTEE CHAIR: $\quad$ Peter Laursen, Ph.D., P.E.

COMMITTEE MEMBER: James R. Cagley, P.E., S.E.

COMMITTEE MEMBER: Kevin Dong, S.E. 


\section{ABSTRACT \\ Optimization of Two-Way Post-Tensioned Concrete Floor Systems}

\section{Gaelyn Krauser}

This thesis investigates a parametric study of a flat plate floor system designed using post-tensioning. The load balanced by the post-tensioning, the slab depth, and the strength of concrete were varied to create the parametric study of a hotel/condominium grid layout. In order to perform the parametric study, research was conducted on the development of post-tensioning, methods of analysis for two-way slab design, and posttensioning methods of analysis. Design was conducted by hand through a series of Excel spreadsheets and compared to results found using the computer analysis program, ADAPT-PT. The designs found in the parametric study were then used to perform a cost analysis across ten cities in the United States: Atlanta, Boston, Chicago, Denver, Houston, Los Angeles, Miami, Phoenix, San Francisco, and Seattle.

The designs from the hand analysis and the ADAPT-PT model provided similar results for the post-tensioning, and both methods provide an adequate design. The use of ADAPT-PT is recommended because of its ease of use and quick calculation capabilities. The designs of the hand analysis were quantified and along with unit prices gathered from contractors and suppliers the cost analysis found that the design with $100 \%$ of the dead load balanced provided the least expensive solution for all the cities, and the design using a 6000 psi strength concrete provide the most expensive solution for all cities. The least expensive slab design was $\$ 9.02$ per square foot in Atlanta, Georgia, and the most expensive slab design was $\$ 24.96$ per square foot in Miami, Florida. A more rigorous parametric study in the future may provide a better optimization for the hotel/condominium slab investigated as the parametric study of this thesis found costs which varied by less than $10 \%$ between the most expensive and least expensive slabs in the ten cities.

Keywords: Post-tensioning, cost analysis, two-way concrete design, parametric study. 


\section{ACKNOWLEDGEMENTS}

I would like to thank Gerard McGuire from ADAPT Corporation for generously allowing me to use ADAPT-PT for the analysis in my thesis. I would also like to thank all of my industry contacts who were willing to give me the cost estimate information that made my cost analysis possible. I would like to thank my father, Larry Krauser, for providing me with the industry contacts and for all his help and advice throughout the process of writing this thesis. Finally, I would like to thank my advisors, Jim Cagley, Kevin Dong, and Peter Laursen, for their help reviewing my work and writing. 


\section{TABLE OF CONTENTS}

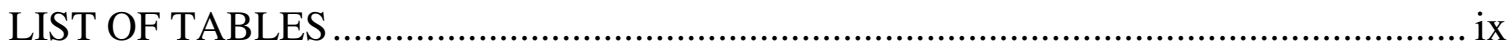

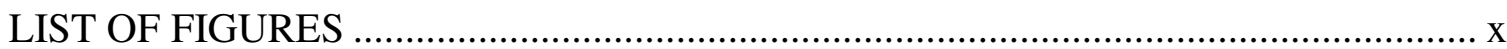

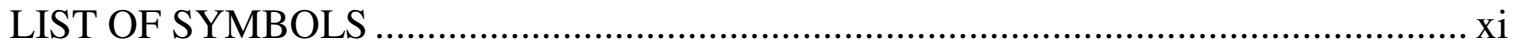

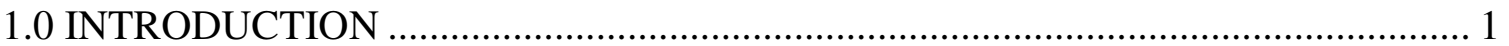

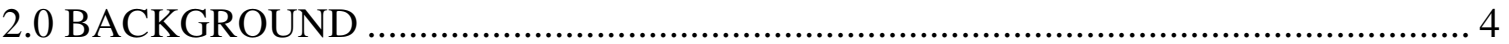

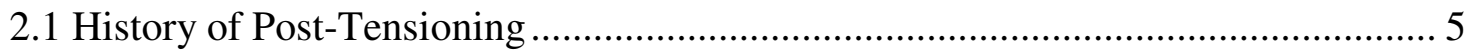

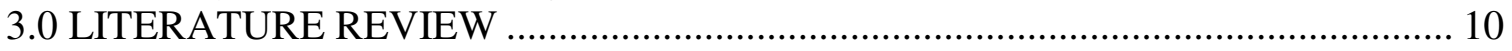

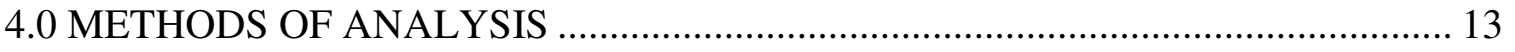

4.1 Yield-Line Analysis ................................................................................... 13

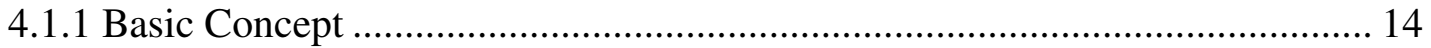

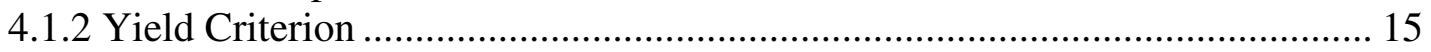

4.1.3 Methods of Solution............................................................................... 16

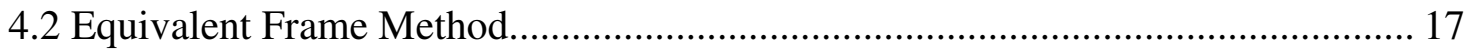

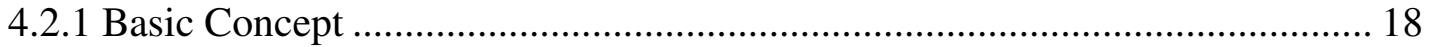

4.2.2 Moment Distribution............................................................................. 19

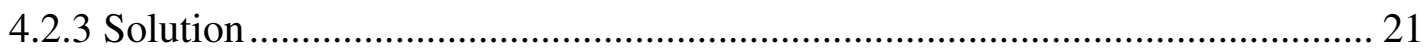

4.3 Post-Tensioning Analysis Procedure ………………................................... 22

4.3.1 Initial Analysis ..................................................................................... 23

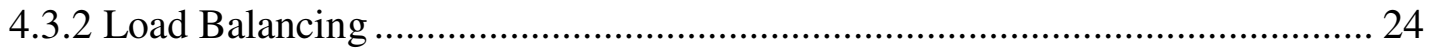

4.3.3 Code Compliance....................................................................................... 26

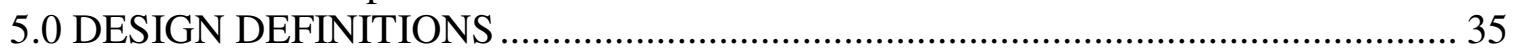

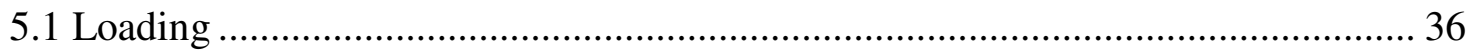

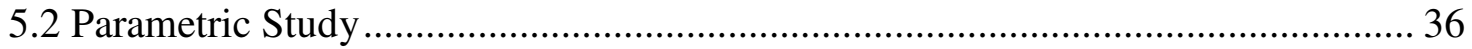

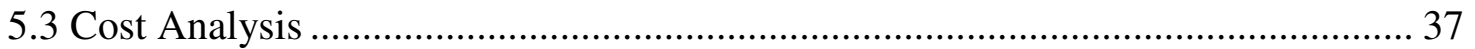

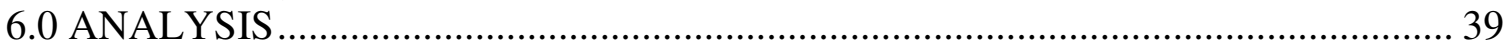

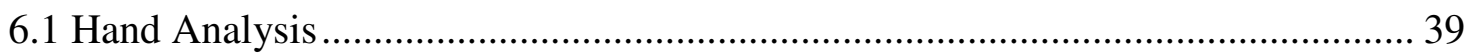

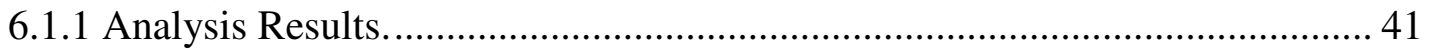

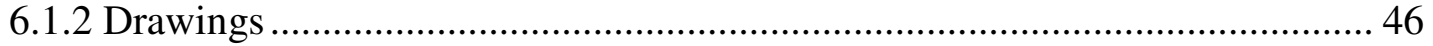

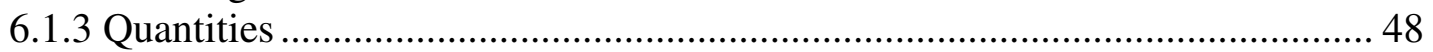

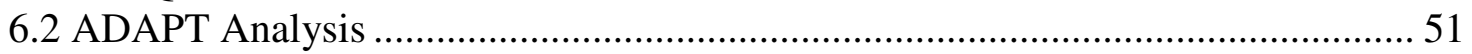

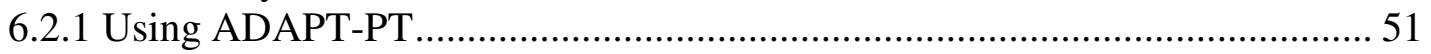

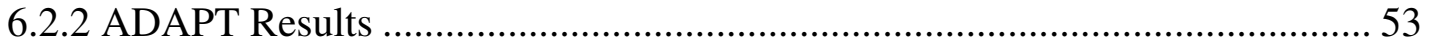

6.3 Comparison Between Hand and ADAPT-PT Designs ............................................ 61

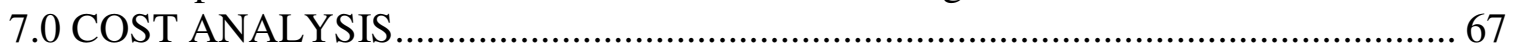

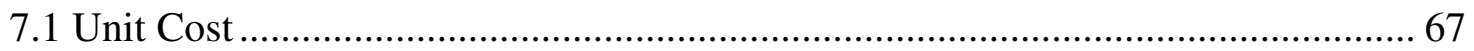

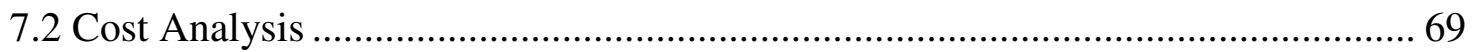

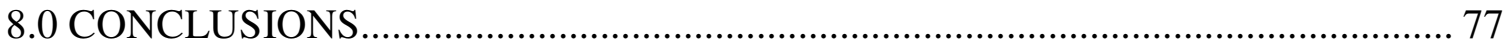

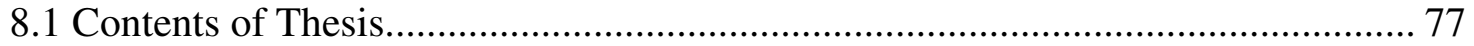

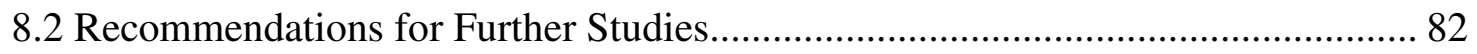

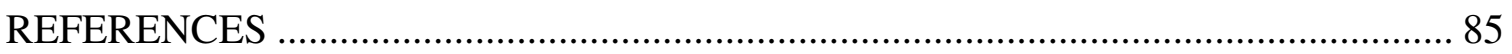

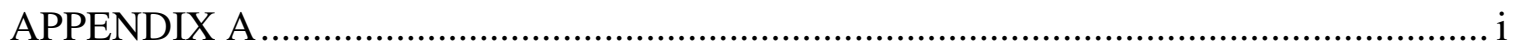

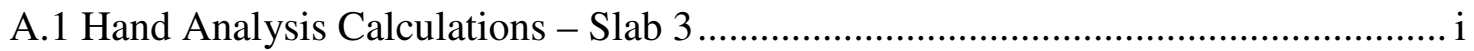

Optimization of Two-Way Post-Tensioned Concrete Floor Systems 


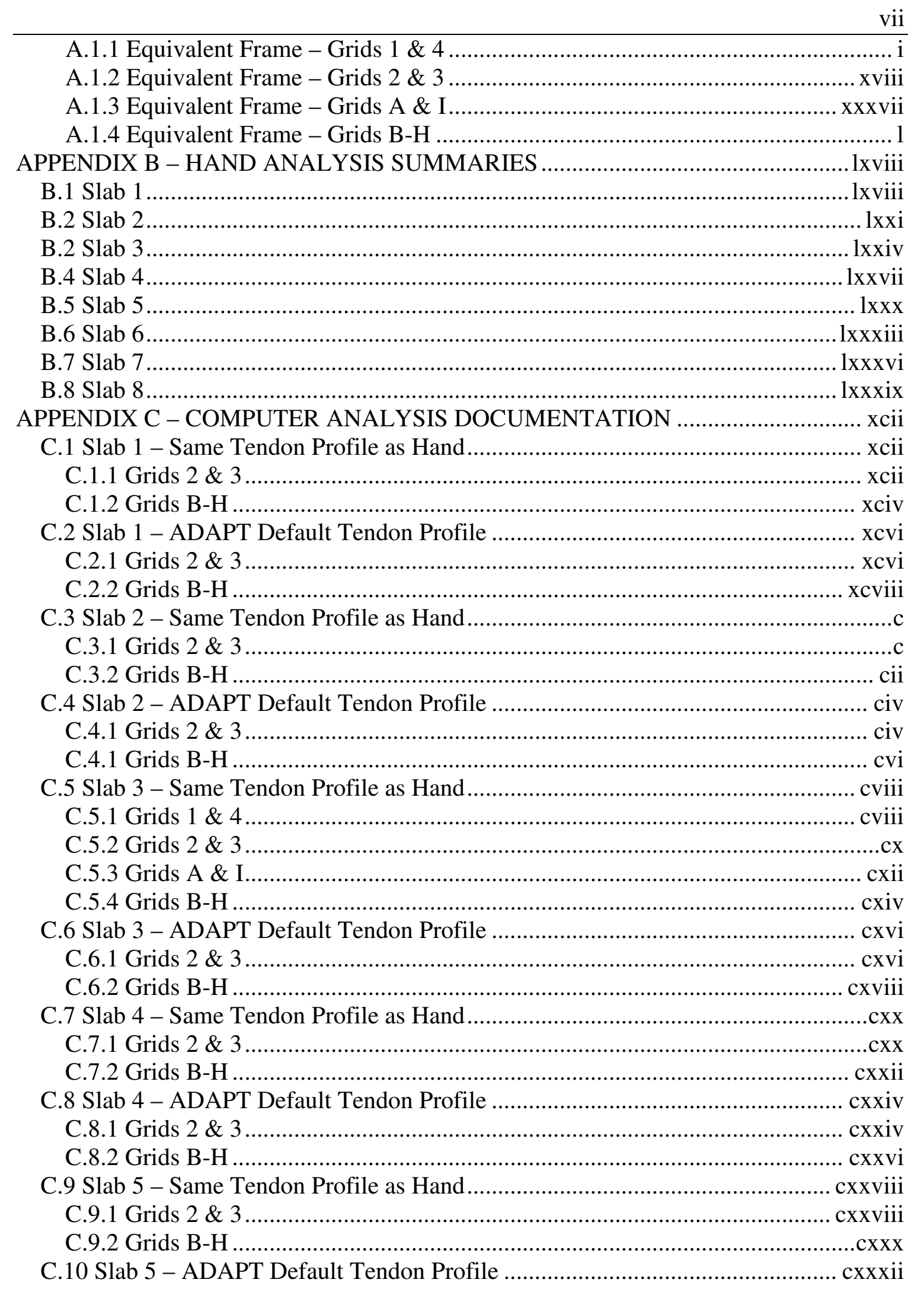


viii

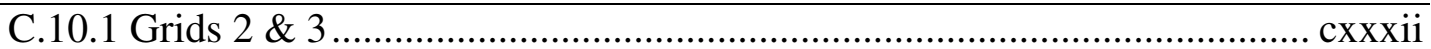

C.10.2 Grids B-H ................................................................................. cxxxiv

C.11 Slab 6 - ADAPT Default Tendon Profile ................................................... cxxxvi

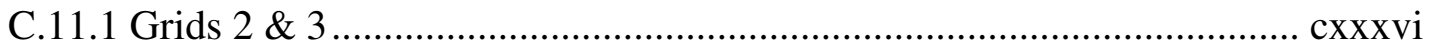

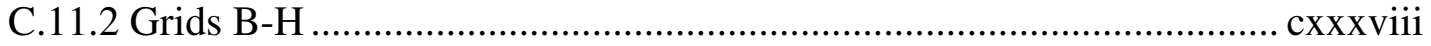

C.12 Slab 7 - ADAPT Default Tendon Profile ......................................................... cxl

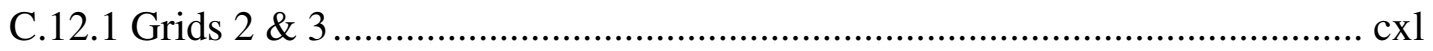

C.12.2 Grids B-H ............................................................................................. cxlii

C.13 Slab 8 - ADAPT Default Tendon Profile .................................................... cxliv

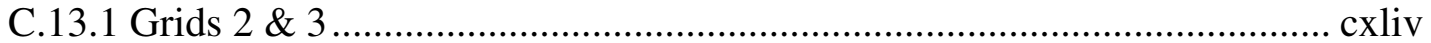

C.13.2 Grids B-H .......................................................................................... cxlvi 


\section{LIST OF TABLES}

Table A: Required Checks for Design.... 28

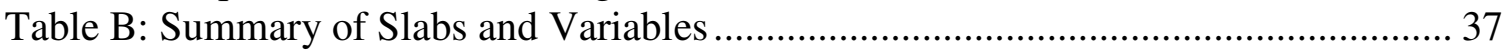

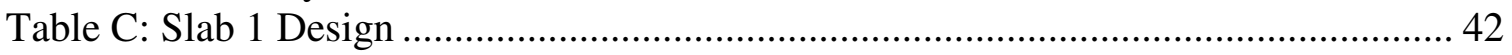

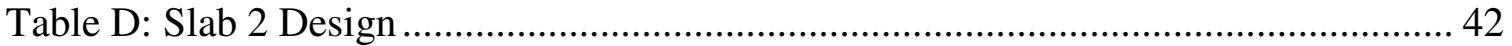

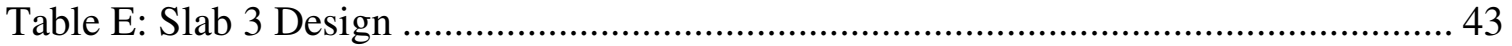

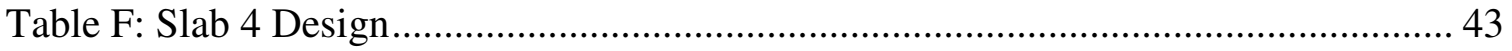

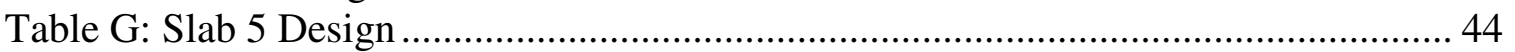

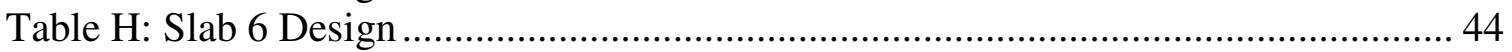

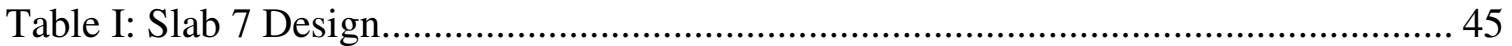

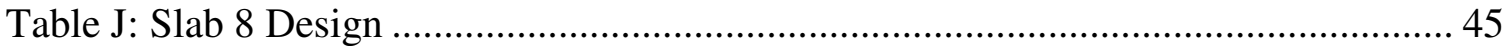

Table K: Summary of Analysis Results..................................................................... 48

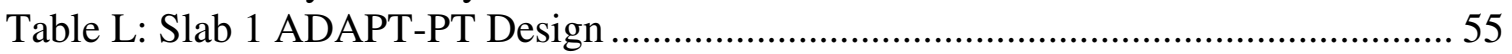

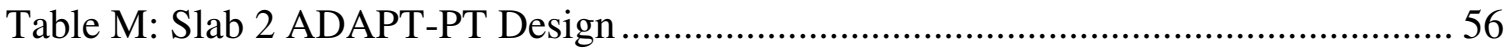

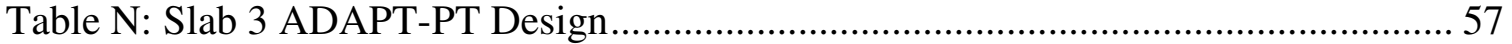

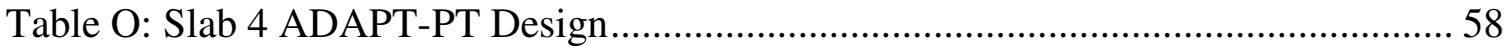

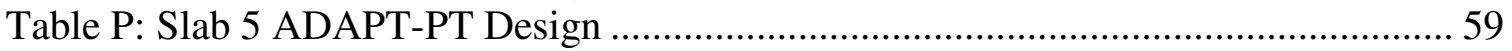

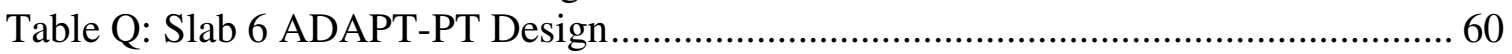

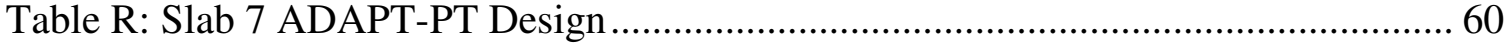

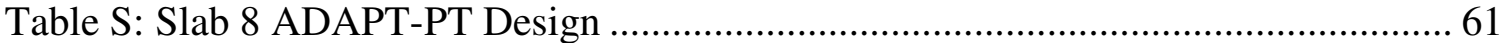

Table T: Comparison of Post-Tensioning Strand Requirements ...................................... 62

Table U: Comparison of Non-Prestressed Reinforcing Requirements ............................. 63

Table V: Material and Installation Prices for 10 U.S. Cities ............................................. 68

Table W: Adjusted Material Quantities ...................................................................... 70

Table X: Slab Prices for 10 U.S. Cities .................................................................... 71

Table Y: Slab Price per Square Foot for 10 U.S. Cities ................................................. 72

Table Z: Price for Each Material and Installation in Slab 1 and Slab 8.......................... 73 


\section{LIST OF FIGURES}

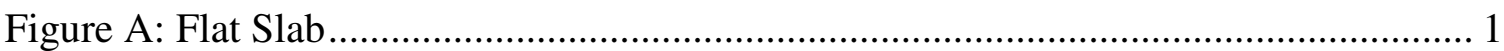

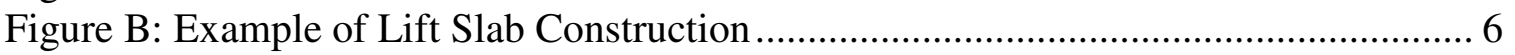

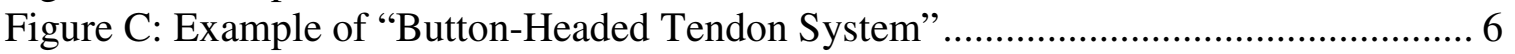

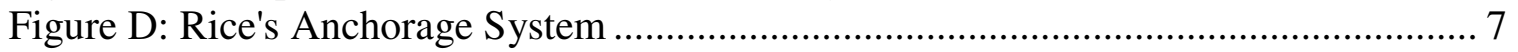

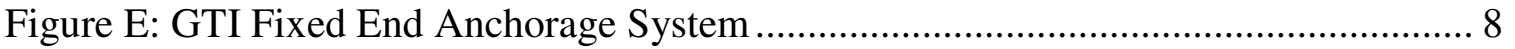

Figure F: Yield-Line Formation......................................................................... 14

Figure G: Equilibrium of an Angled Yield-Line ........................................................ 16

Figure H: Definition of Column and Middle Strips ................................................. 18

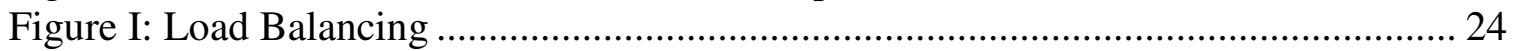

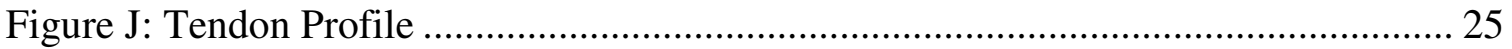

Figure K: Non-prestressed Reinforcement Requirements ......................................... 27

Figure L: Punching Shear for Interior Columns .................................................... 29

Figure M: Punching Shear for an Exterior Column................................................ 30

Figure N: Punching Shear for Corner Columns.......................................................... 31

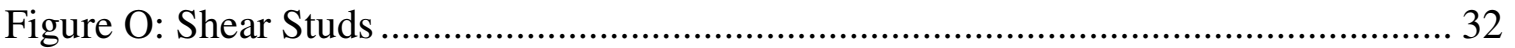

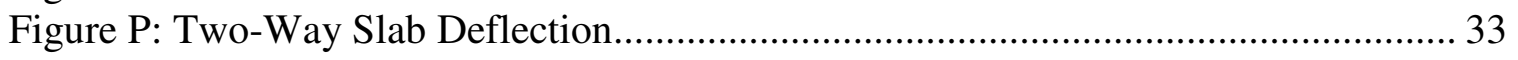

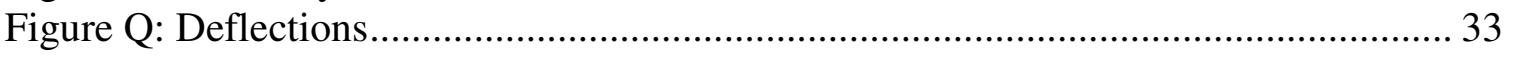

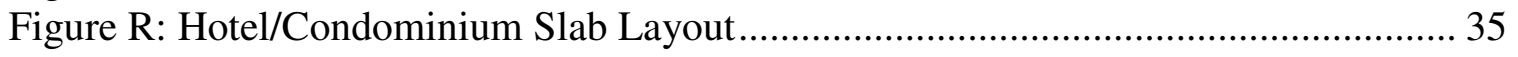

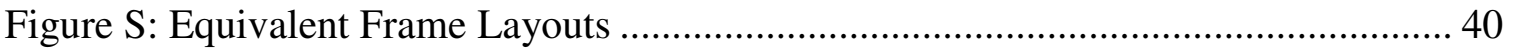

Figure T: Drawing Designations for Post-tensioning Layouts .................................. 46

Figure U: Drawing Designations for Rebar Layouts .................................................. 47

Figure V: Comparison of Rebar and Post-Tensioning Weight for Each Variable in the

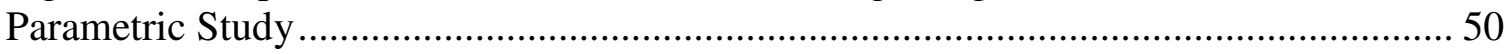

Figure W: ADAPT-PT Model for Equivalent Frame for Grids B through H.................. 52 


\section{LIST OF SYMBOLS}

$\mathrm{A}_{\mathrm{c}}$

$\mathrm{A}_{\mathrm{s}}$

$\alpha_{\mathrm{s}}$

$\mathrm{b}_{0}$

$\beta_{\mathrm{p}}$

$\gamma_{\mathrm{f}}$

$\gamma_{\mathrm{v}}$

d

D

$\delta$

$\Delta_{\mathrm{c}}$

E

$\mathrm{f}_{\mathrm{c}}{ }^{\prime}$

$f_{y}$

$\mathrm{h}$

$\theta$

I

$\mathrm{k}$

K
Area of concrete section resisting shear transfer

Area of nonprestressed longitudinal tension reinforcement

Constant used to compute $\mathrm{V}_{\mathrm{c}}$ in slabs and footings

Perimeter of critical section for punching shear

Factor used to compute $\mathrm{V}_{\mathrm{c}}$ in prestressed slabs

Factor used to determine the unbalanced moment transferred by flexure at slab-column connections

Factor used to determine the unbalanced moment transferred by eccentricity of shear at slab-column connections

Distance from extreme compression fiber to centroid of longitudinal tension reinforcement

Dead load

Deflection, also, the drape of the tendon in a tendon profile

Deflection of the centroid of a plate segment in yield-line analysis

Modulus of elasticity

Specified compressive strength of concrete

Specified yield strength of reinforcement

Thickness of a slab

Angle change at the yield line in yield-line analysis

Moment of inertia

Stiffness factor used in moment distribution

Relative stiffness of a section 


\begin{tabular}{|c|c|}
\hline$\overline{\mathrm{K}_{\mathrm{c}}}$ & Relative stiffness of a column \\
\hline $\mathrm{K}_{\mathrm{ec}}$ & Equivalent column stiffness to include torsional effects \\
\hline $\mathrm{K}_{\mathrm{t}}$ & $\begin{array}{l}\text { Torsional stiffness of attached torsional members used to calculate } \\
\mathrm{K}_{\mathrm{ec}}\end{array}$ \\
\hline 1 & Length \\
\hline $\mathrm{L}$ & Live load \\
\hline $\mathrm{m}_{\mathrm{b}}$ & Moment due to bending \\
\hline $\mathrm{m}_{\mathrm{t}}$ & Moment due to twisting \\
\hline $\mathrm{m}_{\mathrm{x}}$ & Resisting moment of the reinforcement in the $\mathrm{x}$-direction \\
\hline $\mathrm{m}_{\mathrm{y}}$ & Resisting moment of the reinforcement in the y-direction \\
\hline $\mathrm{N}_{\mathrm{c}}$ & Tension force in concrete due to unfactored dead plus live load \\
\hline$v_{\mathrm{c}}$ & Nominal shear resistance provided by concrete \\
\hline$v_{\mathrm{s}}$ & Capacity of shear reinforcement \\
\hline$v_{\mathrm{u}}$ & Shear stress demand on section \\
\hline$\sigma_{\mathrm{g}}$ & Average prestress \\
\hline$\phi$ & Strength reduction factor \\
\hline $\mathrm{V}_{\mathrm{p}}$ & Vertical component of effective prestress fore at section \\
\hline $\mathrm{V}_{\mathrm{s}}$ & Nominal shear strength provided by shear reinforcement \\
\hline W & Uniform load, weight per length \\
\hline $\mathrm{w}_{\mathrm{b}}$ & Balanced uniform load, weight per length \\
\hline $\mathrm{W}_{\mathrm{nb}}$ & Unbalanced uniform load, weight per length \\
\hline $\mathrm{W}$ & Total applied load \\
\hline
\end{tabular}




\subsection{INTRODUCTION}

The purpose of this Master's thesis is to investigate two-way post-tensioned floor design and how the variation of load balancing, slab depth, and concrete strength changes the slab design, culminating in recommendations for post-tensioned design to help determine the most cost-effective solution for a project. This thesis will increase our understanding of the relationship between two-way slab analysis, the post-tensioning design process, and cost-analysis for building practices.

This thesis will require knowledge of the methods for analyzing two-way concrete slab systems as well as design specific to post-tensioned concrete. For the two-way posttensioned floor system, analysis focuses on the flat plate, as illustrated in Figure A below. The flat plate will be analyzed according to a grid system commonly associated with

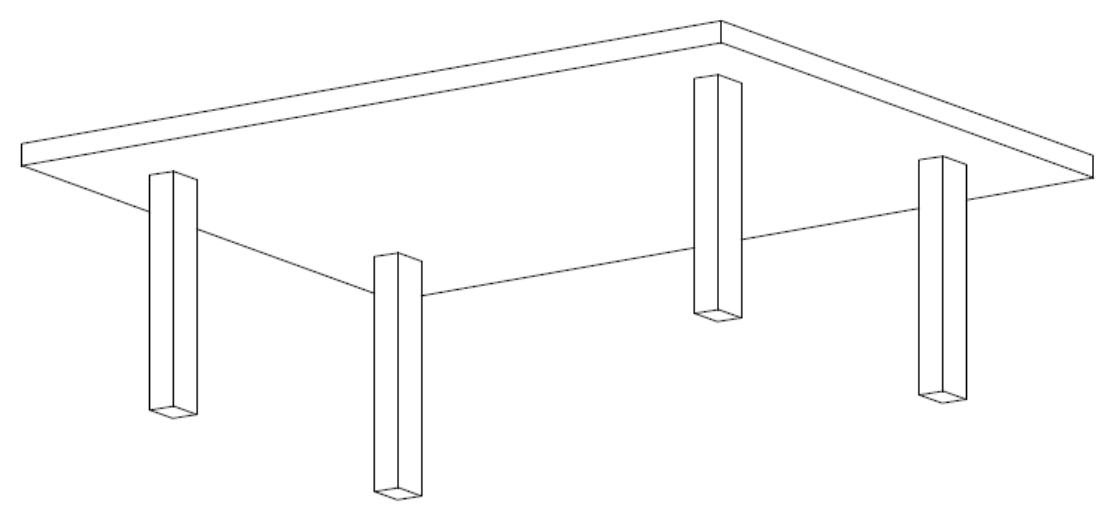

\section{Figure A: Flat Slab}

condominiums and hotels, with an overall footprint of $208^{\prime}$ by $66^{\prime}$, and according to the American Concrete Institute Building Code Requirements for Structural Concrete (ACI 318-05). Design variables will include the amount of load balanced by the post- 
tensioning force, the slab depth, and the strength of concrete. The hand calculations will be treated as an initial analysis of a slab for cost estimate purposes to be further refined in the design process until a final solution is decided upon. Therefore, some assumptions have been made and some checks will not be performed to achieve this initial design, creating slab designs which would be modified in the field as the construction process progresses. In addition to hand calculations, $\mathrm{ADAPT}^{1}$ software will be used to analyze the floor systems, providing a comparison between the computer program solution often used in practice and the solution found in the hand calculations. Parameters for the cost analysis include location, cost of materials, and cost of labor. These parameters, combined with the parameters for design, determine the optimization of the floor system for a building project.

The thesis will progress through the following topics, ending with the conclusions obtained from the analysis performed. First, a background and history of post-tensioning in the United States will describe the development of post-tensioned concrete design. Next, a brief literature review will be presented on the research into this subject conducted to date, followed by an outline of yield-line analysis, equivalent frame analysis, and post-tensioning design procedures learned by the author in order to complete the analysis for this thesis. Presented next is the hand and computer analysis conducted during the parametric study and the respective results. Finally, the cost analysis will be presented with an estimated price for each of the slabs designed in the

\footnotetext{
${ }^{1}$ ADAPT makes software packages for post-tensioned design. Their website is www.adaptsoft.com.
} 
1.0 Introduction 3

parametric study for the ten geographical locations in the United States chosen for the cost analysis. 


\subsection{BACKGROUND}

Post-tensioning is a method of reinforcing concrete using prestressed steel in combination with non-prestressed reinforcement. This highly specialized segment of the construction industry requires complex engineering analysis that often limits its use to firms who have experience with and specialize in post-tensioning. The Post-Tensioning Institute $^{1}$ explains post-tensioning in the Post-Tensioning Manual as a method in which "[t]he force and profile of the [post-tensioning] tendons is designed to produce loads that counteract a portion of the gravity loads which results in the reduction of flexural tensile stresses and deflections" (Gupta 2006). Most structures in the United States which incorporate post-tensioned design may be referred to as "partially prestressed" because they contain both prestressed reinforcing and non-prestressed reinforcing. This combination allows tension and cracking under full service loads but is adequate for the ultimate strength requirements (Naaman 2004).

For post-tensioned concrete design, an engineer specifies the quantity and profile of the post-tensioning forces after completing an analysis of the building. The contractor then installs the tendons and the non-prestressed reinforcement as designated by the engineer on the building plans. Concrete is placed around the strands and rebar, and once the concrete cures to a specified strength, the tendons are tensioned. Post-tensioning can be compared with "pre-tensioning," in which the tendons are stressed prior to pouring the concrete, and released after the concrete has cured.

\footnotetext{
${ }^{1}$ The Post-Tensioning Institute (PTI), formed in 1976, provides research, technical development, marketing, and promotional activities for companies engaged in post-tensioned prestressed construction. Their website is http://www.post-tensioning.org.
} 


\subsection{History of Post-Tensioning}

Eugene Freyssinet began to use high-strength steel wires for prestressed concrete in 1928. Between 1928 and 1939 he developed the first practical system of posttensioning and designed conical shaped wedges for anchoring the wires (Gupta 2006). The early systems used multi-wire tendons grouted in large ducts, which were cast into the concrete section (Stevenson 1994). This practice is referred to as "bonded" posttensioning because the grout creates a bond between the concrete and the strand (Truby 2005). Most early applications of post-tensioning were in bridge design due to the fact that bonded systems require areas large enough to fit the ducts (Stevenson 1994). The first use of post-tensioning in the United States was the Walnut Lane Bridge in Philadelphia in 1949 which used bonded post-tensioning in its precast girders (Gupta 2006).

Building practice in the United States started utilizing post-tensioning in the 1950s in the lift-slab industry. The lift-slab construction method involved pre-casting slabs in a stack on the ground, and then lifting the slabs into place using hydraulic jacks. See Figure B on the next page for an example of this system, which shows the slabs of a building being lifted into place as construction progresses. The slabs often stuck together after being cast and then broke as they were lifted into place. Large deflections also occurred in the slabs due to their long spans. To solve problems associated with this method of construction, the lift-slab industry started utilizing a system of post-tensioning called the "button-headed tendon system." The anchorage pictured in Figure $\mathrm{C}$ on the next page shows a stressing anchor with button head, stressing washer, shim, and bearing 


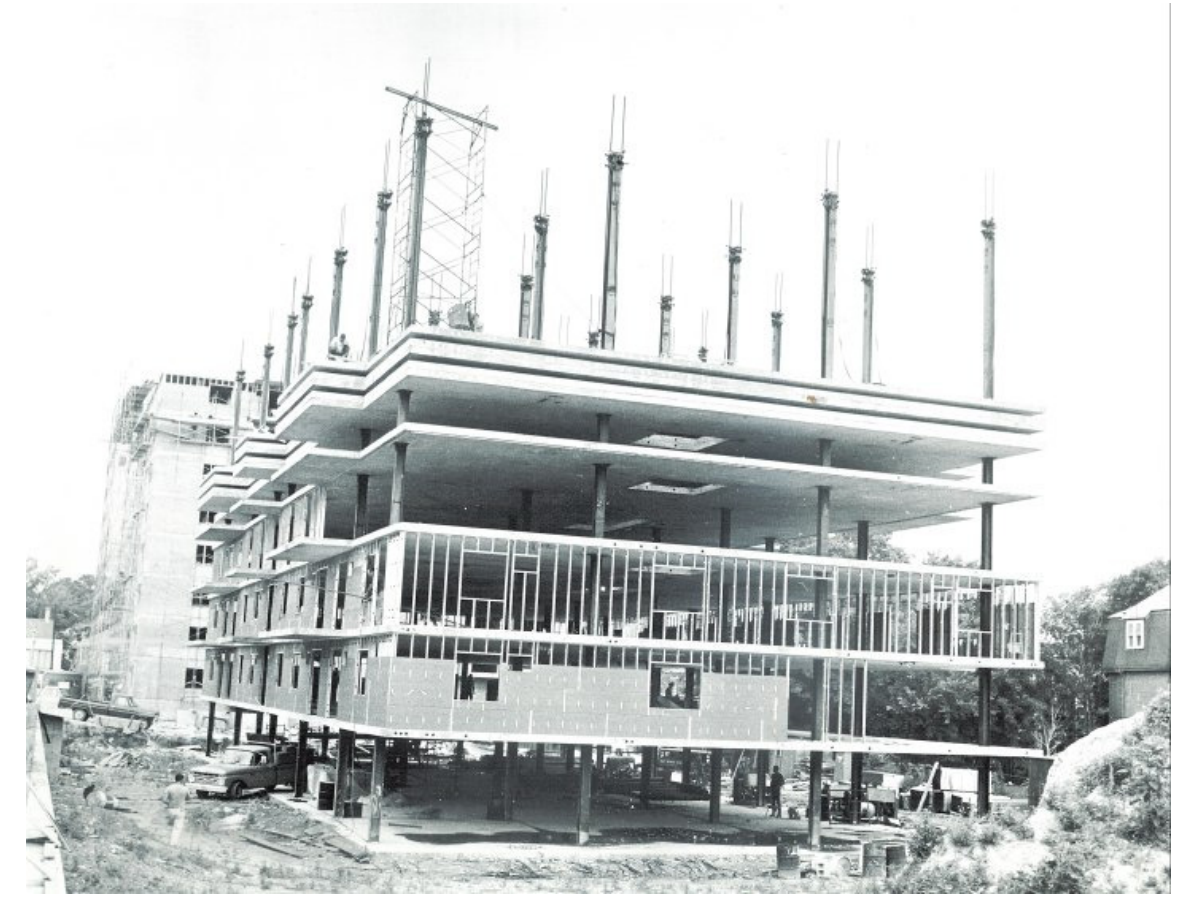

Figure B: Example of Lift Slab Construction

Source: The Baumann Research and Development Corporation website, http://www.brdcorp.com/liftslab.htm

plate. To stress button-headed tendons, a hydraulic jack, attached to the threaded

stressing washer, pulls the tendon until stressed, and then the steel shim is inserted

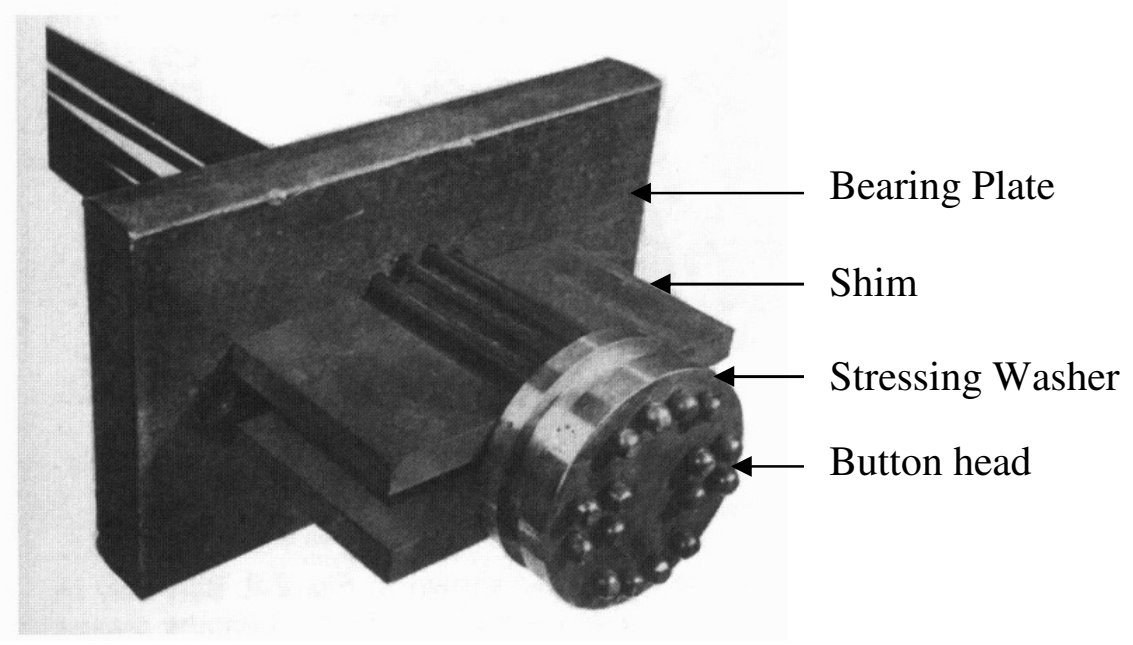

Figure C: Example of "Button-Headed Tendon System" Source: Gupta 2006

Optimization of Two-Way Post-Tensioned Concrete Floor Systems 
between the bearing plate and the stressing washer. Unfortunately, the button-headed tendon system requires precise measurements and construction in order for the system to work properly. To achieve the specified strength of the tendon, the shim length needs to be exactly as long as the calculated elongation. The precision required in construction, along with the need for a second concrete pour to cover the shims and the stressing washer, makes this a cumbersome construction method (Bondy 2001).

In the 1960s, Edward Rice recognized the advantage of strand systems while working for the firm T.Y. Lin International. Post-tensioned strand systems eliminated the need for the exact length of the tendon. Rice invented and patented the first monostrand anchorage system for use in an unbonded post-tensioning system, shown below in Figure D. Today, in unbonded post-tensioning, individual tendon strands are coated with

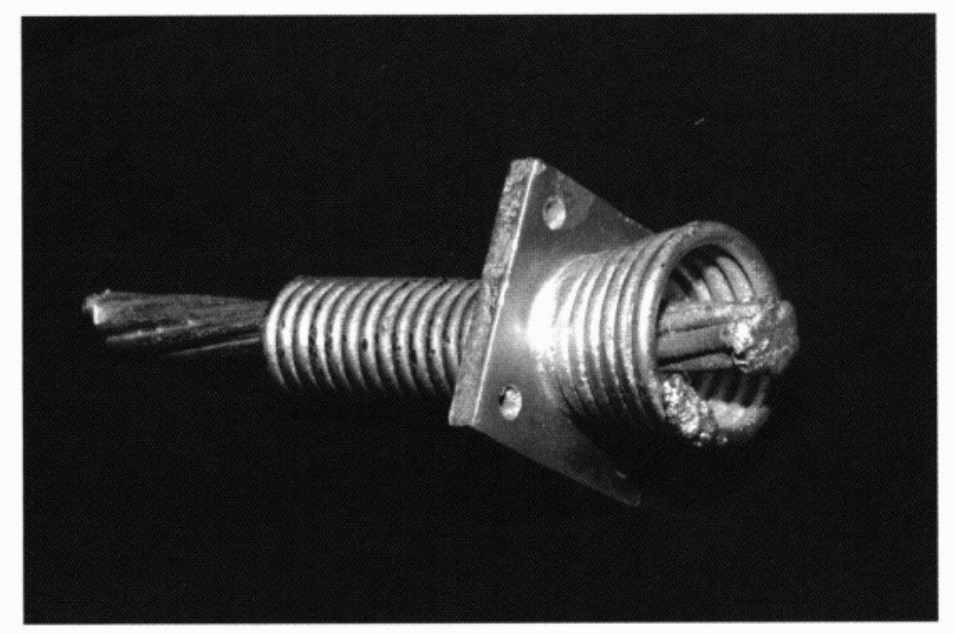

Figure D: Rice's Anchorage System Source: Gupta 2006

corrosion-inhibiting grease and protected by plastic sheathing (Gupta 2006). Because this system is more economical and eliminates the construction issues involved with the button-headed tendon system, it became the post-tensioning system of choice. Rice's 
2.0 Background 8

anchorage system has evolved over the years. Pictured below in Figure E, is an example

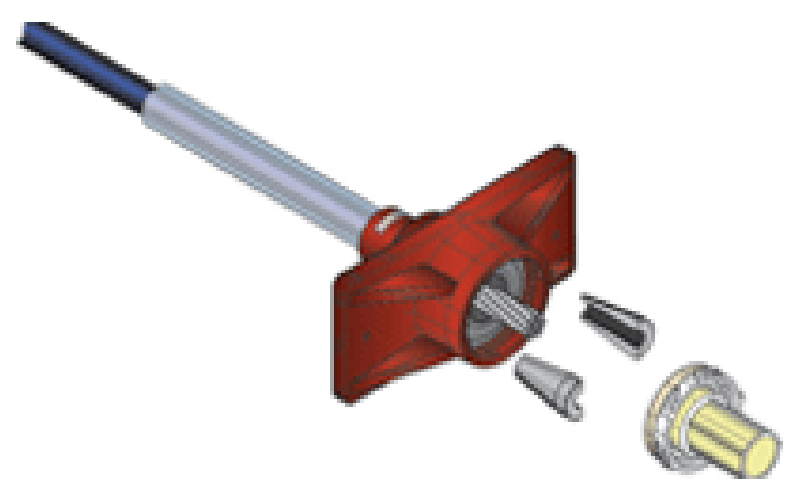

Figure E: GTI Fixed End Anchorage System

Source: GTI website, http://gti-usa.net/0.5-GTI-Zero-Void-Fixed-End-Anchorage.html of a modern anchorage system manufactured by General Technologies, Inc. (GTI). In addition to the fixed end anchors, intermediate anchorage systems have been developed to allow post-tensioning to be used in long slabs which would have otherwise been impossible due to material constraints.

With the introduction of "load balancing" in 1963 by T.Y. Lin, founder of T.Y. Lin International, the popularity of post-tensioning application increased throughout the 1960s and 1970s. Lin proposed simplifying post-tensioning analysis by representing the tendons during the design process with the theoretical loads they would exert upon the concrete member. He then proposed designing the structure for the loads which were not eliminated by the prestressing force with non-prestressed reinforcement (Bondy 2001). Load-balancing is a widely accepted method of design used today in post-tensioning analysis.

Post-tensioning systems provide many benefits. Use of post-tensioning in slabs reduces the amount of concrete required for a structure which offsets increased cost of labor and equipment, decreases the amount of formwork required, decreases the overall 
height of floors which allows more floors for a specified building height, decreases the weight of the building which is a benefit in seismic design, and increases the allowable span length, creating more open space in a structure (Gupta 2006). 


\subsection{LITERATURE REVIEW}

Research into the cost effectiveness of post-tensioned concrete structural systems has been done by Li Shengping and Dr. Robert Tiong, who considered different grid systems and loads to find the most cost effective system for a building in the article "Cost-Effective Reinforced Concrete Structural Systems" (Shengping and Tiong 2004). Shengping and Tiong examined the cost of material, labor, transportation, and necessary equipment. The paper focuses on construction in Singapore and provides an example of how to perform a cost analysis. The variables of material cost and labor cost will be adopted in the cost analysis for this project.

Much has been published on the background and basic principles of posttensioning. An interview of Ken Bondy in Concrete Construction titled "Post-Tensioned Concrete: Five Decades of American Building Construction" recounts his experience and provides good insight into how the post-tensioning industry in the United States evolved (Bondy 2001). Much of the information in the Background section comes from this article.

The article "To Bond or Not to Bond" covers the subject of bonded versus unbonded post-tensioning (Truby 2005). A bonded system is described as a system where the post-tensioning strands are installed within ducts that are filled with cementitious material after the strands have been tensioned, thereby fully bonding the strands to the concrete. Unbonded tendons consist of high-strength, steel strands coated with rustinhibiting, lubricating grease and covered with a high-density polyethylene sheath. Both systems have different ways of transferring load to the tendons from the concrete and 
have different installation procedures, material costs, and applicability to different projects (Truby 2005). Because most post-tensioned slabs in the United States utilize unbonded systems, this thesis focuses its design using unbonded tendons.

The complexity of the post-tensioning design process is a topic often explored in articles to demystify post-tensioning and its variables, such as tendon layout, tendon stressing, and load balancing. Bijan Aalami has published many articles on this subject including "Guidelines for the Design of Post-Tensioned Floors" (Aalami and Jurgens 2003) and "Structural Design of Post-Tensioned Floors" (Aalami and Kelley 2001). These articles include discussions of design guidelines, anchor locations, and additional considerations such as cover for fire resistance, tendon layout, tendon stressing, and selection of nonprestressed reinforcing bar size. When making initial decisions, Aalami suggested looking at the average precompression of the post-tensioning, the percentage of load to balance, and the tendon profile.

VSL, an international firm which designs, manufactures, and installs posttensioning and special construction systems, published a series of reports on posttensioning design and practice. The slab design report from VSL includes design fundamentals, construction procedures, preliminary design guidelines, and detail design (VSL 1985). Another VSL report on post-tensioning in buildings overviews general objectives for building design, applications of post-tensioning in buildings, details and layouts to improve the constructability of the design, and preliminary sizing of posttensioned floors (VSL 1992). Both VSL reports also include related design examples and helped determine analysis procedure for this project. 
Most post-tensioned concrete slab design in the United States uses the concept of "partial prestressing." In his article titled "Partial Prestressing From Theory to Practice," P. Waldron examined the advantages and disadvantages of a partially prestressed system. He explains the idea of partial prestressing as prestressing a structure to a level lower than fully prestressed by providing less area of prestressing steel or stressing the prestressing steel to a lower level, and installing additional unstressed reinforcement to reinforce against the full design moment. Simply put, in partial prestressed slabs, code-specified tensile stresses are allowed under design service loads. Almost all post-tensioned slabs are partially prestressed, but not labeled as such to avoid the misunderstanding that "partial" means the design is not fully completed (Waldron 1984). By varying the load balancing for the slabs designed in this thesis and allowing tensile stresses under the limit $\sqrt{6 f_{c}{ }^{\prime}}$ for two-way slabs, the slabs are considered partially prestressed. 


\subsection{METHODS OF ANALYSIS}

The American Concrete Institute Building Code Requirement for Structural Concrete (ACI 318-05) will govern design for this thesis. Methods of analysis for twoway concrete slabs, as well as methods of analysis for post-tensioned concrete slabs, are presented in accordance with the code requirements. Common methods for analyzing two-way slabs include the direct design method, the equivalent frame method, and the yield-line analysis method. When analyzing post-tensioned slabs, the ACI 318-05 code effectively prohibits use of the direct design method in Section 13.6.1 by requiring all loads analyzed with the direct design method to be due to gravity only. Since the force applied to the slab by the post-tensioning is not due to gravity, the direct design method was not investigated. The Reinforced Concrete: Mechanics and Design textbook provides the basis of understanding for yield-line analysis and equivalent frame method (MacGregor and Wight 2005). Design of post-tensioned concrete slabs in this thesis is generally based on design recommendations by Naaman in his textbook, Prestressed Concrete Analysis and Design (2004).

\subsection{Yield-Line Analysis}

A. Ingerslev first proposed the yield-line analysis method in 1921-1923. K.W. Johansen developed the modern theory used today in his book Yield-Line Theory. This theory is widely used in Scandinavian countries, but is not widely used in the United States. Due to its limited use and the propensity for mistakes in analysis, the yield-line anlysis method will not be used in the actual analysis of the slabs for this thesis. 
However, the method provides a better understanding of slab behavior and theory, and thus is presented here (MacGregor and Wight 2005).

\subsubsection{Basic Concept}

Yield-line analysis uses rigid plastic theory to find both the lines in the slab where the slab will yield and the failure loads corresponding to the moment that causes the yielding. Yield lines are assumed to act like plastic hinges separating elastic plates. The yield lines must be straight because the plates formed in between the yield lines rotate about them. Figure F below illustrates the formation of these yield lines in a

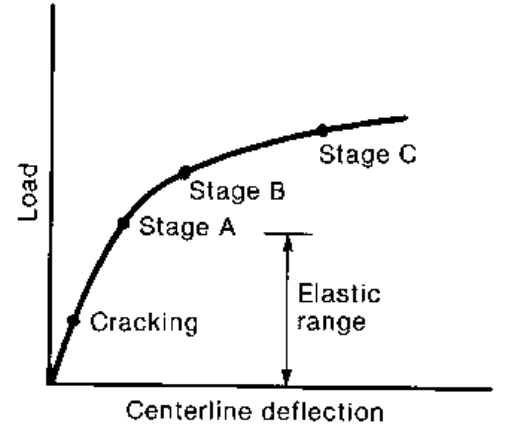

(a) Load-deflection diagram.

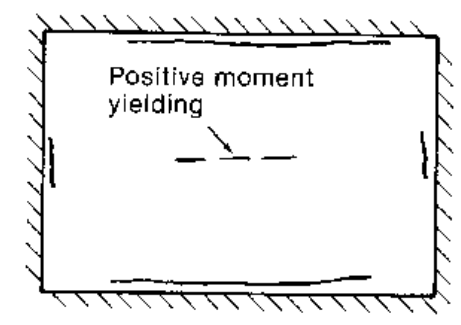

(c) Onset of positive moment ylelding-Stage $B$.

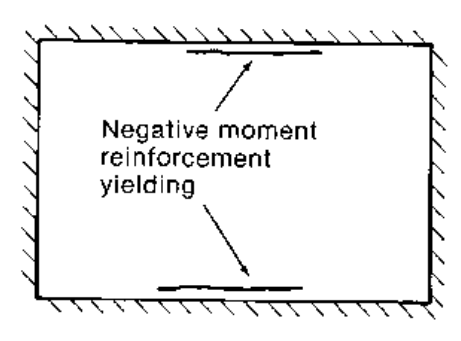

(b) Initial yielding-Stage A.

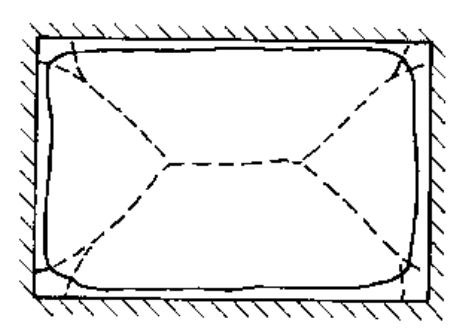

(d) Yield line mechanism-Stage $C$.

Figure F: Yield-Line Formation

Source: MacGregor and Wight 2005

slab. In Figure F, follow (a), a load versus centerline deflection diagram for the slab, through the various stages of yield line analysis. The first yield lines form in (b) at areas 
of highest negative moment. The slab rotates along the yield line as more load is applied because the slab cannot resist more than its yield load at the yield line. The additional moment is redistributed to the elastic areas of the slab. Additional yield lines form in the slab, as shown in (c), and a plastic mechanism eventually forms, as shown in (d). If loads are increased after the formation of this plastic mechanism, the slab collapses. The mechanism shown in (d) corresponds to the plastic mechanism commonly assumed in two-way rectangular slabs (MacGregor and Wight 2005).

\subsubsection{Yield Criterion}

The moment curvature relationship for the yield-line analysis is assumed to be elastic-perfectly plastic. Testing confirms the elastic-perfectly plastic response as a reasonable assumption because slabs rarely exceed $40 \%$ of the steel needed for a balanced concrete section, which creates an essentially elastic-plastic response (MacGregor and Wight 2005). ACI 318-05 defines the capacity of a section as $\phi$ times the nominal strength of the member in Section 9.3, where $\phi$, the strength reduction factor, equals 0.90 for tension controlled sections, 0.65 for compression controlled areas, and 0.75 for areas analyzed for shear and torsion (MacGregor and Wight 2005).

Taking an element represented in Figure $G$ on the next page, the relationships between the resisting moments of the reinforcement, $m_{x}$ and $m_{y}$, the bending moment, $m_{b}$, and the twisting moment, $m_{t}$ are found using equilibrium as follows:

$$
\begin{array}{cc}
m_{b}=m_{x} \sin ^{2} \alpha+m_{y} \cos ^{2} \alpha, & \text { Eq. } 1 \\
m_{t}=\left(\frac{m_{x}-m_{y}}{2}\right) \sin 2 \alpha . & \text { Eq. } 2
\end{array}
$$



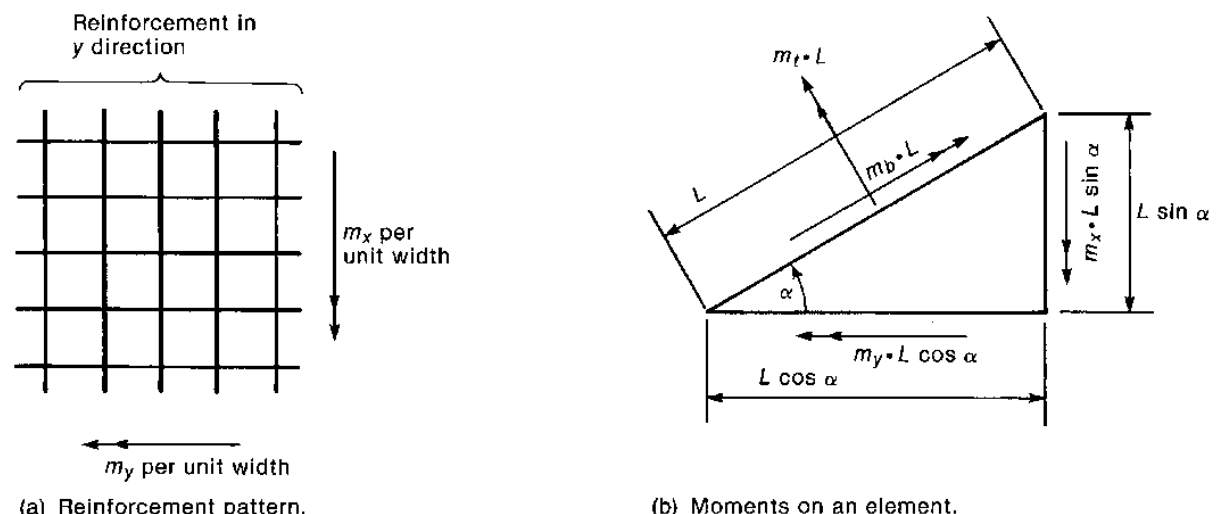

(a) Reinforcement pattern.

(b) Moments on an element

Figure G: Equilibrium of an Angled Yield-Line

Source: MacGregor and Wight 2005

These equations can only be used for orthogonal reinforcing where $m_{x}=m_{y}$, reducing

the equations to

$$
\begin{gathered}
m_{b}=m_{x}=m_{y}, \\
m_{t}=0 .
\end{gathered}
$$

Thus, the reinforcing in both directions resists the bending moment. For yield-lines perpendicular to the reinforcing, only one direction of reinforcement resists the moment (MacGregor and Wight 2005).

\subsubsection{Methods of Solution}

After locating the yield lines in a slab, the moments about the yield lines must be calculated. Either the moment due to applied loads is checked against the moment capacity, or the moment capacity determines the allowable load in yield-line analysis. Two methods exist which calculate the moments along the yield lines. First, the equilibrium method determines equilibrium equations for each plate segment and solves 
for the moments. This method requires considerable care in analysis to ensure that forces are not given the wrong sign or location, thus some building codes prohibit twoway slabs from being analyzed this way. Next, the principle of virtual work may be used to calculate the moments at the yield lines by applying a virtual displacement to the slab. Equation 5 then equates the internal work of the slab (right side) to the external work of the load (left side):

$$
\sum\left(W \Delta_{c}\right)=\sum\left(m_{b} l \theta\right),
$$

where $W$ is total applied load,

$\Delta_{\mathrm{c}}$ is the deflection of the centroid of the plate segment, $m_{b}$ is the bending moment per unit length of yield line,

$l$ is the length of yield line, and

$\theta$ is the angle change at the yield line.

The load derived using virtual work is equal to or higher than the true failure load, i.e. it is an upper bound solution. If an incorrect set of yield-lines is chosen, the derived load carrying capacity will be too large for a given moment and the slab will not perform as expected according to the analysis (MacGregor and Wight 2005).

\subsection{Equivalent Frame Method}

Dean Peabody, Jr. first proposed the equivalent frame method in 1948, which has been incorporated in the ACI Code since 1956. Currently, Section 13.7 of ACI 318-05 describes the equivalent frame method and Section 18.12.1 requires prestressed slab systems use the provisions of Section 13.7 or a more detailed design procedure to 
determine factored moments and shears for the design. Thus, the equivalent frame method will be used in the hand analysis component of this thesis. The equivalent frame method shares many similarities in analysis with the direct-design method, but its more general approach allows it to be used to analyze moments in any practical building frame (MacGregor and Wight 2005).

\subsubsection{Basic Concept}

In the equivalent frame method the slab of a building is divided into middle strips and column strips for analysis. Figure $\mathrm{H}$ below illustrates how the middle and column

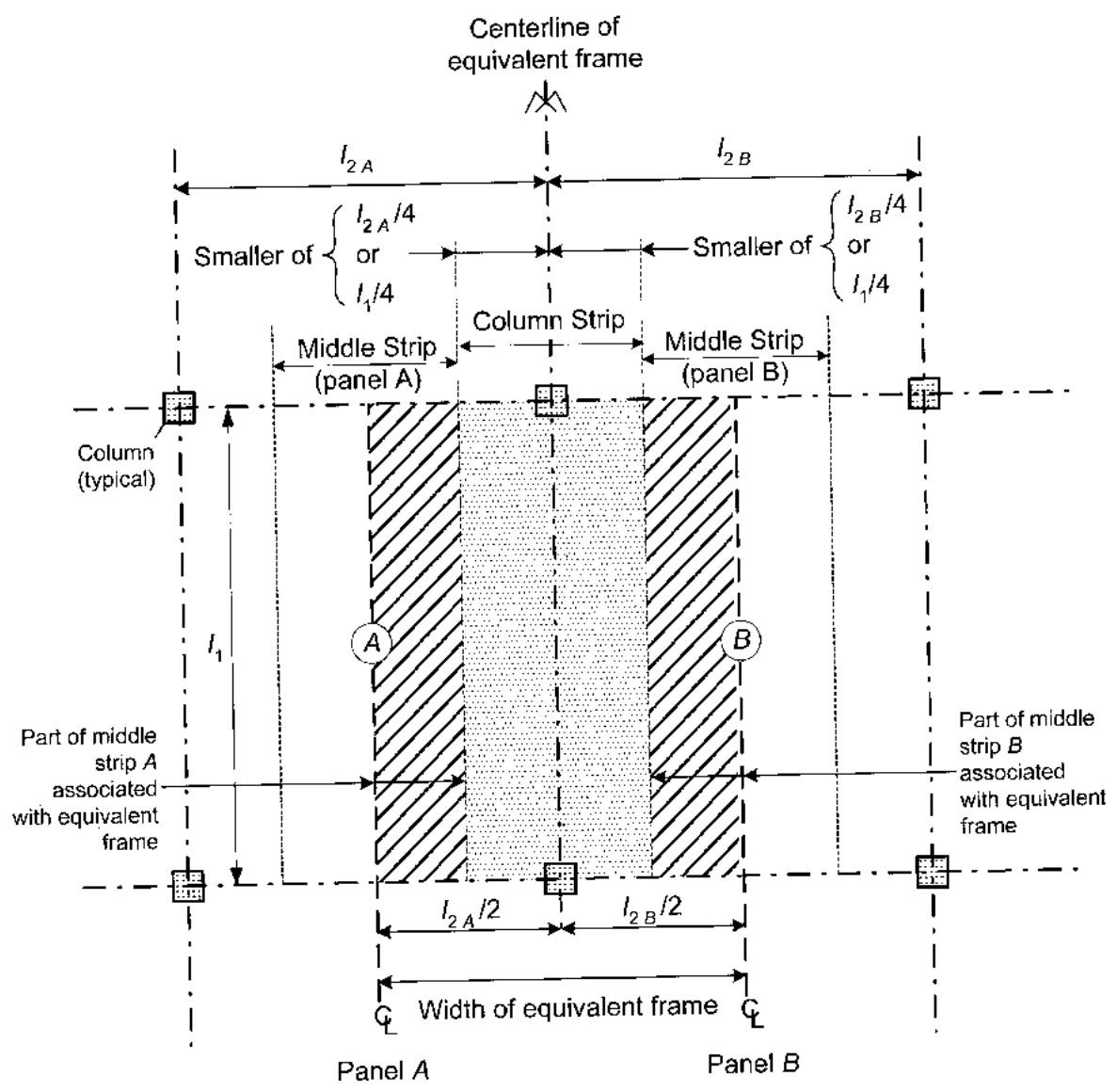

Figure H: Definition of Column and Middle Strips

Source: Naaman 2004

Optimization of Two-Way Post-Tensioned Concrete Floor Systems 
strips are defined in a slab. ACI 318-05 defines the width of a column strip as $0.25 l_{l}$ or $0.25 l_{2}$, whichever is less. The middle strip width is determined by the two column strips that bound it. The moments in the column strip frames are calculated using the moment distribution method. The equivalent frame method assumes the moments to be uniform across the strips. The stiffness of the slab and columns must be found, as well as the carryover factors, in order to determine the moments across the section of frame using moment distribution. The moments and shears may be found using other analysis methods, such as finite element modeling with a computer program. Once the moments are found, they are distributed between the middle strips and the column strips and the reinforcing needed to resist the moments and corresponding shears can be designed (MacGregor and Wight 2005).

\subsubsection{Moment Distribution}

The moment distribution method uses relative stiffness $(K)$, carryover factors (COF), distribution factors (DF), and fixed end moments (FEM), to determine the distribution of moments in a structure. The stiffness is found using the following equation:

$$
K=\frac{k E I}{L}
$$

Where $k$ is a factor determined by the geometry of the section,

$E$ is the elastic modulus for the section,

$I$ is the moment of inertia for the section, and

$L$ is the length of the section. 
For a prismatic member, fixed at the far end, with negligible axial loads, $k$ equals 4.

For the equivalent frame method, members have an increased stiffness due to the connection of the slab to the column. Therefore, $k$ is a number greater than 4 that must be computed or looked up in a table such as Table A-20 in Reinforced Concrete: Mechanics and Design. The COFs are \pm 0.5 and FEMs are $w l^{2} / 12$ for a prismatic member, but must also be computed differently or looked up in a table, such as Table A-20, for the equivalent frame method (MacGregor and Wight 2005).

The stiffness of the columns for the equivalent frame method must be adjusted for torsion due to the attached slab or beams. The equivalent column stiffness becomes

$$
\frac{1}{K_{e c}}=\frac{1}{\sum K_{c}}+\frac{1}{K_{t}}
$$

Where $K_{e c}$ is the equivalent column stiffness,

$\Sigma K_{c}$ is the sum of the flexural stiffnesses of the columns, and

$K_{t}$ is the torsional stiffness of the attached torsional members calculated by

$$
K_{t}=\sum \frac{9 E_{C S} C}{l_{2}\left(1-c_{2} / l_{2}\right)^{3}}
$$

Where $E_{C S}$ is the modulus of elasticity of the slab concrete,

$l_{2}$ is the length of the transverse spans on each side of the column, $c_{2}$ is the width of the column, and

$C$ is a constant, roughly equivalent to a polar moment of inertia, calculated by subdividing the cross section into rectangles and carrying out the following summation 


$$
C=\sum\left[\left(1-0.63 \frac{x}{y}\right) \frac{x^{3} y}{3}\right]
$$

Where $x$ is the shorter side of the rectangle and $y$ is the longer side.

ACI 318 Section 13.7.5 requires the added stiffness of torsional members be considered in design and references this approximation in its commentary. Drop panels are included in the calculation of the torsional stiffness when used in a slab.

When performing the moment distribution, skip loading may need to be taken into account. For a known loading pattern, skip loading is not considered. For live loads less than $75 \%$ of the dead load, the frame is analyzed for a uniform live load across all panels. For live loads more than $75 \%$ of the dead load, ACI 318-05 Section 13.7.6 defines skip loading patterns for the maximum positive and negative moments. In slabs, positive moments usually occur at midspan and negative moments usually occur at supports. The maximum positive moment occurs with a loading pattern where $75 \%$ of the live load is applied to the panel being considered and then alternate panels. The maximum negative moment occurs with a loading pattern where $75 \%$ of the live load is applied on panels adjacent to the panel being investigated (MacGregor and Wight 2005).

\subsubsection{Solution}

Solving the indeterminate frame using moment distribution provides the moments and shears at the center of the support. Subsequently, the member forces must be determined at the critical section. The critical section occurs at the face of the rectilinear supports, but not farther than $0.175 l_{1}$ from the center of a column (ACI 318-05 Section 13.7.7.1). The critical shear is evaluated at this point as well. Section 13.6.4 of ACI 318- 
4.0 Methods of Analysis 22

05 defines the distribution of the moments between the column and middle strips. For a flat plate, $75 \%$ of the negative moment is distributed to the column strip and the remaining $25 \%$ is distributed between the two adjacent half-middle strips; $60 \%$ of the positive moment is distributed to the column strip and the remaining $40 \%$ is divided equally between the two adjacent half-middle strips. Reinforcing can then be designed to resist these moments and shears (MacGregor and Wight 2005).

\subsection{Post-Tensioning Analysis Procedure}

Analyzing and designing post-tensioned slabs differs from the analysis and design of concrete slabs reinforced with non-prestressed reinforcement. The equivalent frame method is ultimately used, unless a computer program is utilized, but some additional analysis must be done before and after using it. Naaman (2004) proposes the following steps as a guideline for designing post-tensioned slabs:

1. Proportion slab thickness based on span-to-depth ratios and fire endurance requirements.

2. Define for each principal direction the frame or frames equivalent to the slab system considered.

3. For each equivalent frame, use the load-balancing approach to determine the prestressing force. The load to be balanced should preferably include the entire dead load. Compute average prestress values due to the balanced load.

4. Analyze the equivalent frame for the unbalanced load and determine corresponding moments and stresses. 
5. Superimpose the average uniform stress from the post-tensioning force with the stresses due to the unbalanced load, and compare the resulting stresses with allowable stresses.

6. Determine minimum nonprestressed reinforcement if required.

7. Detail tendon and bar layout and check if spacing and cover requirements are satisfied.

8. Check ultimate flexural strength requirements.

9. Check shear, and provide shear reinforcement if needed.

10. Compute deflection and compare with deflection limitations.

These guidelines for analysis will be adhered to in this thesis for the hand calculations.

\subsubsection{Initial Analysis}

Deflection, fire ratings, and shear generally determine the thickness of a slab. Accepted ranges of $l / h$ for two-way slabs to limit deflection are 25 to 35 for simple spans, and 35 to 50 for continuous slabs. All slabs analyzed in this thesis will be continuous; therefore, the 35 to 50 range for $l / h$ will be used. Fire ratings require slabs with depths varying between 3 and 7 inches depending on the fire endurance required. However, slabs thinner than 6 inches are not recommended for application. Design for shear will be discussed in Section 4.3.3. It is noted that determination of the frame geometry for posttensioned concrete slabs using the equivalent frame method proceeds in the same way as for non-prestressed slabs (Naaman 2004). 


\subsubsection{Load Balancing}

T.Y. Lin's technique of load balancing is now the most widely used method for design of prestressed concrete slabs. Figure I below illustrates the general approach to load balancing. The load to be balanced, $w_{b}$, must be determined by the designer. It is generally taken as the dead load plus the sustained part of the live load, but can vary considerably in partially prestressed slabs. For this thesis, the dead load will vary as a percentage of the total for the parametric study. The stress in the cross section for the prestressing plus balanced load condition, top of Figure I, is determined to be F/A $A_{C}$, a

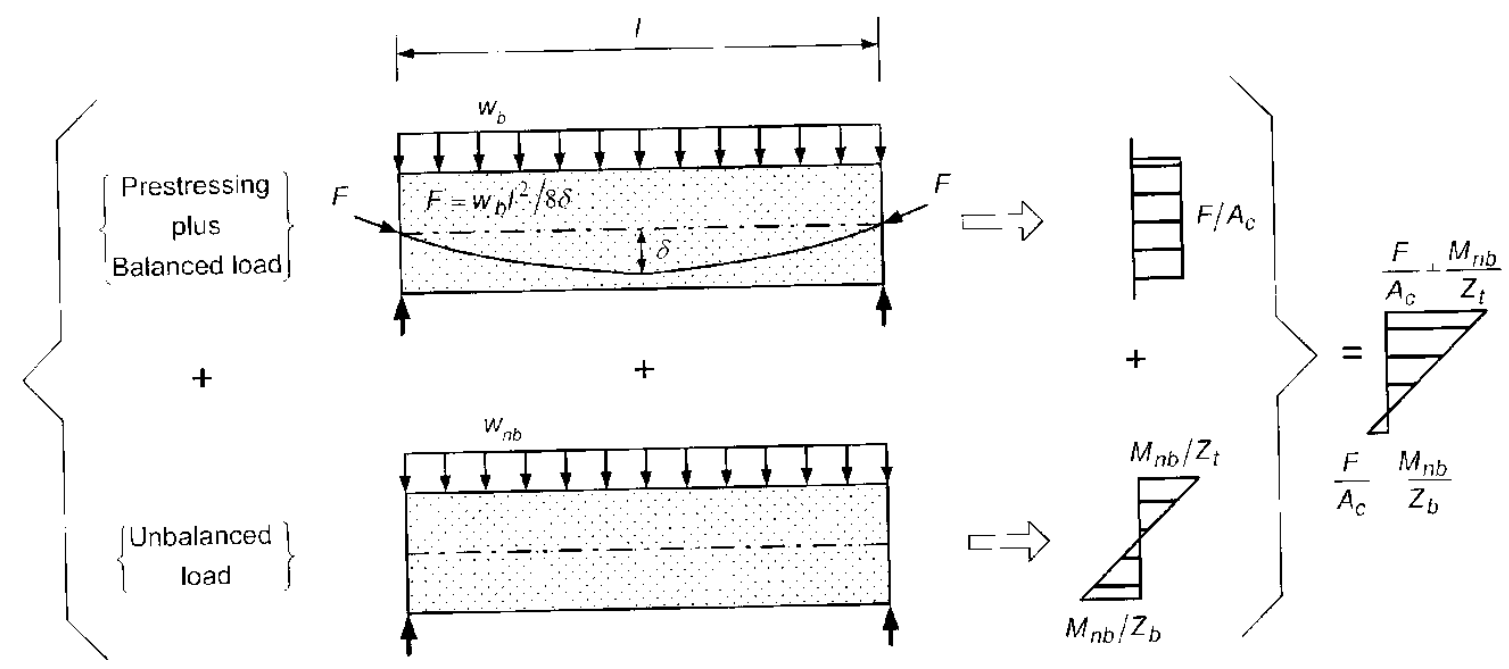

Figure I: Load Balancing

Source: Naaman 2004

constant compressive stress due to the force in the prestressing. The stress is constant because the balanced load and the vertical force in the prestressing are assumed to have equal and opposite forces by the principles of load balancing, and therefore cancel each other and induce no additional stress in the cross section. The unbalanced load then creates a linearly varying stress across the cross section as shown in the bottom of Figure 
I. When combined by superposition, the overall stress diagram becomes the diagram on the right in Figure I (Naaman 2004).

To determine the force in the prestressed tendon, the parabolic shape of the tendon profile provides the following equation of the force due to equilibrium:

$$
F=\frac{w_{b} l^{2}}{8 \delta}
$$

Where $\delta$ is the drape of the post-tensioning tendon.

Once the balanced load is determined, Eq. 10 calculates the prestressing force for each span. For frames with multiple spans and loadings, the highest prestressing force of the individual spans is used for all spans. To achieve the same balanced load for each span, the tendon profile is adjusted. A parabolic tendon profile is assumed for the load balancing as shown below in (a) of Figure J, and (b) illustrates the definition of the tendon drape. The tendon profile has maximum eccentricities at the intermediate supports

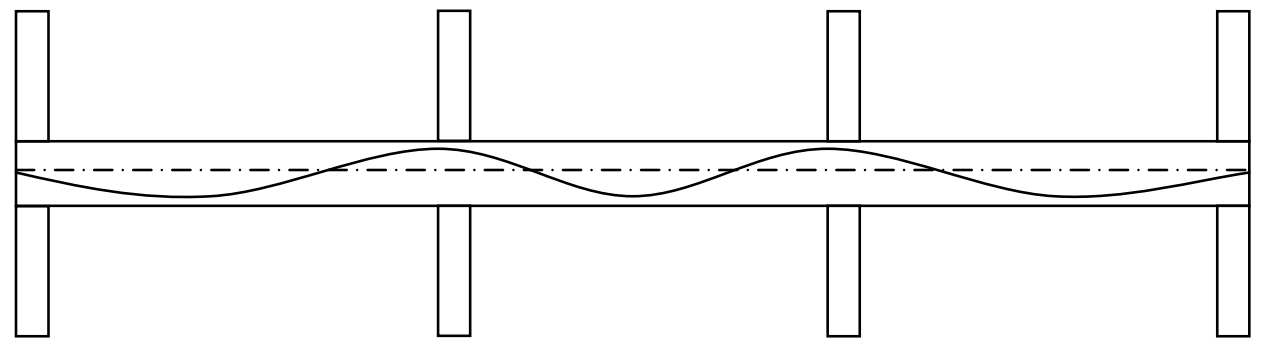

(a)

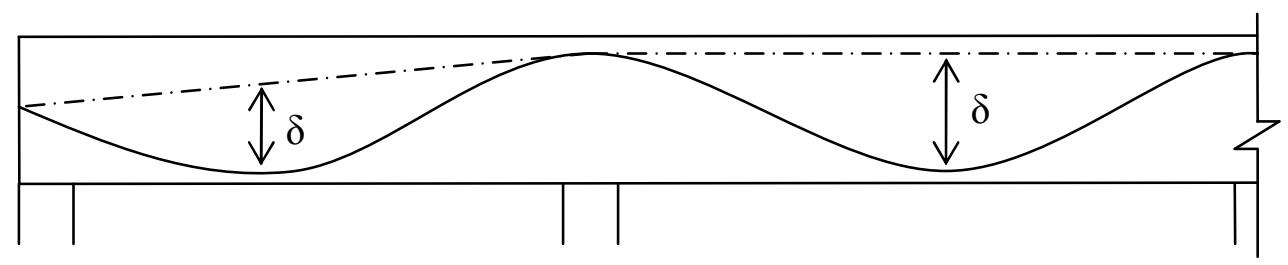

(b)

Figure J: Tendon Profile 
4.0 Methods of Analysis 26

to counteract the negative moment and maximum sags at the midspan to counteract the positive moments. The eccentricity at the end supports must be zero, except when there is a cantilever, in which case, the eccentricity and slope of the profile must be zero at the end of the cantilever.

Once the prestressing force has been calculated, the number of tendons needed to achieve this force is determined. The required force is divided by an effective force in the strands. The effective force is used to account for the loss of force in the prestressing due to the relaxation of the steel and creep and shrinkage of the concrete. Naaman uses an effective force of $160 \mathrm{ksi}$ for a $270 \mathrm{ksi}$ tendon ultimate force (2004). It is also common for the effective force to be taken as $65 \%$ of the ultimate strand strength, which for a 270 ksi strand would be around $175 \mathrm{ksi}$. Calculations may be performed to determine the force directly, but for the scope of this thesis, Naaman's assumption will be used to determine the number of strands needed for the design. Now, the slab can be analyzed for the unbalanced load using the equivalent frame method for a continuous, non-prestressed slab (Naaman 2004).

\subsubsection{Code Compliance}

After completing the elastic analysis of the slab, the slab must be checked to make sure it meets code requirements. For slabs prestressed with unbonded tendons, a minimum average prestress of 125 psi is required by ACI 318-05 Section 18.12.4 and a maximum average prestress of 300 psi is recommended by ACI-ASCE Committee 423 . Average prestress is defined as the final prestressing force after losses divided by the total cross-sectional area of the concrete. The minimum value limits excessive tension and 
cracking, while the maximum value limits excessive elastic shortening and creep

(Naaman 2004). Minimum nonprestressed reinforcement requirements are laid out in

ACI 318-05 Section 18.9, and summarized in Figure K below. ACI 318-05 Section 18.3.3

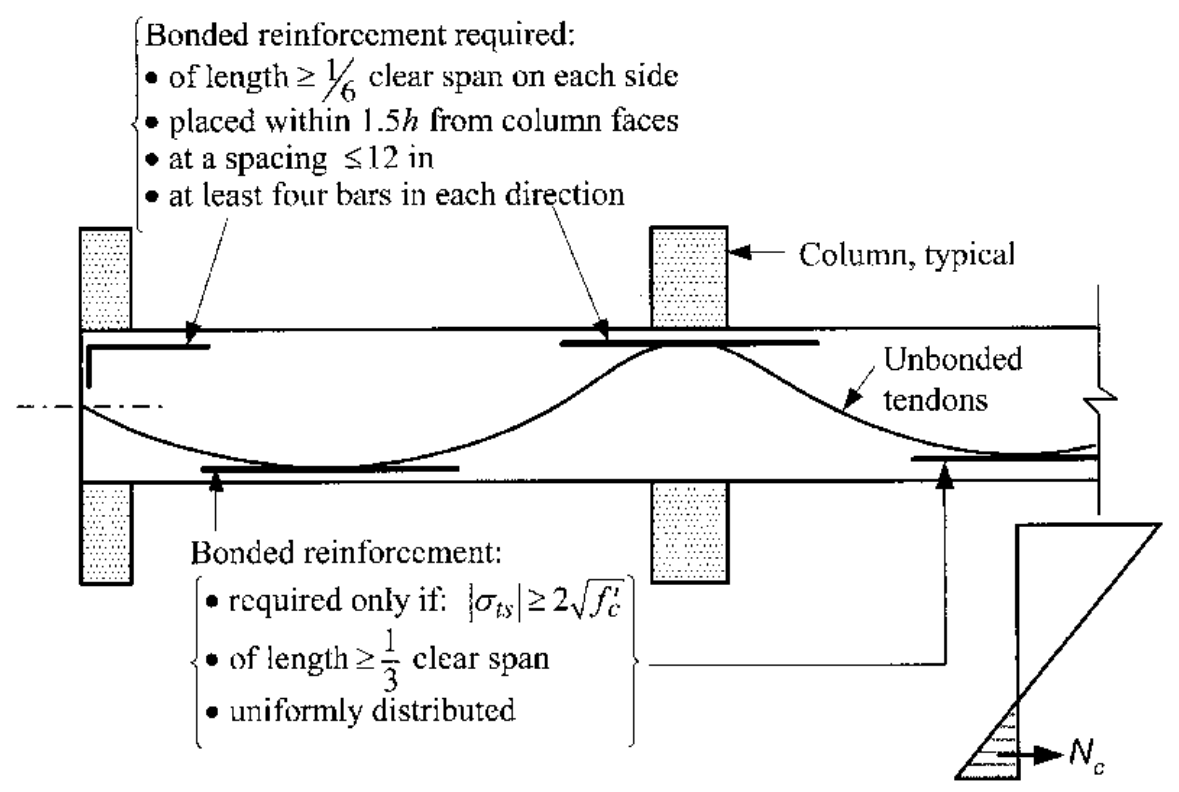

\section{Figure K: Non-prestressed Reinforcement Requirements}

Source: Naaman 2004

requires two-way slab systems to be designed as Class $U$ members, which are assumed to behave as uncracked members. The maximum tensile stress allowed for prestressed twoway concrete slab systems is $6.0 \sqrt{f_{c}}$. See Table A on the next page for a summary of the checks required for design.

As seen in Table A, the slab must be checked for shear in accordance with ACI 318-05. There are two types of shear commonly checked: beam shear and punching shear. Beam shear creates diagonal cracking failure along the plane of principal tension. Beam shear rarely creates a problem in slabs because the plane of principal tension is 


\section{Table A: Required Checks for Design}

\begin{tabular}{ccc}
\hline Check & Limit & Code Reference \\
\hline $\begin{array}{c}\text { Minimum Average } \\
\text { Prestress }\end{array}$ & $125 \mathrm{psi}$ & 18.12 .4 \\
$\begin{array}{c}\text { Maximum Tensile } \\
\text { Stress } \\
\text { Maximum } \\
\text { Compression Stress } \\
\text { Nonpresstressed } \\
\text { Reinforcing } \\
\text { Deflection }\end{array}$ & $6.0 \sqrt{f_{c}{ }^{\prime}}$ & 18.3 .3 \\
Shear & $0.45 f_{c}{ }^{\prime}$ & 18.4 .2 \\
\hline & $2.0 \sqrt{f_{c}{ }^{\prime}}$ & 18.9 .3 \\
\hline$v_{c}=\left(\beta_{p} \sqrt{f_{c}{ }^{\prime}}+0.360\right.$ & 9.5 .4 .1 \\
\hline
\end{tabular}

large and it is unlikely the whole plane will shear off. Therefore, beam shear was ignored in analysis for this thesis. Punching shear occurs at the columns supporting the slab.

Diagonal cracking failure creates a truncated pyramid-shaped or cone-shaped surface which "punches" through the slab. The section is analyzed and only if the shear demand, $v_{u}$, exceeds the shear capacity of the concrete, $\phi v_{c}$, is shear reinforcement needed (Naaman 2004). ACI 318-05 defines the nominal punching shear capacity of concrete as

$$
v_{c}=\left(\beta_{p} \sqrt{f_{c}{ }^{\prime}}+0.3 \sigma_{g}\right) b_{0} d+V_{p}
$$

Where $\sigma_{g}$ is the average prestress value,

$b_{0}$ is the perimeter of the critical section considered for punching shear, $d$ is the distance to the centroid of the tension reinforcement from the extreme compression fiber, $V_{p}$ is the shearing in the section from the post-tensioning tendons, $B_{p}$ is the smaller of 3.5 and $1.5+\frac{\alpha_{s} d}{b_{0}}$ and 
$\alpha_{s}$ is 40 for interior columns, 30 for edge columns, and 20 for corner

columns.

Determining the shear demand varies for interior, exterior, and corner columns. For interior columns, Figure L below illustrates the forces considered. The shear demand is then defined as:

$$
v_{u}=\text { the larger of }\left\{\begin{array}{l}
\frac{V_{u}}{A_{c}}+\frac{\gamma_{v} M_{u} c_{3}}{J_{c}} \\
\text { and } \\
\frac{V_{u}}{A_{c}}-\frac{\gamma_{v} M_{u} c_{4}}{J_{c}}
\end{array}\right.
$$
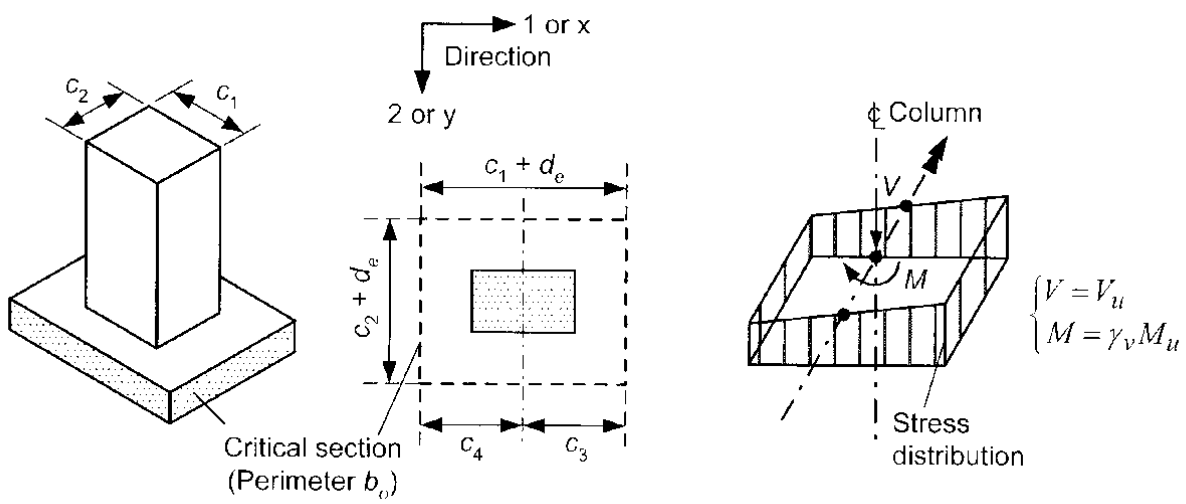

Figure L: Punching Shear for Interior Columns

Source: Naaman 2004

When moment is applied to a section, a fraction of the moment is transferred by flexure and the rest by shear. The variable $\gamma_{\mathrm{v}}$ in Equation 12 is the fraction transferred by shear. For an interior column Equation 13 defines $\gamma_{\mathrm{v}}$.

$$
\gamma_{v}=1-\gamma_{f}=1-\frac{1}{1+\frac{2}{3} \sqrt{\frac{c_{1}+d_{e}}{c_{2}+d_{e}}}}
$$


For exterior columns, Figure M below illustrates the forces considered when the

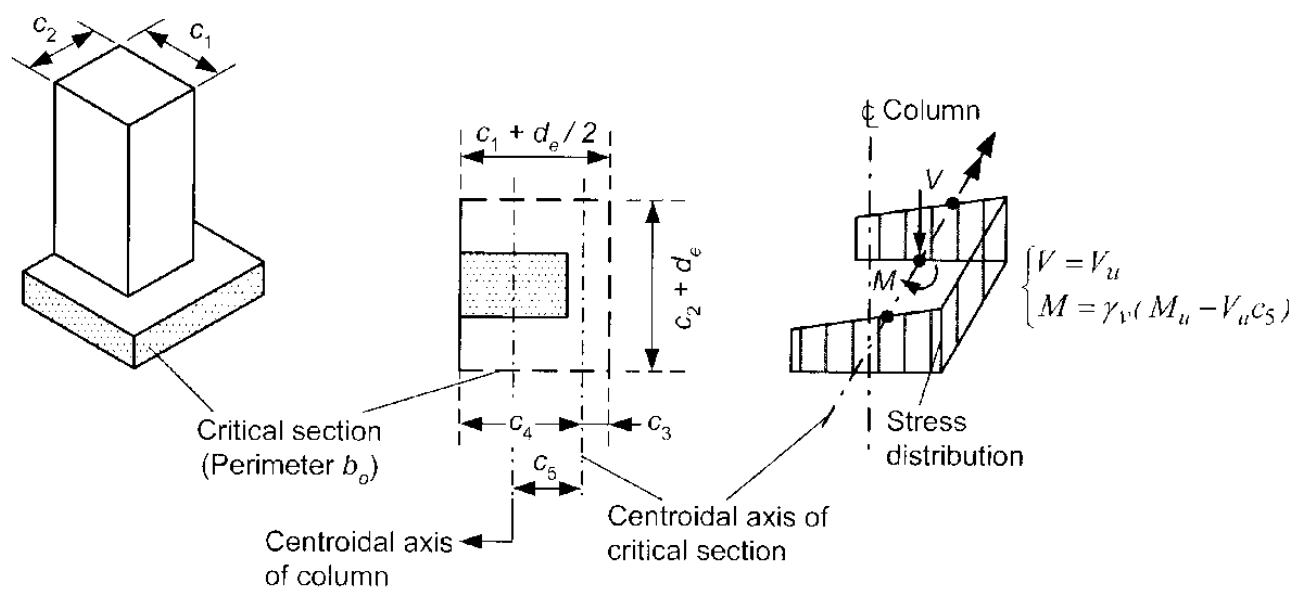

\section{Figure M: Punching Shear for an Exterior Column}

\section{Source: Naaman 2004}

exterior column is located at the end of an equivalent frame. For an equivalent frame with corner and exterior columns, such as along Grid 1, 4, A, or I for this project, the forces are simplified because $V_{u}$ occurs at the centroidal axis of the critical section and no longer contributes to the moment. For exterior columns located at the end of an equivalent frame,

$$
\gamma_{v}=1-\gamma_{f}=1-\frac{1}{1+\frac{2}{3} \sqrt{\frac{c_{1}+d_{e} / 2}{c_{2}+d_{e}}}}
$$

and for exterior columns along Grids 1, 4, A and I,

$$
\gamma_{v}=1-\gamma_{f}=1-\frac{1}{1+\frac{2}{3} \sqrt{\frac{c_{2}+d_{e} / 2}{c_{1}+d_{e}}}} .
$$

For corner columns, Figure $\mathrm{N}$ on the next page illustrates the forces considered. As shown in Figure N, forces from the two equivalent frames defined at the edge are 

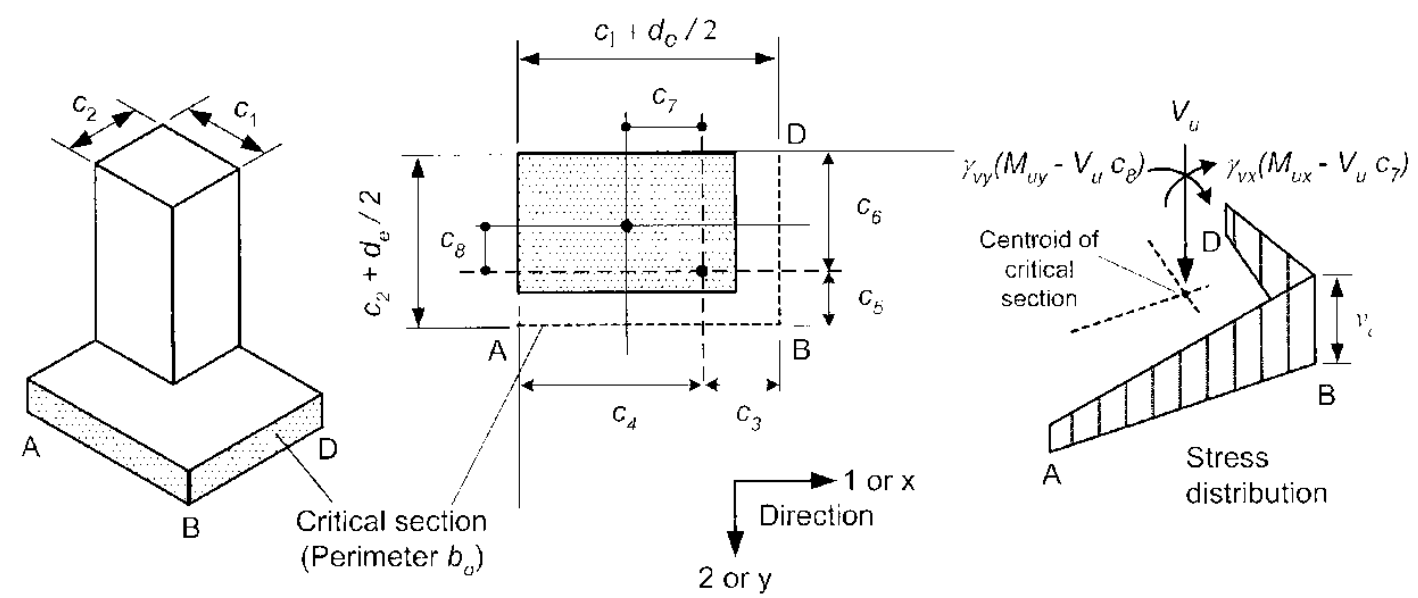

\section{Figure N: Punching Shear for Corner Columns}

Source: Naaman 2004

considered. Therefore, two $\gamma_{\mathrm{v}}$ must be calculated: one corresponding to forces in the $\mathrm{x}$ direction, $\gamma_{\mathrm{vx}}$, defined in Equation 16, and the other corresponding to forces in the ydirection, $\gamma_{\mathrm{vy}}$, defined in Equation 17.

$$
\begin{aligned}
& \gamma_{v x}=1-\frac{1}{1+\frac{2}{3} \sqrt{\frac{c_{1}+d_{e} / 2}{c_{2}+d_{e} / 2}}} \\
& \gamma_{v y}=1-\frac{1}{1+\frac{2}{3} \sqrt{\frac{c_{2}+d_{e} / 2}{c_{1}+d_{e} / 2}}}
\end{aligned}
$$

Punching shear failure is commonly avoided by placing shear studs around the column. Figure $\mathrm{O}$ on the next page provides an illustration of shear studs on rails, commonly referred to as "stud rails." The shear capacity of a shear stud on one of these stud rails is the tensile capacity of the stud, given by Equation 18.

$$
v_{s}=A_{s} f_{y}
$$

Eq. 18 


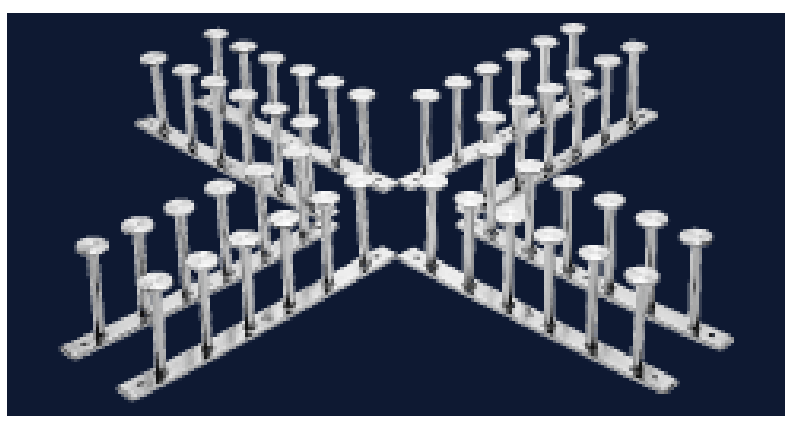

Figure O: Shear Studs

Source: Decon website, $h t t p: / / w w w . d e c o n u s a . c o m$

To determine the required shear strength of the shear rails, Equation 19 is used. Note that the shear capacity of the concrete is defined as $v_{c}=2 \sqrt{f_{c}{ }^{\prime}} * A_{c}$ by ACI 318 .

$$
V_{s}=\left(\frac{v_{u}}{\phi}-2 \sqrt{f_{c}^{\prime}}\right) A_{c}
$$

The required number of shear studs to resist the shear applied to the section is calculated by dividing the force in Equation 19 by the capacity of a single stud.

The slab must also be analyzed to make sure it meets the deflection criteria outlined in ACI 318-05 Section 9.5.4. See Figure P below for an illustration of the deflection. To determine the deflection of the slab, the deflection of the column strip in one direction is added to the deflection of the middle strip in the other direction. The deflection in each direction is calculated as the sum of three deflections, and is shown in Figure Q on the next page. The first deflection calculated, shown in (a), occurs at midspan assuming fixed end conditions at the slab edges. The next two deflections are due to rotations. First, shown in (b), a rotation is applied to the left end of the slab with the right end assumed a fixed end condition. Second, shown in (c), a rotation is applied to the right end with the left end assumed a fixed end condition. When $100 \%$ of the dead load is balanced, the 


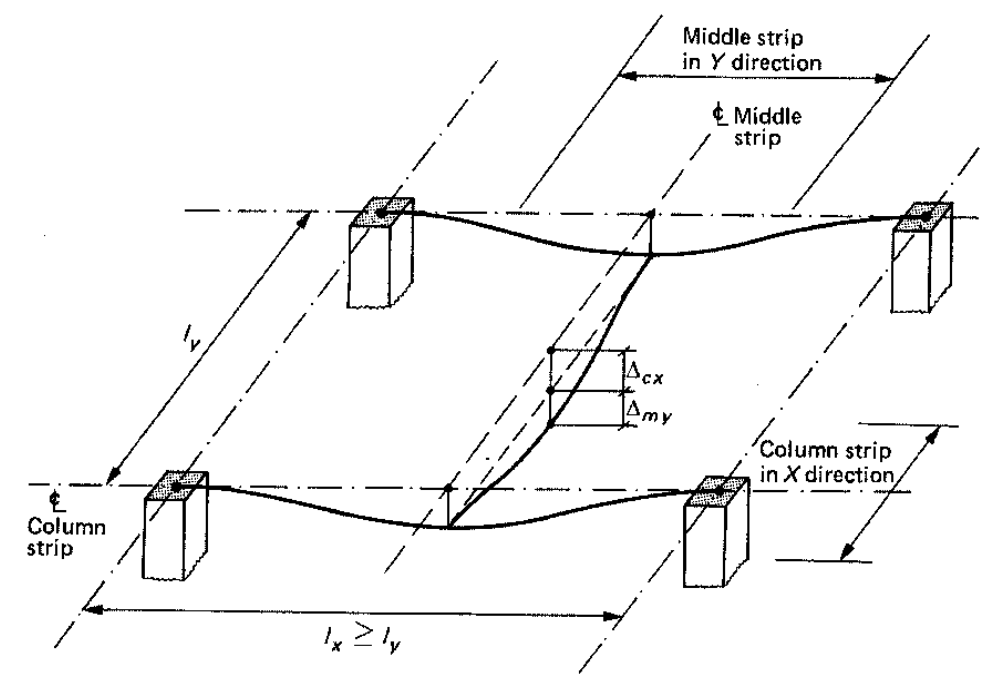

Figure P: Two-Way Slab Deflection

Source: Naaman 2004

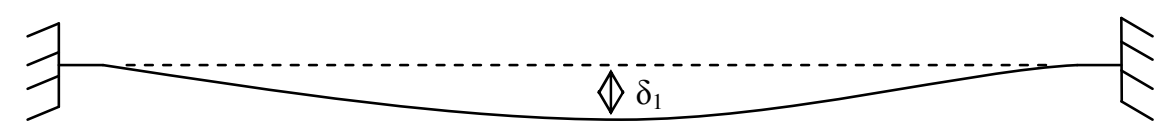

(a) Deflection with both ends fixed

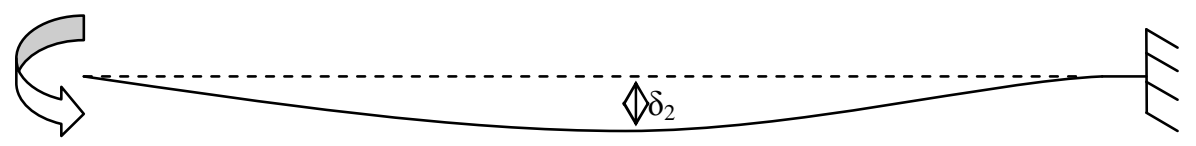

(b) Deflection due to rotation at left end

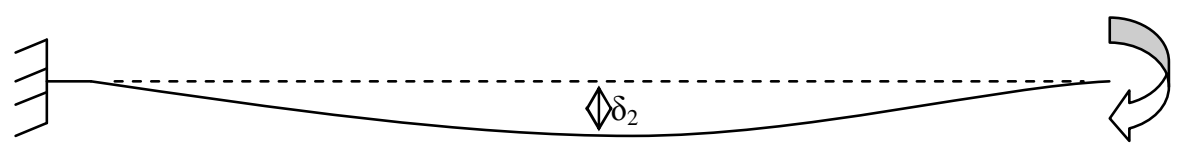

(c) Deflection due to rotation at right end

Figure Q: Deflections

Optimization of Two-Way Post-Tensioned Concrete Floor Systems 
long term deflection is equal to the immediate deflection due to live loading which is then compared to the deflection criteria. When less than $100 \%$ of the dead load is balanced, the long term deflection due to the unbalanced dead load, multiplied by a factor for creep, must be added to the immediate deflection and then compared to the deflection criteria (Nawy 2006). 


\subsection{DESIGN DEFINITIONS}

For this project, the number of design variables will be limited to make the project feasible. As mentioned before, one type of two-way post-tensioned floor system will be investigated, the flat plate as pictured in Figure A on page 1. The flat plate system was chosen because it is the most commonly used two-way post-tensioned concrete slab system. The grid system for this project is one commonly associated with condominiums and hotels: 8 panels with 26' spans by 3 panels of 26' span - 14' span - 26' span for a total $208^{\prime}$ x 66 ' footprint. The layout is shown in Figure R below. This layout is conducive to a floor plan with a central hallway, which is common with hotels and condominiums and

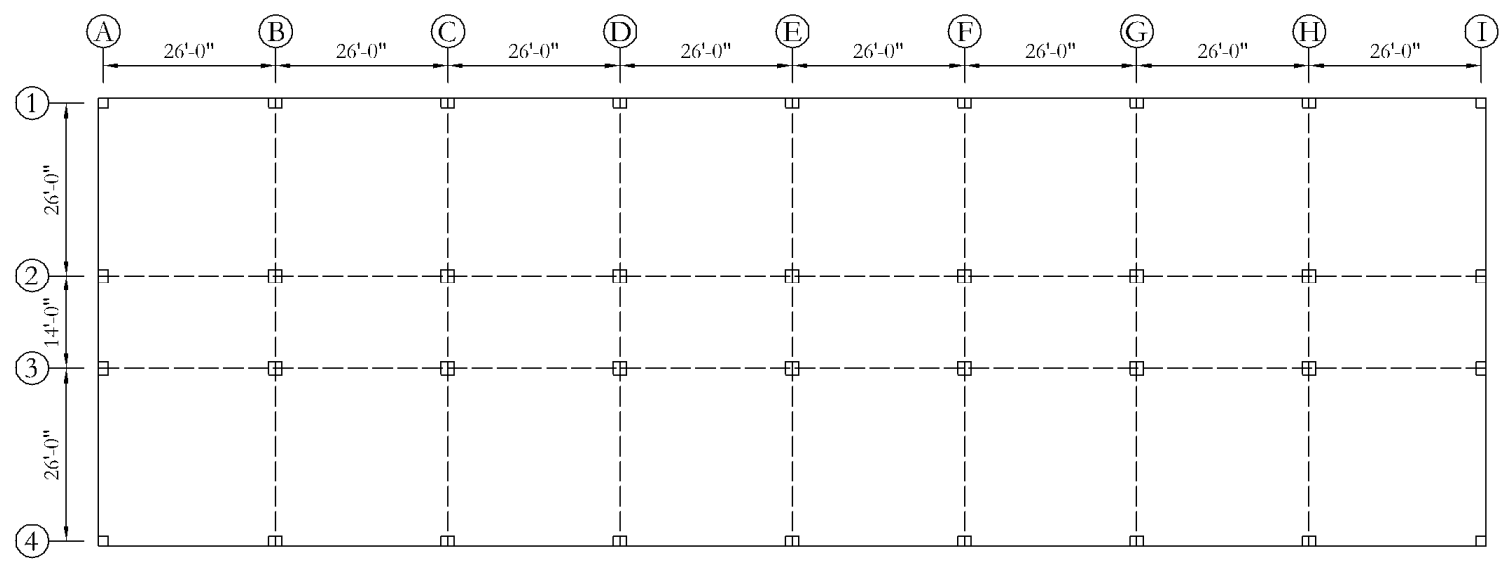

Figure R: Hotel/Condominium Slab Layout

also allows a flexible floor plan in which bays can be added to either end or taken away as the desired layout of the hotel or condominium is determined. For post-tensioned design, the 208' length allows the use of continuous strands of post-tensioning because it is just at the threshold of needing intermediate anchorage points in the slab. 


\subsection{Loading}

The loading for the slab has three components, the dead load, live load, and the superimposed dead load, and remains consistent throughout the parametric study. The dead load is based on the volume of concrete, assuming a concrete weight of $150 \mathrm{pcf}$. The superimposed dead load is assumed a flat $20 \mathrm{psf}$ for partition loading on the slab. For the ultimate limit state, the load combination of 1.2D + 1.6L defined in the 2006 International Building Code (IBC) Section 1605 was used. For service limit states, the load case used was 1.0D + 1.0L. The IBC also designates live loading based on occupancy of the building. The IBC provides two different live loading values for hotels and multifamily houses, one for private rooms and the corridors serving them, and the second for public rooms and the corridors serving them. The second value, for public rooms and the corridors serving them, is $100 \mathrm{psf}$ and was used for this analysis because the actual use of the floor is not specified and to create a conservative design to be refined in further analysis after the initial analysis which the analysis of this thesis represents. Another simplification made was to ignore any applicable live load reduction.

\subsection{Parametric Study}

The parametric study focuses on changes of three different variables, the balanced load, slab depth, and concrete strength. An initial slab depth was determined from a span to depth ratio of 40, giving an 8 inch slab depth. For this initial slab depth, the load balancing of the post-tensioning force varies from $100 \%$ to $75 \%$ of the total dead load applied to give a variety of balanced loads. Also, once analysis commenced, it was found 
that the slab exceeded the allowable tensile stress at the $75 \%$ balanced dead load, and it was decided analysis beyond that would not be useful as the slab would not be adequate according to the code. The slab depth then becomes the changing variable to determine how the amount of concrete affects the non-prestressed reinforcement and shear reinforcing amounts while keeping $85 \%$ of the dead load balanced. A second concrete strength will be the last variable investigated with $85 \%$ of the dead load balanced and the original slab depth. A comparison will then be made to determine how the amount of non-prestressed reinforcement and shear reinforcing amounts change with different concrete strengths. The different slabs designed are summarized below in Table B.

Table B: Summary of Slabs and Variables

\begin{tabular}{cccc}
\hline Slab & $\begin{array}{c}\text { Slab } \\
\text { Thickness (in) }\end{array}$ & $\begin{array}{c}\text { \% of Dead Load } \\
\text { Balanced }\end{array}$ & $\mathbf{f}_{\mathbf{c}} \boldsymbol{\prime}^{\prime}(\mathbf{k s i})$ \\
\hline $\mathbf{1}$ & 8 & 100 & 5 \\
$\mathbf{2}$ & 8 & 90 & 5 \\
$\mathbf{3}$ & 8 & 85 & 5 \\
$\mathbf{4}$ & 8 & 80 & 5 \\
$\mathbf{5}$ & 8 & 75 & 5 \\
$\mathbf{6}$ & 7 & 85 & 5 \\
$\mathbf{7}$ & 9 & 85 & 5 \\
$\mathbf{8}$ & 8 & 85 & 6 \\
\hline
\end{tabular}

To produce a design with a median amount of post-tensioning and non-prestressed reinforcing, the load balancing percentage of $85 \%$ was used for the last three slabs.

\subsection{Cost Analysis}

For the cost analysis, ten different geographical locations and their respective cost of materials and labor will be examined. The cities to be investigated are Atlanta, Boston, 
Chicago, Denver, Houston, Los Angeles, Miami, Phoenix, San Francisco, and Seattle.

These locations were chosen to provide a varied representation of construction costs across the United States and to draw conclusions regarding variance of pricing between locations. The effect of material and labor costs for post-tensioning, rebar, and concrete on the building cost will be examined for the designs listed in Table B. A combination of the material quantities calculated during the parametric study and the costs of the materials and installation will determine the optimal, most cost effective solution for each of the ten geographic locations. 


\subsection{ANALYSIS}

To analyze the eight slabs, two different approaches were taken. First, the slabs were analyzed through hand calculations using the equivalent frame and post-tension design procedures outlined in the previous section. To aid in performing the parametric study quickly, these hand calculations were completed with a series of Excel worksheets. Second, the slabs were analyzed using a computer program, ADAPT-PT. Practicing engineers use computer programs such as ADAPT-PT more commonly than hand calculations because of their ease of use. The comparison between these two sets of calculations will provide a means of checking the two designs to determine which would provide better results for performing a similar cost analysis in the future.

\subsection{Hand Analysis}

In order to easily change the parameters for the slab design, Excel spreadsheets were created. Two equivalent frames for each direction comprise the slab design. In the longitudinal direction, an edge frame 13 feet in width lies along Grids 1 and 4, and an interior frame 20 feet in width lies along Grids 2 and 3. In the transverse direction, an edge frame 13 feet in width lies along Grids A and I, and an interior frame 26 feet in width lies along Grids B through H. See Figure S on the next page for an illustration of these frames. The Excel files created for each of these frame conditions consist of the following worksheets:

- Slab dimensions and stiffnesses for each frame

- Moment distribution for each loading scenario 
- Summary of the results of the moment distribution

- Tendon calculations

- Check of the allowable stress values at critical sections

- Check of the ultimate flexural strength of the critical slab sections

- Punching shear checks at interior, exterior and corner columns

- Deflection check

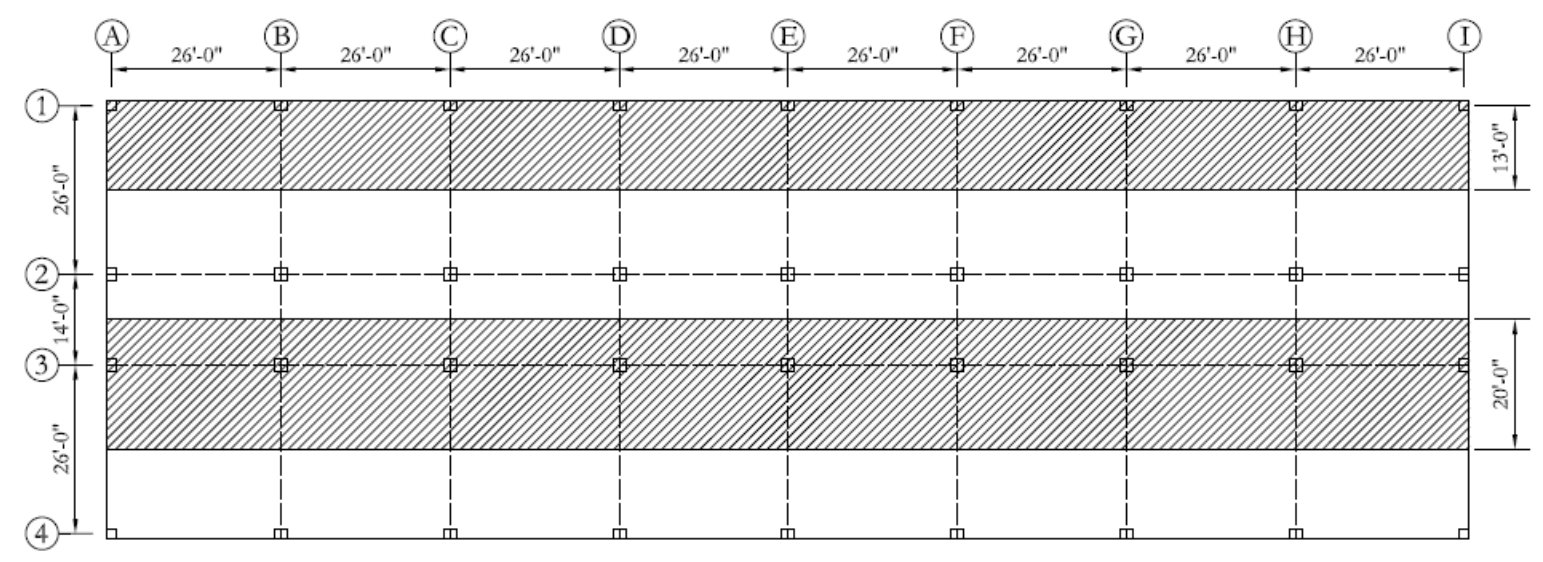

(a) Longitudinal Direction

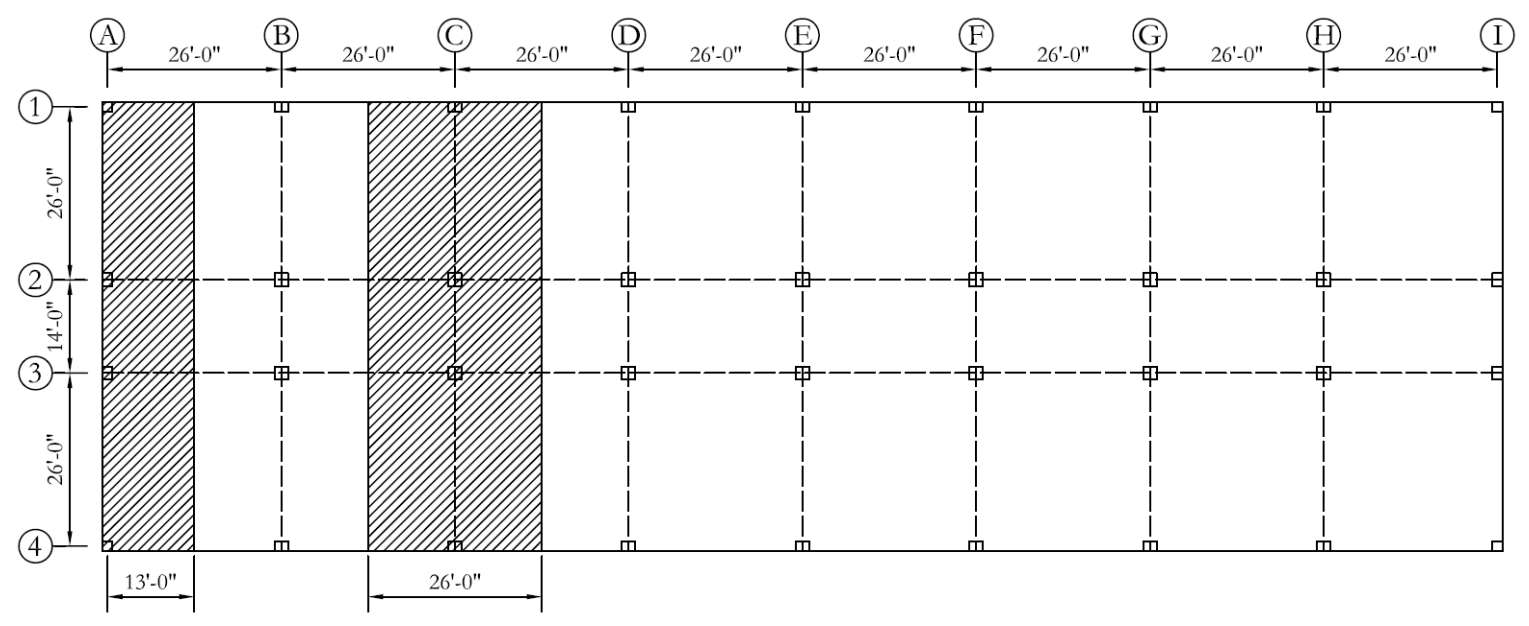

(b) Transverse Direction

Figure S: Equivalent Frame Layouts 
6.0 Analysis 41

A typical set of calculations for one of the slabs, specifically Slab 3 from Table B, can be found in APPENDIX A. The calculations progress through the Excel sheets mentioned before starting with the equivalent frame along Grids 1 and 4, pages $i$ through xvii, then along Grids 2 and 3, pages xviii through xxxvi, then along Grids A and I, pages xxxvii through xlix, and finally, for the frame along Grids B through $\mathrm{H}$, pages 1 through lxiv. Following the calculations specific to these frames are the calculations for the punching shear for the corner columns, pages lxv and lxvi, and the deflection check is on page lxvii.

\subsubsection{Analysis Results.}

Following the analysis in these worksheets, each slab was designed for posttensioning cable layouts, rebar layouts and shear stud requirements. APPENDIX B HAND ANALYSIS SUMMARIES contains summary tables, the same as Table C through Table $\mathrm{J}$ which follow, as well as a drawing of the post-tensioning and rebar layouts for each slab design. These summary tables detail the number of strands of posttensioning for each frame, the number and size of the rebar at each column type, the size and spacing of rebar in the spans as required, and the number of shear studs required for each column type for each of the eight slabs designed.

The "outside columns" refer to the two columns on the edge of the equivalent frame and "inside columns" refer to the columns on the inside of the equivalent frame. For the equivalent frames along Grids 1, 4, A and I, the outside column designation refers to the corner columns, and the inside column designation refers to columns along the exterior of the slab. For the equivalent frames along Grids 2, 3, and B through $\mathrm{H}$, the outside column 
designation refers to columns along the exterior of the slab, and the inside column

designation refers to columns in the interior of the slab. In turn, "outside spans" are the two spans on the outside of the equivalent frame, and "inside spans" refers to the spans between the outside spans. Refer to Figure $S$ for the equivalent frame layouts of the slab.

\section{Table C: Slab 1 Design}

\begin{tabular}{|c|c|c|c|c|c|}
\hline & \multicolumn{4}{|c|}{ Frames } \\
\hline & & $1 \& 4$ & $2 \& 3$ & A \& I & B-H \\
\hline \multirow{3}{*}{$E$} & Total PT & 15 & 23 & 15 & 29 \\
\hline & Over Columns & 15 & 23 & 4 & 4 \\
\hline & Uniform & & & $\begin{array}{l}24,2 \text { @ } \\
22 \text { "o.c. }\end{array}$ & $\begin{array}{l}24,2 @ \\
22 \text { "o.c. }\end{array}$ \\
\hline \multirow{5}{*}{ 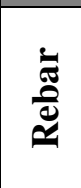 } & & & & & \\
\hline & Outside Columns & & & $3 \# 5$ & $3 \# 5$ \\
\hline & Inside Columns & $3 \# 5$ & $5 \# 5$ & $3 \# 5$ & $3 \# 5$ \\
\hline & Outside Spans & & & & \\
\hline & Inside Spans & & & & \\
\hline & & & & & \\
\hline \multirow{3}{*}{$\begin{array}{l}\bar{\varpi} \\
\bar{\varpi} \\
\bar{E}\end{array}$} & Exterior Columns & 0 & 16 & 0 & 18 \\
\hline & Interior Columns & & 24 & & 28 \\
\hline & Corner Columns & \multicolumn{4}{|c|}{0} \\
\hline
\end{tabular}

\section{Table D: Slab 2 Design}

\begin{tabular}{|c|c|c|c|c|c|}
\hline & & $1 \& 4$ & $2 \& 3$ & A \& I & B-H \\
\hline \multirow{3}{*}{ E } & Total PT & 13 & 20 & 13 & 26 \\
\hline & Over Columns & 13 & 20 & 4 & 4 \\
\hline & Uniform & & & $\begin{array}{l}\text { 20, @ } \\
26 \text { "o.c. }\end{array}$ & $\begin{array}{c}\text { 22, @ 24" } \\
\text { o.c. }\end{array}$ \\
\hline \multirow{5}{*}{ 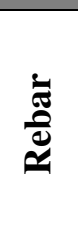 } & & & & & \\
\hline & Outside Columns & & & $2 \# 5$ & $3 \# 5$ \\
\hline & Inside Columns & 4 \#5 & 5 \#5 & $4 \# 5$ & $7 \# 5$ \\
\hline & Outside Spans & \#7@ @2"o.c. & \#7@ @20"o.c. & $\begin{array}{c}\# 7 @ \\
24 " \text { o.c. }\end{array}$ & $\begin{array}{c}\text { \#7 @ } \\
18 \text { "o.c. }\end{array}$ \\
\hline & Inside Spans & \#7 @ 26"o.c. & \#7 @ 24"o.c. & & \\
\hline \multirow{3}{*}{ 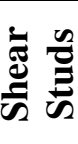 } & Exterior Columns & 0 & 16 & 0 & 18 \\
\hline & Interior Columns & & 24 & & 28 \\
\hline & Corner Columns & \multicolumn{4}{|c|}{(} \\
\hline
\end{tabular}

Optimization of Two-Way Post-Tensioned Concrete Floor Systems 


\section{Table E: Slab 3 Design}

\begin{tabular}{|c|c|c|c|c|c|}
\hline & \multicolumn{4}{|c|}{ Frames } \\
\hline & & $1 \& 4$ & $2 \& 3$ & A \& I & $\mathrm{B}-\mathrm{H}$ \\
\hline \multirow{3}{*}{$\bar{A}$} & Total PT & 13 & 19 & 13 & 25 \\
\hline & Over Columns & 13 & 19 & 4 & 4 \\
\hline & Uniform & & & $\begin{array}{c}20,2 @ \\
26 \text { "o.c. }\end{array}$ & $\begin{array}{c}20,2 @ \\
26 \text { "o.c. }\end{array}$ \\
\hline & & & & & \\
\hline \multirow{4}{*}{ 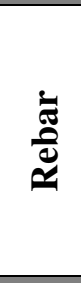 } & Outside Columns & & & $2 \# 5$ & $4 \# 5$ \\
\hline & Inside Columns & $4 \# 5$ & $5 \# 5$ & $4 \# 5$ & $7 \# 5$ \\
\hline & Outside Spans & $\begin{array}{c}\text { \#7 @ } \\
22 \text { "o.c. }\end{array}$ & $\begin{array}{c}77 @ \\
20 \text { "o.c. }\end{array}$ & $\begin{array}{c}\text { \#7 @ } \\
24 \text { "o.c. }\end{array}$ & $\begin{array}{c}\text { \#7 @ } \\
18 \text { "o.c. }\end{array}$ \\
\hline & Inside Spans & $\begin{array}{c}\# 7 @ \\
26 " \text { "o.c. }\end{array}$ & $\begin{array}{c}\# 7 @ \\
22 \text { "o.c. }\end{array}$ & & \\
\hline \multirow{3}{*}{ 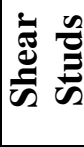 } & Exterior Columns & 0 & 16 & 0 & 18 \\
\hline & Interior Columns & & 24 & & 28 \\
\hline & Corner Columns & \\
\hline
\end{tabular}

\section{Table F: Slab 4 Design}

\begin{tabular}{|c|c|c|c|c|c|}
\hline & \multicolumn{4}{|c|}{ Frames } \\
\hline & & $1 \& 4$ & $2 \& 3$ & A \& I & B-H \\
\hline \multirow{3}{*}{ E } & Total PT & 12 & 18 & 12 & 23 \\
\hline & Over Columns & 12 & 18 & 4 & 4 \\
\hline & Uniform & & & $\begin{array}{l}18,2 @ \\
30 \text { "o.c. }\end{array}$ & $\begin{array}{l}\text { 18,2 @ } \\
30 \text { "o.c. }\end{array}$ \\
\hline \multirow{4}{*}{ 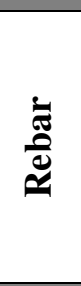 } & Outside Columns & & & $2 \# 5$ & $3 \# 5$ \\
\hline & Inside Columns & $4 \# 5$ & $6 \# 5$ & $4 \# 5$ & $7 \# 5$ \\
\hline & Outside Spans & $\begin{array}{c}\# 7 @ \\
\text { 20"o.c. }\end{array}$ & $\begin{array}{c}\text { \#7 @ } \\
18 \text { "o.c. }\end{array}$ & $\begin{array}{c}\# 7 @ \\
22 " \text { o.c. }\end{array}$ & $\begin{array}{c}\text { \#7 @ } \\
18 \text { "o.c. }\end{array}$ \\
\hline & Inside Spans & $\begin{array}{c}\# 7 @ \\
24 \text { "o.c. }\end{array}$ & $\begin{array}{c}\# 7 @ \\
22 \text { "o.c. }\end{array}$ & & \\
\hline \multirow{3}{*}{ 宬 } & Exterior Columns & 0 & 16 & 0 & 20 \\
\hline & Interior Columns & & 24 & & 28 \\
\hline & Corner Columns & \multicolumn{4}{|c|}{0} \\
\hline
\end{tabular}




\section{Table G: Slab 5 Design}

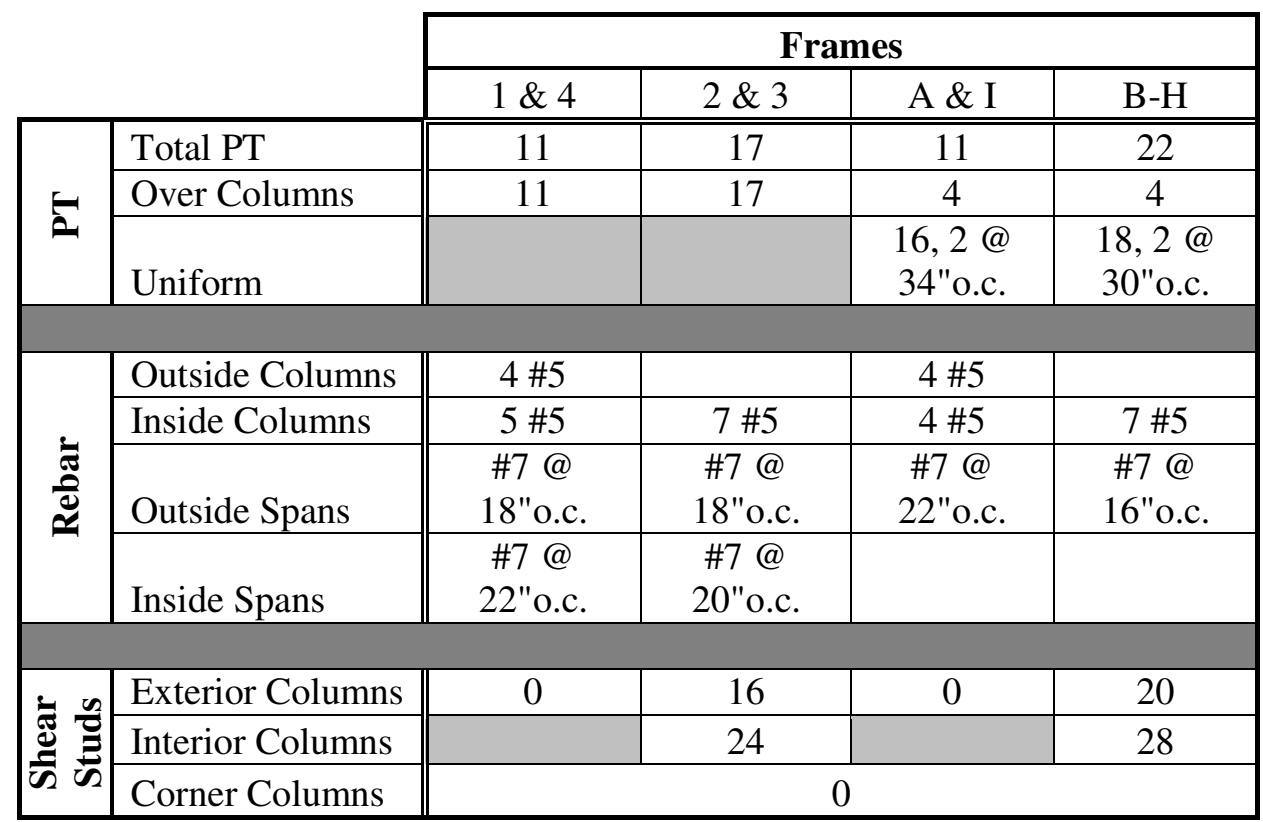

\section{Table H: Slab 6 Design}

\begin{tabular}{|c|c|c|c|c|c|}
\hline & \multicolumn{4}{|c|}{ Frames } \\
\hline & & $1 \& 4$ & $2 \& 3$ & A \& I & B-H \\
\hline \multirow{3}{*}{ È } & Total PT & 14 & 21 & 14 & 27 \\
\hline & Over Columns & 14 & 21 & 4 & 4 \\
\hline & Uniform & & & $\begin{array}{l}22,2 @ \\
24 " \text { o.c. }\end{array}$ & $\begin{array}{l}22,2 @ \\
24 " \text { o.c. }\end{array}$ \\
\hline 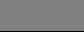 & & & & & \\
\hline \multirow{4}{*}{ 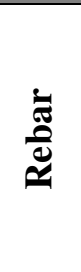 } & Outside Columns & & & & \\
\hline & Inside Columns & $3 \# 5$ & $5 \# 5$ & $3 \# 5$ & $6 \# 5$ \\
\hline & Outside Spans & $\begin{array}{c}\text { \#7 @ } \\
\text { 20"o.c. }\end{array}$ & $\begin{array}{c}\text { \#7 @ } \\
18 \text { "o.c. }\end{array}$ & $\begin{array}{c}\text { \#7 @ } \\
24 \text { "o.c. }\end{array}$ & $\begin{array}{c}\text { \#7 @ } \\
18 \text { "o.c. }\end{array}$ \\
\hline & Inside Spans & $\begin{array}{c}\text { \#7@ } \\
24 \text { "o.c. }\end{array}$ & $\begin{array}{c}\# 7 @ \\
22 \text { "o.c. }\end{array}$ & & \\
\hline \multirow{3}{*}{ 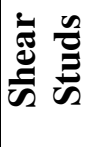 } & Exterior Columns & 0 & 18 & 0 & 20 \\
\hline & Interior Columns & & 24 & & 28 \\
\hline & Corner Columns & \multicolumn{4}{|c|}{0} \\
\hline
\end{tabular}




\section{Table I: Slab 7 Design}

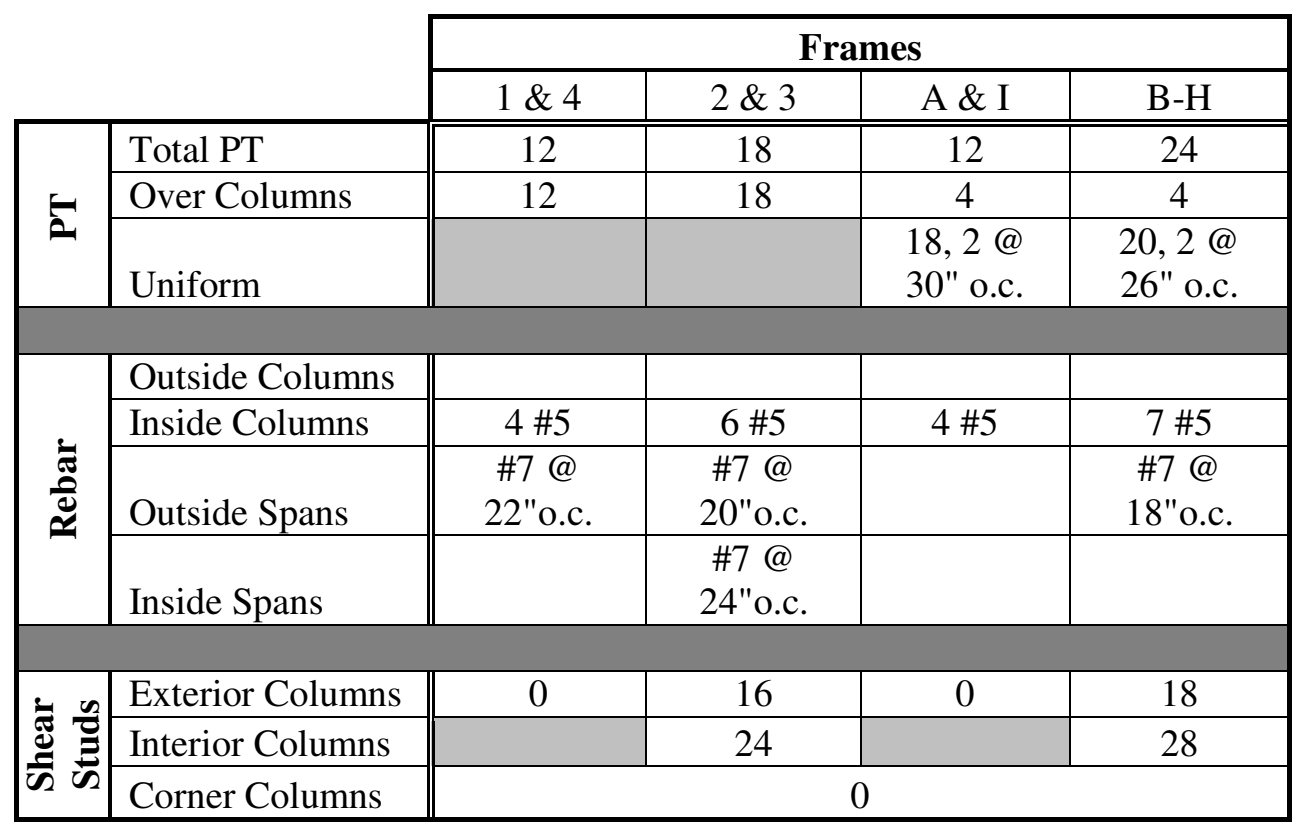

\section{Table J: Slab 8 Design}

\begin{tabular}{|c|c|c|c|c|c|}
\hline & \multicolumn{4}{|c|}{ Frames } \\
\hline & & $1 \& 4$ & $2 \& 3$ & A \& I & B-H \\
\hline \multirow{3}{*}{ E } & Total PT & 13 & 18 & 12 & 24 \\
\hline & Over Columns & 13 & 18 & 4 & 4 \\
\hline & Uniform & & & $\begin{array}{l}18,2 @ \\
30 " \text { o.c. }\end{array}$ & $\begin{array}{l}20,2 \text { @ } \\
26 " \text { o.c. }\end{array}$ \\
\hline & & & & & \\
\hline \multirow{4}{*}{ 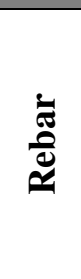 } & Outside Columns & & & $2 \# 5$ & 4 \#5 \\
\hline & Inside Columns & 4 \#5 & $5 \# 5$ & 4 \#5 & $7 \# 5$ \\
\hline & Outside Spans & $\begin{array}{c}\# 7 @ \\
22 \text { "o.c. }\end{array}$ & $\begin{array}{l}\text { \#7 @ } \\
20 \text { "o.c. }\end{array}$ & $\begin{array}{c}\# 7 @ \\
24 ” \text { o.c. }\end{array}$ & $\begin{array}{c}\text { \#7 @ } \\
18 \text { "o.c. }\end{array}$ \\
\hline & Inside Spans & $\begin{array}{c}\text { \#7 @ } \\
26 \text { "o.c. }\end{array}$ & $\begin{array}{c}\text { \#7 @ } \\
22 \text { "o.c. }\end{array}$ & & \\
\hline \multirow{3}{*}{ 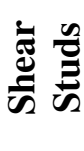 } & Exterior Columns & 0 & 14 & 0 & 16 \\
\hline & Interior Columns & & 20 & & 24 \\
\hline & Corner Columns & \multicolumn{4}{|c|}{0} \\
\hline
\end{tabular}




\subsubsection{Drawings}

The drawings of the designs tabulated in these tables are located in Appendix B. For each design, the post-tensioning strand layout is first, detailing the number of strands, where they are located, their spacing if uniform strands, and their distance from the bottom of the slab to the center of the strand. Figure $\mathrm{T}$ below provides examples of the different designations used in the tendon layouts. The designation in (a) is for the uniform strands. The example shown details 2 strands placed every 26 inches for the space designated by the arrows. The designation in (b) is for banded strands. The example shown in (b) details 19 strands banded together along the line representing the strand.

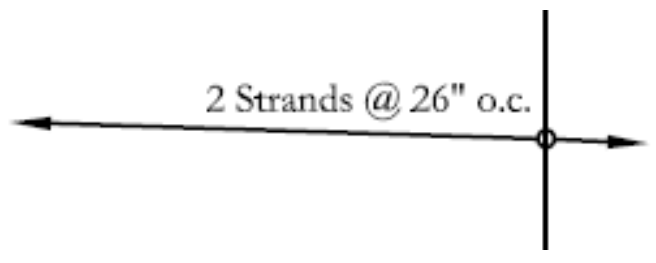

(a) Uniform Strands

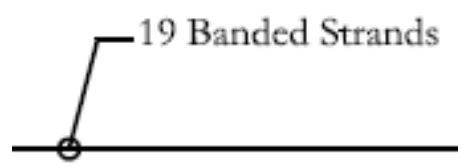

(b) Banded Strands

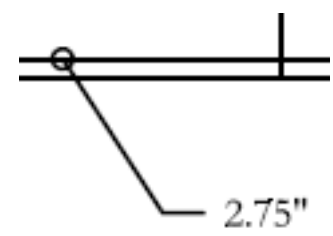

(c) Tendon Profile

Figure T: Drawing Designations for Post-tensioning Layouts 
6.0 Analysis 47

The designation in (c) is for the tendon profile, i.e. the location of the strand along the profile. The example shown in (c) details the center of the strand be placed 2.75 inches above the bottom of the slab. The rebar layout follows the post-tensioning layout giving designations for placement of the bars, bar sizes, and spacing as required. Figure $\mathrm{U}$ below and on the next page provides examples of the different designations used in the rebar

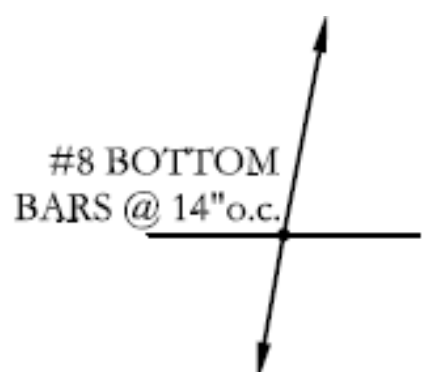

(a) Bottom Bars

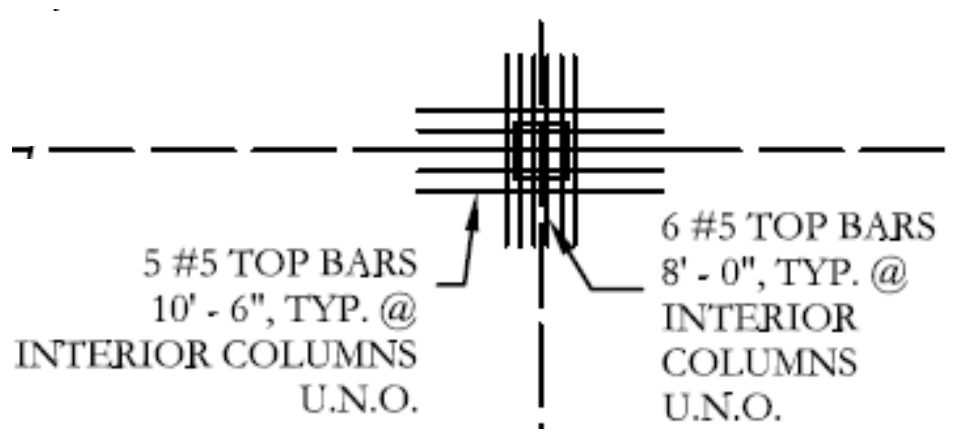

(b) Top Bars

\section{Figure U: Drawing Designations for Rebar Layouts}

layouts. The designation in (a) is for bottom bars, bars in the spans which are located in the bottom of the slab. The example shown in (a) details a \#8 bar of rebar placed every 14 inches for the space designated by the arrows. The designation in (b) is for top bars, bars over the columns which are located in the top of the slab. The example shown in (b) details five \#5 bars of rebar, 10'-6" long, and six \#5 bars of rebar, 8'-0" long, placed over the interior columns. 


\subsubsection{Quantities}

From these slab designs, quantities were compiled for each of the four materials, concrete, rebar, shear stud rails, and post-tensioning, to be used in the cost analysis. Shear studs are typically priced by stud rail, so while the number of actual studs varied from slab to slab, the number of stud rails for each slab was the same. Table K below summarizes the total quantity for each slab by material; refer back to Table B for the slab definitions. The post-tension strand weights have been rounded up to the nearest hundred pounds and the rebar weights are rounded to the nearest tenth of a ton for this summary. The tabulated values of rebar weights in Appendix E of The American Concrete Institute Building Code Requirement for Structural Concrete (ACI 318-05) were used for the rebar weights, and the bare strand weight of a 1/2" post-tensioning strand is taken as 0.525 pounds per linear foot (2005).

Table K: Summary of Analysis Results

\begin{tabular}{ccccccc}
\hline Slab & $\begin{array}{c}\mathbf{f}_{\mathbf{c}} \\
(\mathbf{k s i})\end{array}$ & $\begin{array}{c}\text { Total } \\
\text { Concrete } \\
\mathbf{( y d}^{\mathbf{3}} \mathbf{)}\end{array}$ & $\begin{array}{c}\text { Total Post- } \\
\text { Tensioning } \\
(\mathbf{l b s})\end{array}$ & $\begin{array}{c}\text { Rebar } \\
\text { (tons) }\end{array}$ & $\begin{array}{c}\text { Number } \\
\text { of Shear } \\
\text { Studs }\end{array}$ & $\begin{array}{c}\text { Number of } \\
\text { Stud Rails }\end{array}$ \\
\hline $\mathbf{1}$ & 5 & 340 & 16400 & 0.8 & 864 & 148 \\
\hline $\mathbf{2}$ & 5 & 340 & 14500 & 8.7 & 864 & 148 \\
\hline $\mathbf{3}$ & 5 & 340 & 14000 & 9.1 & 864 & 148 \\
\hline $\mathbf{4}$ & 5 & 340 & 13000 & 10.8 & 872 & 148 \\
\hline $\mathbf{5}$ & 5 & 340 & 12300 & 11.3 & 872 & 148 \\
\hline $\mathbf{6}$ & 5 & 300 & 15200 & 9.1 & 880 & 148 \\
$\mathbf{7}$ & 5 & 380 & 13200 & 7.5 & 864 & 148 \\
\hline $\mathbf{8}$ & 6 & 340 & 14000 & 9.1 & 736 & 148 \\
\hline
\end{tabular}

From Table K some observations can be made of these findings. Slab 1, designed with $100 \%$ of the dead load balanced, requires the most post-tensioning. Slab 5, designed with $75 \%$ of the dead load balanced, requires the most rebar. Slab 7, designed with $85 \%$ 
of the dead load balanced and a slab depth of 9", has the most concrete, and Slab 6 with a slab depth of 7" has the least amount of concrete. The effect of the variables identified for the parametric study can also be observed in Table $\mathrm{K}$, and are further illustrated in Figure V below and on the next page. Slabs 1 through 5 explore the effect of

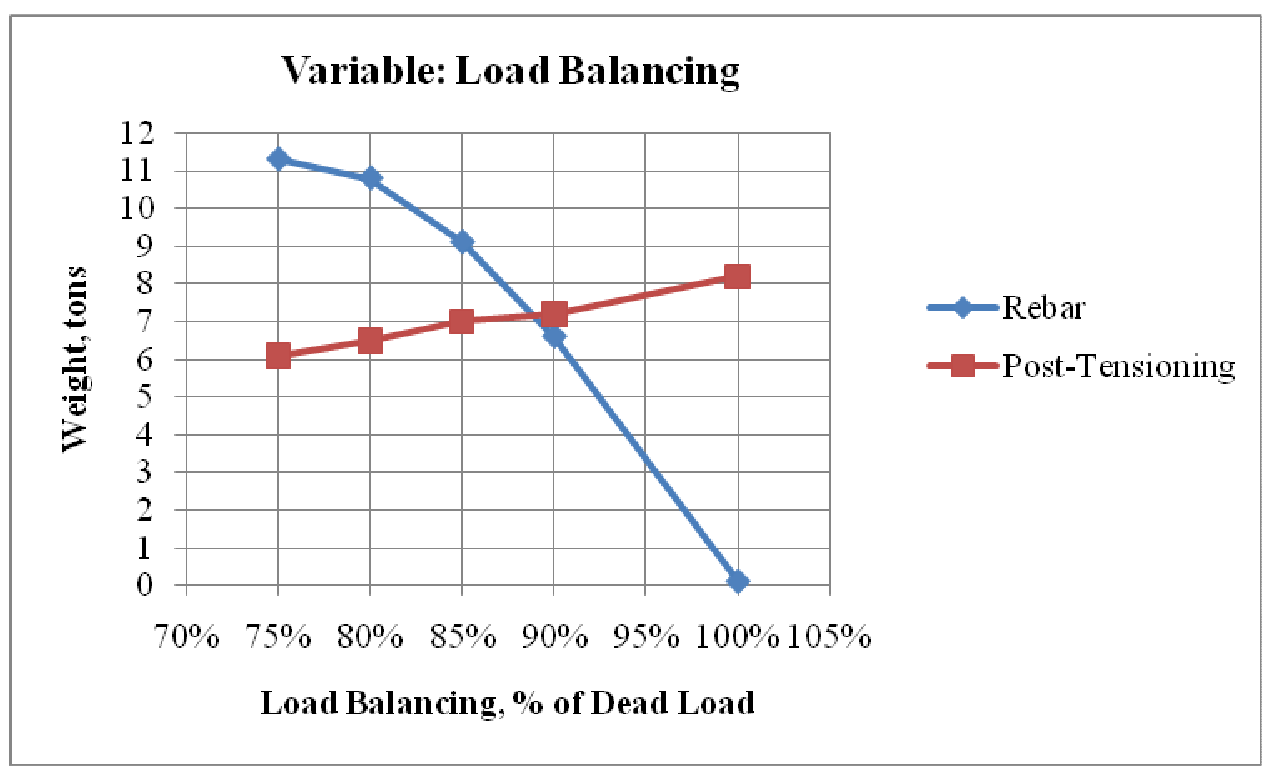

(a) First Variable

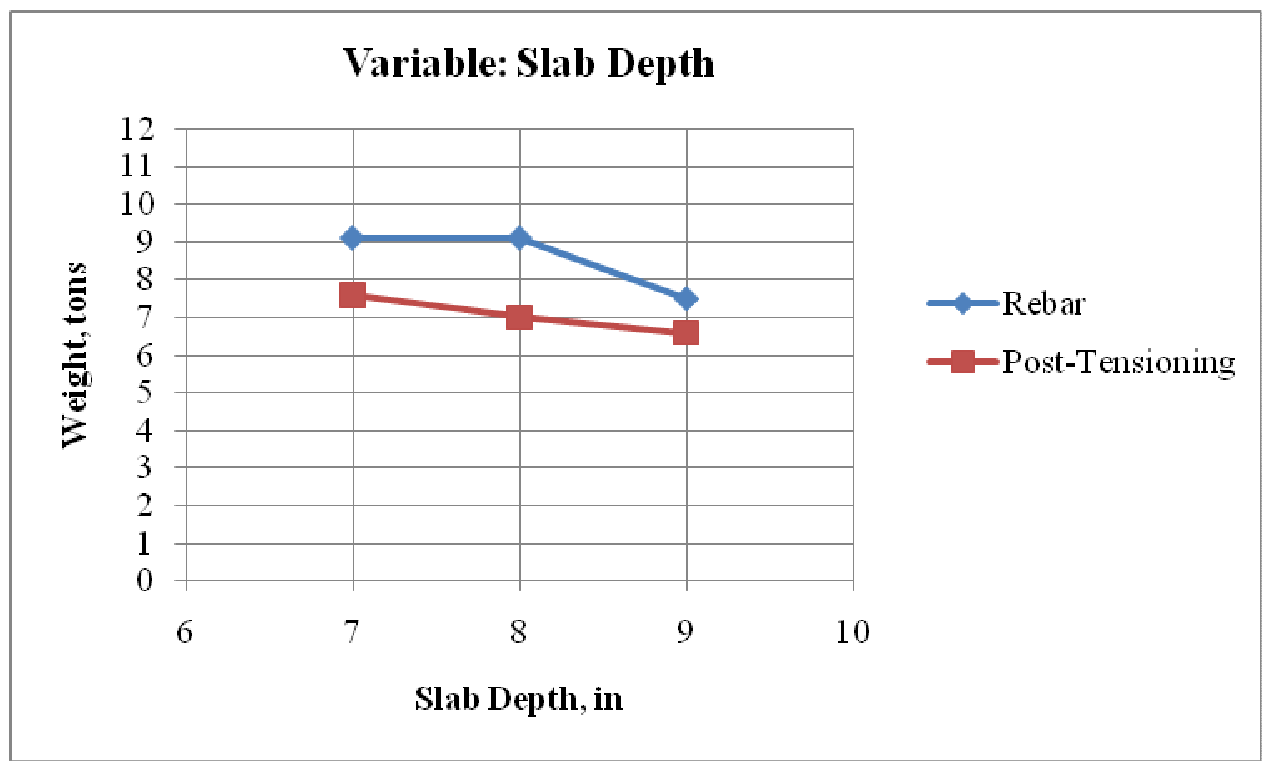

(b) Second Variable 


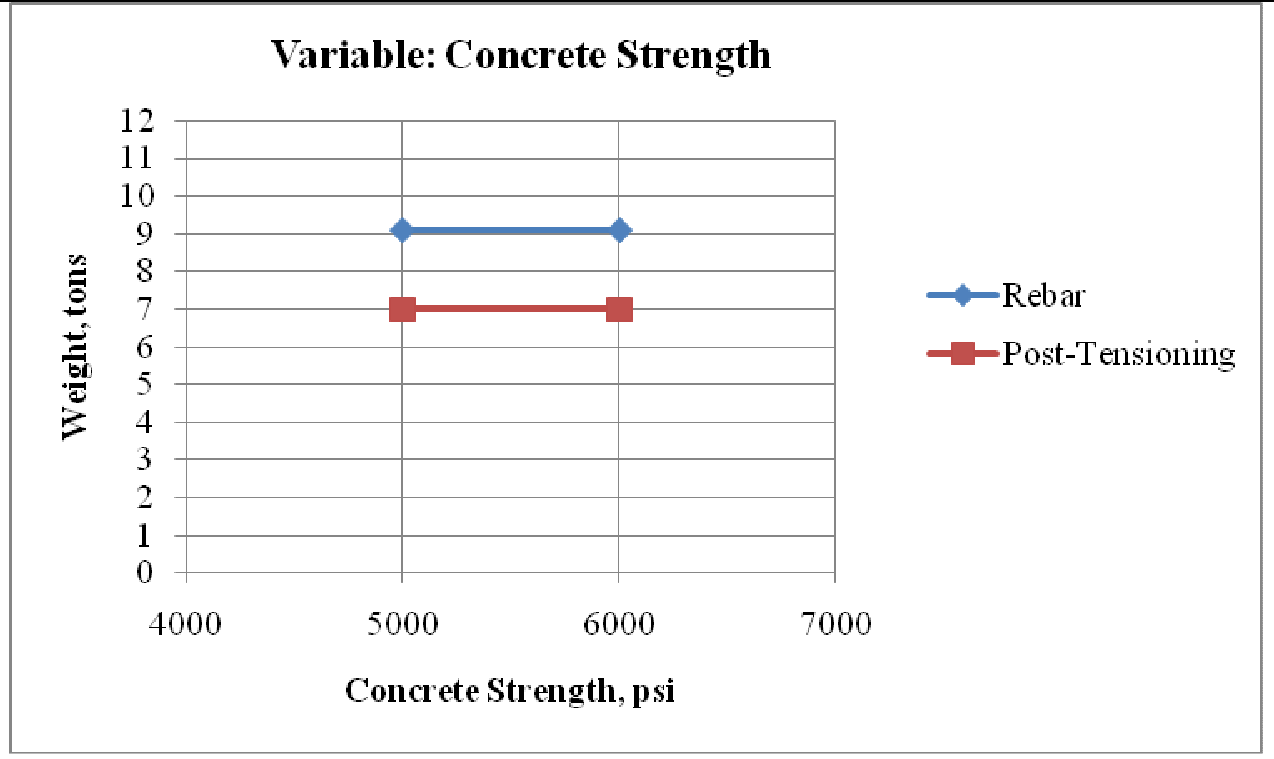

(c) Third Variable

Figure V: Comparison of Rebar and Post-Tensioning Weight for Each Variable in the Parametric Study

the first variable, the amount of dead load balanced by the post-tensioning, shown in (a) of Figure V. Slab 2, 90\% of the dead load balanced, sees a significant jump in the amount of rebar required to reinforce the slab compared to Slab 1, 100\% of the dead load balanced, increasing by 8 tons between the two. After this jump, the rebar increases by around 1 ton to the next slab to counteract the decrease in post-tensioning. The posttensioning weight does not see as significant a jump between the slabs, though the difference between Slab 1 and Slab 2 is the greatest, like the rebar. The number of shear studs required has little variation for Slabs 1 through 5. Slabs 3, 6, and 7 explore the effect of the second variable, slab depth, shown in (b) of Figure V. Slab 6, with a slab depth of 7", has the most post-tensioning, but the same amount of rebar as Slab 3, with a slab depth of 8". Slab 7, with a slab depth of 9", required the least amount of both post- 
tensioning and rebar. Slabs 3 and 8 explore the effect of the last variable, concrete strength, shown in (c) of Figure V. Slab 8, with 6000 psi strength concrete, requires the same amount of post-tensioning and rebar, but 128 fewer shear studs than Slab 3, with 6000 psi strength concrete. The values in Table $\mathrm{K}$ will be used in the cost analysis to determine optimal solutions in different cities across the United States.

\subsection{ADAPT Analysis}

The computer program ADAPT-PT was used to provide a comparison to the results obtained by hand calculations. The program calculates the post-tensioning and rebar required for two-way concrete slabs, one-way concrete slabs, and concrete beams. Only the interior frames of the eight slabs from Table B were designed using ADAPT-PT to compare to the results tabulated in Table $\mathrm{C}$ through Table J. ADAPT-PT analyzes twoway slabs with the equivalent frame method, and therefore should provide very similar results for the post-tensioning to those found in the hand analysis. Discrepancies between the hand and the ADAPT-PT analysis can be explained by the fact that the rebar calculated by ADAPT-PT is determined using an envelope approach, calculating the highest and lowest stresses throughout the slab to determine the amount of rebar needed to resist the stresses, which was not used in the hand analysis.

\subsubsection{Using ADAPT-PT}

To create the slab or beam to be analyzed in ADAPT-PT, the user inputs specific variables through a series of windows in the program. These inputs include, but are not limited to, the design code, slab geometry, support geometry and stiffness, boundary 
conditions, loads, material properties, code requirements, tendon profile, load balancing values, and load combinations. For the load combinations, ADAPT-PT includes the load combinations associated with the design code specified, for this project 1.2DL $+1.6 \mathrm{LL}$ for strength design, and allows the user to input new combinations to check or change the code combinations if necessary. Figure $\mathrm{W}$ below is an example of the ADAPT-PT model for the equivalent frame for Grids B through H. After inputting the slab, the user selects "Execute" and the program calculates a slab design. ADAPT-PT allows the user to change this design in two different ways; the post-tensioned force can be changed, which changes the number of strands in the slab, and the tendon profile can be changed, which affects the load balanced by the strands. If the designer chooses to

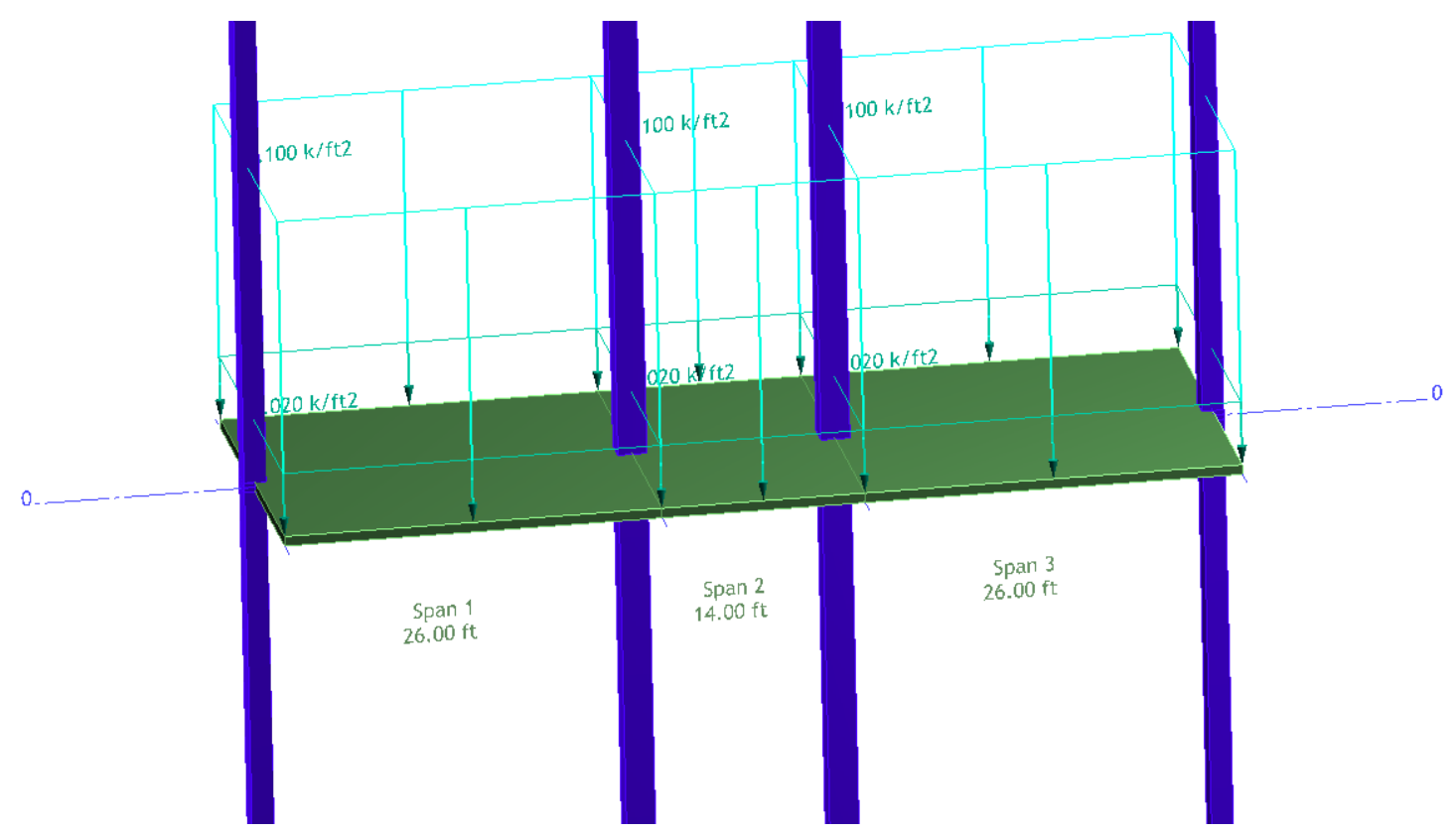

Figure W: ADAPT-PT Model for Equivalent Frame for Grids B through H 
6.0 Analysis 53

change either of these two variables, the design is "recycled" and the calculations are repeated to determine if the requirements are met. ADAPT-PT provides the rebar and shear stud requirements in a report called the Summary Report.

\subsubsection{ADAPT Results}

The results from ADAPT-PT are tabulated in Table L through Table S, on the following pages, in a manner similar to the results from the hand analysis. The tables are set up the same as Table $\mathrm{C}$ through Table $\mathrm{J}$, providing the required number of posttensioning strands for each frame, the required size and number of rebar, and the shear stud requirements. The spacing of the uniform strands was not tabulated because ADAPT-PT does not distinguish between banded and uniform tendons. The total number of bars is tabulated in Table L through Table $\mathrm{S}$ for the spans because ADAPT-PT does not provide spacing information. The designations of "inside column/span" and "outside column/span" remain the same as for Table C through Table J. The shear stud requirements are tabulated as either required (RE) or not required (NR) because ADAPTPT does not provide the number of studs required.

For slabs 1-5, two different iterations are tabulated: first the design with the same tendon profile as the profile used in the hand analysis, and second the default design from ADAPT-PT. Both results are tabulated to illustrate how varying the tendon profile affects the amount of post-tensioning required. The last three slabs were analyzed only using the default design from ADAPT-PT based on a load balancing ratio ranging from 75\%-100\% to see how close the results came to the hand analysis where $85 \%$ load balancing was assumed the most effective ratio. The ADAPT-PT Recycling window detailing the post- 
6.0 Analysis 54

tensioning design and the Summary Report detailing the rebar and shear design for all of the slabs can be found in Appendix C, pages xcii through cxlvii. The rebar requirements tabulated in the tables comes from ADAPT-PT's Summary Report for the envelope design, so it includes rebar for all code requirements. To provide a more complete comparison, Slab 3 includes the ADAPT-PT design for the equivalent frames along Grids 1 and 4, and along Grids A and I. ADAPT-PT did not allow the columns to be moved to the edge of the slab as they are in the actual layout, so the columns remain in the center of the slab as shown in Figure W, but the loads and other geometry remained the same, as if the columns were in the correct location. 


\section{Table L: Slab 1 ADAPT-PT Design}

Same Profile

\begin{tabular}{|c|c|c|c|c|c|}
\hline & & \multicolumn{4}{|c|}{ Frames } \\
\hline & & $1 \& 4$ & $2 \& 3$ & A \& I & B-H \\
\hline \multirow{3}{*}{ 는 } & Total PT & & 21 & & 27 \\
\hline & Over Columns & & & & \\
\hline & Uniform & & & & \\
\hline \multirow{4}{*}{ 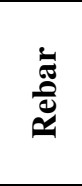 } & Outside Columns & & $5 \# 5$ & & $7 \# 5$ \\
\hline & Inside Columns & & $7 \# 5$ & & $7 \# 5$ \\
\hline & Outside Spans & & $3 \# 7$ & & $6 \# 7$ \\
\hline & Inside Spans & & $2 \# 7$ & & \\
\hline \multirow{3}{*}{ 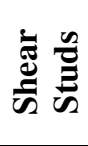 } & Exterior Columns & & $(\mathrm{NR})$ & & $(\mathrm{RE})$ \\
\hline & Interior Columns & & NR & & $\mathrm{RE}$ \\
\hline & Corner Columns & & & & \\
\hline
\end{tabular}

\section{ADAPT Default}

\begin{tabular}{|c|c|c|c|c|c|}
\hline & & \multicolumn{4}{|c|}{ Frames } \\
\hline & & $1 \& 4$ & $2 \& 3$ & A \& I & $\mathrm{B}-\mathrm{H}$ \\
\hline \multirow{3}{*}{$\underline{a}$} & Total PT & & 28 & & 40 \\
\hline & Over Columns & & & & \\
\hline & Uniform & & & & \\
\hline & & & & & \\
\hline \multirow{4}{*}{ 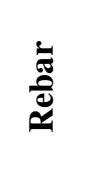 } & Outside Columns & & $5 \# 5$ & & $7 \# 5$ \\
\hline & Inside Columns & & $7 \# 5$ & & $7 \# 5$ \\
\hline & Outside Spans & & & & \\
\hline & Inside Spans & & & & \\
\hline & & & & & \\
\hline \multirow{3}{*}{ 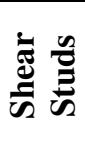 } & Exterior Columns & & NR & & NR \\
\hline & Interior Columns & & NR & & NR \\
\hline & Corner Columns & & & & \\
\hline
\end{tabular}




\section{Table M: Slab 2 ADAPT-PT Design}

Same Profile

\begin{tabular}{|c|c|c|c|c|c|}
\hline & & \multicolumn{4}{|c|}{ Frames } \\
\hline & & $1 \& 4$ & $2 \& 3$ & A \& I & B-H \\
\hline \multirow{3}{*}{$\underline{\omega}$} & Total PT & & 19 & & 24 \\
\hline & Over Columns & & & & \\
\hline & Uniform & & & & \\
\hline \multirow{4}{*}{ 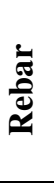 } & Outside Columns & & $5 \# 5$ & & $7 \# 5$ \\
\hline & Inside Columns & & 7 \#5 & & $7 \# 5$ \\
\hline & Outside Spans & & $5 \# 7$ & & $8 \# 7$ \\
\hline & Inside Spans & & $4 \# 7$ & & \\
\hline \multirow{3}{*}{ 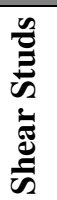 } & $\begin{array}{l}\text { Exterior } \\
\text { Columns }\end{array}$ & & NR & & $\mathrm{RE}$ \\
\hline & Interior Columns & & NR & & $\mathrm{RE}$ \\
\hline & Corner Columns & & & & \\
\hline
\end{tabular}

\section{ADAPT Default}

\begin{tabular}{|c|c|c|c|c|c|}
\hline & & \multicolumn{4}{|c|}{ Frames } \\
\hline & & $1 \& 4$ & $2 \& 3$ & A \& I & B-H \\
\hline \multirow{3}{*}{$\hat{a}$} & Total PT & & 26 & & 36 \\
\hline & Over Columns & & & & \\
\hline & Uniform & & & & \\
\hline \multirow{4}{*}{ 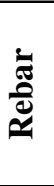 } & Outside Columns & & $5 \# 5$ & & $7 \# 5$ \\
\hline & Inside Columns & & $7 \# 5$ & & $7 \# 5$ \\
\hline & Outside Spans & & $2 \# 7$ & & $3 \# 7$ \\
\hline & Inside Spans & & $2 \# 7$ & & \\
\hline \multirow{3}{*}{ 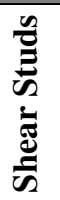 } & $\begin{array}{l}\text { Exterior } \\
\text { Columns }\end{array}$ & & NR & & RE \\
\hline & Interior Columns & & NR & & RE \\
\hline & Corner Columns & & & & \\
\hline
\end{tabular}




\section{Table N: Slab 3 ADAPT-PT Design}

Same Profile

\begin{tabular}{|c|c|c|c|c|c|}
\hline & \multicolumn{4}{|c|}{ Frames } \\
\hline & & $1 \& 4$ & $2 \& 3$ & A \& I & $\mathrm{B}-\mathrm{H}$ \\
\hline \multirow{3}{*}{$\underline{a}$} & Total PT & 12 & 18 & 12 & 23 \\
\hline & Over Columns & & & & \\
\hline & Uniform & & & & \\
\hline & & & & & \\
\hline \multirow{4}{*}{ 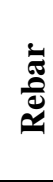 } & Outside Columns & 4 \#5 & $5 \# 5$ & $4 \# 5$ & 7 \#5 \\
\hline & Inside Columns & $7 \# 5$ & $7 \# 5$ & $5 \# 5$ & $7 \# 5$ \\
\hline & Outside Spans & $4 \# 7$ & $6 \# 7$ & $4 \# 7$ & $8 \# 7$ \\
\hline & Inside Spans & $3 \# 7$ & $4 \# 7$ & & \\
\hline & & & & & \\
\hline \multirow{3}{*}{ 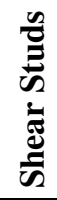 } & $\begin{array}{l}\text { Exterior } \\
\text { Columns }\end{array}$ & NR & NR & & $\mathrm{RE}$ \\
\hline & Interior Columns & & NR & & $\mathrm{RE}$ \\
\hline & Corner Columns & & & & \\
\hline
\end{tabular}

\section{ADAPT Default}

\begin{tabular}{|c|c|c|c|c|c|}
\hline & & \multicolumn{4}{|c|}{ Frames } \\
\hline & & $1 \& 4$ & $2 \& 3$ & A \& I & B-H \\
\hline \multirow{3}{*}{$\bar{\Delta}$} & Total PT & & 24 & & 34 \\
\hline & Over Columns & & & & \\
\hline & Uniform & & & & \\
\hline \multirow{5}{*}{ 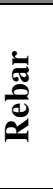 } & & & & & \\
\hline & Outside Columns & & $5 \# 5$ & & $7 \# 5$ \\
\hline & Inside Columns & & $7 \# 5$ & & 7 \#5 \\
\hline & Outside Spans & & $3 \# 7$ & & $5 \# 7$ \\
\hline & Inside Spans & & $2 \# 7$ & & \\
\hline \multirow{3}{*}{ 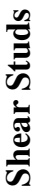 } & $\begin{array}{l}\text { Exterior } \\
\text { Columns } \\
\end{array}$ & & NR & & $\mathrm{RE}$ \\
\hline & Interior Columns & & NR & & $\mathrm{RE}$ \\
\hline & Corner Columns & & & & \\
\hline
\end{tabular}




\section{Table O: Slab 4 ADAPT-PT Design}

Same Profile

\begin{tabular}{|c|c|c|c|c|c|}
\hline & & \multicolumn{4}{|c|}{ Frames } \\
\hline & & $1 \& 4$ & $2 \& 3$ & A \& I & B-H \\
\hline \multirow{3}{*}{ 氖 } & Total PT & & 17 & & 22 \\
\hline & Over Columns & & & & \\
\hline & Uniform & & & & \\
\hline \multirow{4}{*}{ 䒕 } & Outside Columns & & $5 \# 5$ & & $7 \# 5$ \\
\hline & Inside Columns & & $7 \# 5$ & & $7 \# 5$ \\
\hline & Outside Spans & & 7 \#7 & & $10 \# 7$ \\
\hline & Inside Spans & & $5 \# 7$ & & \\
\hline \multirow{3}{*}{ 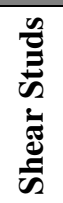 } & $\begin{array}{l}\text { Exterior } \\
\text { Columns }\end{array}$ & & NR & & $\mathrm{RE}$ \\
\hline & Interior Columns & & NR & & $\mathrm{RE}$ \\
\hline & Corner Columns & & & & \\
\hline
\end{tabular}

\section{ADAPT Default}

\begin{tabular}{|c|c|c|c|c|c|}
\hline & & \multicolumn{4}{|c|}{ Frames } \\
\hline & & $1 \& 4$ & $2 \& 3$ & A \& I & B-H \\
\hline \multirow{3}{*}{$\hat{\Lambda}$} & Total PT & & 23 & & 37 \\
\hline & Over Columns & & & & \\
\hline & Uniform & & & & \\
\hline & & & & & \\
\hline \multirow{4}{*}{ 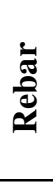 } & Outside Columns & & $5 \# 5$ & & $7 \# 5$ \\
\hline & Inside Columns & & $7 \# 5$ & & $7 \# 5$ \\
\hline & Outside Spans & & 4 \#7 & & 4 \#7 \\
\hline & Inside Spans & & $3 \# 7$ & & \\
\hline & & & & & \\
\hline \multirow{3}{*}{ 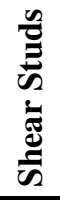 } & $\begin{array}{l}\text { Exterior } \\
\text { Columns }\end{array}$ & & NR & & RE \\
\hline & Interior Columns & & NR & & $\mathrm{RE}$ \\
\hline & Corner Columns & & & & \\
\hline
\end{tabular}




\section{Table P: Slab 5 ADAPT-PT Design}

\section{Same Profile}

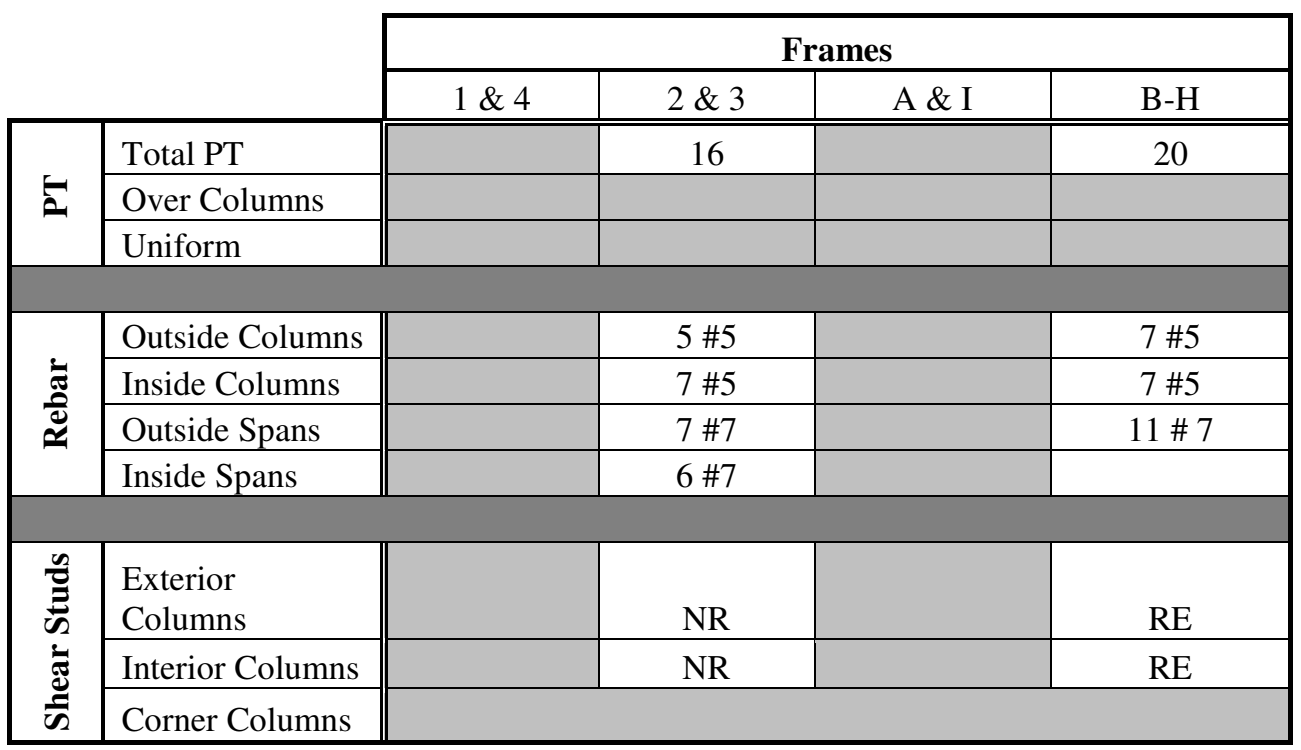

\section{ADAPT Default}

\begin{tabular}{|c|c|c|c|c|c|}
\hline & \multicolumn{4}{|c|}{ Frames } \\
\hline & & $1 \& 4$ & $2 \& 3$ & A \& I & B-H \\
\hline \multirow{3}{*}{$\bar{a}$} & Total PT & & 21 & & 36 \\
\hline & Over Columns & & & & \\
\hline & Uniform & & & & \\
\hline & & & & & \\
\hline \multirow{4}{*}{ 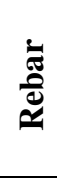 } & Outside Columns & & $5 \# 5$ & & $7 \# 5$ \\
\hline & Inside Columns & & $7 \# 5$ & & $7 \# 5$ \\
\hline & Outside Spans & & $5 \# 7$ & & $5 \# 7$ \\
\hline & Inside Spans & & $4 \# 7$ & & \\
\hline \multirow{4}{*}{ 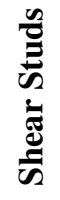 } & & & & & \\
\hline & Exterior & & NR & & $\mathrm{RF}$ \\
\hline & Interior Columns & & NR & & $\mathrm{RE}$ \\
\hline & Corner Columns & & & & \\
\hline
\end{tabular}




\section{Table Q: Slab 6 ADAPT-PT Design}

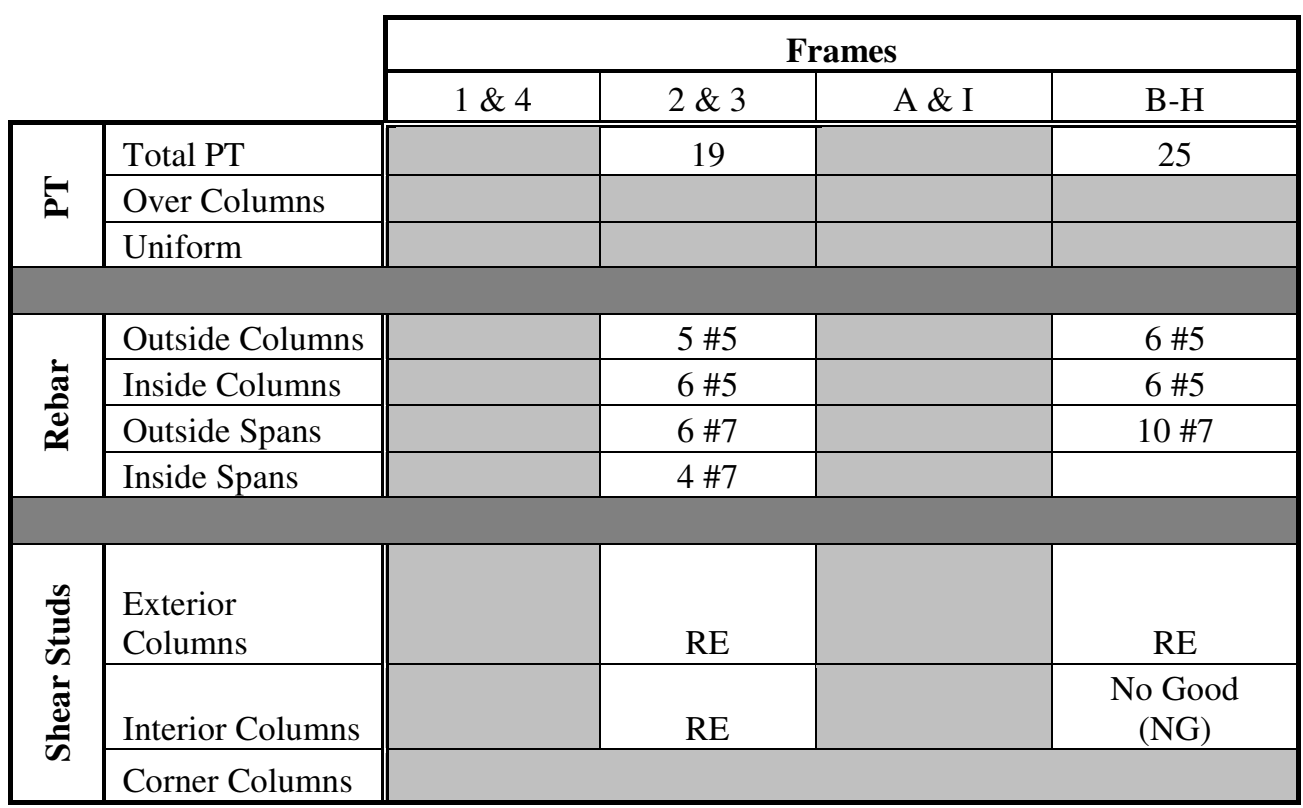

\section{Table R: Slab 7 ADAPT-PT Design}

\begin{tabular}{|c|c|c|c|c|c|}
\hline & \multicolumn{4}{|c|}{ Frames } \\
\hline & & $1 \& 4$ & $2 \& 3$ & A \& I & B-H \\
\hline \multirow{3}{*}{$\bar{a}$} & Total PT & & 19 & & 28 \\
\hline & Over Columns & & & & \\
\hline & Uniform & & & & \\
\hline & & & & & \\
\hline \multirow{4}{*}{ 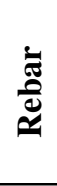 } & Outside Columns & & $6 \# 5$ & & $7 \# 5$ \\
\hline & Inside Columns & & $7 \# 5$ & & $7 \# 5$ \\
\hline & Outside Spans & & $7 \# 7$ & & $11 \# 7$ \\
\hline & Inside Spans & & $2 \# 7$ & & \\
\hline \multirow{3}{*}{ 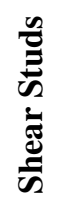 } & $\begin{array}{l}\text { Exterior } \\
\text { Columns }\end{array}$ & & NR & & NR \\
\hline & Interior Columns & & NR & & $\mathrm{RE}$ \\
\hline & Corner Columns & & & & \\
\hline
\end{tabular}




\section{Table S: Slab 8 ADAPT-PT Design}

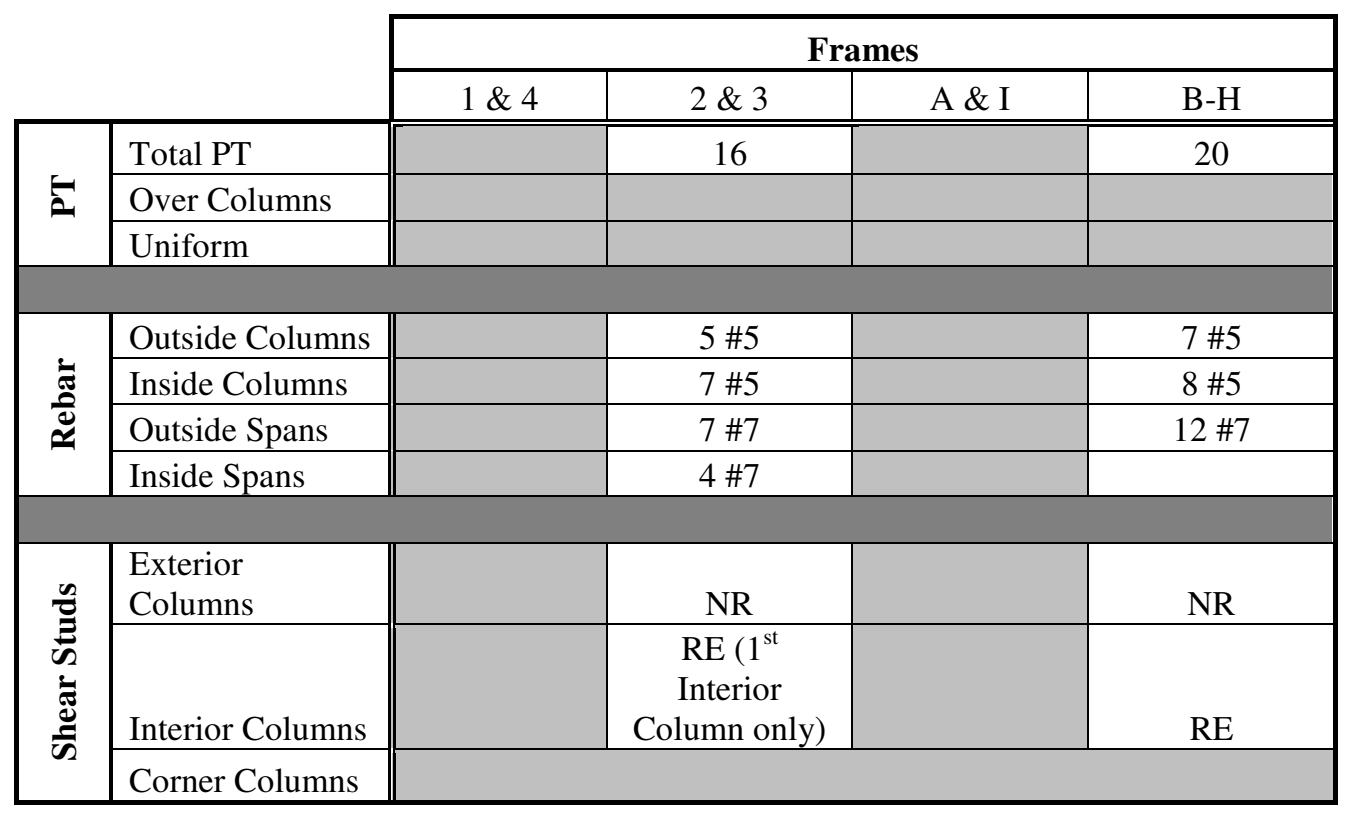

\subsection{Comparison Between Hand and ADAPT-PT Designs}

The results found in the hand analysis share some similarities and some differences to the results found in the ADAPT-PT analysis. The post-tensioning design for both came out very similar, but the rebar and shear stud reinforcing varied between the two. In general, the ADAPT-PT analysis required more non-prestressed reinforcing over the columns than the hand analysis, but less non-prestressed reinforcing in the spans than the hand analysis. The ADAPT-PT also required less shear reinforcing than the hand analysis.

The required number of post-tensioning tendons in the ADAPT-PT solutions correlates well with the numbers from the hand analysis. For Slabs 1 through 5, when two different tendon profiles were tabulated, the tendons required for the profile used in the 
6.0 Analysis 62

hand analysis varied by one or two strands. Also, the tendons required for Slabs 6, 7, and 8 , while they varied by more strands than Slabs 1 through 5, were close to the numbers found in the hand analysis. Table $\mathrm{T}$ below provides a comparison of the number of post-tensioning strands needed for the two different equivalent frames found with the Table T: Comparison of Post-Tensioning Strand Requirements

\begin{tabular}{|c||c|c|c|c|c|c|}
\hline \multicolumn{1}{|c||}{} & \multicolumn{2}{c|}{ Hand } & \multicolumn{2}{c|}{$\begin{array}{c}\text { ADAPT } \\
\text { (Same Profile) }\end{array}$} & \multicolumn{2}{c|}{$\begin{array}{c}\text { ADAPT } \\
\text { (Default) }\end{array}$} \\
\cline { 2 - 7 } Slab & $\mathbf{2 ~ \& ~ 3}$ & B-H & $\mathbf{2 ~ \& ~ 3}$ & B-H & $\mathbf{2 ~ \& ~ 3}$ & B-H \\
\hline \hline $\mathbf{1}$ & 23 & 29 & 21 & 27 & 28 & 40 \\
\hline $\mathbf{2}$ & 20 & 26 & 19 & 24 & 26 & 36 \\
\hline $\mathbf{3}$ & 19 & 25 & 18 & 23 & 24 & 34 \\
\hline $\mathbf{4}$ & 18 & 23 & 17 & 22 & 23 & 37 \\
\hline $\mathbf{5}$ & 17 & 22 & 16 & 20 & 21 & 36 \\
\hline $\mathbf{6}$ & 21 & 27 & & & 19 & 25 \\
\hline $\mathbf{7}$ & 18 & 24 & & & 15 & 28 \\
\hline $\mathbf{8}$ & 18 & 24 & & & 16 & 20 \\
\hline
\end{tabular}

hand analysis and the ADAPT-PT analysis. These discrepancies are most likely due to ADAPT-PT's use of $175 \mathrm{ksi}$ as the final effective strength of the post-tensioning instead of the $160 \mathrm{ksi}$ used in the hand analysis. From Table N, it can be seen that results from ADAPT-PT for the equivalent frame along Grids 1 and 4, and along Grids A and I are also within a one-strand difference from the hand analysis.

The rebar designed by ADAPT-PT did not compare as well to the hand analysis as the post-tensioning. Overall, ADAPT-PT found that more reinforcing was required over the columns than the hand calculations and less reinforcing was needed in the spans than the hand calculations. Table $\mathrm{U}$ on the next page tabulates a comparison of the nonprestressed reinforcing requirements between the hand analysis and the ADAPT-PT 
6.0 Analysis 63

analysis. The results tabulated from ADAPT-PT are from the analysis using the same tendon profile as the hand analysis. Table $U$ provides the number of bars required at each

Table U: Comparison of Non-Prestressed Reinforcing Requirements

\begin{tabular}{|c|c|c|c|c|c|c|c|c|c|c|}
\hline & & Slab & 1 & 2 & 3 & 4 & 5 & 6 & 7 & 8 \\
\hline \multirow{8}{*}{ 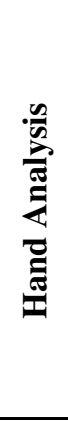 } & \multirow{4}{*}{$\begin{array}{l}m \\
\ddot{z} \\
\sim\end{array}$} & 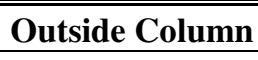 & & & & & & & & \\
\hline & & Inside Column & $5 \# 5$ & $5 \# 5$ & $5 \# 5$ & $6 \# 5$ & 7 \#5 & $5 \# 5$ & $6 \# 5$ & $5 \# 5$ \\
\hline & & Outside Span & & $12 \# 7$ & $12 \# 7$ & $14 \# 7$ & $14 \# 7$ & $14 \# 8$ & $12 \# 7$ & $12 \# 7$ \\
\hline & & Inside Span & & $10 \# 7$ & $11 \# 7$ & $11 \# 7$ & $13 \# 7$ & $13 \# 7$ & $10 \# 7$ & $11 \# 7$ \\
\hline & \multirow{4}{*}{ ف) } & Outside Column & $3 \# 5$ & $3 \# 5$ & $4 \# 5$ & $3 \# 5$ & & & & \\
\hline & & Inside Column & $3 \# 5$ & $7 \# 5$ & $7 \# 5$ & $7 \# 5$ & $6 \# 5$ & $6 \# 5$ & $7 \# 5$ & $7 \# 5$ \\
\hline & & Outside Span & & $18 \# 7$ & $18 \# 7$ & $18 \# 7$ & $18 \# 7$ & $18 \# 7$ & $18 \# 7$ & $18 \# 7$ \\
\hline & & Inside Span & & & & & & & & \\
\hline \multirow{8}{*}{ 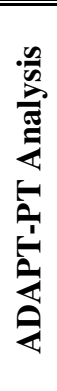 } & \multirow{4}{*}{$\begin{array}{l}m \\
\ddot{N} \\
\sim\end{array}$} & " Outside Column & $5 \# 5$ & $5 \# 5$ & $5 \# 5$ & $5 \# 5$ & $5 \# 5$ & $5 \# 5$ & $6 \# 5$ & $5 \# 5$ \\
\hline & & Inside Column & $7 \# 5$ & $7 \# 5$ & $7 \# 5$ & $7 \# 5$ & $7 \# 5$ & $6 \# 5$ & $7 \# 5$ & $7 \# 5$ \\
\hline & & Outside Span & $3 \# 7$ & $5 \# 7$ & $6 \# 7$ & $7 \# 7$ & $7 \# 7$ & $6 \# 7$ & $7 \# 7$ & $7 \# 7$ \\
\hline & & Inside Span & $2 \# 7$ & $4 \# 7$ & $4 \# 7$ & $5 \# 7$ & $6 \# 7$ & $4 \# 7$ & $2 \# 7$ & $4 \# 7$ \\
\hline & \multirow{4}{*}{ 呄 } & Outside Column & $7 \# 5$ & $7 \# 5$ & $7 \# 5$ & $7 \# 5$ & $7 \# 5$ & $6 \# 5$ & $7 \# 5$ & $7 \# 5$ \\
\hline & & Inside Column & $7 \# 5$ & $7 \# 5$ & $7 \# 5$ & 7 \#5 & $7 \# 5$ & $6 \# 5$ & $7 \# 5$ & $8 \# 5$ \\
\hline & & Outside Span & $6 \# 7$ & $8 \# 7$ & $8 \# 7$ & $10 \# 7$ & $11 \# 7$ & $10 \# 7$ & $11 \# 7$ & $12 \# 7$ \\
\hline & & Inside Span & & & & & & & & \\
\hline
\end{tabular}

condition as well as the size of the rebar; for example, " $5 \# 5$ " is read as five number five size bars of rebar. One of the most obvious differences is that ADAPT-PT found rebar was required for the outside columns for the equivalent frame along Grids 2 and 3 for all the slabs, whereas the hand analysis found this rebar was not required. According to ACI 318-05, non-prestressed reinforcing is required when the stress exceeds $2.0 \sqrt{f_{c}{ }^{\prime}}$. For the hand analysis, the stress at these columns did not exceed this requirement, though Slabs 5 and 6 were close to the limit. Another reason for this discrepancy is that the hand analysis took into consideration the fact that along Grids 2 and 3 the post-tensioning tendons are banded together, and therefore the ultimate flexural strength check within $1.5 \mathrm{~h}$ of the 
column was not performed. Not assuming banded tendons would require more reinforcing at the columns to ensure the strength requirement is met.

The difference between the amount of reinforcing in the spans between the two analyses also varies. The amount of reinforcing required in the spans, positive moment areas, is defined in Section 18.9.3.2 of ACI 318-05 as

$$
A_{s}=\frac{N_{c}}{0.5 f_{y}}
$$

Where $\mathrm{N}_{\mathrm{c}}$ is defined by ACI 318-05 as the tension force in the concrete due to the unfactored dead load plus live load.

Section 18.9.3.2 also specifies the reinforcement be uniformly distributed over the precompressed tensile zone. For most of the frames the hand analysis calculated the required non-prestressed reinforcing to be about twice that found using ADAPT-PT. This is probably due to ADAPT-PT's ability to calculate the stresses in the section more accurately than the hand analysis. The effect of the post-tensioning force on the overall stress of the section can be more accurately modeled using ADAPT-PT than the hand analysis which assumes a compressive effect on the section under the load balancing assumption. However, the requirements found in the hand analysis seem more reasonable due to the constraint in the code that this reinforcing be uniformly distributed. ADAPTPT requires a range of 2 to $12 \# 7$ bars in the spans, providing a distribution of at most bars at $120 "$ on center, and the least, bars at $26 "$ on center, neither of which provide much of a distribution of bars across the frame. The hand analysis on the other hand provides bars spaced at most $26 "$ on center and the least $16 "$ on center. 
In several instances, ADAPT-PT indicated shear studs were not required in areas where the hand calculations required them. For Slab 8, ADAPT-PT indicated only the first interior column required shear reinforcing, whereas the hand calculations required shear reinforcing at all interior columns. Because the worst case scenario, the first interior column, was used to design the reinforcement needed for all columns, there most likely is not a difference between the hand calculations and the ADAPT-PT analysis. ADAPT-PT is also able to calculate the shear resistance added by the posttensioning tendon force more accurately than the hand calculations, resulting in less shear reinforcement required by ADAPT-PT than by the hand analysis. For the hand analysis, the shear in the tendons through the critical section was estimated as the total force in the tendons divided by an estimated radius of six feet for the circle formed by the tendon profile. Often this component is conservatively left out entirely for hand analysis, but ADAPT-PT can easily include it in the calculations performed by the program.

The comparison of the hand analysis to the ADAPT-PT analysis illustrates the pros and cons to each analysis. The similarities between the hand analysis and the ADAPT-PT analysis indicate both methods are adequate. However, using ADAPT-PT for the analysis was much faster than the hand analysis, and allowed a quicker means of changing parameters than the hand analysis. Therefore, it is recommended that ADAPTPT be used for this process. The requirements found for the non-prestressed reinforcement varied between the two methods. The reinforcement required over the columns was found to be closer than that required in the spans between the two analysis. Again, the ease of use with ADAPT-PT leads to the recommendation of using ADAPT- 
6.0 Analysis 66

PT over the hand calculations. ADAPT-PT also found more reinforcing was required over the columns than the hand calculations, making it the more conservative approach. The requirements found for the spans from the hand analysis appear to be more reasonable than those found using ADAPT-PT because more non-prestressed reinforcing was required leading to a more uniform distribution of this reinforcing across the equivalent frame. The ADAPT-PT analysis provides the user with whether or not shear reinforcing is required, but the user must then use some other means to actually calculate the shear reinforcing. Therefore, the hand analysis provides a better means of calculating this requirement. The general trends seen across the parametric study can be observed in both methods, so the cost analysis should provide similar trends regardless of which analysis results are used. 


\subsection{COST ANALYSIS}

To complete the parametric study, a cost analysis was performed for 10 cities across the United States for each of the 8 slabs. To perform this cost analysis, material quantities were tabulated using the designs determined in the hand analysis summarized in Section 6.1, starting on page 39. Then unit cost information was researched by contacting contractors and suppliers in industry and by using the Cost Index compiled by Engineering News Record (ENR) every month. The price for each slab was then determined using the material quantities and the unit costs.

\subsection{Unit Cost}

Prices for the material and installation costs of post-tensioning, rebar and concrete, both 5000 psi and 6000 psi, were compiled using a combination of quote prices from contractors and suppliers and prices from the Cost Index compiled by ENR (2009). Starting with a list of post-tensioning supplier contacts provided by Larry Krauser, posttensioning material and installation costs were gathered, along with further contacts for rebar material and installation costs, and concrete material and installation costs (2009). Any gaps in this process were filled with ratios from the prices gathered and from the Cost Index from ENR (2009). It was assumed that the ratios would suffice for this project because the prices will not be used for an actual project. It is also important to note that the unit prices found during this process are unique to this thesis because of fluctuating prices in the market. The prices compiled for this thesis can be found in Table $\mathrm{V}$ on the next page. The prices may not be a true average indicative of the city because in most 
Table V: Material and Installation Prices for 10 U.S. Cities

\begin{tabular}{|c|c|c|c|c|}
\hline & $\begin{array}{c}\text { Post- } \\
\text { Tensioning } \\
(\mathrm{PT})(\$ / \mathrm{lb}) \\
\end{array}$ & $\begin{array}{c}\text { PT } \\
\text { Installation } \\
(\$ / \mathbf{l b}) \\
\end{array}$ & Rebar (\$/ton) & $\begin{array}{c}\text { Rebar } \\
\text { Installation } \\
(\$ / \text { ton }) \\
\end{array}$ \\
\hline Atlanta & 0.95 & 0.6 & 850 & 250 \\
\hline Boston & 1.25 & 1.9 & 800 & 800 \\
\hline Chicago & $\begin{array}{l}1.05 \\
1.43 \\
\end{array}$ & $\begin{array}{c}1.93 \\
1.4\end{array}$ & 800 & 950 \\
\hline Denver & 1.00 & 0.5 & 625 & 275 \\
\hline Houston & 1.08 & 0.48 & 635 & 265 \\
\hline Los Angeles & 1.05 & 0.67 & 855 & 535 \\
\hline Miami & $\begin{array}{l}1.22 \\
1.20 \\
\end{array}$ & $\begin{array}{l}0.65 \\
0.58\end{array}$ & $\begin{array}{l}688 \\
620 \\
\end{array}$ & $\begin{array}{l}285 \\
240 \\
\end{array}$ \\
\hline Phoenix & $\begin{array}{l}1.10 \\
0.90 \\
\end{array}$ & 0.9 & 600 & 500 \\
\hline San Francisco & 1.05 & 0.8 & 835 & 575 \\
\hline Seattle & $\begin{array}{l}1.00 \\
1.03\end{array}$ & $\begin{array}{l}0.78 \\
0.63\end{array}$ & $\begin{array}{l}725 \\
900\end{array}$ & $\begin{array}{l}465 \\
425 \\
\end{array}$ \\
\hline
\end{tabular}

\begin{tabular}{|c|c|c|c|}
\hline & \multicolumn{2}{|c|}{ Concrete $\left(\$ / y d^{3}\right)$} & \multirow{2}{*}{$\begin{array}{c}\text { Concrete } \\
\text { Installation } \\
(\$ / \mathbf{s f}) \\
\end{array}$} \\
\hline & $\begin{array}{c}\mathbf{5 0 0 0} \\
\text { psi } \\
\end{array}$ & $\begin{array}{c}\text { 6000 } \\
\text { psi }\end{array}$ & \\
\hline Atlanta & 133 & 143 & 3.60 \\
\hline Boston & 143 & 153 & 9.68 \\
\hline Chicago & 142 & 152 & 10.92 \\
\hline Denver & 130 & 140 & 4.55 \\
\hline Houston & 138 & 148 & 4.27 \\
\hline Los Angeles & 134 & 144 & 4.68 \\
\hline Miami & 91 & 94 & 20.00 \\
\hline Phoenix & 136 & 146 & 11.50 \\
\hline $\begin{array}{l}\text { San } \\
\text { Francisco }\end{array}$ & 135 & 145 & 3.37 \\
\hline Seattle & 140 & 150 & 4.26 \\
\hline
\end{tabular}

Sources:
(Bromley 2009)
(Curry 2009)
(Dietrich 2009)
(ENR 2009)
(Cross 2009)
(Dickinson 2009)
(Eigenhus 2009)
(Harger 2009) 
7.0 Cost Analysis 69

$\begin{array}{llll}(\text { Keck 2009) } & \text { (MacRobert 2009) } & \text { (Postma 2009) } & \text { (Stoll 2009) } \\ (\text { Khosa 2009) } & (\text { Patel 2009) } & \text { (Price 2009) } & \text { (Valdes 2009) } \\ (\text { Klausmeyer 2009) } & (\text { Pena 2009) } & \text { (Reising 2009) } & \text { (Vance 2009) } \\ (\text { Kori 2009) } & \text { (Pomeroy 2009) } & \text { (Rusillo 2009) } & \text { (Wolfe 2009) }\end{array}$

cases, the unit cost is quoted from one source. Any cell with multiple values was averaged for the final cost analysis. To protect the costs quoted by the contractors and suppliers, the sources are attributed to the table rather than a specific number.

From Table V, it can be observed that Boston has the highest cost for posttensioning material, $\$ 1.25 / \mathrm{lb}$, and installation, $\$ 1.90 / \mathrm{lb}$; Atlanta has the highest cost for rebar material, $\$ 850 /$ ton; Chicago has the highest cost for rebar installation, $\$ 950 /$ ton; Boston has the highest price for concrete material, $\$ 143 / \mathrm{yd}^{3}$ for $5000 \mathrm{psi}$ concrete and $\$ 153 / \mathrm{yd}^{3}$ for $6000 \mathrm{psi}$ concrete; and Miami has the highest cost for concrete installation, $\$ 20.00 /$ sf. Atlanta has the lowest cost for post-tensioning material, $\$ 0.95 / \mathrm{lb}$, and installation, $\$ 0.60 / \mathrm{lb}$; Phoenix has the lowest cost for rebar material, $\$ 600 /$ ton; Atlanta has the lowest cost for rebar installation, $\$ 250 /$ ton; Miami has the lowest cost for concrete material, $\$ 91 / \mathrm{yd}^{3}$ for $5000 \mathrm{psi}$ concrete and $\$ 94 / \mathrm{yd}^{3}$ for $6000 \mathrm{psi}$ concrete; and San Francisco has the lowest cost for concrete installation, \$3.37/sf.

\subsection{Cost Analysis}

To perform the cost analysis on the 8 slabs designed in Table B, the designs found in the hand analysis were used because the requirements were more completely tabulated for this process than for the ADAPT-PT analysis. Weight for support/back-up bars and trim steel was added to the quantities found in the hand analysis for each slab to provide a 
7.0 Cost Analysis 70

more accurate quantity of rebar. Support bars are used to profile the tendons at correct heights and back-up bars help distribute the force at the anchorage points of the posttensioning into the concrete; these were estimated at $0.25 \mathrm{psf}$. Trim steel is used around any openings in the slab and was estimated at $0.15 \mathrm{psf}$ (Krauser 2009). Overall, support/back-up bars and trim steel added 2.7 tons of rebar weight to each slab. Table W below provides the revised numbers from Table $\mathrm{K}$. The number of shear rails was not Table W: Adjusted Material Quantities

\begin{tabular}{|c|c|c|c|}
\hline \multirow{2}{*}{ Slab } & \multicolumn{3}{|c|}{ Slab Totals } \\
\cline { 2 - 4 } & Prestress (lbs) & Rebar (tons) & Concrete $\left(\mathbf{y d}^{\mathbf{3}}\right.$ ) \\
\hline \hline $\mathbf{1}$ & 16373 & 3.5 & 339.0 \\
\hline $\mathbf{2}$ & 14415 & 11.4 & 339.0 \\
\hline $\mathbf{3}$ & 13954 & 11.8 & 339.0 \\
\hline $\mathbf{4}$ & 12963 & 13.5 & 339.0 \\
\hline $\mathbf{5}$ & 12214 & 14.0 & 339.0 \\
\hline $\mathbf{6}$ & 15164 & 11.8 & 296.6 \\
\hline $\mathbf{7}$ & 13205 & 10.2 & 381.3 \\
\hline $\mathbf{8}$ & 13954 & 11.8 & 339.0 \\
\hline
\end{tabular}

included in Table $\mathrm{W}$ because shear rails are a specialized material not included in the ENR cost index, nor provided by the rebar material providers or contractors contacted for the research in this paper. The price for stud rails in Denver and Miami were quoted and provide an estimate of shear stud cost on the overall price. Stud rails in Denver were quoted as $\$ 45$ per rail, and in Miami as $\$ 18$ per rail, adding a total of $\$ 6660$ to the slab prices in Denver and \$2664 to the slab prices in Miami. While this cost does not add a significant amount to the slabs priced in this thesis, prices for the other cities are unknown and therefore the cost estimate from this thesis should not be taken as a complete cost estimate. Another reason this estimate should not be assumed complete is 
7.0 Cost Analysis 71

that only the gravity slab is included in this cost; for a real project, there are many

elements which would need to be included, such as the lateral force resisting system

elements, columns, foundations, etc.

From the revised weight estimates in Table W, the cost analysis was performed.

The price for each slab in the 10 cities can be found below in Table $\mathrm{X}$. The price

estimates are rounded up to the nearest $\$ 100$. Several conclusions can be made using

Table X: Slab Prices for 10 U.S. Cities

\begin{tabular}{|c||c|c|c|c|c|}
\hline \multicolumn{1}{|c||}{ Slab } & \multicolumn{5}{c|}{ Price } \\
\cline { 2 - 6 } & Atlanta & Boston & Chicago & Denver & Houston \\
\hline \hline $\mathbf{1}$ & $\$ 123,800$ & $\$ 238,600$ & $\$ 251,800$ & $\$ 134,300$ & $\$ 134,200$ \\
\hline $\mathbf{2}$ & $\$ 129,500$ & $\$ 245,100$ & $\$ 259,900$ & $\$ 138,500$ & $\$ 138,200$ \\
\hline $\mathbf{3}$ & $\$ 129,200$ & $\$ 244,300$ & $\$ 259,300$ & $\$ 138,200$ & $\$ 137,900$ \\
\hline $\mathbf{4}$ & $\$ 129,500$ & $\$ 243,900$ & $\$ 259,400$ & $\$ 138,200$ & $\$ 137,900$ \\
\hline $\mathbf{5}$ & $\$ 128,900$ & $\$ 242,400$ & $\$ 258,100$ & $\$ 137,500$ & $\$ 137,100$ \\
\hline $\mathbf{6}$ & $\$ 125,500$ & $\$ 242,100$ & $\$ 256,800$ & $\$ 134,500$ & $\$ 133,900$ \\
\hline $\mathbf{7}$ & $\$ 131,900$ & $\$ 245,500$ & $\$ 260,300$ & $\$ 141,100$ & $\$ 141,100$ \\
\hline $\mathbf{8}$ & $\$ 132,600$ & $\$ 247,700$ & $\$ 262,700$ & $\$ 141,600$ & $\$ 141,300$ \\
\hline
\end{tabular}

\begin{tabular}{|c||c|c|c|c|c|}
\hline \multirow{2}{*}{ Slab } & \multicolumn{5}{|c|}{ Price } \\
\cline { 2 - 6 } & $\begin{array}{c}\text { Los } \\
\text { Angeles }\end{array}$ & Miami & Phoenix & $\begin{array}{c}\text { San } \\
\text { Francisco }\end{array}$ & Seattle \\
\hline \hline $\mathbf{1}$ & $\$ 142,800$ & $\$ 338,500$ & $\$ 239,000$ & $\$ 127,400$ & $\$ 138,400$ \\
\hline $\mathbf{2}$ & $\$ 150,400$ & $\$ 342,200$ & $\$ 244,000$ & $\$ 134,900$ & $\$ 148,000$ \\
\hline $\mathbf{3}$ & $\$ 150,200$ & $\$ 341,700$ & $\$ 243,600$ & $\$ 134,600$ & $\$ 144,700$ \\
\hline $\mathbf{4}$ & $\$ 150,800$ & $\$ 341,500$ & $\$ 243,500$ & $\$ 135,200$ & $\$ 145,200$ \\
\hline $\mathbf{5}$ & $\$ 150,200$ & $\$ 340,600$ & $\$ 242,700$ & $\$ 134,500$ & $\$ 144,500$ \\
\hline $\mathbf{6}$ & $\$ 146,600$ & $\$ 340,100$ & $\$ 240,100$ & $\$ 131,100$ & $\$ 140,900$ \\
\hline $\mathbf{7}$ & $\$ 152,300$ & $\$ 342,700$ & $\$ 246,100$ & $\$ 136,700$ & $\$ 147,400$ \\
\hline $\mathbf{8}$ & $\$ 153,600$ & $\$ 342,700$ & $\$ 247,000$ & $\$ 138,000$ & $\$ 148,100$ \\
\hline
\end{tabular}

Optimization of Two-Way Post-Tensioned Concrete Floor Systems 
7.0 Cost Analysis 72

Table $\mathrm{X}$ about price estimates in the 10 U.S. cities included in the cost analysis. First, for all the cities, Slab 1, with $100 \%$ of the dead load balanced by the post-tensioning, was the least expensive, and Slab 8, using 6000 psi strength concrete, was the most expensive. Second, Miami had the most expensive slabs and Atlanta had the least expensive. A second table for the cost estimates, Table $\mathrm{Y}$, is presented below. This table breaks the price down as dollars per square foot, a number that can be used to estimate an entire Table Y: Slab Price per Square Foot for 10 U.S. Cities

\begin{tabular}{|c||c|c|c|c|c|}
\hline \multicolumn{1}{|c||}{ Slab } & \multicolumn{5}{|c|}{ Price per Square Foot } \\
\cline { 2 - 6 } & Atlanta & Boston & Chicago & Denver & Houston \\
\hline \hline $\mathbf{1}$ & $\$ 9.02$ & $\$ 17.38$ & $\$ 18.34$ & $\$ 9.78$ & $\$ 9.78$ \\
\hline $\mathbf{2}$ & $\$ 9.43$ & $\$ 17.85$ & $\$ 18.93$ & $\$ 10.09$ & $\$ 10.07$ \\
\hline $\mathbf{3}$ & $\$ 9.41$ & $\$ 17.80$ & $\$ 18.89$ & $\$ 10.07$ & $\$ 10.05$ \\
\hline $\mathbf{4}$ & $\$ 9.43$ & $\$ 17.77$ & $\$ 18.90$ & $\$ 10.07$ & $\$ 10.05$ \\
\hline $\mathbf{5}$ & $\$ 9.39$ & $\$ 17.66$ & $\$ 18.80$ & $\$ 10.02$ & $\$ 9.99$ \\
\hline $\mathbf{6}$ & $\$ 9.14$ & $\$ 17.64$ & $\$ 18.71$ & $\$ 9.80$ & $\$ 9.75$ \\
\hline $\mathbf{7}$ & $\$ 9.61$ & $\$ 17.88$ & $\$ 18.96$ & $\$ 10.28$ & $\$ 10.28$ \\
\hline $\mathbf{8}$ & $\$ 9.66$ & $\$ 18.04$ & $\$ 19.14$ & $\$ 10.31$ & $\$ 10.29$ \\
\hline
\end{tabular}

\begin{tabular}{|c||c|c|c|c|c|}
\hline \multicolumn{1}{|c||}{ Slab } & \multicolumn{5}{|c|}{ Price per Square Foot } \\
\cline { 2 - 6 } & $\begin{array}{c}\text { Los } \\
\text { Angeles }\end{array}$ & Miami & Phoenix & $\begin{array}{c}\text { San } \\
\text { Francisco }\end{array}$ & Seattle \\
\hline \hline $\mathbf{1}$ & $\$ 10.40$ & $\$ 24.66$ & $\$ 17.41$ & $\$ 9.28$ & $\$ 10.08$ \\
\hline $\mathbf{2}$ & $\$ 10.96$ & $\$ 24.93$ & $\$ 17.77$ & $\$ 9.83$ & $\$ 10.78$ \\
\hline $\mathbf{3}$ & $\$ 10.94$ & $\$ 24.89$ & $\$ 17.74$ & $\$ 9.80$ & $\$ 10.54$ \\
\hline $\mathbf{4}$ & $\$ 10.98$ & $\$ 24.88$ & $\$ 17.74$ & $\$ 9.85$ & $\$ 10.58$ \\
\hline $\mathbf{5}$ & $\$ 10.94$ & $\$ 24.81$ & $\$ 17.68$ & $\$ 9.80$ & $\$ 10.53$ \\
\hline $\mathbf{6}$ & $\$ 10.68$ & $\$ 24.77$ & $\$ 17.49$ & $\$ 9.55$ & $\$ 10.26$ \\
\hline $\mathbf{7}$ & $\$ 11.09$ & $\$ 24.96$ & $\$ 17.93$ & $\$ 9.96$ & $\$ 10.74$ \\
\hline $\mathbf{8}$ & $\$ 11.19$ & $\$ 24.96$ & $\$ 17.99$ & $\$ 10.05$ & $\$ 10.79$ \\
\hline
\end{tabular}


building price by its square footage. For example, if it were assumed the condominium/hotel design for this thesis were 10 stories total, the total price would be 208 feet multiplied by 66 feet multiplied by 10 and then multiplied by the price per square foot. The price per square foot can also be used to determine the price of the slab if, for example, a bay were added to the slab. This is helpful as the overall dimensions may change in the design process to adjust to the owner's requests or needs without completely redesigning the slab.

The difference in price between the slabs for each city had a small percentage of variation, under $15 \%$ difference between the most expensive and the least expensive slab for all the cities. To analyze the effect of the different material pricing, the cost and percentage of each material and its corresponding installation for Slab 1 and Slab 8 was calculated. Slab 1 and Slab 8 were chosen because they are the least expensive and the most expensive designs, respectively, calculated for this thesis. The results can be found below and on the next page in Table $\mathrm{Z}$. The price of the concrete makes up the majority

\section{Table Z: Price for Each Material and Installation in Slab 1 and Slab 8}

\begin{tabular}{|c|c|c|c|c|c|c|}
\hline & & \multicolumn{5}{|c|}{ Slab 1} \\
\hline & & Atlanta & Boston & Chicago & Denver & Houston \\
\hline \multirow{3}{*}{ 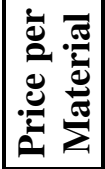 } & PT & $\$ 25,378$ & $\$ 51,575$ & $\$ 47,482$ & $\$ 24,560$ & $\$ 25,542$ \\
\hline & Rebar & $\$ 3,900$ & $\$ 5,673$ & $\$ 3,191$ & $\$ 3,191$ & $\$ 3,191$ \\
\hline & Concrete & $\$ 94,503$ & $\$ 181,359$ & $\$ 198,043$ & $\$ 106,528$ & $\$ 105,395$ \\
\hline \multirow{3}{*}{$\begin{array}{l}8 \pi \\
0\end{array}$} & PT & $21 \%$ & $22 \%$ & $19 \%$ & $18 \%$ & $19 \%$ \\
\hline & Rebar & $3 \%$ & $2 \%$ & $1 \%$ & $2 \%$ & $2 \%$ \\
\hline & Concrete & $76 \%$ & $76 \%$ & $79 \%$ & $79 \%$ & $79 \%$ \\
\hline
\end{tabular}


7.0 Cost Analysis 74

Table Z: Price for Each Material and Installation in Slab 1 and Slab 8, cont.

\begin{tabular}{|c|c|c|c|c|c|c|}
\hline & \multirow[b]{2}{*}{ Slab } & \multicolumn{5}{|c|}{ Slab 1} \\
\hline & & $\begin{array}{c}\text { Los } \\
\text { Angeles }\end{array}$ & Miami & Phoenix & $\begin{array}{c}\text { San } \\
\text { Francisco }\end{array}$ & Seattle \\
\hline \multirow{3}{*}{ 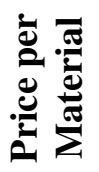 } & PT & $\$ 28,162$ & $\$ 29,799$ & $\$ 31,109$ & $\$ 30,290$ & $\$ 27,998$ \\
\hline & Rebar & $\$ 4,928$ & $\$ 3,251$ & $\$ 3,900$ & $\$ 4,999$ & $\$ 4,460$ \\
\hline & Concrete & $\$ 109,668$ & $\$ 305,406$ & $\$ 203,971$ & $\$ 92,023$ & $\$ 105,936$ \\
\hline \multirow{3}{*}{ 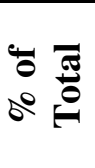 } & PT & $20 \%$ & $9 \%$ & $13 \%$ & $24 \%$ & $20 \%$ \\
\hline & Rebar & $3 \%$ & $1 \%$ & $2 \%$ & $4 \%$ & $3 \%$ \\
\hline & Concrete & $77 \%$ & $90 \%$ & $85 \%$ & $72 \%$ & $77 \%$ \\
\hline
\end{tabular}

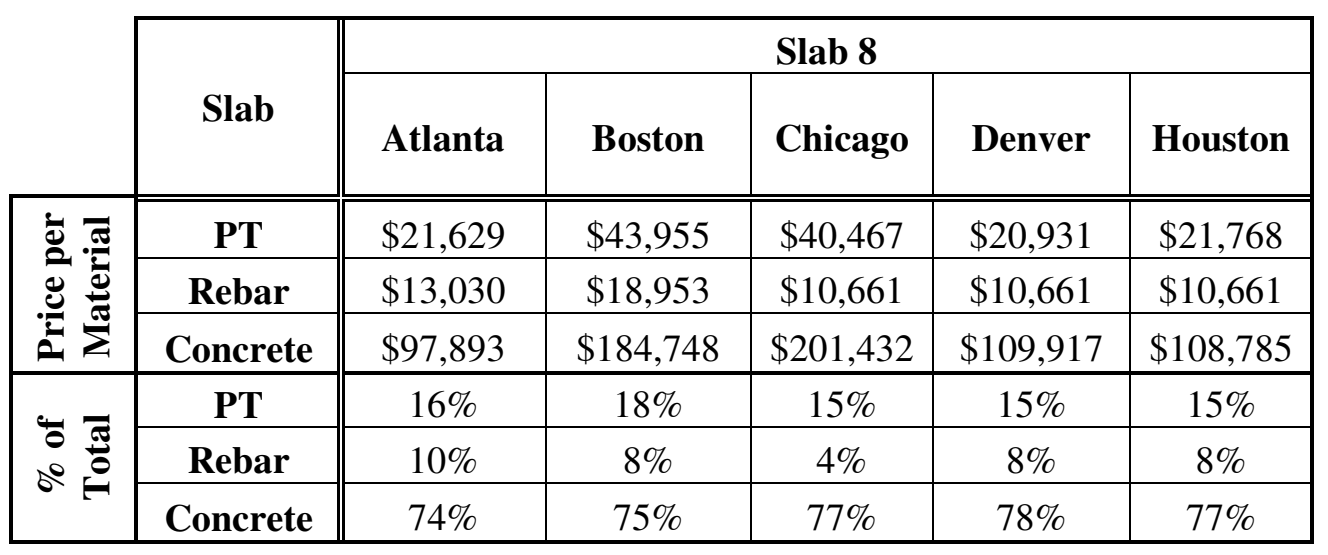

\begin{tabular}{|c|c|c|c|c|c|c|}
\hline & \multirow[b]{2}{*}{ Slab } & \multicolumn{5}{|c|}{ Slab 8} \\
\hline & & $\begin{array}{c}\text { Los } \\
\text { Angeles }\end{array}$ & Miami & Phoenix & $\begin{array}{c}\text { San } \\
\text { Francisco }\end{array}$ & Seattle \\
\hline \multirow{3}{*}{ 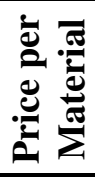 } & PT & $\$ 24,001$ & $\$ 25,396$ & $\$ 26,513$ & $\$ 25,815$ & $\$ 23,861$ \\
\hline & Rebar & $\$ 16,465$ & $\$ 10,862$ & $\$ 13,030$ & $\$ 16,702$ & $\$ 14,902$ \\
\hline & Concrete & $\$ 113,058$ & $\$ 306,423$ & $\$ 207,361$ & $\$ 95,413$ & $\$ 109,326$ \\
\hline \multirow{3}{*}{$\begin{array}{l}-\pi \\
0 \\
0\end{array}$} & PT & $16 \%$ & $7 \%$ & $11 \%$ & $19 \%$ & $16 \%$ \\
\hline & Rebar & $11 \%$ & $3 \%$ & $5 \%$ & $12 \%$ & $10 \%$ \\
\hline & Concrete & $74 \%$ & $89 \%$ & $84 \%$ & $69 \%$ & $74 \%$ \\
\hline
\end{tabular}

of the slab cost for all the cities. For Slab 1, the percentage the price of concrete material and installation in relation to the total cost varies from $72 \%$ in San Francisco to $90 \%$ in Miami, and for Slab 8, the percentage varies from 69\% in San Francisco to $89 \%$ in 
7.0 Cost Analysis 75

Miami. The domination of the concrete material and installation costs of the total costs cause the low variation in costs between the slabs for each city because the concrete material changes very little from slab to slab. This in turn causes the effect of the rebar and post-tensioning changes between slabs to be lost in the overall price. The percent of the total price for the post-tensioning costs drops a couple percentage points between Slab 1 and Slab 8, as does the percent of the total price for the concrete costs. The percent of the total price for the rebar picks up these drops and increases from Slab 1 to Slab 8; the largest increase is 8\%, tabulated for Los Angeles and San Francisco.

To conclude the cost analysis of the 8 slabs designed, the best cost optimization for all 10 of the U.S. cities is Slab 1, the 8" slab with $100 \%$ of the dead load balanced and a concrete strength of $5000 \mathrm{psi}$. Of the individual variables investigated in the parametric study, and referring back to the values in Table $\mathrm{X}$ and Table $\mathrm{Y}$, the following cost optimizations are observed. A comparison of the prices for Slabs 1 through 5, which explore the effect of the first variable, the amount of dead load balanced by the posttensioning, reveals that Slab 1 is the optimal solution. For Atlanta, Chicago, Los Angeles, San Francisco, and Seattle, the most expensive of Slabs 1 through 5 was Slab 4, with $80 \%$ of the dead load balanced. For Boston, Denver, Houston, and Phoenix, the most expensive of Slabs 1 through 5 was Slab 3, with 85\% of the dead load balanced. For Miami, the most expensive was Slab 2, with $90 \%$ of the dead load balanced. A comparison of the prices for Slab 3, Slab 6, and Slab 7, which explore the effect of the second variable, the depth of the slab, reveals that Slab 6, with a 7" slab depth, provides the optimal solution. For all the cities, Slab 3, the 8 " slab, provides the most expensive 
7.0 Cost Analysis 76

solution. Finally, a comparison of the prices for Slabs 3 and 8, which explore the effect of the third variable, the concrete strength, reveals that Slab 3, with 5000 psi concrete strength, is the optimal solution for all the cities. 


\subsection{CONCLUSIONS}

Throughout this thesis, different methods of analysis were investigated in order to perform a parametric study of a post-tensioned concrete flat plate for a hotel/condominium layout, reference Figure R on page 35, with the resulting material quantities used in a cost analysis. A brief background on the development of posttensioning and a literature review on the research completed up to this point on the subjects investigated in this thesis lead into the main contents of the thesis, methods of analysis for two-way concrete design and post-tensioned concrete design, parametric study completed through hand and computer analysis, and the cost analysis conducted on results of the parametric study completed by hand.

\subsection{Contents of Thesis}

Three different methods of analysis were investigated in Section 4.0 of this thesis. First, the yield-line analysis was presented. The yield-line analysis uses virtual work to determine moments and shears along yield lines, or plastic hinges, and determines reinforcement requirements based on these moments and shears. This method was not used in the hand analysis because there is a high likelihood of making errors while using this method. The equivalent frame method was investigated and presented next. This method divides a slab into frames, usually centered along a line of columns. These frames are analyzed using moment distribution to determine the moments and shears for which to design the reinforcing. Last, design methods specific to post-tensioning were investigated. The technique of load-balancing determines the required post-tensioning 
8.0 Conclusions 78

force through equilibrium and was employed in the design of the slabs. The equivalent frame method then analyzes the effect of the unbalanced load to design additional reinforcing requirements per the code, which for this thesis is the American Concrete Institute Building Code Requirements for Structural Concrete (ACI 318-05). The requirements of the code specific to prestressed concrete design include provisions for the minimum bonded, or non-prestressed reinforcing, in areas of positive and negative moments, maximum tensile stress in the cross section, $6 \sqrt{f_{c}{ }^{\prime}}$, maximum compressive stress in the cross section, $.45 \mathrm{f}_{\mathrm{c}}{ }^{\prime}$, and punching shear reinforcing requirements. See Table A on page 28 for a complete list of these requirements and code references.

The parametric study conducted in this thesis investigated three different variables: the load balanced by the post-tensioning, the slab depth and the concrete strength. The parametric study was limited to one slab layout and analysis was completed through hand calculations and the computer program ADAPT-PT. Table B on page 37 defines the eight slabs investigated in the parametric study. Excel worksheets were created to perform the parametric study in the hand analysis of Section 6.1. The reinforcing requirements for the post-tensioning, rebar, and shear studs are tabulated in Table $\mathrm{C}$ through Table $\mathrm{J}$, starting on page 42. The Excel sheets for the design of Slab 3 of Table B can be found in Appendix A starting on page i, and the summaries for the designs of all the slabs, as well as drawings for the post-tensioning requirements and the rebar requirements, can be found in Appendix B starting on page lxviii. The material quantities from the results of the hand analysis are tabulated in Table K on page 48. Slab 1, 100\% dead load balanced, 8 " slab depth, and 5000 psi concrete strength, required the 
8.0 Conclusions 79

most post-tensioning and the least amount of rebar. Slab 5, 75\% dead load balanced, 8" slab depth, and 5000 psi concrete strength, required the least amount of post-tensioning and the most rebar. Slab 6, 85\% dead load balanced, 7" slab depth, and 5000 psi concrete strength, required the least amount of concrete, and Slab 7, 85\% dead load balanced, 9" slab depth, and 5000 psi concrete strength, required the most concrete.

The ADAPT-PT analysis, investigated in Section 6.2, provided a second parametric study. Using the same 8 slabs, the middle equivalent frames were modeled in ADAPT-PT and the resulting design was compared to the designs of the hand calculations. The design of the post-tensioning for both analyses was very similar, with discrepancies of one to two strands between the two. The design calculated by ADAPTPT used an effective final prestress force of $175 \mathrm{ksi}$, versus the $160 \mathrm{ksi}$ final effective force used in the hand calculations, resulting in a lower number of strands required in the design. The rebar and shear stud requirements had larger discrepancies than what was found for the post-tensioning. The rebar required over the columns gave similar results, but ADAPT-PT required more reinforcing over most columns than the hand calculations. The biggest discrepancy between the hand calculations and the ADAPT-PT design is the required non-prestressed reinforcing in the spans. ADAPT-PT required a much smaller amount of rebar than the hand calculations, but reasons for this were not determined. The requirement in the code calls for a uniform distribution of the reinforcing in this area, and therefore the rebar requirements calculated by hand seem to be a more reasonable solution. ADAPT-PT found that less shear reinforcing was required than the hand calculations, most likely due to the fact that the hand calculations considered the worst 
case scenario as the design for all the columns. After this comparison, the material quantities for each of the eight slabs designed in the hand calculations were compiled for the cost analysis. ADAPT-PT allowed many variables to be changed easily, and reassessed the design quickly making it a valuable tool in the design process to revise the design in an effort to find an optimal solution for a slab.

The total quantities of the materials, post-tensioning, rebar, and concrete, for each slab were multiplied by pricing gathered from suppliers and contractors in ten different cities in the United States, as well as from the Cost Index published by Engineering News Record. The prices for the slab ranged from $\$ 123,800, \$ 9.02$ per square foot, for a slab designed with $100 \%$ of the dead load balanced for an 8 " slab with 5000 psi concrete built in Atlanta, Georgia, to $\$ 342,700, \$ 24.96$ per square foot, for a slab designed with $85 \%$ of the dead load balanced for an 8" slab with 6000 psi concrete built in Miami, Florida. The material and installation cost of concrete accounted for between $67 \%$ and $90 \%$ of the total cost of the slabs designed in the parametric study, masking the effect of the changing post-tensioning and rebar quantities of the slabs. The price of concrete dominates the cost of the slabs designed in this thesis because it is a smaller slab and concrete installation involves formwork, placing and finishing which are not needed for the other materials in as large of quantities. The pricing varies between the different cities according to union costs, material availability, labor availability, and other labor and material costs. Without further research, the exact nature of these discrepancies cannot be determined.

For all ten cities investigated, the least expensive slab was Slab 1 of Table B, with $100 \%$ of the dead load balanced, an 8" slab thickness and a concrete strength of 5000 psi. 
The most expensive slab for all the cities was Slab 8, with $85 \%$ of the dead load balanced, an 8" slab thickness and a concrete strength of 6000 psi. For the three variables investigated in the parametric study, Slab 1 with $100 \%$ of the dead load balanced, provided the least expensive solution for the load balancing; Slab 6, with a 7" slab thickness, provided the least expensive solution for the slab thickness; and Slab 3, with a concrete strength of $5000 \mathrm{psi}$, was the least expensive solution for all the cities for the concrete strength.

Based on these findings, the optimization of the slab layout investigated in this thesis is not worthwhile because of the low variance in the pricing. A more thorough parametric study may result in different results and a more worthwhile optimization but was not within the scope of this thesis. The cost estimate does not include the effect of a more standardized material layout versus an optimized material layout. For construction purposes, a more standardized layout provides a cheaper solution due to a reduction in the labor component of the cost due to repeatability of formwork and patterns. A more thorough parametric study may also allow a better use of the post-tensioning to be found as the span to depth ratio used was a conservative one and the limits of this material were not pushed. The results found seem reliable as the two methods performed, hand analysis and ADAPT-PT analysis, correlate well. The required reinforcing quantities found to provide the optimal solution of the parametric study and cost analysis, corresponding to a slab with $100 \%$ of the dead load balanced, an 8" slab depth, and a 5000 psi concrete strength, provides an adequate solution to the design problem, but could be further investigated for a more rigorous exploration. 


\subsection{Recommendations for Further Studies}

Several ideas and analyses from this thesis can be added to in the future, including gaining a better understanding of two-way slab behavior with a 3-D analysis, exploring different grid systems and building types for the slab design, researching different cities or other variables for the cost analysis, and a deeper exploration of the tendon layout. The methods explored in this thesis simplified the two-way action of the slab to determine the moments and shears to use in design of the reinforcement. A 3-D analysis of the entire slab using a program such as RISA 3-D or ETABS would provide a comparison for the moments and shears found using the methods presented in this thesis to determine how accurately they obtain the moments and shears.

Different slab layouts will provide different results from those found in this thesis; therefore it is important to treat each project differently. The slab layout used does not take true advantage of post-tensioning, with lesser spans and a deeper base slab depth. A slab design with larger spans will change the post-tensioning design and make the posttensioning a more integral part of the design. Also, a change in the slab depth using a span to depth ratio of 45 rather than 40 as recommended by the PTI Manual for two-way slabs, might increase the need for post-tensioning for the project. It is possible that the use of post-tensioning is what makes a project feasible due to the spans and other design constraints. The regular layout of the columns in this thesis may not necessarily be a realistic representation of buildings; further exploration with non-regular column placement could provide a more in-depth analysis of some of the advantages of post- 
tensioning. For alternative types of design, the post-tensioning could play a more prominent role in the cost analysis as well.

Along with exploration of how different slab layouts might affect the cost analysis, expanding the cost analysis to include more cities, obtaining more data from contractors and suppliers, and including more elements of the building in the cost analysis would improve upon the cost analysis conducted in this thesis. The ten cities chosen for the cost analysis of this thesis provide a good comparison of prices across the United States, but could always be expanded to include more cities. The data used for the cost analysis in this thesis often came from one source in a city or was estimated using ratios established from the data obtained. More research into the prices and more data from the cities where the cost analysis is conducted will provide a more accurate representative price for that city. The stud rail pricing was neglected in this thesis due to time constraints, so further research into their cost and installation would provided a better estimate of the pricing of the slabs. Other elements such as the lateral system, columns, seismic design of the slab, and other building elements were neglected in the cost analysis because they were not considered in the design for this thesis, but would allow a cost analysis to be conducted on an entire building.

The post-tensioning design conducted for this thesis used the same number of strands across the entire slab length. In the field, this number is often varied by using "added tendons." These added tendons are used in the controlling span for a span or two to decrease the number of strands needed for the entire slab by using the full tendon profile to its advantage. The column lines allowed the post-tensioning to be laid in 
straight lines across the slab, but tendons can also curve in the plan if the columns do not form straight lines. Further research into these issues and the cost analysis, building layout, and ADAPT-PT rebar design would build upon the ideas set out in this thesis and add to the general knowledge of the field of engineering. 


\section{REFERENCES}

(Aalami and Jurgens 2003) Aalami, Bijan O., and Jennifer D. Jurgens. "Guidelines for the Design of Post-Tensioned Floors." Concrete International. 25.3 (2003) 77-83.

(Aalami and Kelley 2001) Aalami, Bijan O., and Gail S. Kelley "Structural Design of Post-Tensioned Floors.” Concrete International. 23.1 (2001) 31-36.

(American Concrete Institute 2005) American Concrete Institute. Building Code Requirements for Structural Concrete and Commentary. 2005.

(Bondy 2001) Bondy, Kenneth. "Post-Tensioned Concrete: Five Decades of American Building Construction." Concrete Construction. (Dec. 2001) 1-6.

(Bromley 2009) Bromley, Pete. Jones Concrete. Phoenix, AZ. "P-T slab." E-mail to the author. 15 June 2009.

(Cross 2009) Cross, Ramsey. Dalco Industries. Denver, CO. "Re: Cost Estimate.” E-mail to the author. 14 May 2009.

(Curry 2009) Curry, Paul. Harris Rebar. Phoenix, AZ. Telephone interview. 19 May 2009.

(Dickinson 2009) Dickinson, Billy. Dywidag-Systems International. Atlanta, GA. "Re: Cost Estimate." E-mail to the author. 28 April 2009.

(Dietrich 2009) Dietrich, Robb. Dywidag-Systems International. Chicago, IL "Re: Cost Estimate." E-mail to the author. 8 May 2009.

(Eigenhus 2009) Eigenhus, Jeff. Middle Georgia Concrete Constructors, Inc. Telephone interview. Atlanta, GA. 15 June 2009.

(ENR 2009) ENR: Engineering News Record. 2009. McGraw-Hill Companies, Inc. 21 May 2009. <www.enr.com>

(Gupta 2006) Gupta, Pawan R., chief ed. Post-Tensioning Manual. $6^{\text {th }}$ ed. Phoenix: PostTensioning Institute, 2006.

(Harger 2009) Harger, Dan. VSL. Denver, CO. "Re: Cost Estimate." E-mail to the author. 27 April 2009. 
(Harman 1994) Harman, D. Kirk. "Design and Construction of Post-Tensioned Concrete Floor Systems." Structures Congress XII: Proceedings of Papers Presented at the Structures Congress '94. April 1994, Atlanta, GA.

(Keck 2009) Keck, Matt. Lafarge. Atlanta, GA. Telephone interview. 19 May 2009.

(Khosa 2009) Khosa, Neel. Amsysco. Chicago, IL. "Re: Cost Estimate." E-mail to the author. 13 May 2009.

(Klausmeyer, Eric) Klausmeyer, Eric. United Forming, Inc. Miami, FL. "Re: Cost Estimate." E-mail to the author. 4 May 2009.

(Kori 2009) Kori, Dawn. Post-Tension Cables. Seattle, WA. "Re: Cost Estimate.” E-mail to the author. 27 April 2009.

(Krauser 2009) Krauser, Larry. General Technologies, Inc. Stafford, TX. "RE: Bill Griffin - Alpha Systems, Inc.” E-mail to the author.

(MacGregor and Wight 2005) MacGregor, James G. and James K. Wight. Reinforced Concrete: Mechanics and Design. Fourth Edition. Upper Saddle River, New Jersey: Pearson Prentice Hall, 2005.

(MacRobert 2009) MacRobert, Roy. Supermix Concrete / Superblock / Superpaver. Miami, FL. "Re: Cost Estimate." E-mail to the author. 2 May 2009.

(Naaman 2004) Naaman, Antoine E. Prestressed Concrete Analysis and Design. Second Edition. Ann Arbor, Michigan: Techno Press 3000, 2004.

(Nawy 2006) Nawy, Edward G. Prestressed Concrete: A Fundamental Approach. Fifth Edition. Upper Saddle River, New Jersey: Pearson Prentice Hall, 2006.

(Nelson 2009) Nelson, Craig. Prairie Material. Chicago, IL. Telephone interview. 19 May 2009.

(Patel 2009) Patel, Sharu. Dywidag-Systems International. Long Beach, CA. "Re: Cost Estimate." E-mail to the author. 27 April 2009.

(Pena 2009) Pena, Jose. Ameristeel. Miami, FL.Telephone interview. 1 May 2009.

(Pomeroy 2009) Pomeroy, David. Harris Rebar. Seattle, WA. "Re: Cost Estimate.” Email to the author. 27 April 2009.

(Postma 2009) Postma, Matt. Ozinga. Chicago, IL. Telephone interview. 19 May 2009. 
(Price 2009) Price, Russell. Suncoast P-T. Houston, TX. "Re: Cost Estimate.” E-mail to the author. 27 April 2009.

(Reising 2009) Reising, Paul. Pacer Steel. Seattle, WA. "Master's Thesis.” E-mail to the author. 4 May 2009.

(Rusillo 2009) Rusillo, Mike. Barker Steel. Milford, MA. "Re: Cost Estimate.” E-mail to the author. 1 May 2009.

(Shengping and Tiong 2004) Shengping, Li, and Tiong, Robert. "Cost-Effective Reinforced Concrete Structural Systems." AACE International Transactions. 8186, Morgantown: 2004.

(Stevenson 1994) Stevenson, A. M. Post-Tensioned Concrete Floors in Multi-Storey Buildings. Crowthorne, England: British Cement Association, 1994.

(Stoll 2009) Stoll, Barney. Post Tension of Nevada. Henderson, NV. "PT Prices.” E-mail to the author. 27 April 2009.

(Truby 2005) Truby, Andy. “To Bond or Not to Bond ." Concrete. 39.10 (2005) 52-54.

(Waldron 1984) Waldron, P. "Partial Prestressing From Theory to Practice." Concrete. 18.10 (1984) 7-8.

(Wolfe 2009) Wolfe, Curtis. CLW Concrete Construction. Fort Meyers, FL. Telephone interview. 28 April 2009.

(Valdez 2009) Valdez, Mario. VSL. Miami, FL. "Re: Cost Estimate.” E-mail to the author. 28 April 2009.

(Vance 2009) Vance, Mark. Albrecht Birkenbuel. Seattle, WA. Telephone interview. 15 May 2009.

(VSL 1985) VSL. Post-Tensioned Slabs. 1985.

(VSL 1992) VSL. Post-Tensioned in Buildings. 1992. 


\section{APPENDIX A}

\section{A.1 Hand Analysis Calculations - Slab 3}

\section{A.1.1 Equivalent Frame - Grids $1 \& 4$}

Set - Up for Moment Distribution

Initials
$\begin{aligned} & \frac{\text { Slab Depth }}{8 \text { in }} \\ & \frac{\text { Loading }}{\text { Dead Load }} \\ & \text { Superimposed Dead Lo } \\ & \text { Live Load } \\ & \frac{\text { Tendons }}{A_{s}}=0.153 \text { in }^{2} \\ & f_{p e}=160 \mathrm{ksi}^{2} \\ & \frac{\text { Concrete }}{\mathrm{f}_{c}^{\prime}}=5000 \mathrm{psi} \\ & E_{c}=4030509 \mathrm{psi}\end{aligned}$

Stiffnesses

$\underline{\text { Slab }}$

$\begin{array}{llll}\mathrm{b}= & 156 \text { in } & \mathrm{l}=6656 \mathrm{in}^{4} \\ \mathrm{~d}= & 8 \text { in } & \mathrm{K}=343936738 \\ \mathrm{l}=312 \text { in } & \end{array}$

Column

\begin{tabular}{|c|c|c|}
\hline Exte & erior Column & Corner Column \\
\hline $\mathrm{c}_{1}$ & 18 in & 18 in \\
\hline $\mathrm{C}_{2}$ & 24 in & $c_{2}=$ \\
\hline$I_{1}$ & $=312 \mathrm{in}$ & 312 in \\
\hline $\mathrm{I}_{2}$ & 156 in & 156 in \\
\hline h & $=136$ in & 136 in \\
\hline 1 & $=20736 \mathrm{in}^{4}$ & $1=8748$ in $^{4}$ \\
\hline K & $=2458136108$ & $K=1037026171$ \\
\hline C & 3235.84 & $C=2211.84$ \\
\hline$k$ & 1241986312 & $\mathrm{~K}_{\mathrm{t}}=581402625.6$ \\
\hline
\end{tabular}


Set - Up for Moment Distribution, cont.

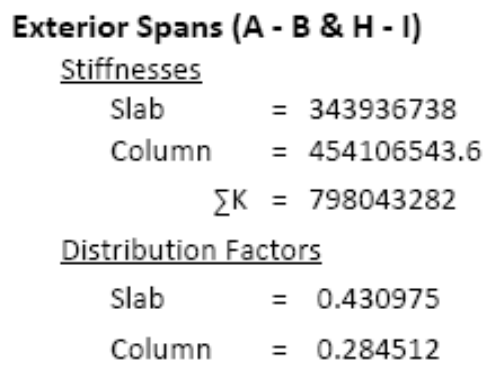

Distribution Factors

$\begin{array}{ll}\text { Slab } & =0.4096 \\ \text { Column } & =0.2952\end{array}$




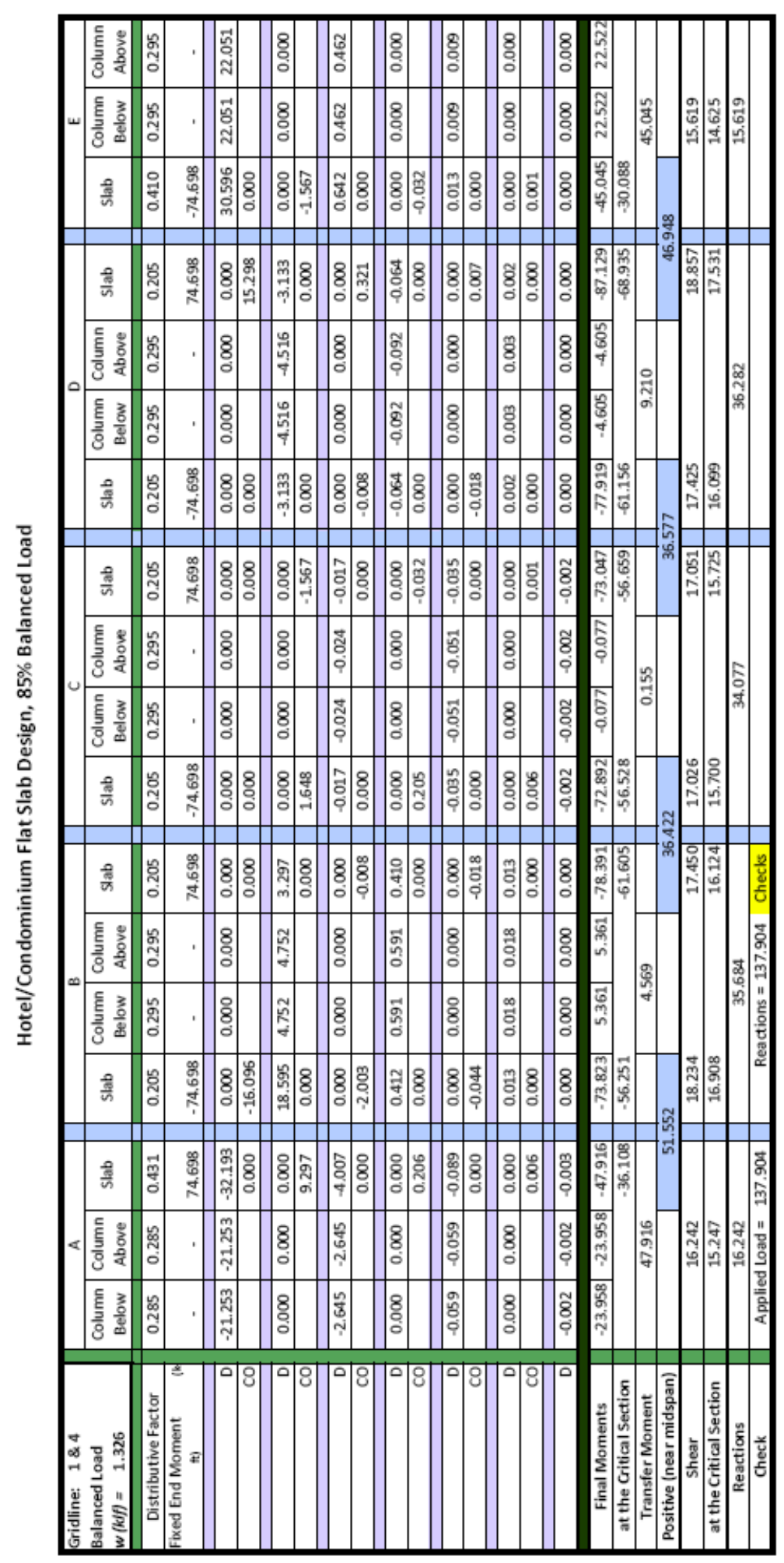

Optimization of Two-Way Post-Tensioned Concrete Floor Systems 


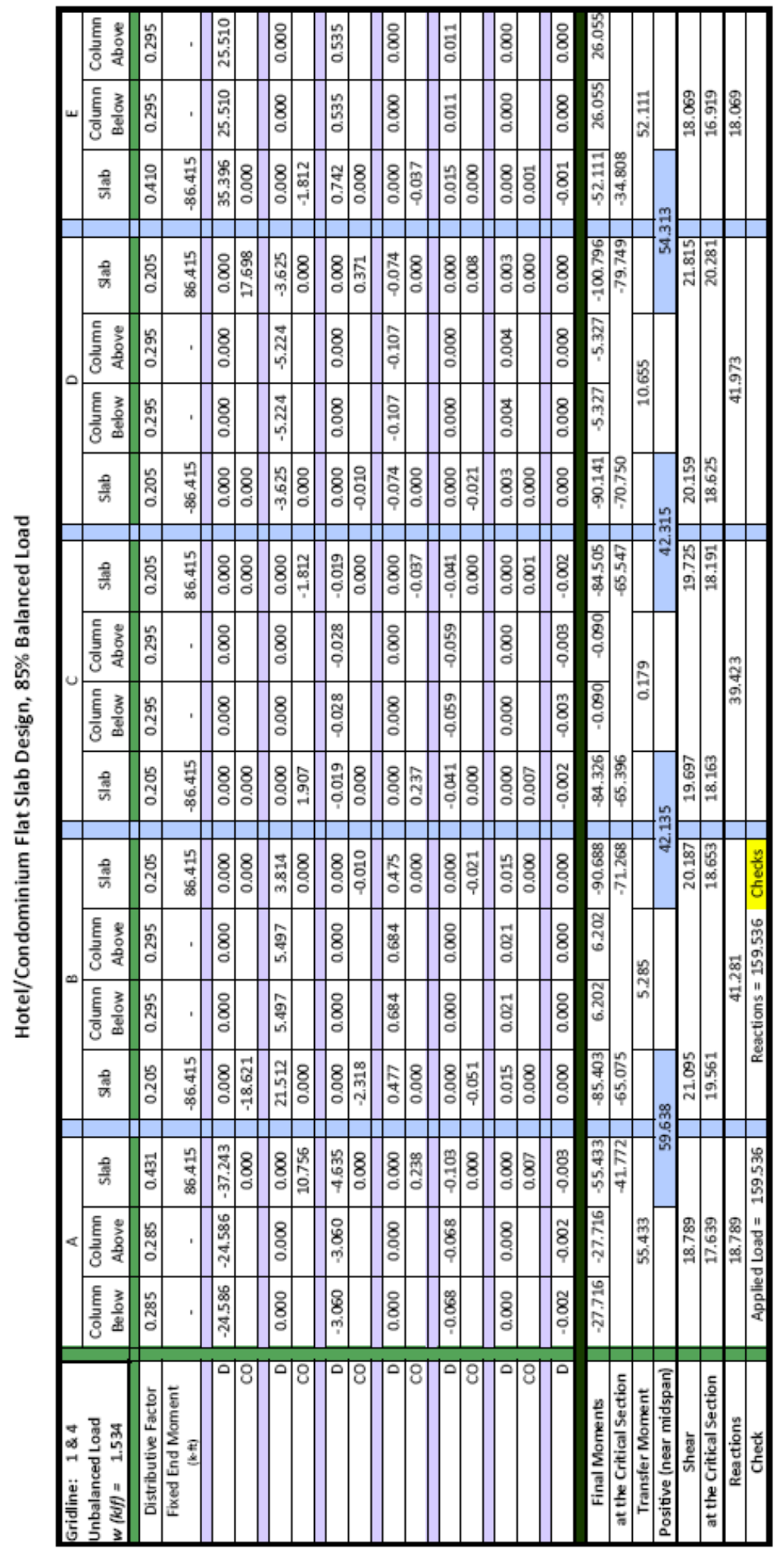




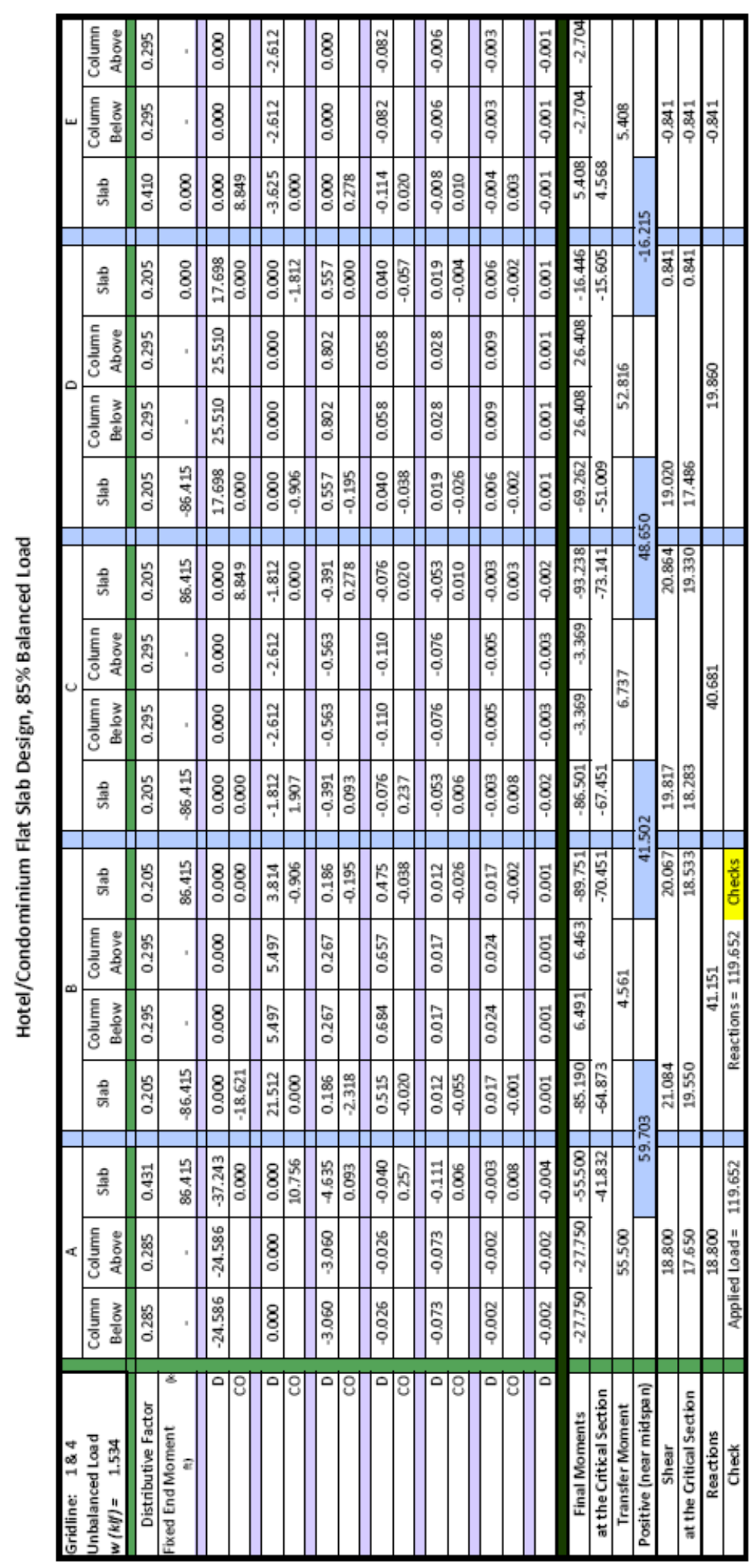




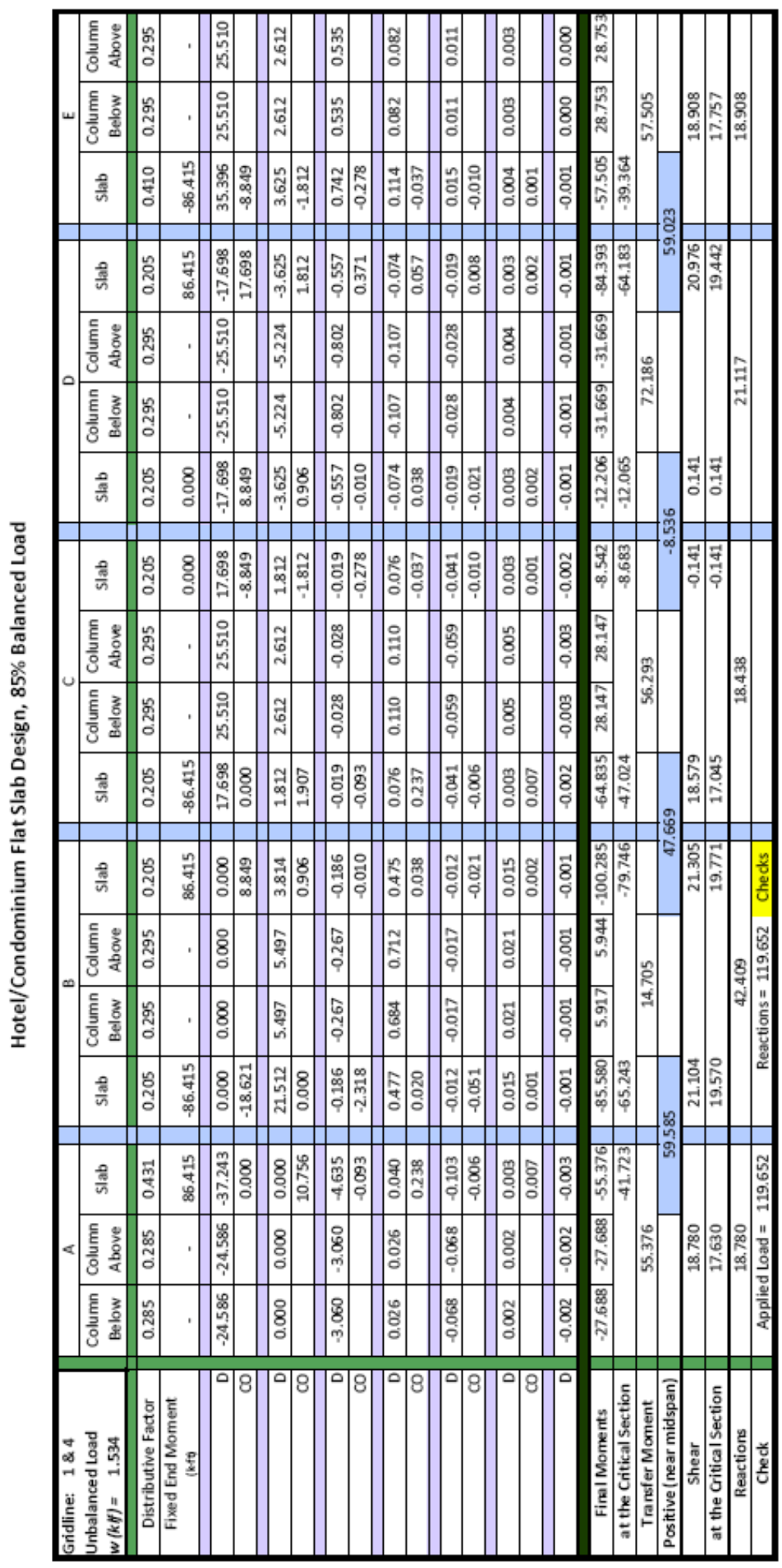




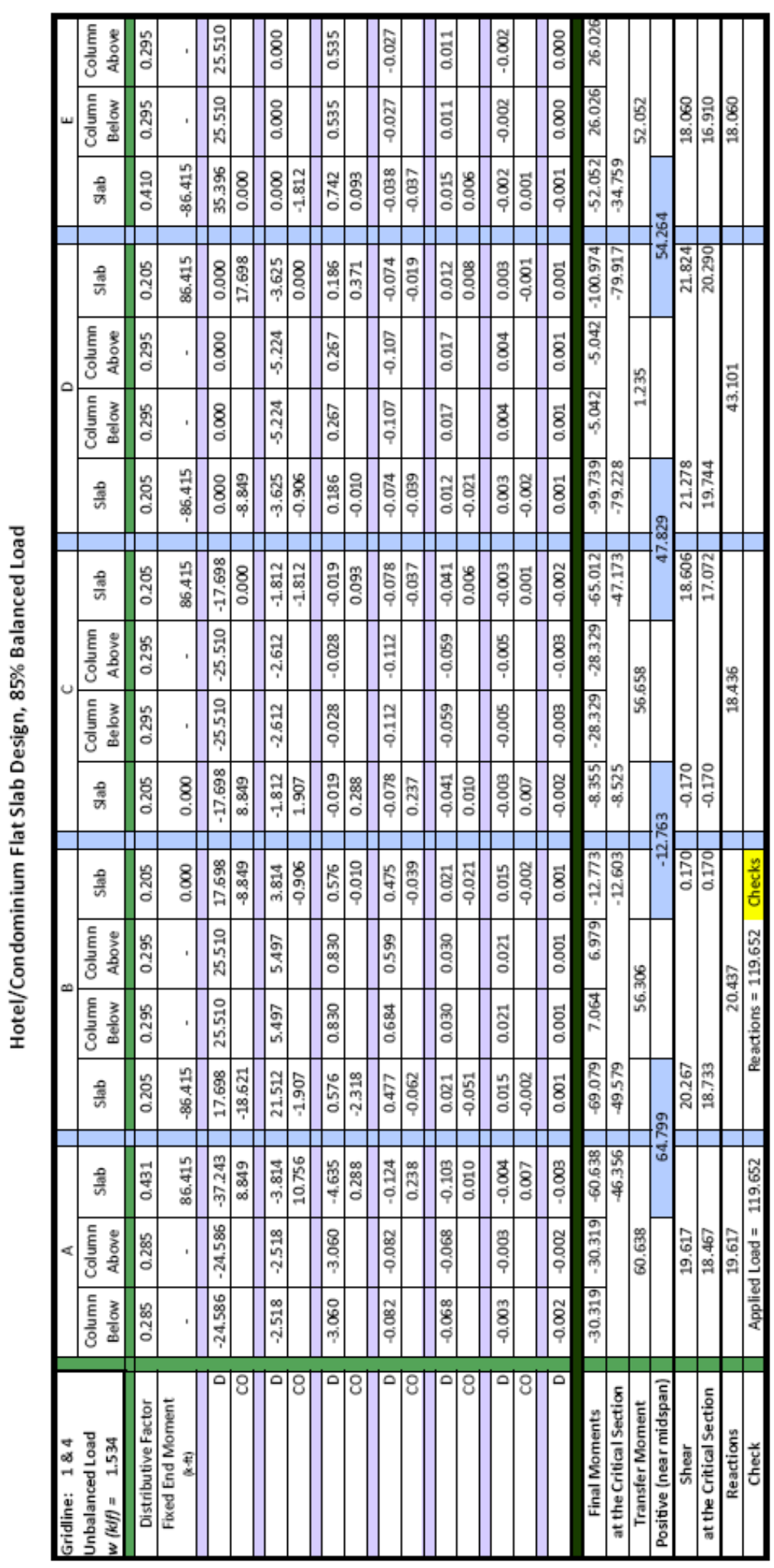


Appendix viii

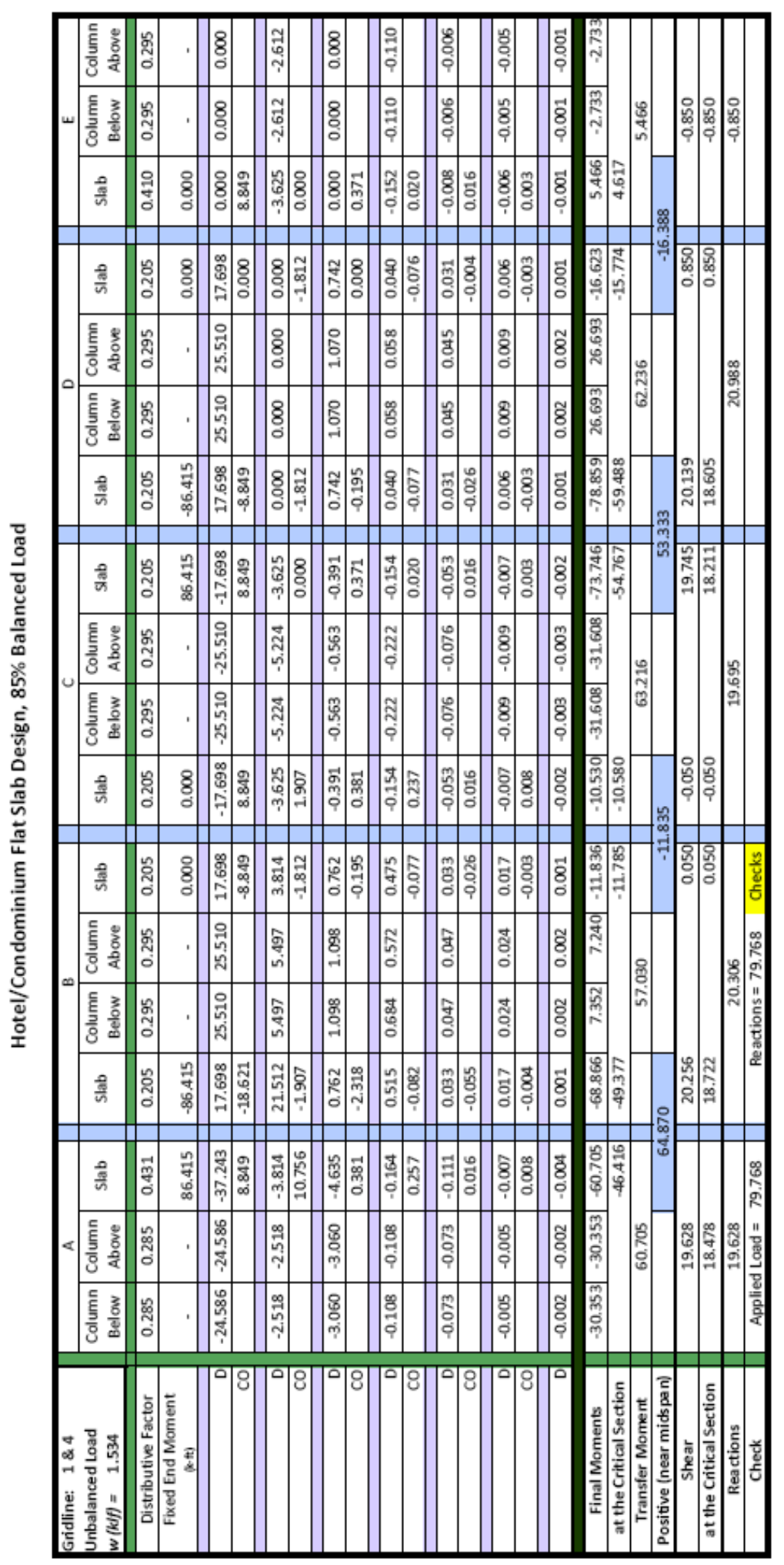

Optimization of Two-Way Post-Tensioned Concrete Floor Systems 


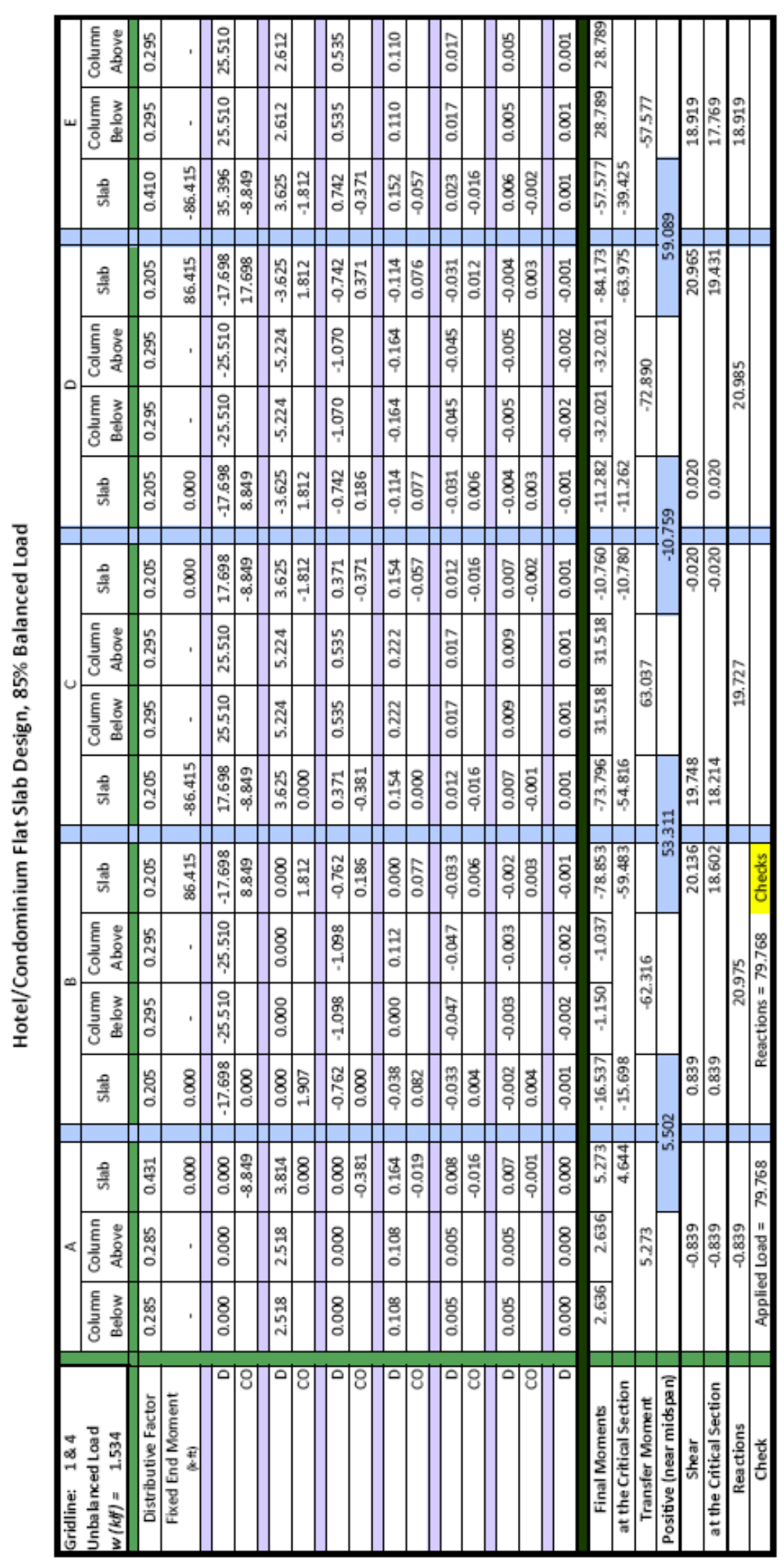

Optimization of Two-Way Post-Tensioned Concrete Floor Systems 


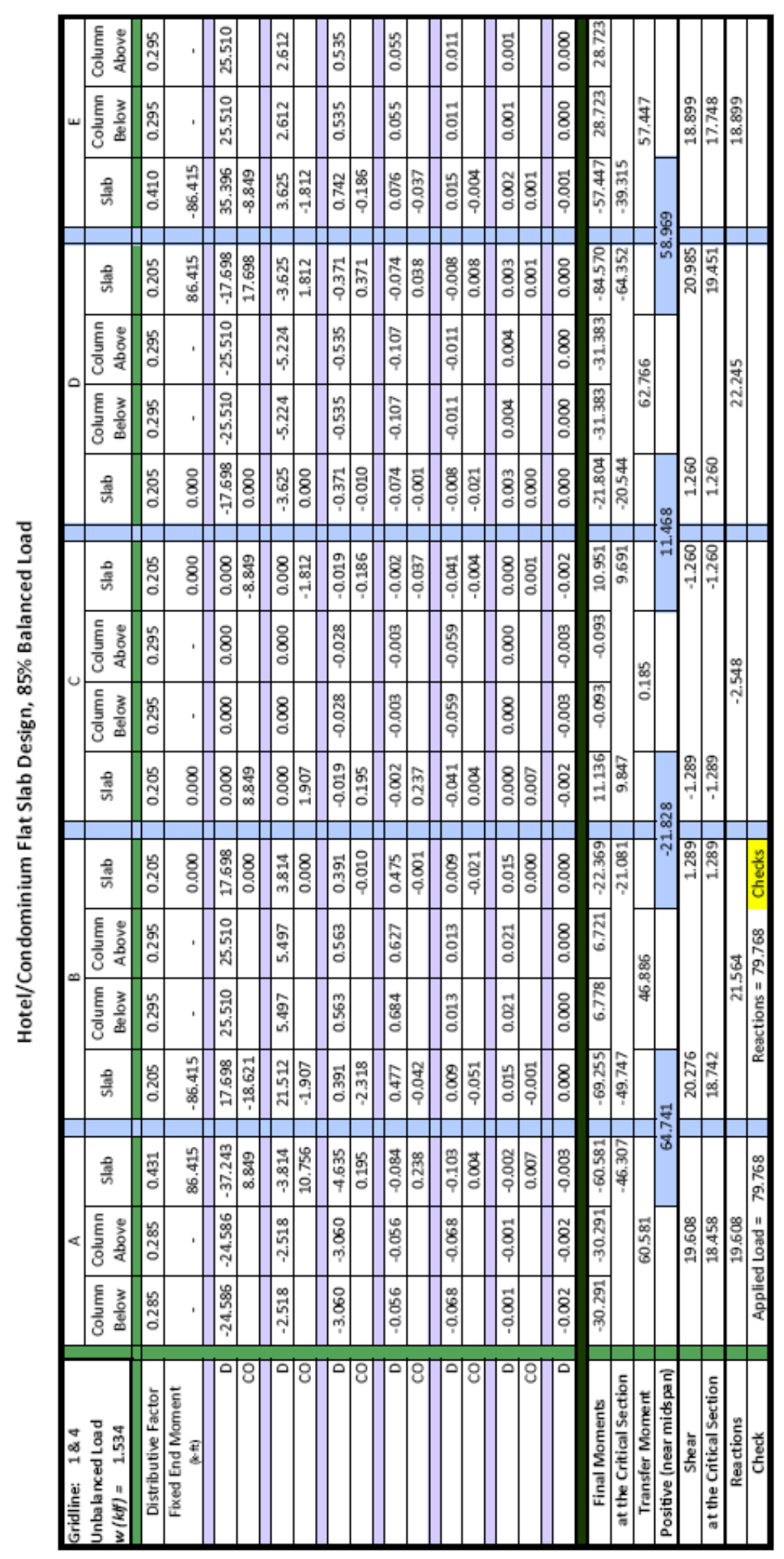

Optimization of Two-Way Post-Tensioned Concrete Floor Systems 


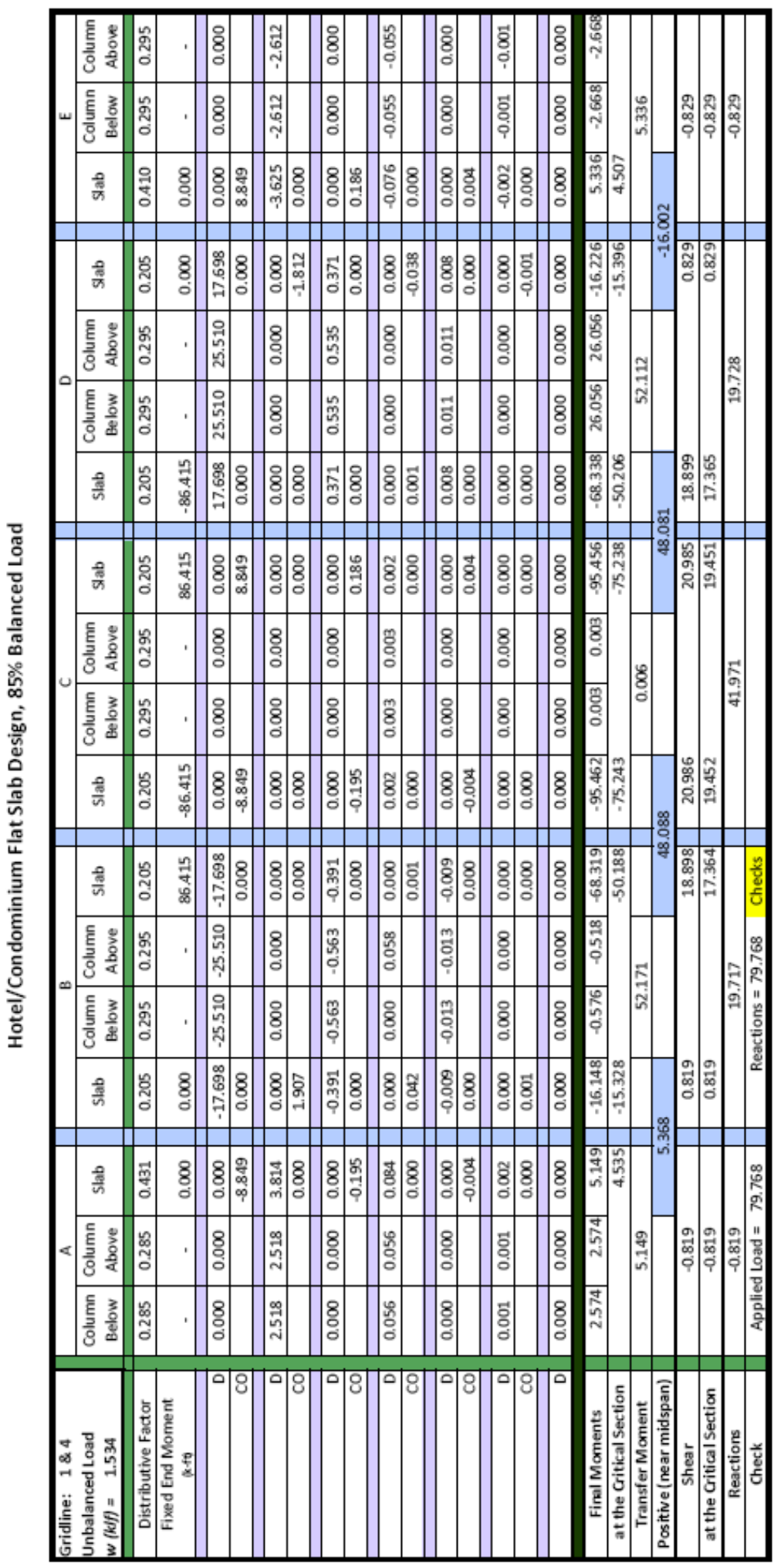




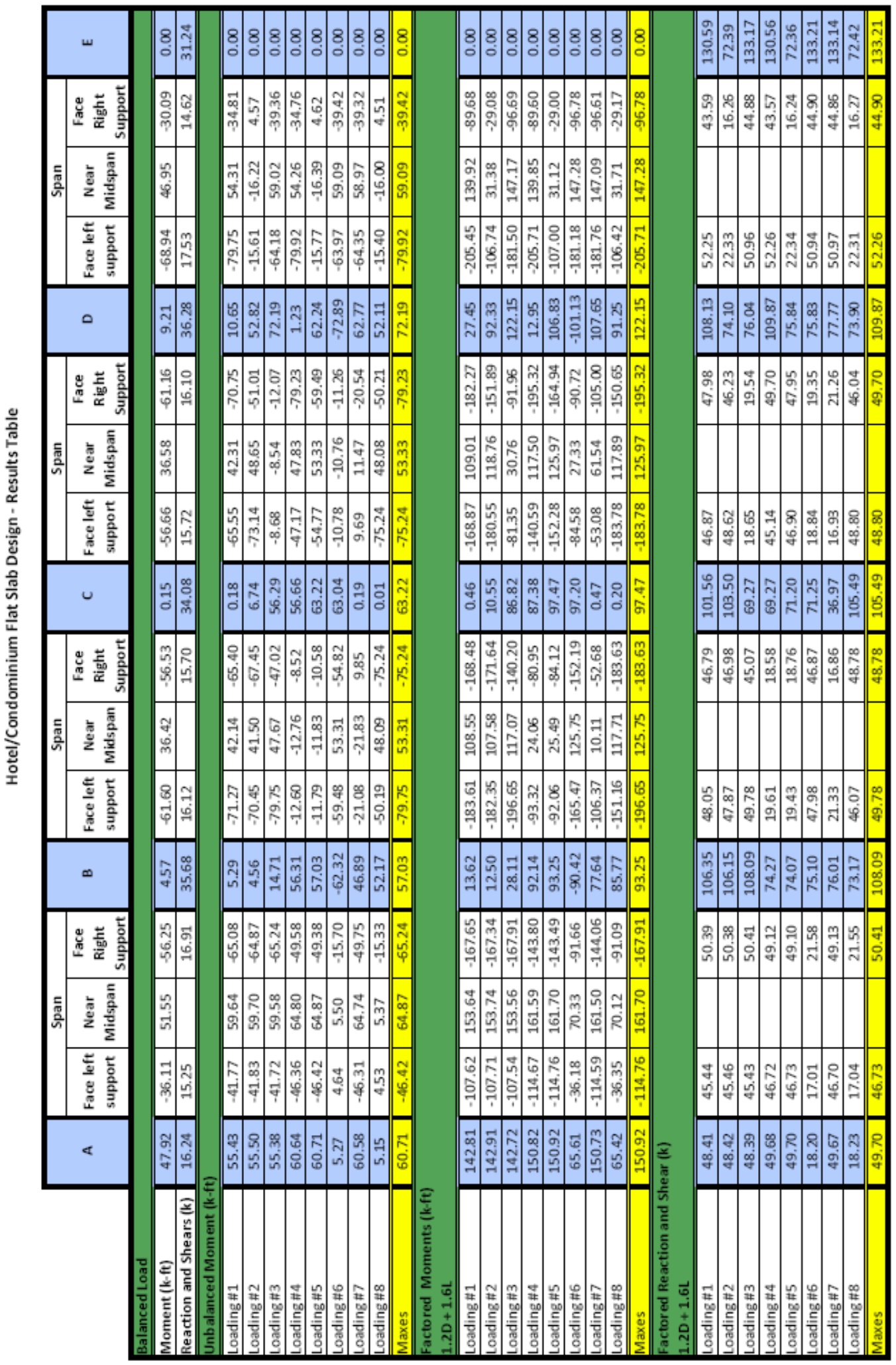

Optimization of Two-Way Post-Tensioned Concrete Floor Systems 


\section{Tendon Worksheet}

\section{Tendon Profile}

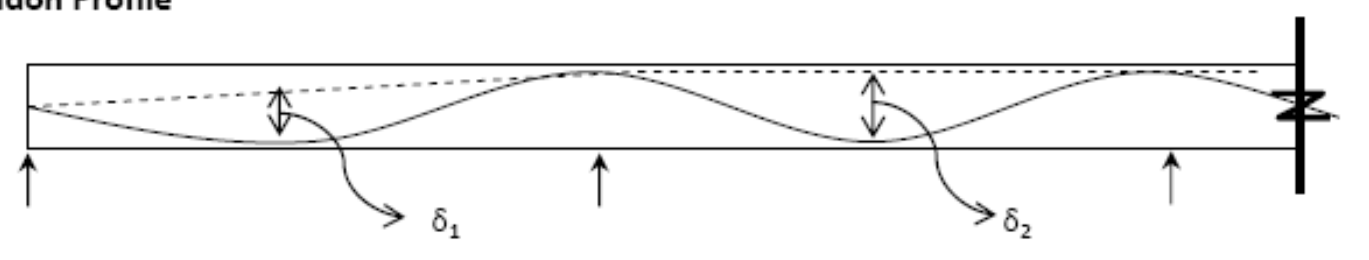
$\delta_{1}=4.5$ in
$A_{p s}=0.153 \mathrm{in}^{2}$
$\delta_{2}=6$ in
$f_{p s}=160 \mathrm{ksi}$

\section{Force Required}

$$
\begin{aligned}
& \text { Balanced Load }=1.33 \mathrm{klf} \\
& F_{1}=\frac{\left.W_{b}\right|^{2}}{8 \delta_{1}}=299 \mathrm{k} \quad \text { Governs } \\
& F_{2}=\frac{\left.W_{b}\right|^{2}}{8 \delta_{2}}=224 \mathrm{k}
\end{aligned}
$$

\section{Strands Required}

$$
\begin{aligned}
& \mathrm{N}=\frac{\mathrm{F}}{\mathrm{A}_{\mathrm{ps}} \mathrm{f}_{\mathrm{ps}}}=12.2056 \text { Use } 13 \text { Strands } \mathrm{F}=318.24 \mathrm{k} \\
& \rightarrow \quad \delta_{1}=4.23 \\
& \rightarrow \quad \delta_{2}=4.23
\end{aligned}
$$

\section{Average Prestress}

$$
\sigma_{g}=\frac{N_{p s} f_{p s}}{W d}=255 \quad p s i
$$

\section{Tendon Distribution:}

Banded, therefore no need to check Moment Resistance within $1.5 \mathrm{~h}$ of column 


\section{Stress Check}

Intials

$$
\begin{array}{ll}
\mathrm{z}=\frac{\mathrm{Id}^{2}}{6}=1664 \mathrm{in}^{3} & \sigma_{\mathrm{t}}=\sigma_{\mathrm{g}}+\frac{\mathrm{M}}{\mathrm{Z}_{\mathrm{t}}} \\
\sigma_{\mathrm{g}}=255 \mathrm{psi} & \sigma_{\mathrm{b}}=\sigma_{\mathrm{g}}-\frac{\mathrm{M}}{\mathrm{Z}_{\mathrm{b}}}
\end{array}
$$

\section{Checks}

Positive Moment:

$\sigma<.45 f_{c}^{\prime}=2250$ psi

Negative Moment:

$\sigma>-6 V \mathrm{f}_{\mathrm{c}}{ }^{\prime}=-424 \mathrm{psi}$

\section{Reinforcing Check}

Needed if $\sigma>2 \mathrm{vf}_{\mathrm{c}}{ }^{\prime} \quad=141.4 \mathrm{psi}$

Stresses at Exterior Support
$\sigma_{\mathrm{t}}=-79.7$ psi $\quad$ OK $\quad$ No additional Reinforcing Needed
$\sigma_{\mathrm{b}}=589.7$ psi $\mathrm{OK}$

\section{Stresses at Midspan of Outside Span}

$$
\begin{array}{lllll}
\sigma_{\mathrm{t}}= & 722.8 & \text { psi } & \text { OK } \\
\sigma_{\mathrm{b}}=-212.8 & \text { psi } & \text { OK } & \text { Reinforcing Required }
\end{array}
$$

$$
\text { Use \#7 bars@22 "o.c }
$$

\section{Stresses at Critical Interior Support}

$$
\begin{aligned}
\sigma_{\mathrm{t}}=-320.1 \text { psi } & \mathrm{OK} \quad \begin{array}{c}
\text { Reinforcing Required } \\
\text { Use } 4 \quad \# 5 \text { bars }
\end{array}
\end{aligned}
$$

$\sigma_{b}=830.1$ psi $\quad \mathrm{K}$

\section{Stresses at Midspan of Critical Inside Span}

$$
\begin{aligned}
& \sigma_{\mathrm{t}}=681.1 \text { psi } \mathrm{OK} \\
& \sigma_{\mathrm{b}}=-171.1 \text { psi } \quad \text { OK } \quad \begin{array}{r}
\text { Reinforcing Required } \\
\text { Use \# } 7 \text { bars @ } 26 \text { "o.c }
\end{array}
\end{aligned}
$$




\section{Ultimate Flexural Strength}

$$
f_{p s}=f_{p e}+7.5=167 \mathrm{ksi}
$$

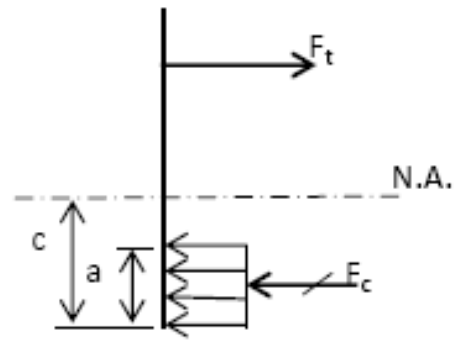

$$
\begin{aligned}
\phi M_{n} & =\phi\left(A_{p s} f_{p s}+A_{s} f_{y}\right)(d-a / 2) \\
a & =\frac{A_{p s} f_{p s}+A_{s} f_{y}}{.85^{*} f_{c}^{\prime} b} \\
c & =\frac{a}{\beta_{1}}
\end{aligned}
$$

\section{Check Interior Supports}

$$
\begin{aligned}
\mathrm{A}_{\mathrm{ps}} & =1.989 \mathrm{in}^{2} \quad \mathrm{f}_{\mathrm{y}}=60 \mathrm{ksi} \\
\mathrm{A}_{\mathrm{s}} & =1.24 \mathrm{in}^{2} \quad \beta_{1}=0.8 \\
\mathrm{a}= & 0.613217 \mathrm{in} \\
\mathrm{c}= & 0.766521 \mathrm{in} \quad \phi=0.9 \\
\phi \mathrm{M}_{\mathrm{n}}=2815.063 \mathrm{k}-\mathrm{in} & =234.5886 \mathrm{k}-\mathrm{ft} \\
\mathrm{M}_{\mathrm{u}} & =-205.713 \mathrm{k}-\mathrm{ft} \quad<\phi \mathrm{Mn} \text {, therefore OK }
\end{aligned}
$$

\section{Check Span}

$$
\begin{aligned}
\mathrm{A}_{p s} & =1.989 \quad \mathrm{in}^{2} \quad \mathrm{f}_{\mathrm{y}}=60 \mathrm{ksi} \\
\mathrm{A}_{\mathrm{s}} & =3.6 \text { in }^{2} \quad \beta_{1}=0.8 \\
\mathrm{a} & =0.826792 \mathrm{in} \\
\mathrm{c} & =1.03349 \mathrm{in} \quad \phi=0.9 \\
\phi \mathrm{M}_{\mathrm{n}} & =3742.826 \mathrm{k}-\mathrm{in} \\
& =311.9022 \mathrm{k}-\mathrm{ft} \\
\mathrm{M}_{\mathrm{u}} & =161.6953 \mathrm{k}-\mathrm{ft} \quad<\phi \mathrm{Mn} \text {, therefore OK }
\end{aligned}
$$




\section{Punching Shear - Exterior Columns}
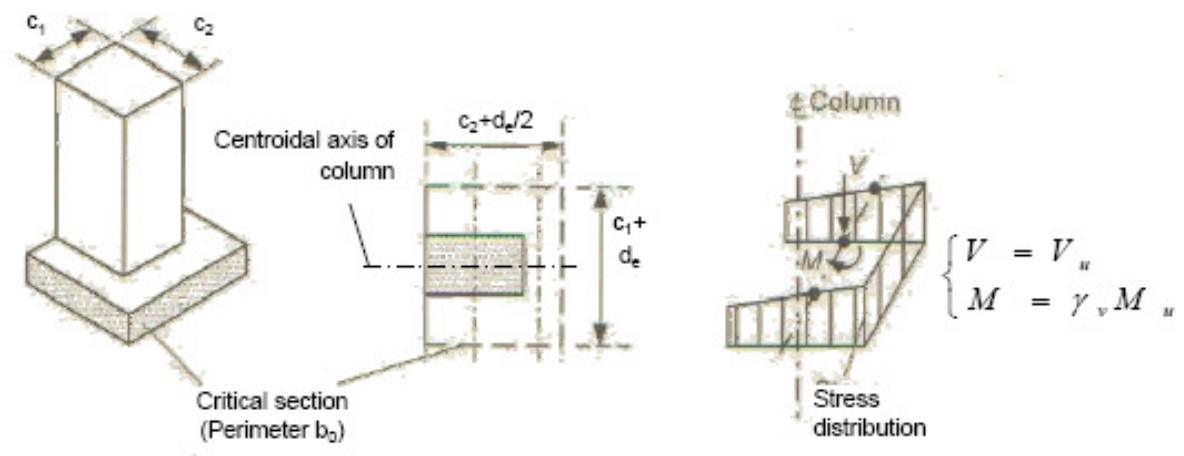

\section{Definitions}

$$
\begin{aligned}
& b_{0}=\left(c_{1}+2 c_{2}+2 d_{e}\right) \\
& c_{3}=\frac{\left(c_{1}+d_{e}\right)}{2} \\
& A_{c}=b_{0} d_{e} \\
& J_{c}=2\left(c_{2}+d_{e} / 2\right) d_{e} c_{3}+\frac{\left(c_{1}+d_{e}\right) d_{e}^{3}}{12}+\frac{\left(c_{1}+d_{e}\right)^{3} d_{e}}{12} \\
& v_{c}=\beta_{p} \sqrt{f_{c}^{\prime}}+0.3 \sigma_{g}+\frac{V_{p}}{b_{0} d_{e}} \\
& \beta_{p}=\text { smaller of }\left\{\begin{array}{l}
3.5 \\
1.5+\frac{\alpha_{s} d_{e}}{b_{0}}
\end{array} \quad \alpha_{s}=30\right. \\
& v_{u}=\frac{V_{u}}{A_{c}}+\frac{\gamma_{v} M_{u} c_{3}}{J_{c}} \\
& \text { Check: } \phi v_{\mathrm{c}}>v_{\mathrm{u}} \text { ? }
\end{aligned}
$$

\section{Stud Rail Reinforcing:}

$$
V_{s}=\left(\frac{v_{u}}{\phi}-2 \sqrt{f_{c}^{\prime}}\right) A_{c} \quad \text { \# of Studs }=\frac{V_{s}}{f_{y} A_{s}}
$$




\section{Punching Shear - Exterior Columns}

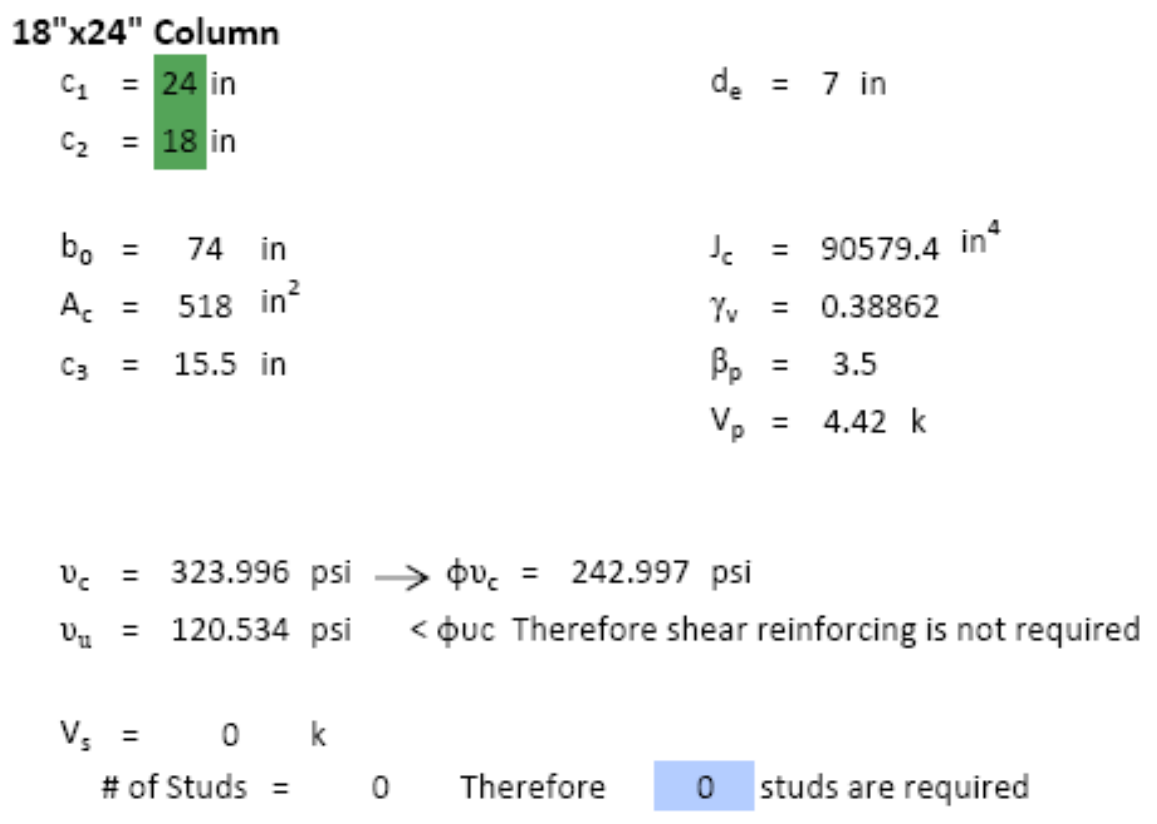


Appendix xviii

A.1.2 Equivalent Frame - Grids $2 \& 3$

Set - Up for Moment Distribution

Initials

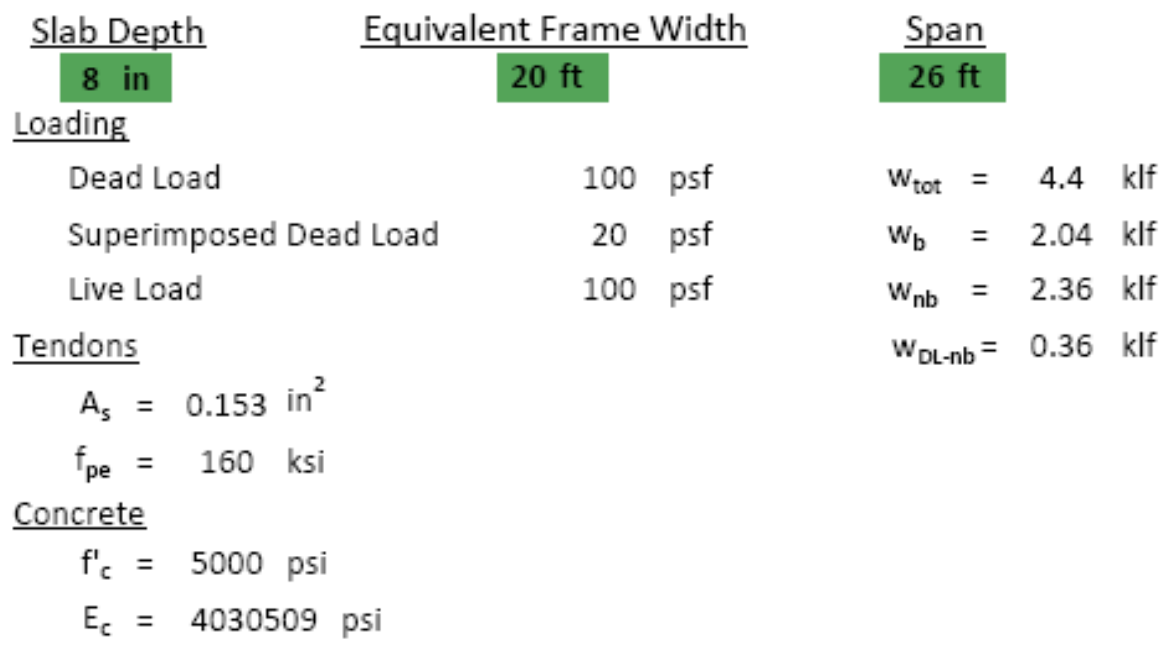

\section{Stiffnesses}

$\underline{\text { Slab }}$

$\begin{array}{lll}\mathrm{b}=240 \text { in } & \mathrm{I}=10240 \mathrm{in}^{4} \\ \mathrm{~d}= & 8 \text { in } & \mathrm{K}=\mathbf{5 2 9 1 3 3 4 4 4} \\ \mathrm{I}=312 \text { in } & \end{array}$

$\underline{\text { Column }}$

\begin{tabular}{rlrl} 
Interior Column & \multicolumn{2}{c}{ Exterior Column } \\
$\mathrm{C}_{1}$ & $=24$ in & $\mathrm{C}_{1}=24$ in \\
$\mathrm{C}_{2}=24$ in & $\mathrm{C}_{2}=18$ in \\
$\mathrm{I}_{1}=312$ in & $\mathrm{I}_{1}=312$ in \\
$\mathrm{I}_{2}=240$ in & $\mathrm{I}_{2}=240$ in \\
$\mathrm{h}=136$ in & $\mathrm{h}=136$ in \\
$\mathrm{I}$ & $=27648$ in $^{4}$ & $\mathrm{I}$ & $=11664 \mathrm{in}^{4}$ \\
$\mathrm{~K}_{\mathrm{c}}$ & $=3277514811$ & $\mathrm{~K}$ & $=1382701561$ \\
$\mathrm{C}$ & $=3235.84$ & $\mathrm{C}$ & $=2211.84$ \\
$\mathrm{~K}_{\mathrm{t}}$ & $=1587805449$ & $\mathrm{~K}_{\mathrm{t}}=807793688.7$ \\
$\mathrm{~K}_{\mathrm{ec}}=1278192627$ & $\mathrm{~K}_{\mathrm{ec}}=625175524$
\end{tabular}


Set - Up for Moment Distribution, cont.

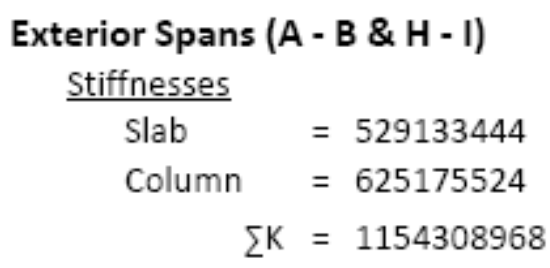

Distribution Factors

$\begin{array}{ll}\text { Slab } & =0.458398 \\ \text { Column } & =0.270801\end{array}$

Interior Spans (B - C through G - H)

Stiffnesses

Slab $=529133444$

Column $=1278192627$

$\Sigma K=2336459514$

Distribution Factors

$\begin{array}{ll}\text { Slab } & =0.226468 \\ \text { Column } & =0.273532\end{array}$

At Line of Symmetry (E)

Stiffnesses

$$
\begin{aligned}
\text { Slab } & =529133444 \\
\text { Column } & =639096313.5 \\
\Sigma \mathrm{K} & =1168229757
\end{aligned}
$$

Distribution Factors

$$
\begin{array}{ll}
\text { Slab } & =0.452936 \\
\text { Column } & =0.273532
\end{array}
$$




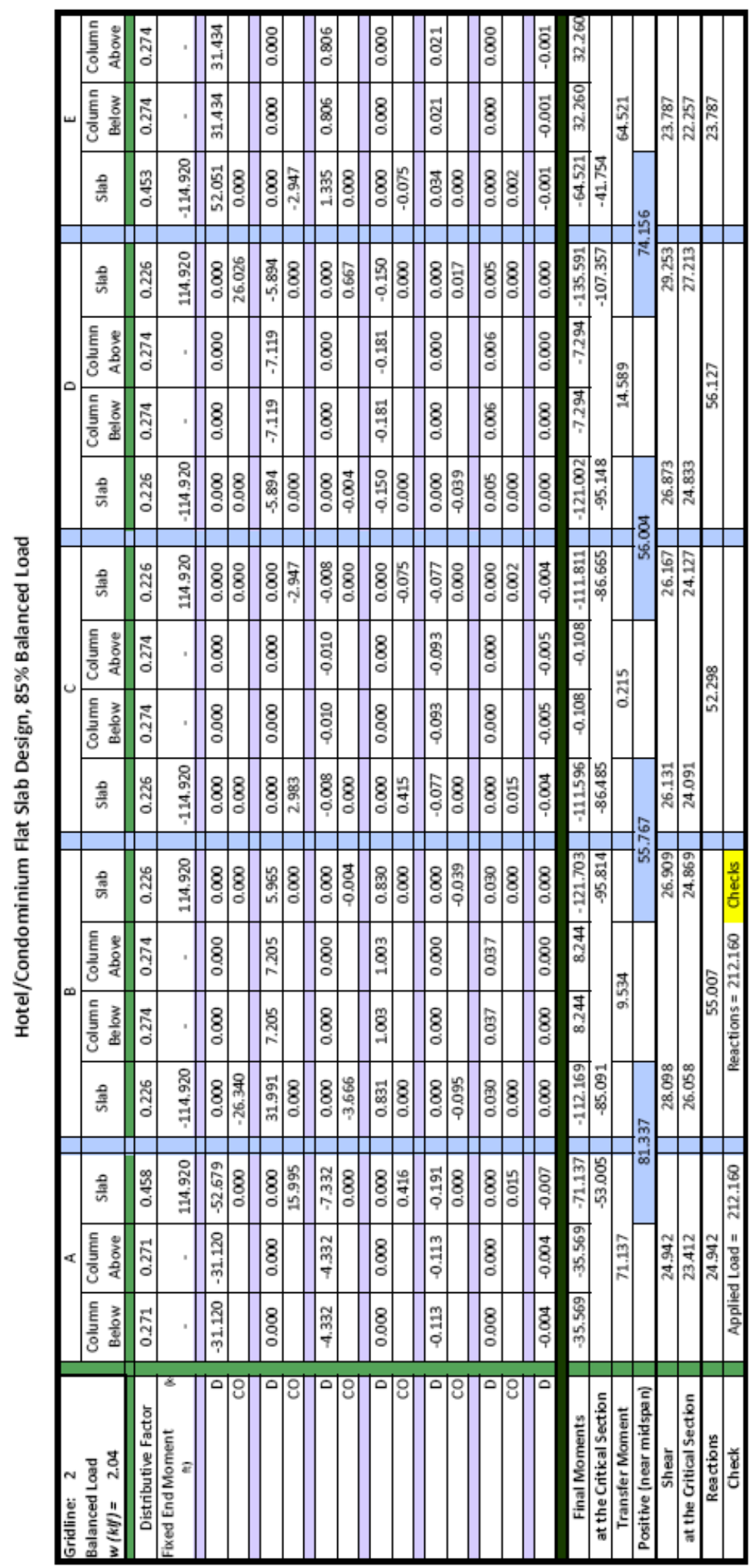




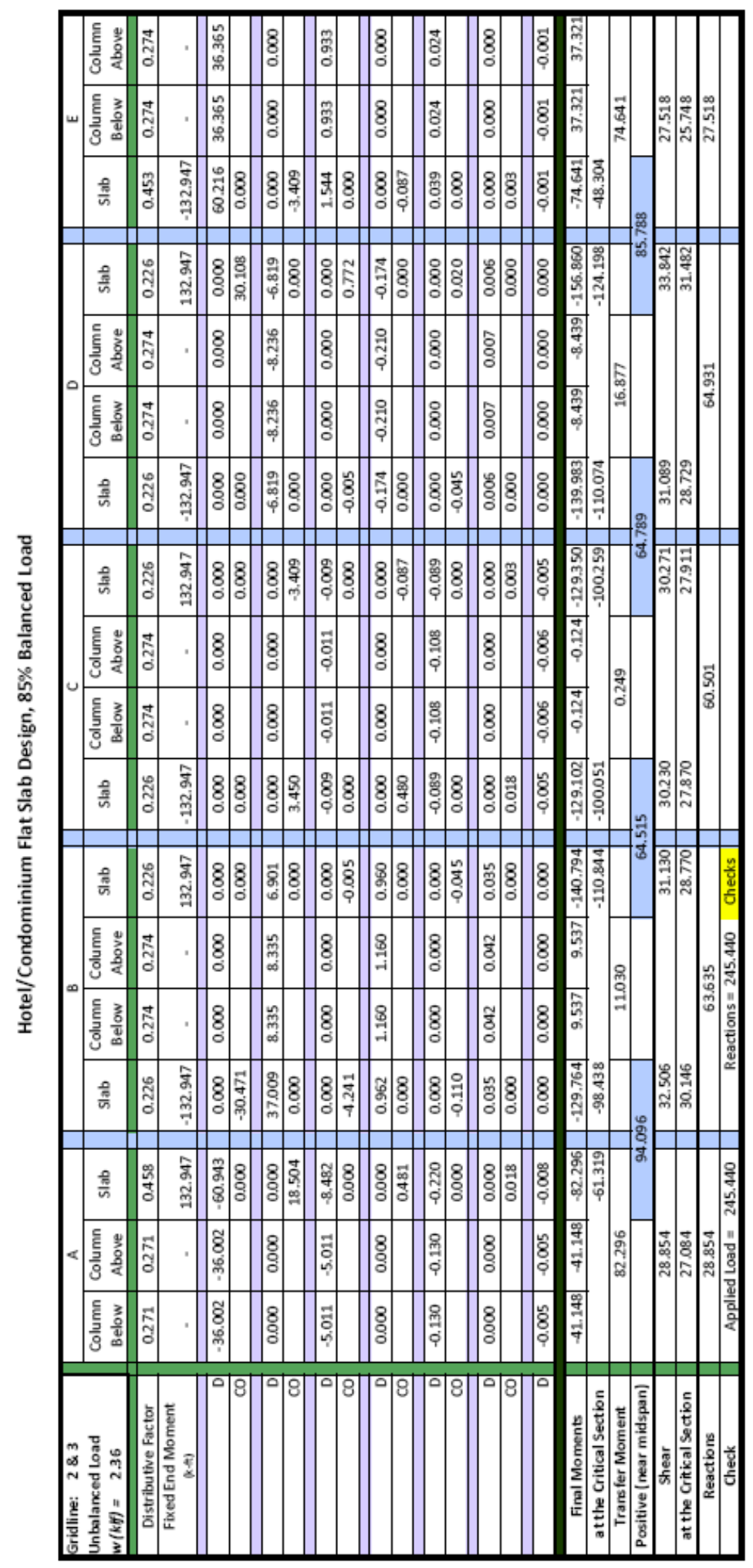


Appendix $\quad$ xxii

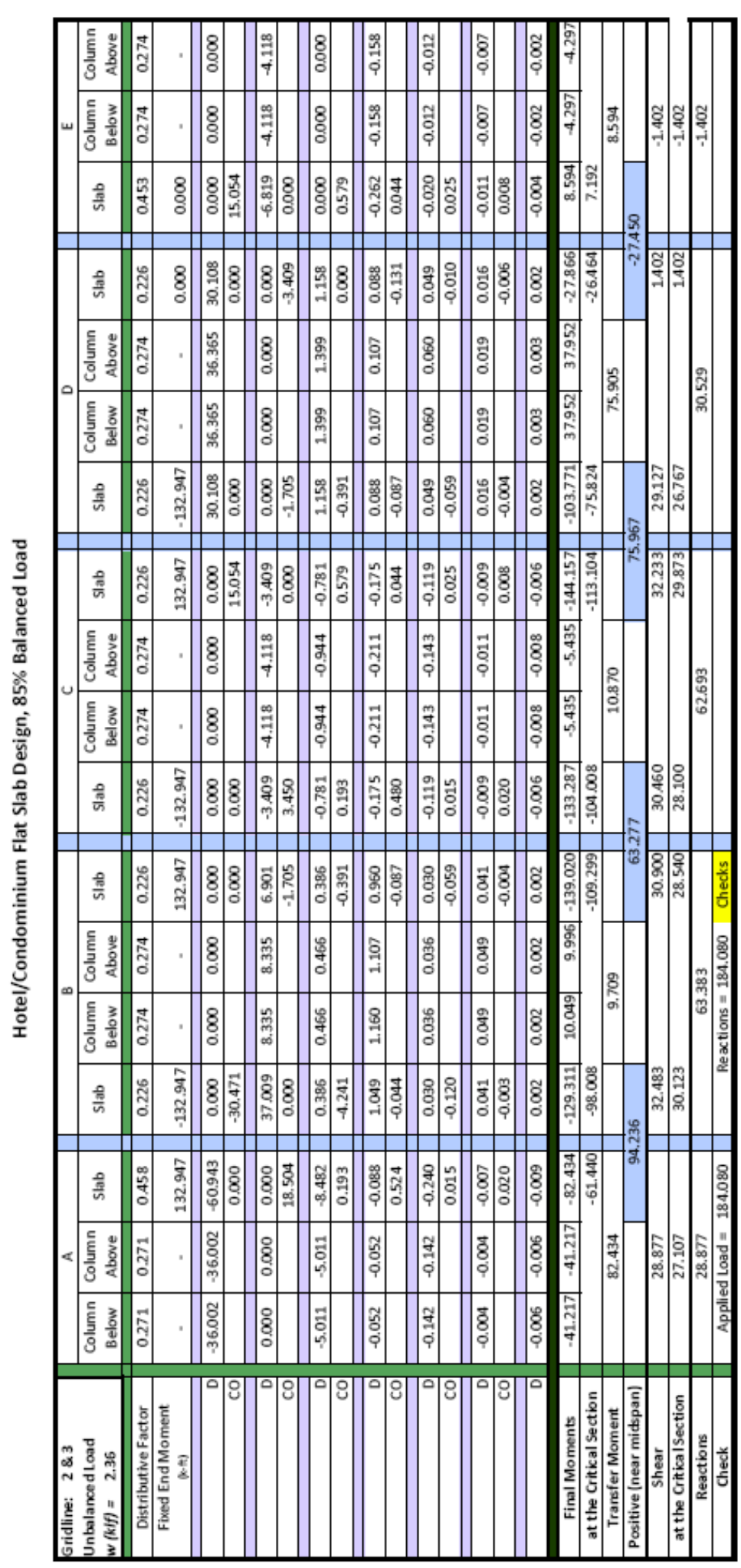

Optimization of Two-Way Post-Tensioned Concrete Floor Systems 
Appendix $\quad$ xxiii

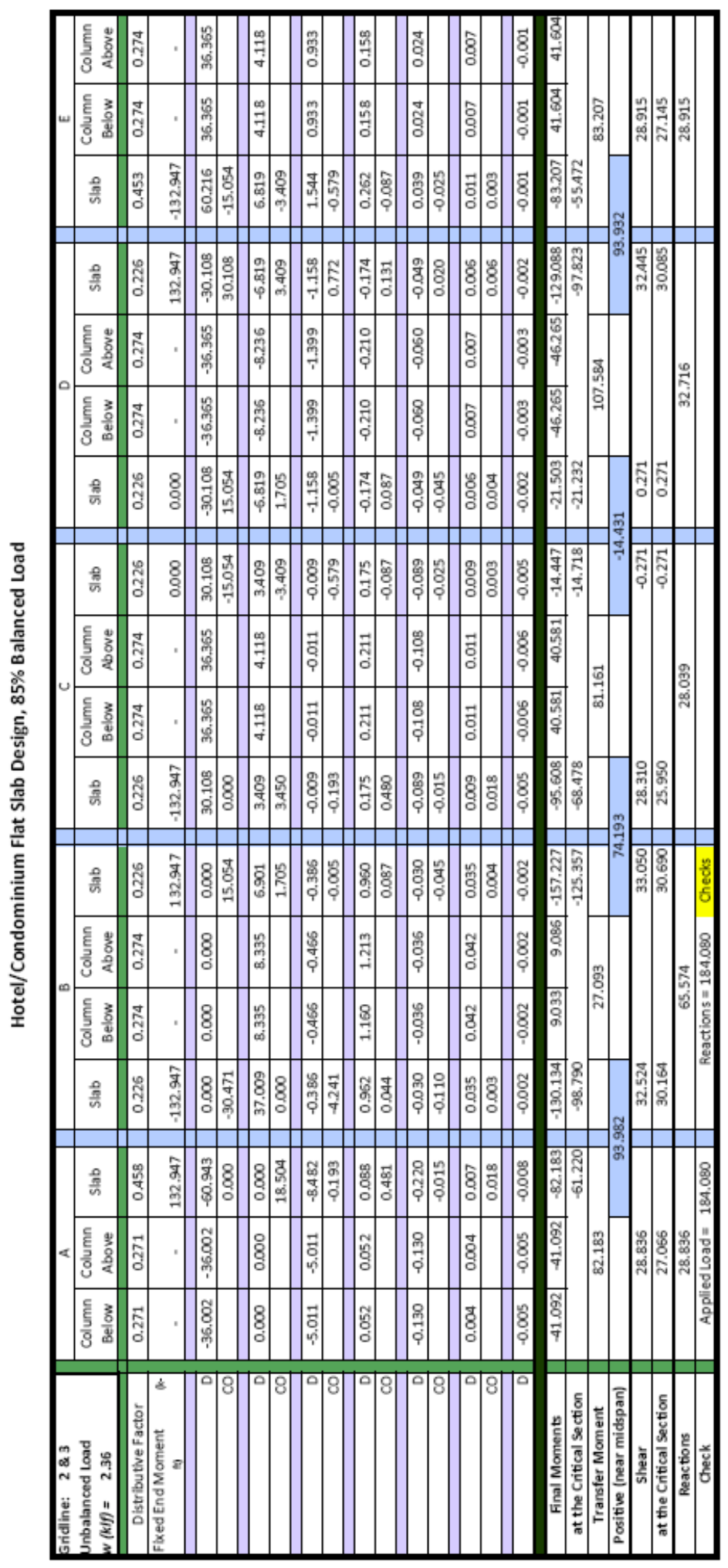

Optimization of Two-Way Post-Tensioned Concrete Floor Systems 
Appendix $\quad$ xxiv

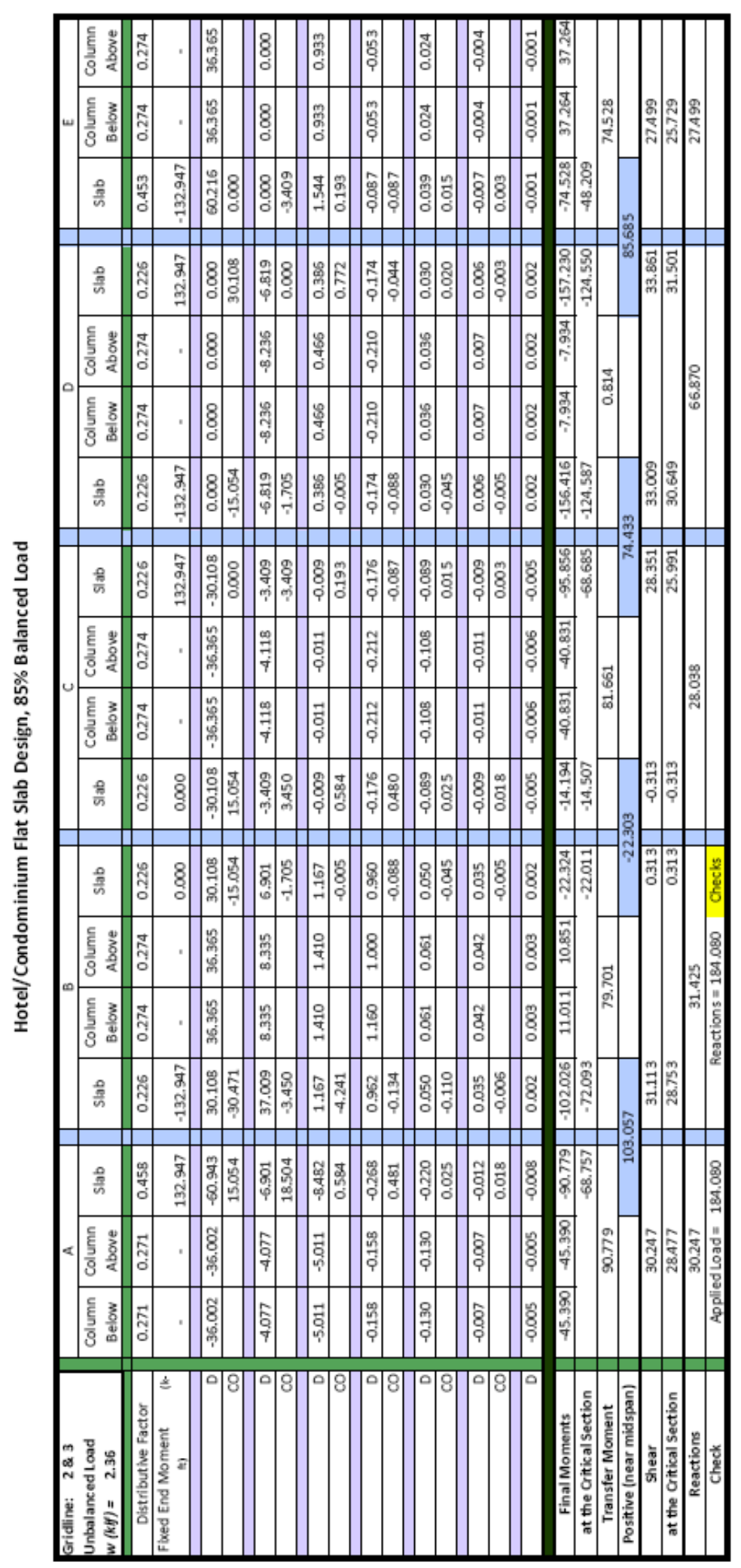

Optimization of Two-Way Post-Tensioned Concrete Floor Systems 
Appendix $\quad x x v$

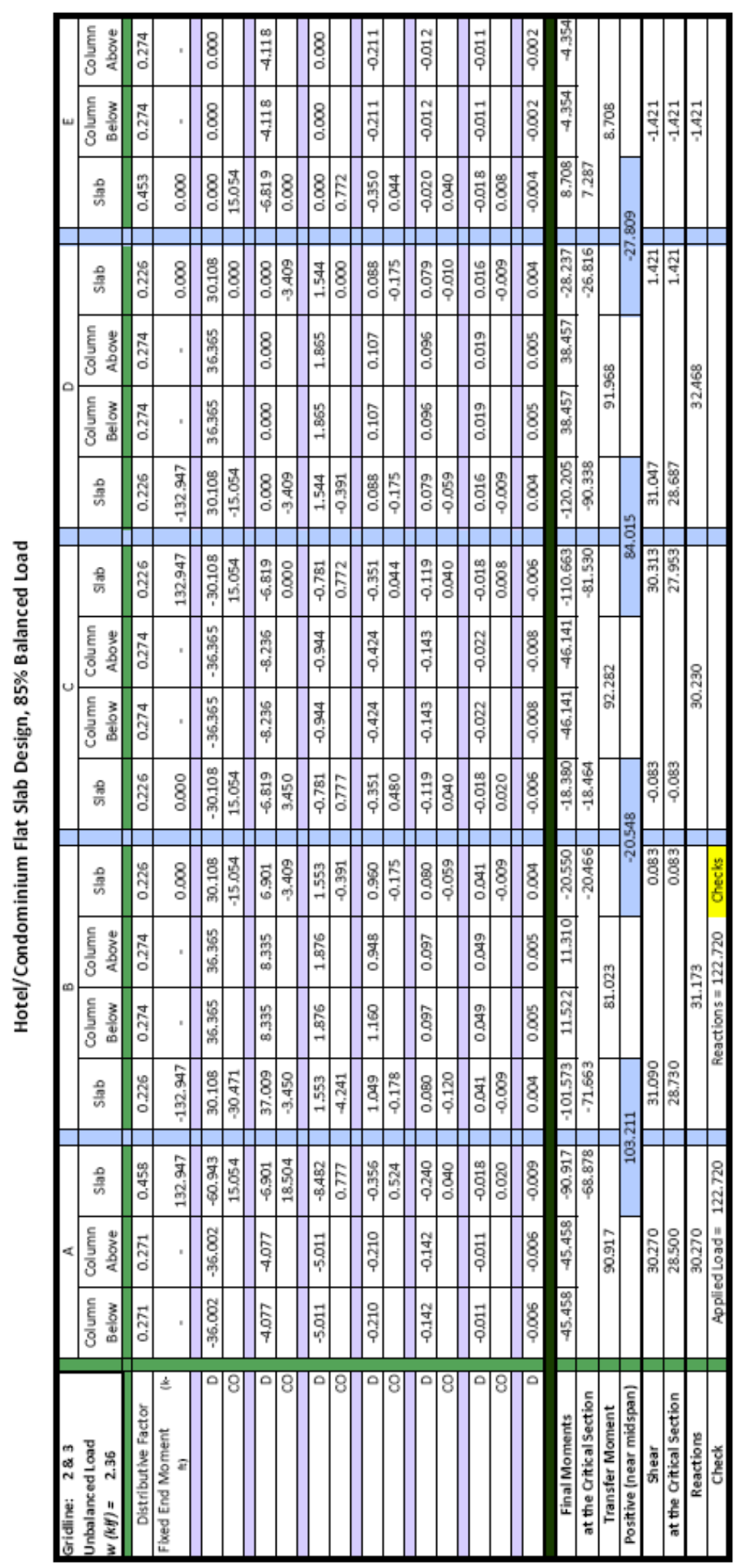

Optimization of Two-Way Post-Tensioned Concrete Floor Systems 
Appendix $\quad$ xxvi

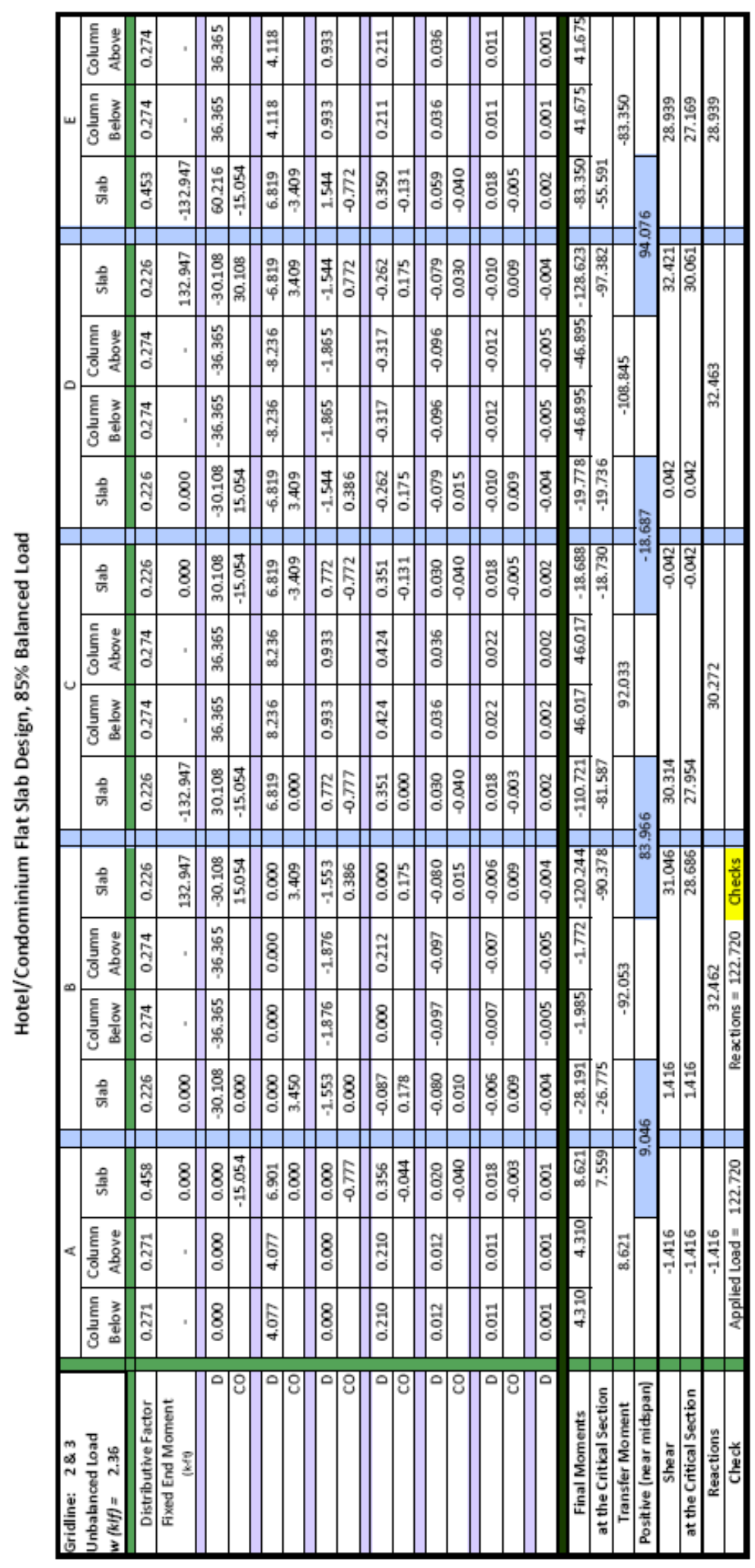

Optimization of Two-Way Post-Tensioned Concrete Floor Systems 
Appendix xxvii

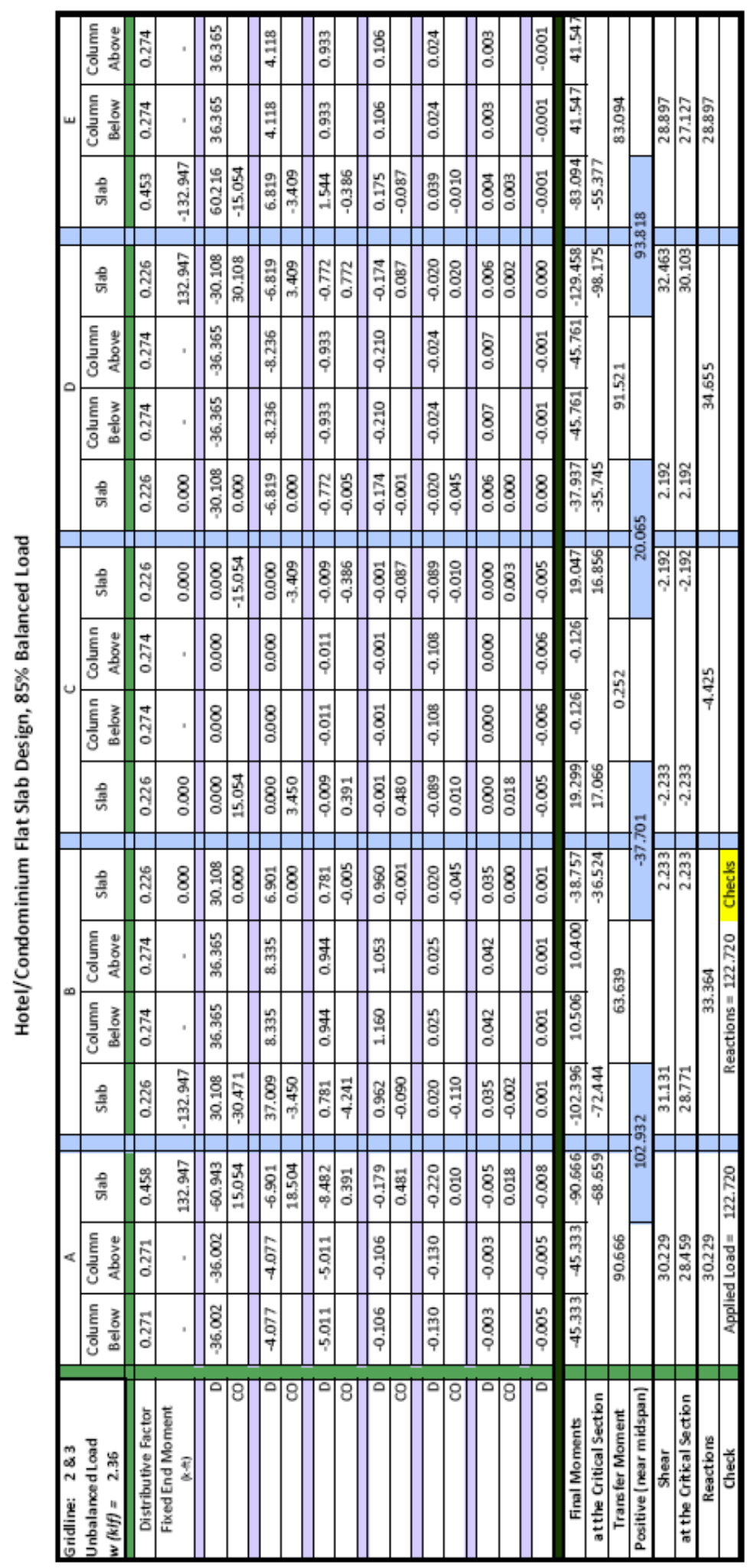

Optimization of Two-Way Post-Tensioned Concrete Floor Systems 
Appendix xxviii

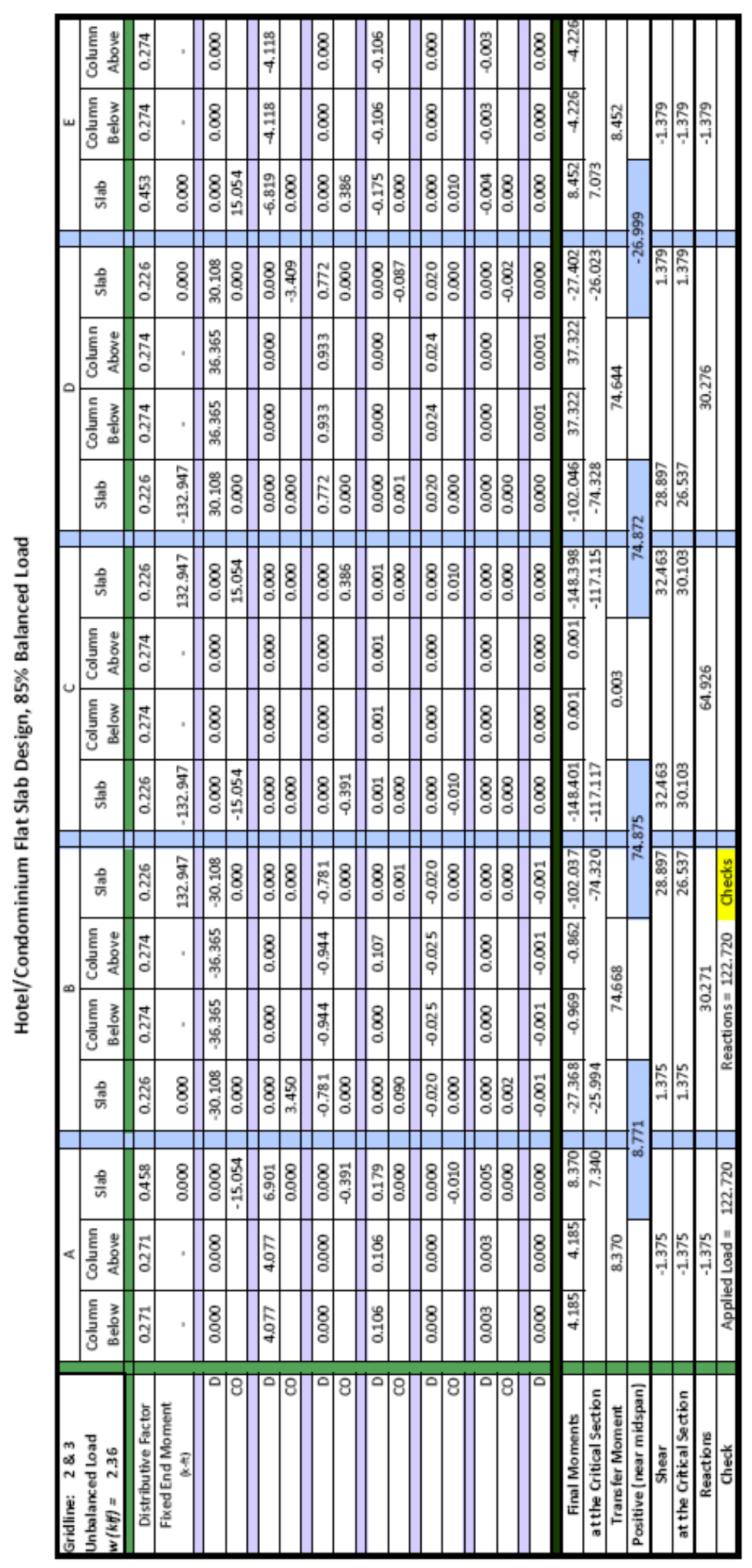

Optimization of Two-Way Post-Tensioned Concrete Floor Systems 
Appendix $\quad$ xxix

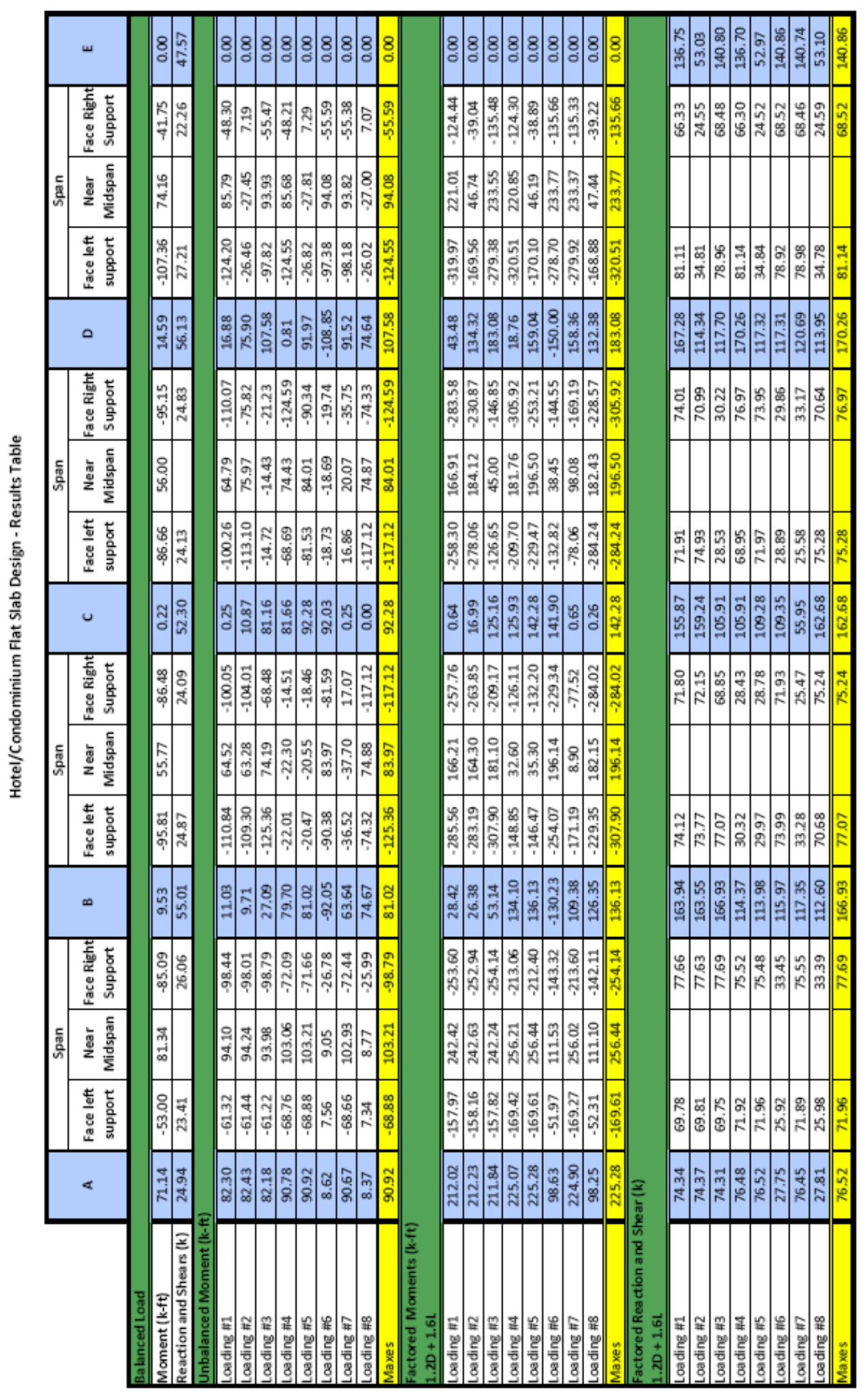

Optimization of Two-Way Post-Tensioned Concrete Floor Systems 


\section{Tendon Worksheet}

\section{Tendon Profile}

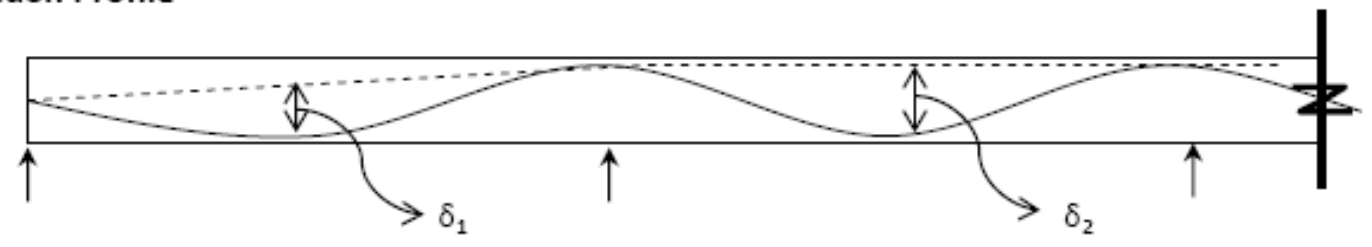
$\delta_{1}=4.5$ in
$A_{p s}=0.153 \mathrm{in}^{2}$
$\delta_{2}=6$ in
$f_{p s}=160 \mathrm{ksi}$

Force Required

$$
\begin{aligned}
& \text { Balanced Load }=2.04 \mathrm{klf} \\
& F_{1}=\frac{\left.w_{b}\right|^{2}}{8 \delta_{1}}=460 \mathrm{k} \quad \text { Governs } \\
& F_{2}=\frac{\left.w_{b}\right|^{2}}{8 \delta_{2}}=345 \mathrm{k}
\end{aligned}
$$

\section{Strands Required}

$$
\begin{aligned}
& N=\frac{F}{A_{p s} f_{p s}}=18.7778 \text { Use } 19 \text { Strands } F=465.12 \mathrm{k} \\
& \rightarrow \quad \delta_{1}=4.45 \\
& \rightarrow \quad \delta_{2}=4.45
\end{aligned}
$$

\section{Average Prestress}

$$
\sigma_{g}=\frac{N A_{p s} f_{p s}}{W d}=242.25 p s i
$$

\section{Tendon Distribution:}

Banded, therefore no need to check Moment Resistance within 1.5h of column 


\section{Stress Check}

Intials

$$
\begin{array}{ll}
\mathrm{Z}=\frac{\mathrm{Id}^{2}}{6}=2560 \mathrm{in}^{3} & \sigma_{\mathrm{t}}=\sigma_{\mathrm{g}}+\frac{\mathrm{M}}{\mathrm{Z}_{\mathrm{t}}} \\
\sigma_{\mathrm{g}}=242.3 \mathrm{psi} & \sigma_{\mathrm{b}}=\sigma_{\mathrm{g}}-\frac{\mathrm{M}}{\mathrm{Z}_{\mathrm{b}}}
\end{array}
$$

\section{Checks}

Positive Moment:

$$
\sigma<.45 f_{c}{ }^{\prime}=2250 \mathrm{psi}
$$

Negative Moment:

\section{Reinforcing Check}

Needed if $\sigma>2 \mathrm{vf}_{\mathrm{c}}{ }^{\prime} \quad=141.4 \mathrm{psi}$

Stresses at Exterior Support
$\sigma_{\mathrm{t}}$
-80.6 psi
OK
No additional Reinforcing Needed
$\sigma_{\mathrm{b}}=565.1 \mathrm{psi} \quad \mathrm{OK}$

Stresses at Midspan of Outside Span

$$
\begin{array}{llll}
\sigma_{\mathrm{t}}=726.1 & \text { psi } & \text { OK } \\
\sigma_{\mathrm{b}}=-241.6 & \text { psi } & \text { OK } & \text { Reinforcing Required }
\end{array}
$$$$
\text { Use \# } 7 \text { bars@ } 20 \text { "o.c }
$$

\section{Stresses at Critical Interior Support}

$$
\begin{array}{lllll}
\sigma_{\mathrm{t}}= & -345.4 & \text { psi } & \text { OK } & \begin{array}{r}
\text { Reinforcing Required } \\
\text { Use } 5 \# 5 \text { bars }
\end{array} \\
\sigma_{\mathrm{b}}=829.9 \text { psi } & \text { OK } & &
\end{array}
$$

\section{Stresses at Midspan of Critical Inside Span}

$$
\begin{aligned}
& \sigma_{\mathrm{t}}=683.2 \text { psi } \mathrm{OK} \\
& \sigma_{b}=-198.7 \text { psi } \text { OK Reinforcing Required } \\
& \text { Use \#7 bars@22 "o.c }
\end{aligned}
$$




\section{Ultimate Flexural Strength}

$$
f_{p s}=f_{p e}+7.5=167 \mathrm{ksi}
$$

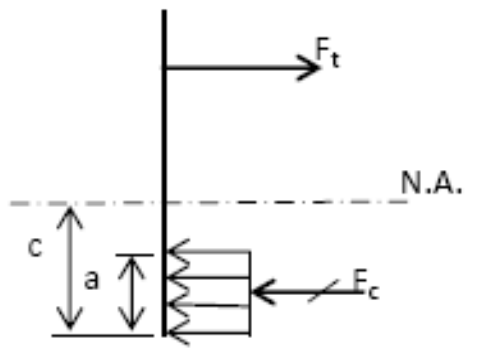

$$
\begin{aligned}
\phi M_{n} & =\phi\left(A_{p s} f_{p s}+A_{s} f_{y}\right)(d-a / 2) \\
a & =\frac{A_{p s} f_{p s}+A_{s} f_{y}}{.85^{*} f_{c}{ }^{\prime} b} \\
c & =\frac{a}{\beta_{1}}
\end{aligned}
$$

\section{Check Interior Supports}

$$
\begin{aligned}
\mathrm{A}_{p s} & =2.907 \mathrm{in}^{2} \quad \mathrm{f}_{\mathrm{y}}=60 \mathrm{ksi} \\
\mathrm{A}_{\mathrm{s}} & =1.55 \mathrm{in}^{2} \quad \beta_{1}=0.8 \\
\mathrm{a} & =0.567126 \mathrm{in} \\
\mathrm{c} & =0.708908 \mathrm{in} \quad \phi=0.9 \\
\phi \mathrm{M}_{\mathrm{n}} & =4017.348 \mathrm{k} \text {-in } \\
& =334.779 \mathrm{k}-\mathrm{ft} \\
\mathrm{M}_{\mathrm{u}} & =-320.508 \mathrm{k}-\mathrm{ft} \quad<\phi \mathrm{Mn} \text {, therefore OK }
\end{aligned}
$$

\section{Check Span}

$$
\begin{aligned}
\mathrm{A}_{\mathrm{ps}} & =2.907 \mathrm{in}^{2} \quad \mathrm{f}_{\mathrm{y}}=60 \mathrm{ksi} \\
\mathrm{A}_{\mathrm{s}} & =6.545455 \mathrm{in}^{2} \quad \beta_{1}=1.034 \\
\mathrm{a}= & 0.860977 \mathrm{in} \\
\mathrm{c}= & 0.832344 \mathrm{in} \quad \phi=0.9 \\
\phi \mathrm{M}_{\mathrm{n}} & =5982.765 \mathrm{k} \text {-in } \\
& =498.5638 \mathrm{k}-\mathrm{ft} \\
\mathrm{M}_{\mathrm{u}} & =256.4447 \mathrm{k}-\mathrm{ft} \quad<\phi \mathrm{Mn} \text {, therefore OK }
\end{aligned}
$$




\section{Punching Shear - Interior Columns}
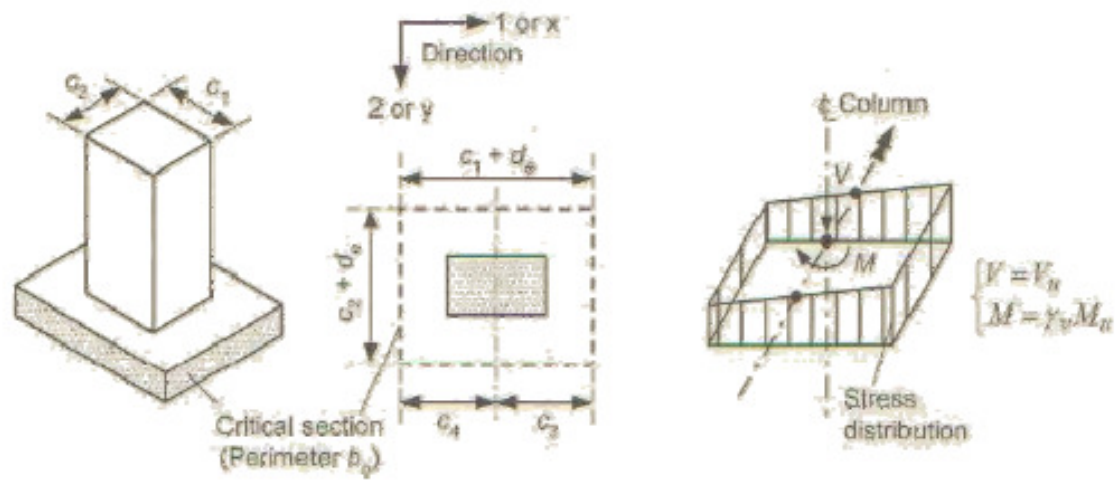

Definitions

$$
\begin{aligned}
& c_{3}=c_{4}=\frac{\left(c_{1}+d_{e}\right)}{2} \quad J_{c}=\frac{d_{e}\left(c_{1}+d_{e}\right)^{3}}{6}+\frac{\left(c_{1}+d_{e}\right) d_{e}^{3}}{6}+\frac{d_{e}\left(c_{2}+d_{e}\right)\left(c_{1}+d_{e}\right)^{2}}{2} \\
& b_{0}=2\left(c_{1}+c_{2}+2 d_{e}\right) \quad A_{c}=d_{e} b_{0} \\
& \gamma_{v}=1-\frac{1}{1+\frac{2}{3} \sqrt{\frac{c_{1}+d_{e}}{c_{2}+d_{e}}}} \\
& v_{c}=\beta_{p} \sqrt{f_{c}^{\prime}}+0.3 \sigma_{g}+\frac{v_{p}}{b_{0} d_{e}} \\
& \beta_{p}=\text { smaller of }\left\{\begin{array}{l}
3.5 \\
1.5
\end{array} \quad \alpha_{s}=40\right. \\
& v_{u}=\frac{v_{u} d_{e}}{A_{c}}+\frac{\gamma_{v} M_{u} c_{3}}{J_{c}} \\
& \text { Check: } \quad \phi v_{c}>v_{u} ?
\end{aligned}
$$

\section{Stud Rail Reinforcing:}

$$
\begin{aligned}
& V_{s}=\left(\frac{v_{u}}{\phi}-2 \sqrt{f_{c}{ }_{c}^{\prime}}\right) A_{c} \\
& \# \text { of Studs }=\frac{V_{s}}{f_{y} A_{s}}
\end{aligned}
$$

Note:

Assuming $1 / 2^{\mathrm{l}}$ stud rails, $\mathrm{A}_{5}=0.196 \mathrm{in}^{2}$, with $\mathrm{f}_{\mathrm{y}}=50 \mathrm{ksi}$. 


\section{Punching Shear - Interior Columns}

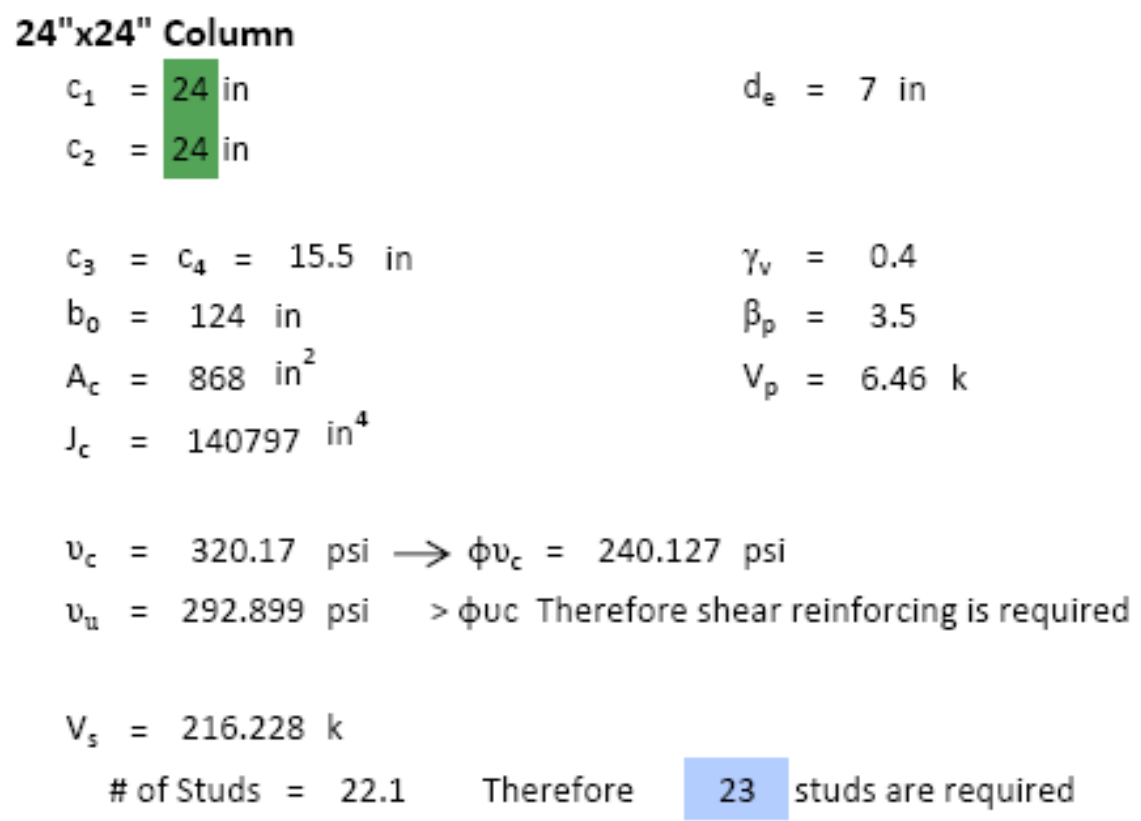




\section{Punching Shear - Exterior Columns}

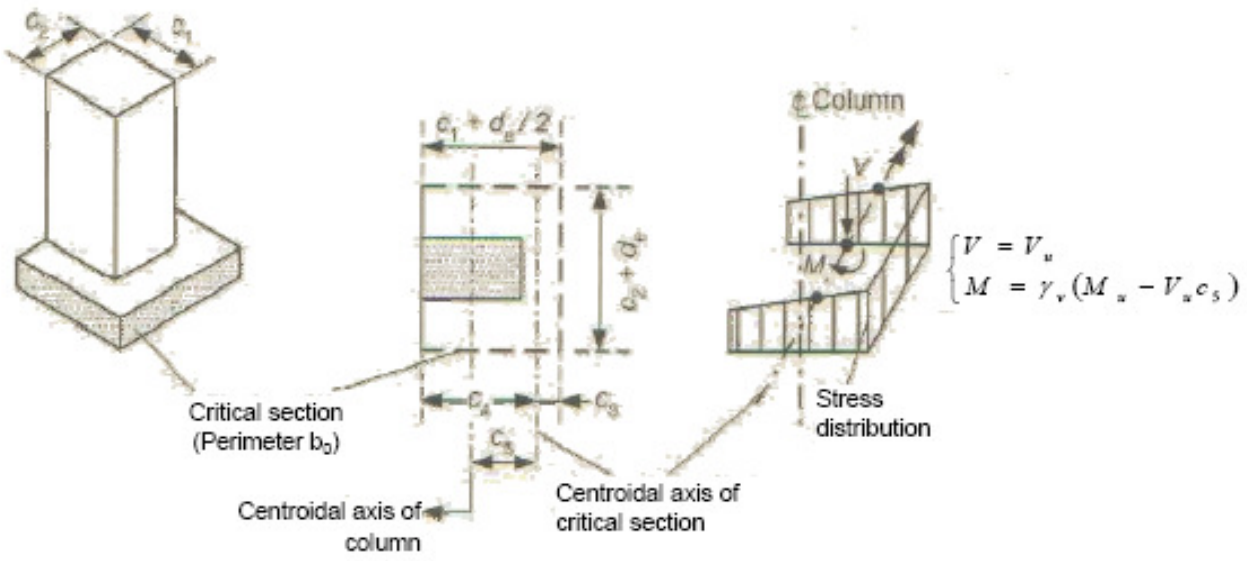

\section{Definitions}

$$
\begin{array}{ll}
b_{0}=\left(2 c_{1}+c_{2}+2 d_{e}\right) & c_{3}=\frac{d_{e}\left(c_{1}+1 / 2 d_{e}\right)^{2}}{A_{c}} \\
A_{c}=b_{0} d_{e} & \begin{array}{r}
c_{4}=\left(c_{1}+1 / 2 d_{e}\right)-c_{3} \\
c_{5}=c_{4}-1 / 2 c_{1}
\end{array} \\
J_{c}=\frac{\left(c_{1}+1 / 2 d_{e}\right) d_{e}{ }^{3}}{6}+\frac{2 d_{e}\left(c_{3}{ }^{3}+c_{4}{ }^{3}\right)}{3}+d_{e}\left(c_{2}+d_{e}\right) c_{3}{ }^{2}
\end{array}
$$

$v_{u}=$ larger of $\left\{\begin{array}{l}\frac{V_{u}}{A_{c}}+\frac{\gamma_{v}\left(M_{u}-V_{u} c_{5} c_{3}\right.}{J_{c}} \\ \frac{V_{u}}{A_{c}}-\frac{\gamma_{v}\left(M_{u}-V_{u} c_{5} c_{4}\right.}{J_{c}}\end{array}\right.$

Check: $\quad \phi v_{\mathrm{c}}>v_{\mathrm{u}}$ ?

\section{Stud Rail Reinforcing:}

$$
V_{s}=\frac{v_{u}}{\phi}-2 \text { f } f_{c}^{\prime} A_{c} \quad \text { \# of Studs }=\frac{V_{s}}{f_{y} A_{s}}
$$




\section{Punching Shear - Exterior Columns}

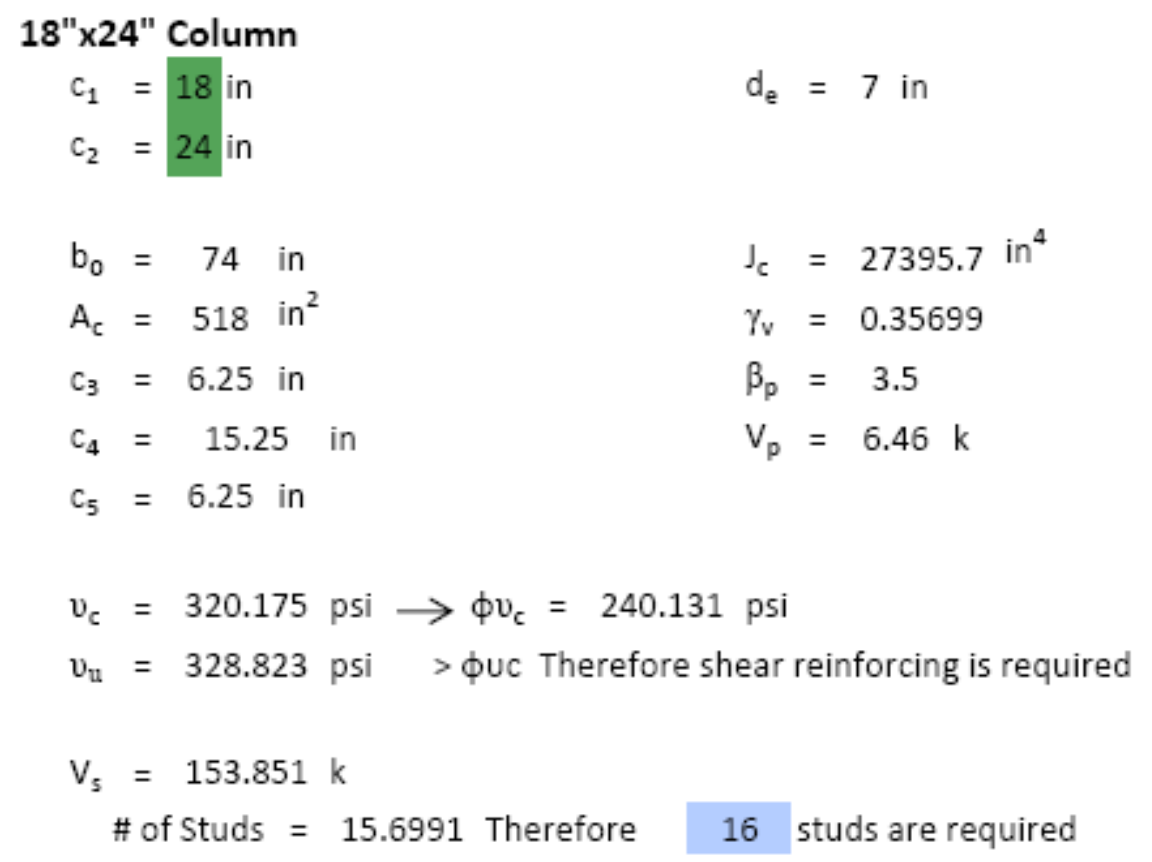




\section{A.1.3 Equivalent Frame - Grids A \& I}

\section{Set - Up for Moment Distribution}

Initials

\begin{tabular}{|c|c|c|c|}
\hline Slab Depth & ent Frame Width & Span 1-2 & Span 2-3 \\
\hline 8 in & $13 \mathrm{ft}$ & $26 \mathrm{ft}$ & $14 \mathrm{ft}$ \\
\hline \multicolumn{4}{|l|}{ Loading } \\
\hline Dead Load & 100 psf & $\mathrm{w}_{\text {tot }}=2.86$ & klf \\
\hline Superimposed Dead Load & 20 psf & $\mathrm{w}_{\mathrm{b}}=1.326$ & klf \\
\hline Live Load & 100 psf & $\mathrm{w}_{\mathrm{nb}}=1.534$ & klf \\
\hline \multicolumn{2}{|l|}{ Tendons } & $w_{\text {DL-nb }}=0.234$ & klf \\
\hline \multicolumn{4}{|l|}{$\begin{aligned} A_{s} & =0.153 \mathrm{in}^{2} \\
f_{p e} & =160 \mathrm{ksi}\end{aligned}$} \\
\hline \multicolumn{4}{|l|}{ Concrete } \\
\hline \multicolumn{3}{|l|}{$\mathrm{f}_{c}^{\prime}=5000 \mathrm{psi}$} & \\
\hline
\end{tabular}

\section{Stiffnesses}

$\underline{\text { Slab }}$

$\begin{array}{lll}\mathrm{b}=156 \text { in } & I_{12}=312 \text { in } & \mathrm{K}_{12}=343936738 \\ \mathrm{~d}=8 \text { in } & I_{23}=168 \text { in } & K_{23}=638739657 \\ \mathrm{I}=6656 \mathrm{in}^{4} & & \end{array}$

$\underline{\text { Column }}$

Exterior Column

Corner Column

$c_{1}=18$ in

$c_{1}=18$ in

$c_{2}=24$ in

$\mathrm{c}_{2}=18 \mathrm{in}$

$I_{1}=312 \mathrm{in}$

$I_{1}=312 \mathrm{in}$

$I_{2}=156 \mathrm{in}$

$I_{2}=156 \mathrm{in}$

$\mathrm{h}=136 \mathrm{in}$

$\mathrm{h}=136 \mathrm{in}$

$I=20736$ in $^{4}$

$\mathrm{I}=8748 \mathrm{in}^{4}$

$\mathrm{K}=2458136108$

$K=1037026171$

$C=3235.84$

$\mathrm{C}=2211.84$

$K_{t}=1086929420$

$\mathrm{K}_{\mathrm{t}}=742964414$

$\mathrm{K}_{\mathrm{ec}}=890131838 \quad \mathrm{~K}_{\mathrm{ec}}=547013815$ 


\section{Set - Up for Moment Distribution, cont.}

\section{$1 \& 4$}

Stiffnesses

$$
\begin{aligned}
\text { Slab } & =343936738 \\
\text { Column } & =547013815 \\
\Sigma \mathrm{K} & =890950553
\end{aligned}
$$

Distribution Factors

$$
\begin{array}{ll}
\text { Slab } & =0.386033 \\
\text { Column } & =0.306983
\end{array}
$$

\section{$2 \& 3$}

Stiffnesses

$$
\begin{aligned}
\text { Slab }_{12} & =343936738 \\
\text { Slab }_{23} & =638739657 \\
\text { Column } & =890131838 \\
\Sigma \mathrm{K} & =1872808234
\end{aligned}
$$

Distribution Factors

$$
\begin{array}{ll}
\text { Slab }_{12} & =0.183648 \\
\text { Slab }_{23} & =0.34106 \\
\text { Column } & =0.237646
\end{array}
$$


Appendix $\quad$ xxxix

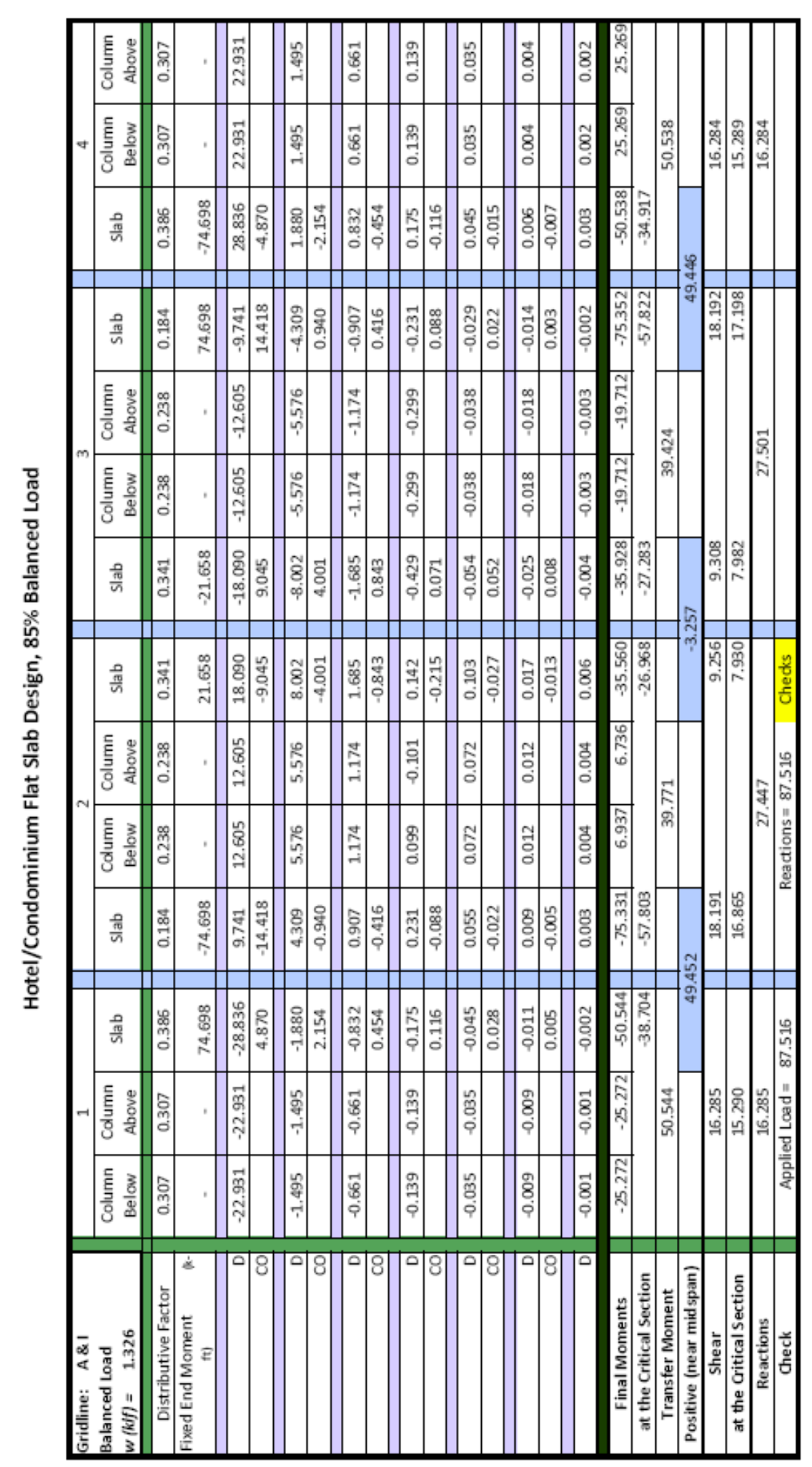

Optimization of Two-Way Post-Tensioned Concrete Floor Systems 


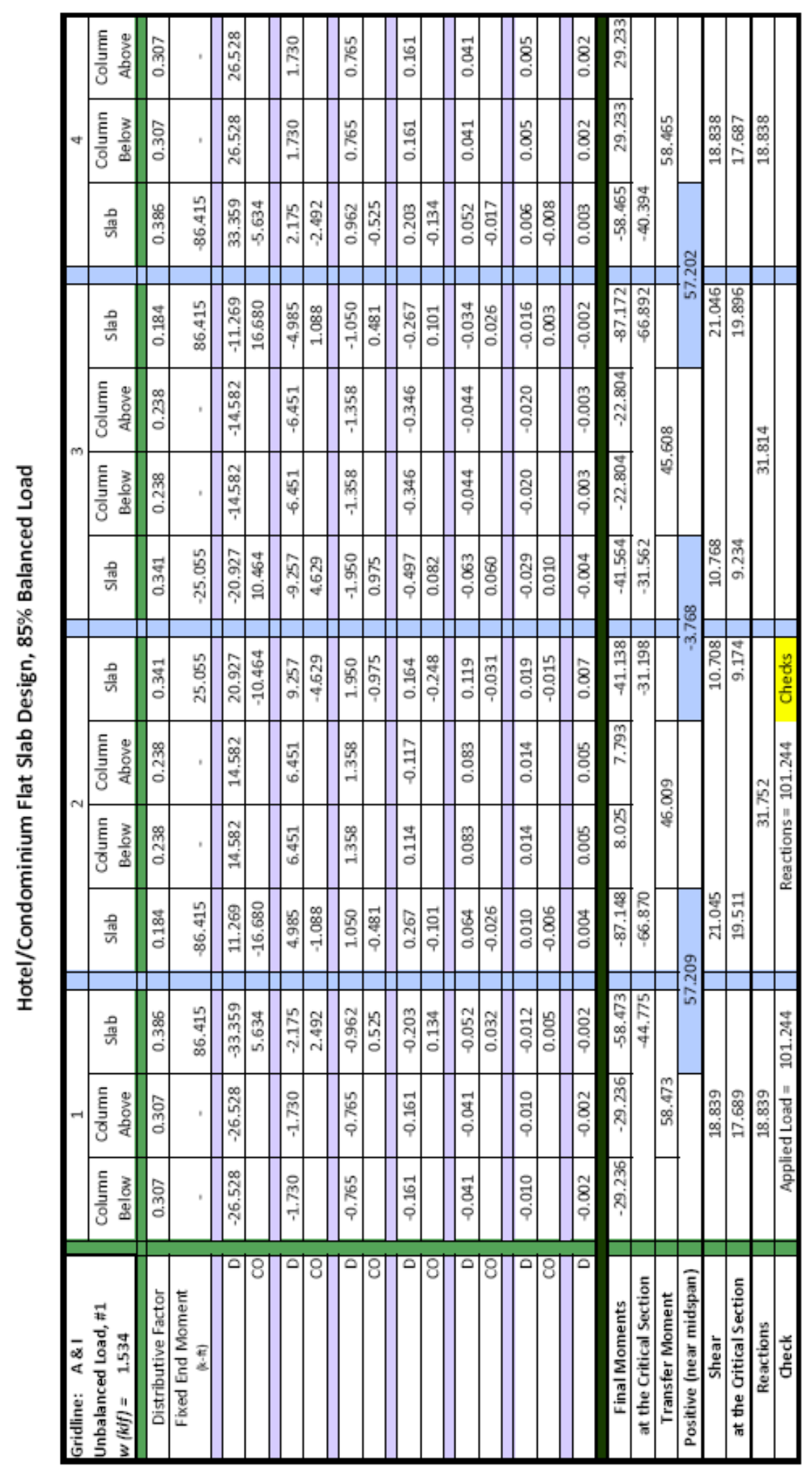




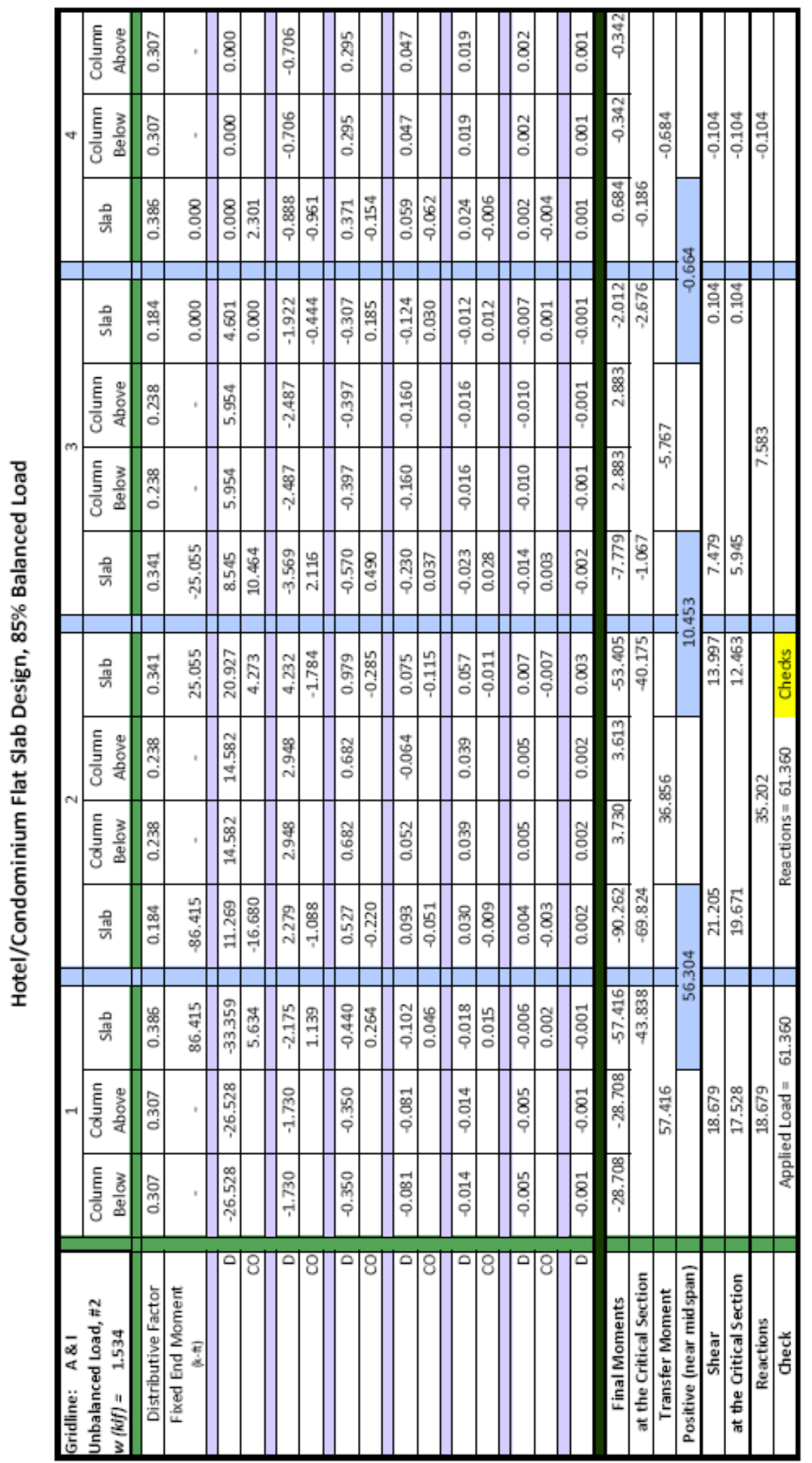


Appendix xlii

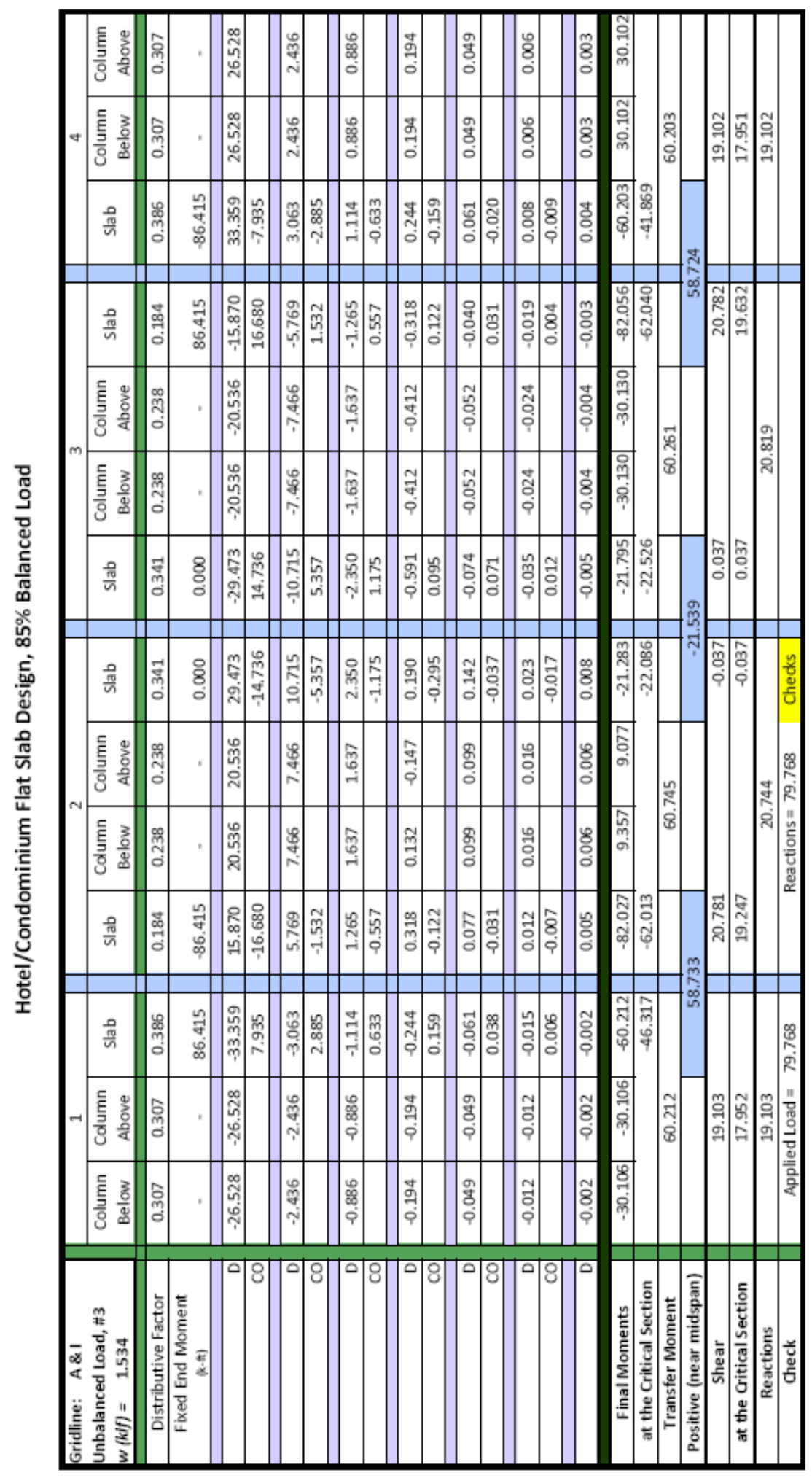

Optimization of Two-Way Post-Tensioned Concrete Floor Systems 
Appendix xliii

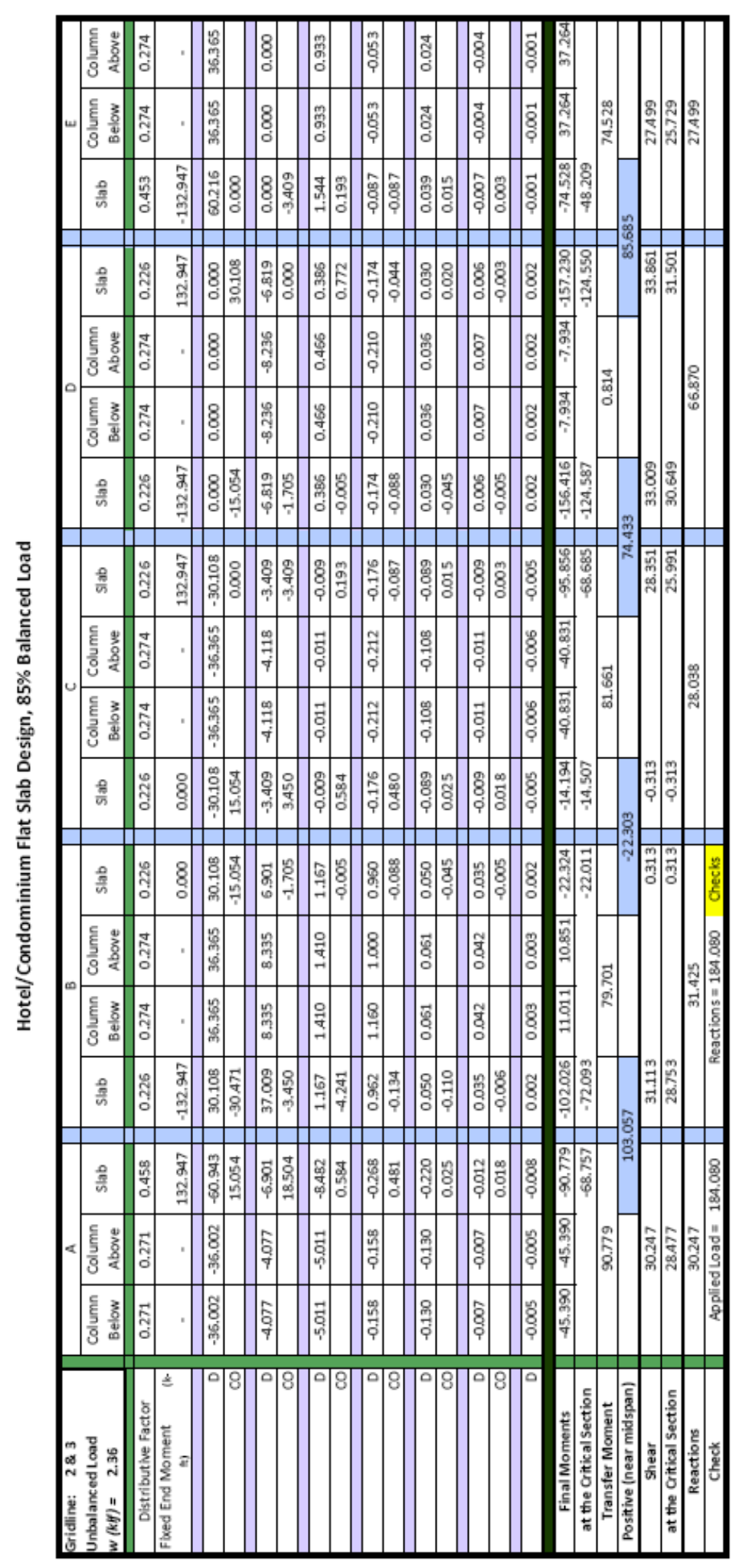

Optimization of Two-Way Post-Tensioned Concrete Floor Systems 
Appendix xliv

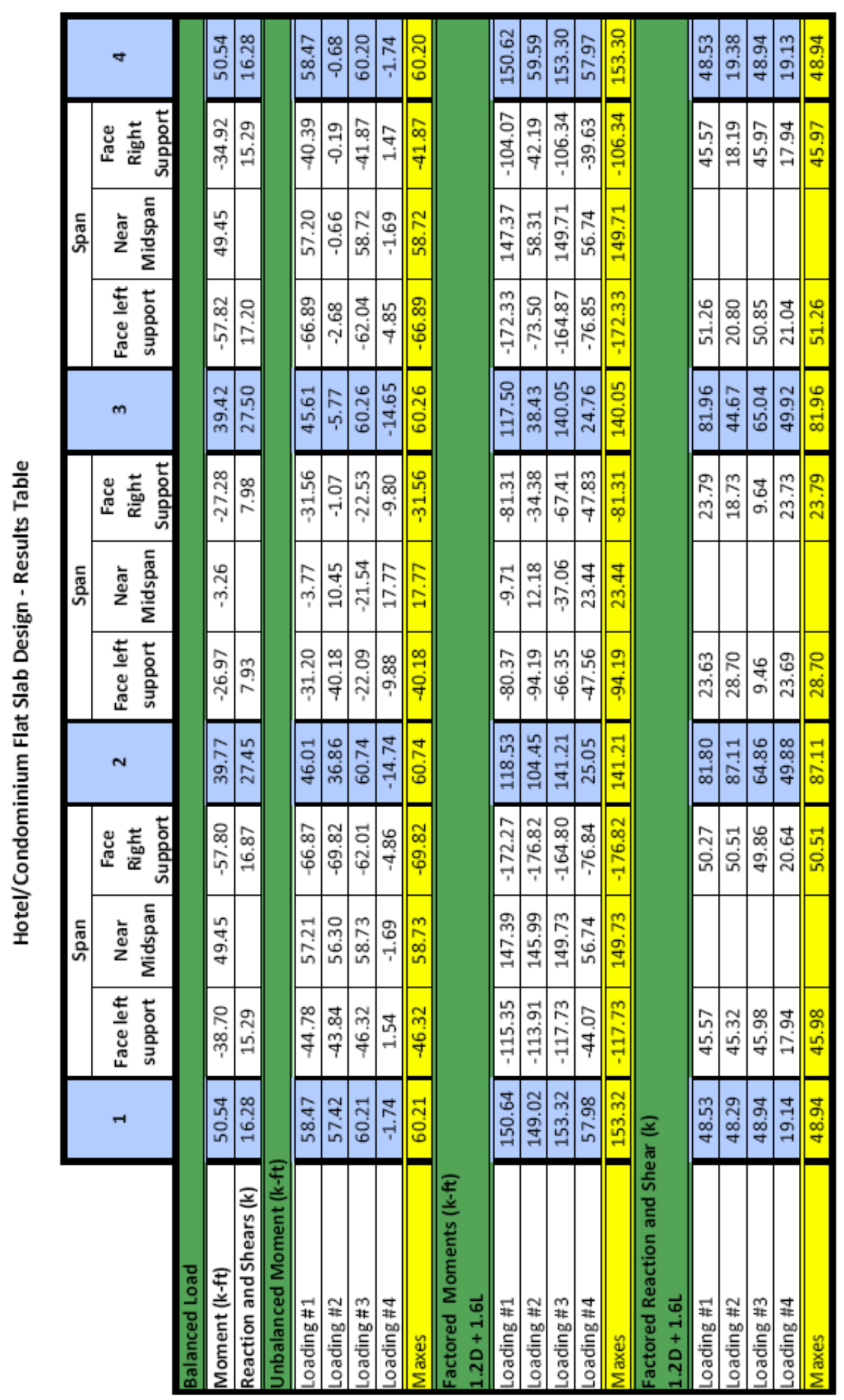




\section{Tendon Worksheet}

Tendon Profile

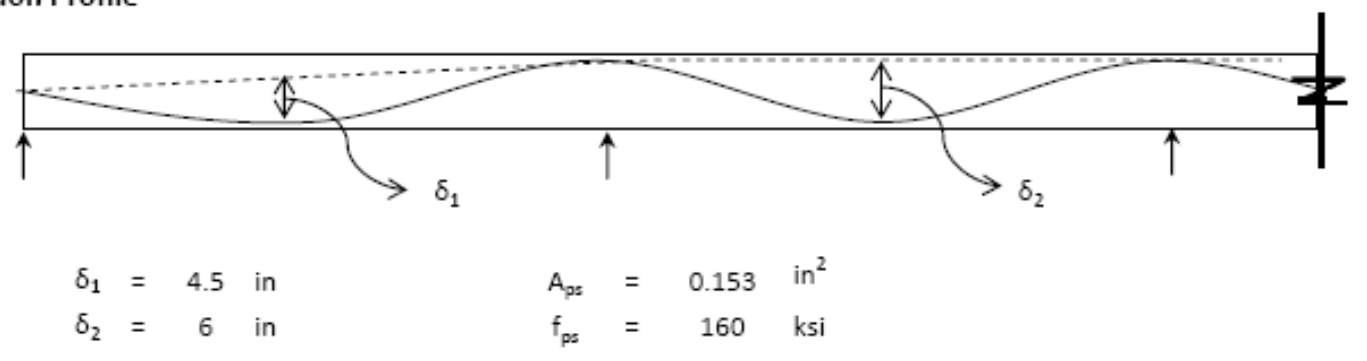

Force Required

$$
\begin{aligned}
& \text { Balanced Load }=1.326 \mathrm{klf} \\
& \mathrm{F}_{1}=\frac{\left.\mathrm{w}_{\mathrm{b}}\right|^{2}}{8 \delta_{1}}=298.8 \mathrm{k} \quad \text { Governs } \\
& \mathrm{F}_{2}=\frac{\left.\mathrm{w}_{\mathrm{b}}\right|^{2}}{8 \delta_{2}}=64.97 \mathrm{k}
\end{aligned}
$$

Strands Required

$$
\begin{aligned}
& \mathrm{N}=\frac{\mathrm{F}}{\mathrm{A}_{\mathrm{ps}} \mathrm{f}_{\mathrm{ps}}}=12.20556 \text { Use } 13 \text { Strands } \mathrm{F}=318.24 \mathrm{k} \\
& \longrightarrow \quad \delta_{1}=4.225 \\
& \longrightarrow \quad \delta_{2}=1.225
\end{aligned}
$$

Average Prestress

$$
\sigma_{5}=\frac{\mathrm{NA}_{p s} \mathrm{f}_{p s}}{\mathrm{Wd}}=255 \quad \text { psi }
$$

\section{Tendon Distribution:}

Uniform, therefore need to check Moment Resistance within $1.5 \mathrm{~h}$ of column 


\section{Stress Check}

Intials

$$
\begin{array}{ll}
\mathrm{Z}=\frac{\mathrm{Id}^{2}}{6}=1664 \mathrm{in}^{3} & \sigma_{\mathrm{t}}=\sigma_{\mathrm{g}}+\frac{\mathrm{M}}{\mathrm{Z}_{\mathrm{t}}} \\
\sigma_{\mathrm{g}}=255 \mathrm{psi} & \sigma_{\mathrm{b}}=\sigma_{\mathrm{g}}-\frac{\mathrm{M}}{\mathrm{Z}_{\mathrm{b}}}
\end{array}
$$

\section{Checks}

Positive Moment:

$$
\sigma<.45 \mathrm{f}_{\mathrm{c}}{ }^{\prime}=2250 \mathrm{psi}
$$

Negative Moment:

$\sigma>-6 \mathrm{Vf}_{\mathrm{c}}^{\prime}=-424 \mathrm{psi}$

\section{Reinforcing Check}

$$
\text { Needed if } \sigma>2 \mathrm{Vf}_{\mathrm{c}}{ }^{\prime}=141 \mathrm{psi}
$$

\section{Stresses at Exterior Support}
$\sigma_{\mathrm{t}}=-79.0$ psi $\mathrm{OK}$
No additional Reinforcing Needed
$\sigma_{\mathrm{b}}=589.0$ psi $\mathrm{OK}$

Stresses at Midspan of Outside Span

$$
\begin{array}{llll}
\sigma_{\mathrm{t}}=678.6 \text { psi } & \text { OK } \\
\sigma_{\mathrm{b}}=-168.6 \mathrm{psi} & \text { OK } \quad \text { Reinforcing Required }
\end{array}
$$

\section{Stresses at Critical Interior Support}

$$
\begin{array}{llll}
\sigma_{\mathrm{t}}=-248.5 & \text { psi } & \text { OK } & \begin{array}{c}
\text { Reinforcing Required } \\
\text { Use } 4 \text { \# }
\end{array} \\
\sigma_{\mathrm{b}}=758.5 \text { psi } & \text { OK } &
\end{array}
$$

\section{Stresses at Midspan of Inside Span}

$$
\begin{aligned}
& \sigma_{\mathrm{t}}=383.2 \text { psi } \quad \text { OK } \\
& \sigma_{\mathrm{b}}=126.8 \text { psi } \quad \text { OK } \quad \text { No additional Reinforcing Needed }
\end{aligned}
$$




\section{Ultimate Flexural Strength}

$$
f_{p s}=f_{p e}+7.5=167 \mathrm{ksi}
$$

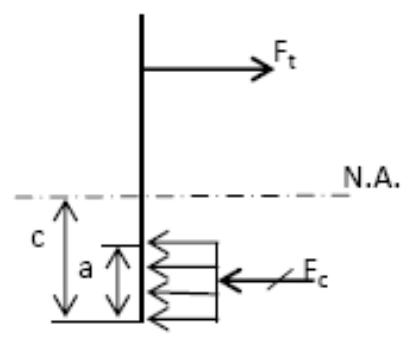

$$
\begin{aligned}
\phi M_{n} & =\phi\left(A_{p s} f_{p s}+A_{s} f_{y}\right)(d-a / 2) \\
a & =\frac{A_{p s} f_{p s}+A_{s} f_{y}}{.85^{*} f_{c}^{\prime} b} \\
c & =\frac{a}{\beta_{1}}
\end{aligned}
$$

Check Interior Supports

$$
\begin{aligned}
\mathrm{A}_{\mathrm{ps}} & =1.989 \mathrm{in}^{2} \quad \mathrm{f}_{\mathrm{y}}=60 \mathrm{ksi} \\
\mathrm{A}_{\mathrm{s}} & =0.936 \mathrm{in}^{2} \quad \beta_{1}=0.8 \\
\mathrm{a}= & 0.58571 \mathrm{in} \\
\mathrm{c}= & 0.73213 \mathrm{in} \quad \phi=0.9 \\
\phi \mathrm{M}_{\mathrm{n}}= & 2693.58 \mathrm{k} \text {-in } \\
= & 224.465 \mathrm{k}-\mathrm{ft} \\
\mathrm{M}_{\mathrm{u}}= & -176.82 \mathrm{k}-\mathrm{ft} \\
& <\phi \mathrm{Mn} \text {, therefore OK }
\end{aligned}
$$

\section{Check Span}

$$
\begin{aligned}
\mathrm{A}_{p 5}= & 1.989 \mathrm{in}^{2} \quad \mathrm{f}_{\mathrm{y}}=60 \mathrm{ksi} \\
\mathrm{A}_{s}= & 3.9 \mathrm{in}^{2} \quad \beta_{1}=0.8 \\
\mathrm{a}= & 0.85394 \mathrm{in} \\
\mathrm{c}= & 1.06743 \mathrm{in} \quad \phi=0.9 \\
\phi \mathrm{M}_{\mathrm{n}}= & 3858.81 \mathrm{k} \text {-in } \\
= & 321.568 \mathrm{k} \text {-ft } \\
\mathrm{M}_{\mathrm{u}}= & 149.731 \mathrm{k} \text {-ft } \\
& <\phi \mathrm{Mn} \text {, therefore OK }
\end{aligned}
$$

\section{Check Within $1.5 \mathrm{~h}$ of Columns}

$$
\begin{aligned}
\mathrm{A}_{\mathrm{ps}} & =0.918 \mathrm{in}^{2} \quad \mathrm{f}_{\mathrm{y}}=60 \mathrm{ksi} \\
\mathrm{A}_{\mathrm{s}} & =1.24 \mathrm{in}^{2} \quad \beta_{1}=0.8 \\
\mathrm{a} & =0.34345 \mathrm{in} \\
\mathrm{c} & =0.42931 \mathrm{in} \quad \phi=0.9 \\
\phi \mathrm{M}_{\mathrm{n}} & =1604.29 \mathrm{k}-\mathrm{in} \\
& =133.691 \mathrm{k}-\mathrm{ft} \\
\mathrm{M}_{\mathrm{u}} & =-108.1 \mathrm{k}-\mathrm{ft} \quad<\phi \mathrm{Mn} \text {, therefore OK }
\end{aligned}
$$




\section{Punching Shear - Exterior Columns}
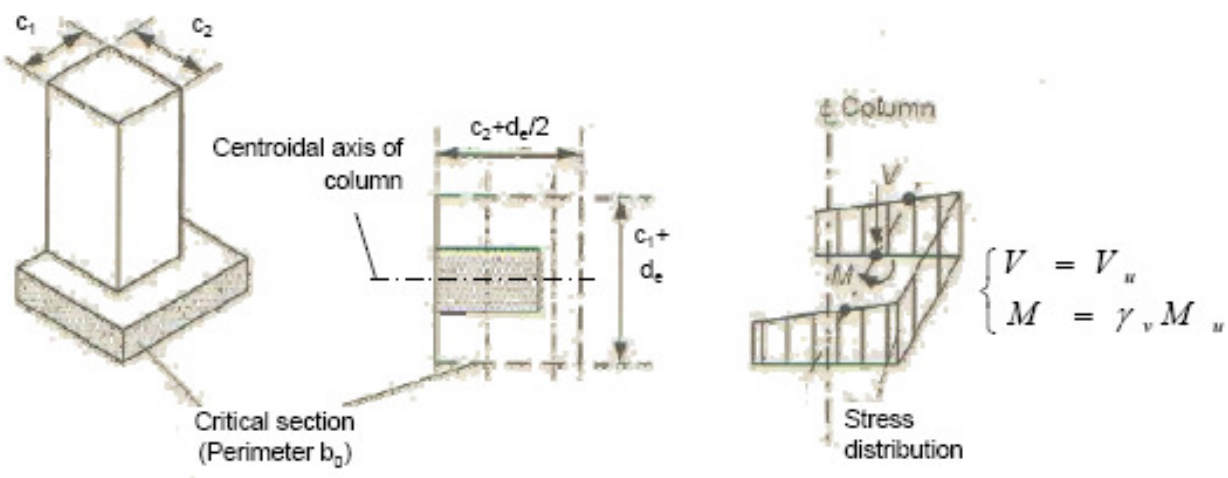

\section{Definitions}

$$
\mathrm{b}_{0}=\left(\mathrm{c}_{1}+2 \mathrm{c}_{2}+2 \mathrm{~d}_{\mathrm{e}}\right) \quad \mathrm{c}_{3}=\frac{\left(\mathrm{c}_{1}+\mathrm{d}_{\mathrm{e}}\right)}{2}
$$

$A_{c}=b_{0} d_{e}$

$J_{c}=2\left(c_{2}+d_{e} / 2\right) d_{e} c_{3}+\frac{\left(c_{1}+d_{e}\right) d_{e}^{3}}{12}+\frac{\left(c_{1}+d_{e}\right)^{3} d_{e}}{12}$

$v_{c}=\beta_{p} \sqrt{f_{c}{ }^{\prime}}+0.3 \sigma_{g}+\frac{v_{p}}{b_{0} d_{e}}$

$\beta_{p}=$ smaller of $\left\{\begin{array}{l}3.5 \\ 1.5+\frac{\alpha_{s} d_{e}}{b_{0}}\end{array} \quad \alpha_{s}=30\right.$

$v_{u}=\frac{V_{u}}{A_{c}}+\frac{\gamma_{v} M_{u} c_{3}}{J_{c}}$

Check: $\phi v_{\mathrm{c}}>v_{\mathrm{u}}$ ?

\section{Stud Rail Reinforcing:}

$$
V_{s}=\left(\frac{v_{u}}{\phi}-2 \sqrt{f_{c}^{\prime}}\right) A_{c} \quad \text { \# of Studs }=\frac{V_{s}}{f_{y} A_{s}}
$$




\section{Punching Shear - Exterior Columns}

$\begin{aligned} \text { 18"x24" Column } & \\ c_{1}=24 \text { in } & d_{e}=7 \text { in } \\ c_{2}=18 \text { in } & J_{c}=90579.4 \text { in }^{4} \\ b_{0}=74 \text { in } & \gamma_{v}=0.38862 \\ A_{c}=518 \text { in }^{2} & \beta_{p}=3.5 \\ c_{3}=15.5 \text { in } & v_{p}=4.42 \mathrm{k}\end{aligned}$




\section{A.1.4 Equivalent Frame - Grids B-H}

\section{Set - Up for Moment Distribution}

Initials

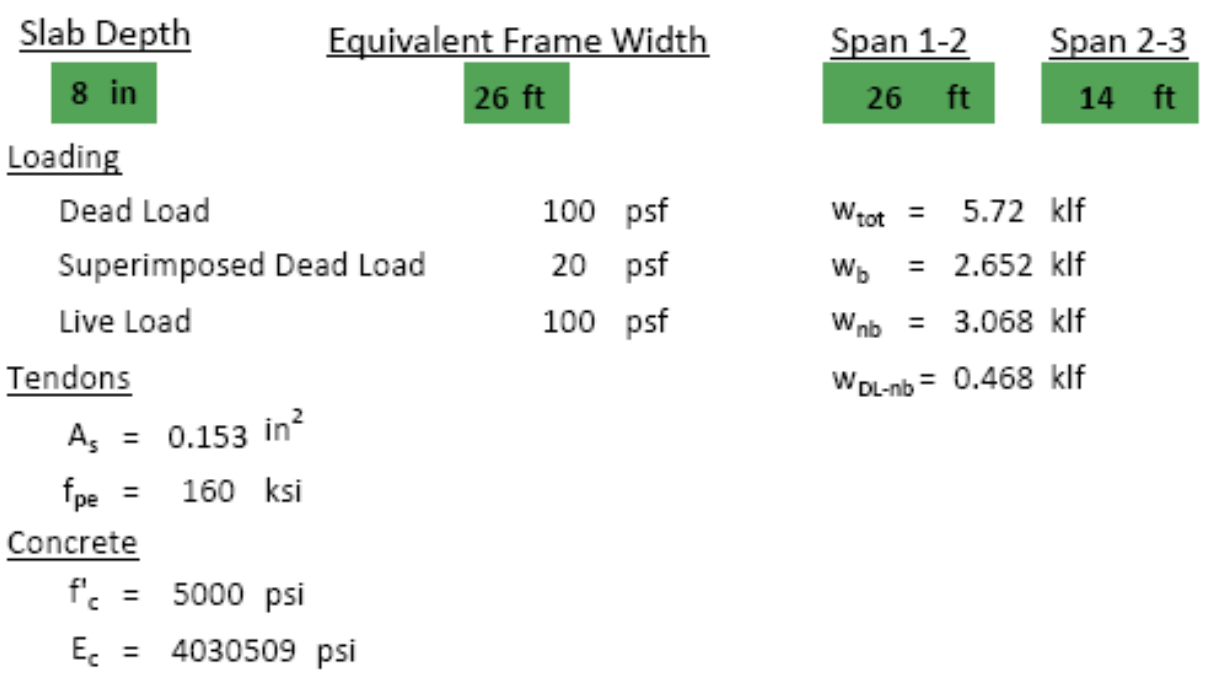

\section{Stiffnesses}

$\underline{\text { Slab }}$

$$
\begin{array}{lll}
\mathrm{b}=312 \text { in } & I_{12}=312 \text { in } & \mathrm{K}_{12}=687873477 \\
\mathrm{~d}=8 \text { in } & I_{23}=168 \text { in } & K_{23}=1277479314 \\
\mathrm{I}=13312 \mathrm{in}^{4} & &
\end{array}
$$

Column

$$
\begin{array}{rlrl}
\text { Interior Column } & \text { Exterior Column } \\
\mathrm{C}_{1} & =24 \text { in } & \mathrm{C}_{1}=24 \mathrm{in} \\
\mathrm{C}_{2}=24 \text { in } & \mathrm{C}_{2}=18 \mathrm{in} \\
I_{1}=240 \mathrm{in} & I_{1}=312 \mathrm{in} \\
I_{2}=312 \mathrm{in} & I_{2}=312 \mathrm{in} \\
\mathrm{h}=136 \mathrm{in} & \mathrm{h}=136 \mathrm{in} \\
\mathrm{I} & =27648 \mathrm{in}^{4} & \mathrm{I} & =11664 \mathrm{in}^{4} \\
\mathrm{~K}_{\mathrm{c}} & =3277514811 & \mathrm{~K} & =1382701561 \\
\mathrm{C} & =3235.84 & \mathrm{C} & =2211.84 \\
\mathrm{~K}_{\mathrm{t}} & =956645707 & \mathrm{~K}_{\mathrm{t}}=653909724 \\
\mathrm{~K}_{\mathrm{ec}} & =834812565 & \mathrm{~K}_{\mathrm{ec}}=528855964
\end{array}
$$




\section{Set - Up for Moment Distribution, cont.}

\section{$1 \& 4$}

$$
\begin{aligned}
\frac{\text { Stiffnesses }}{\text { Slab }} & =343936738 \\
\text { Column } & =547013815 \\
\Sigma \mathrm{K} & =890950553
\end{aligned}
$$

Distribution Factors

$$
\begin{array}{ll}
\text { Slab } & =0.386033 \\
\text { Column } & =0.306983
\end{array}
$$

\section{$2 \& 3$}

$$
\begin{aligned}
\frac{\text { Stiffnesses }}{\text { Slab }_{12}} & =343936738 \\
\text { Slab }_{23} & =638739657 \\
\text { Column } & =890131838 \\
\Sigma \mathrm{K} & =1872808234
\end{aligned}
$$

Distribution Factors
Slab $_{12}=0.183648$
Slab $_{23}=0.34106$
Column $=0.237646$ 


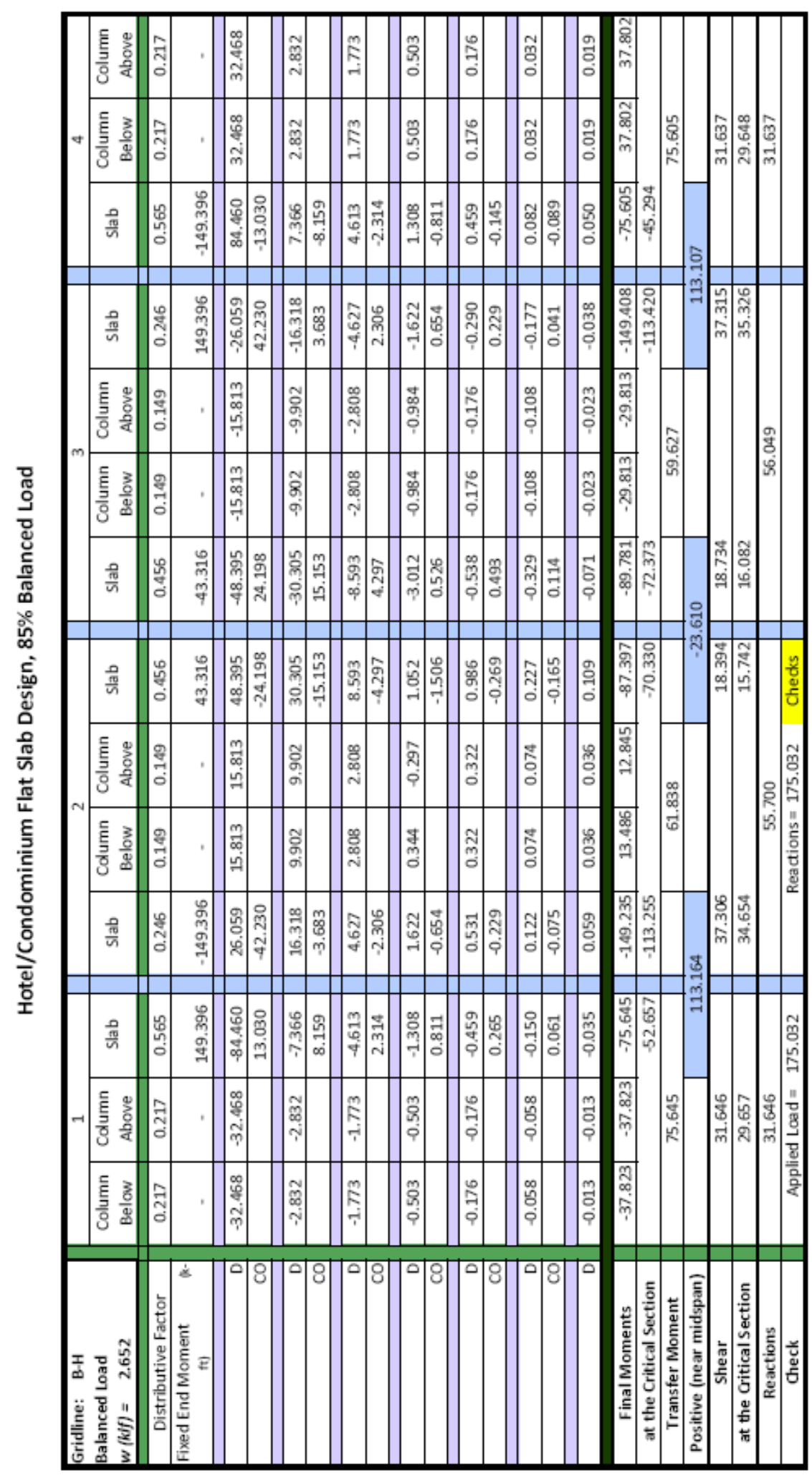

Optimization of Two-Way Post-Tensioned Concrete Floor Systems 


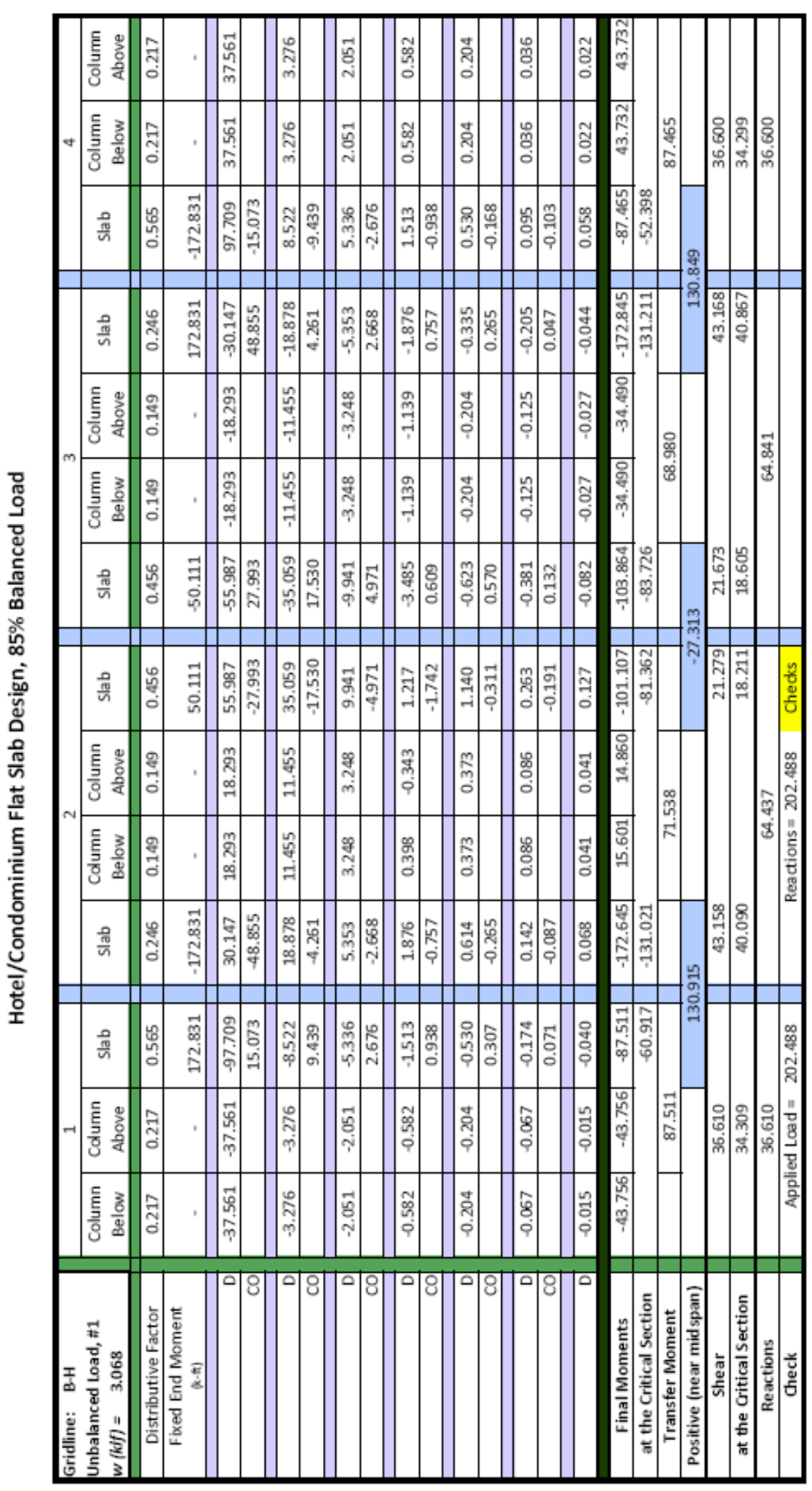

Optimization of Two-Way Post-Tensioned Concrete Floor Systems 


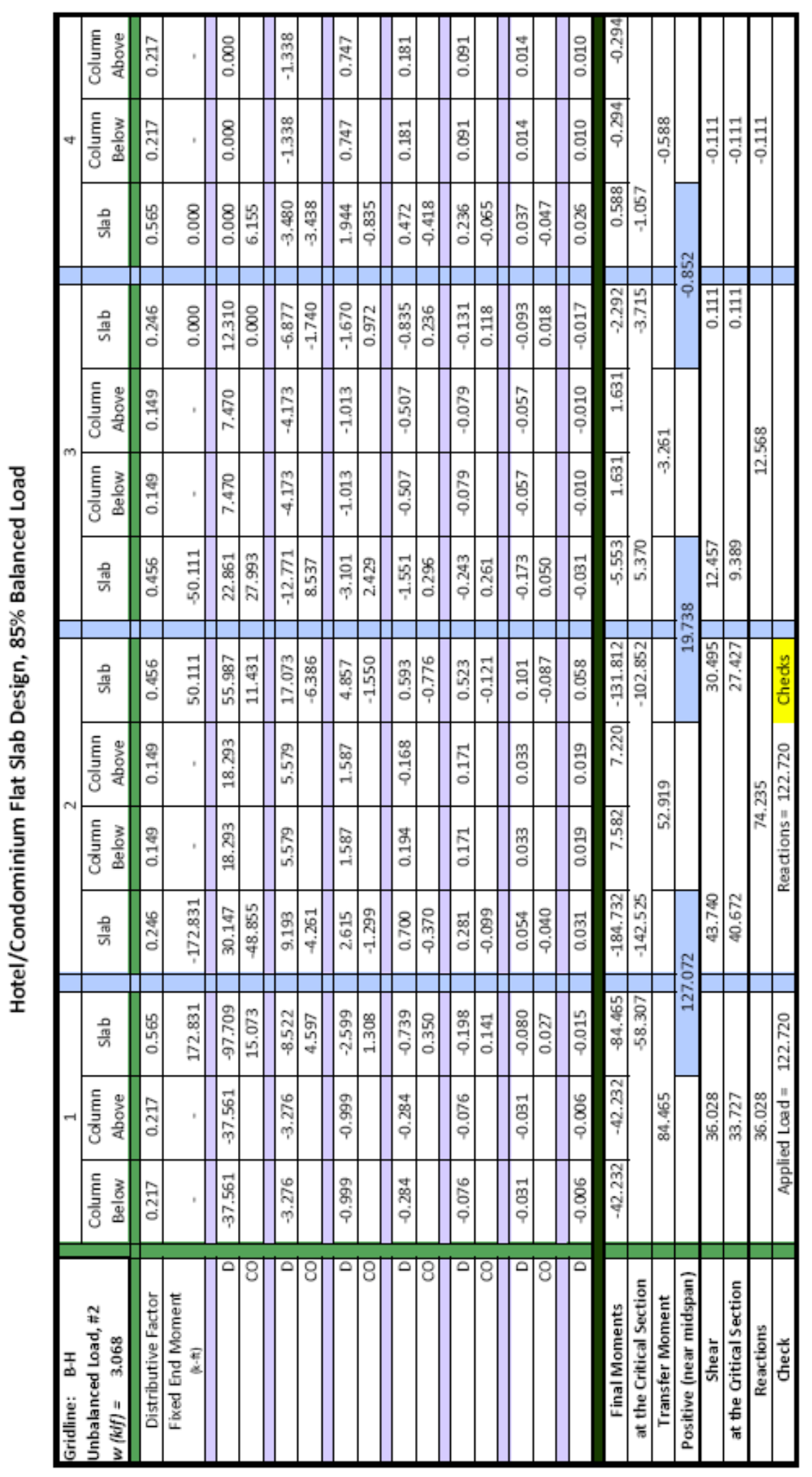




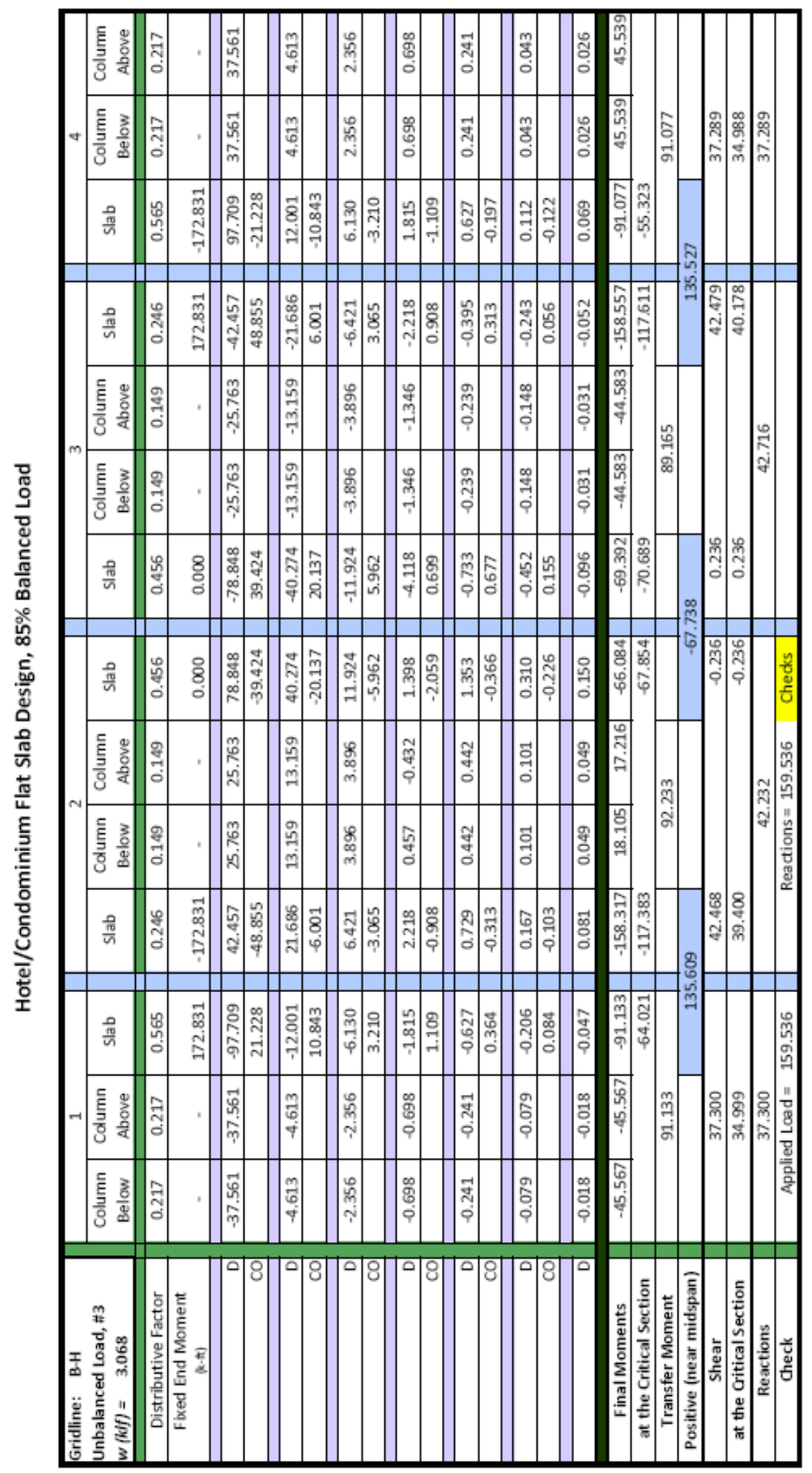

Optimization of Two-Way Post-Tensioned Concrete Floor Systems 


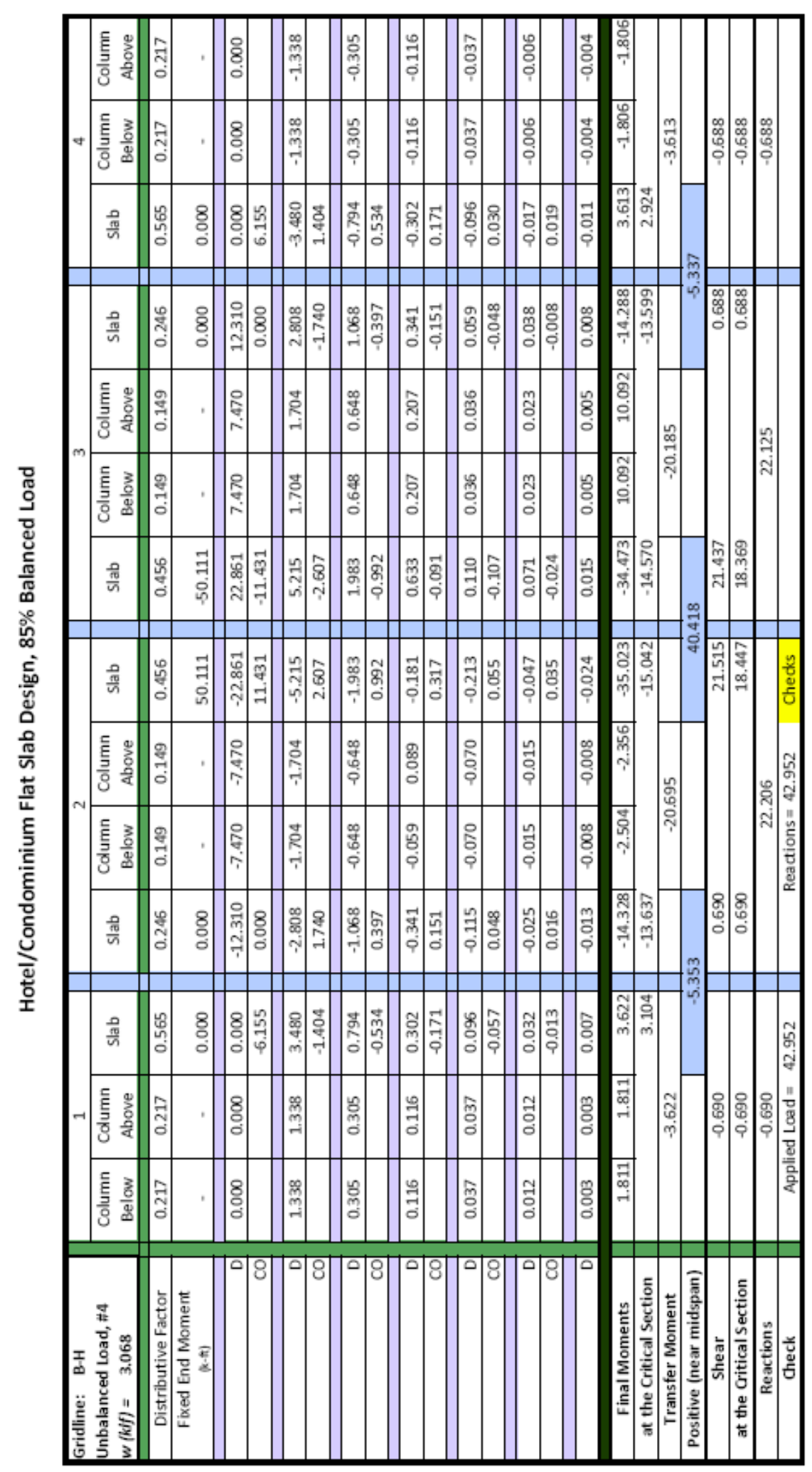

Optimization of Two-Way Post-Tensioned Concrete Floor Systems 


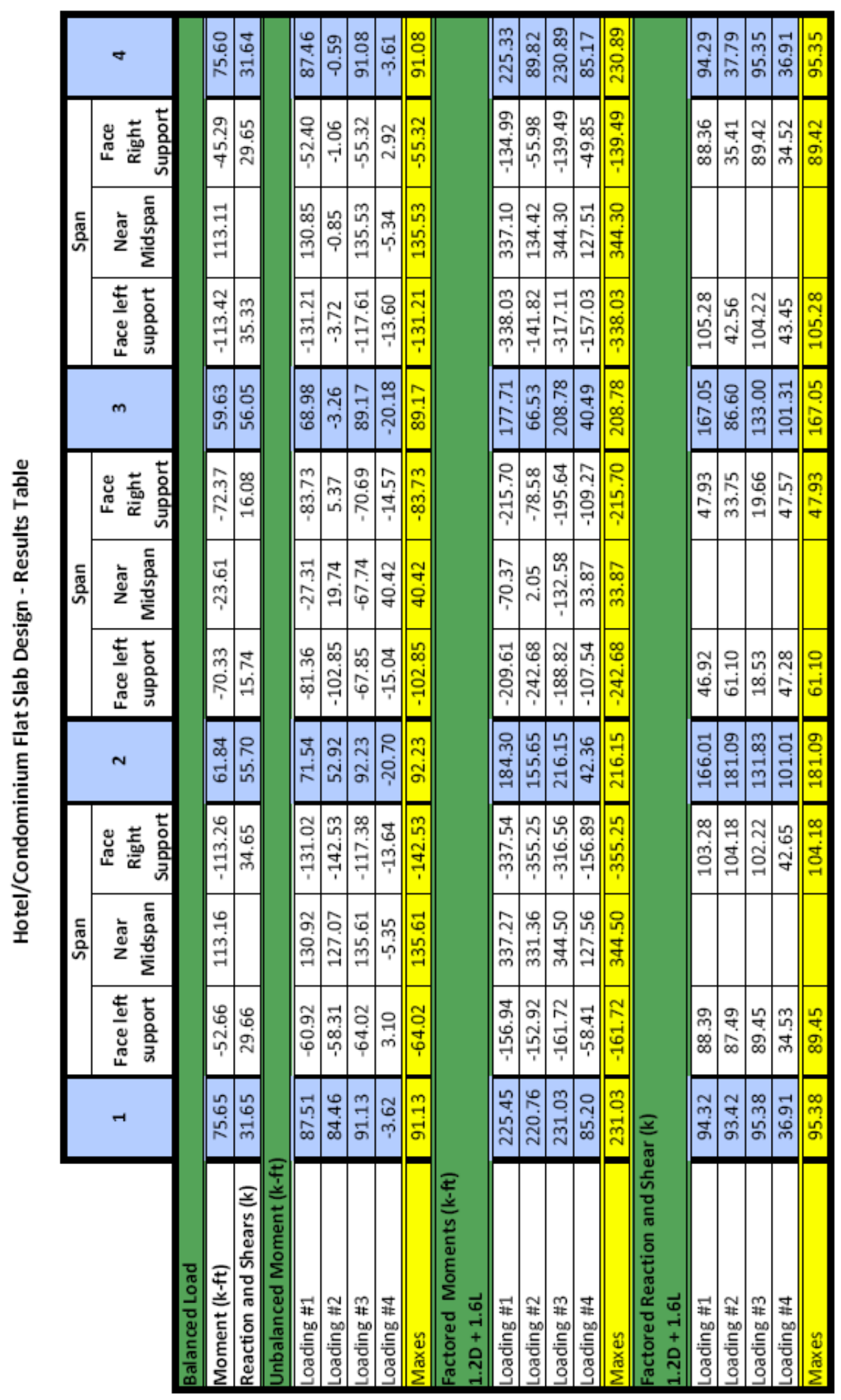




\section{Tendon Worksheet}

Tendon Profile

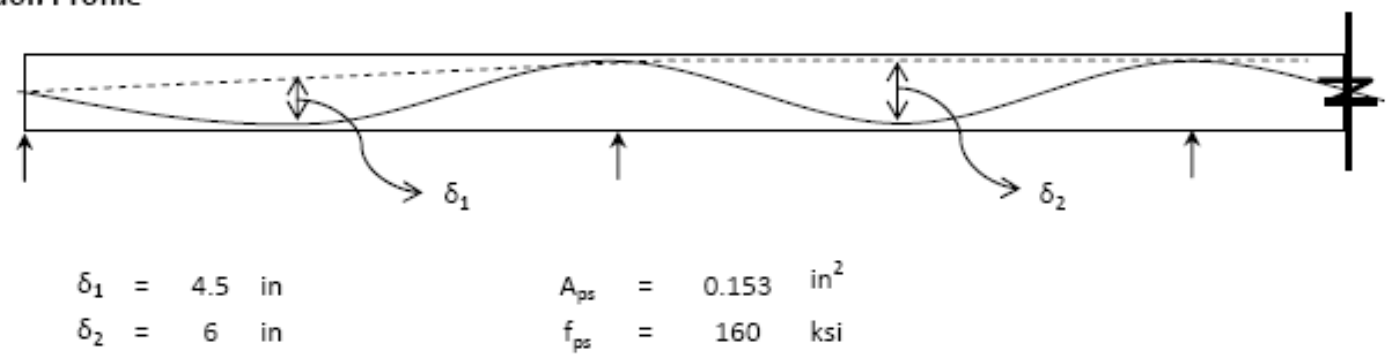

Force Required

$$
\begin{aligned}
& \text { Balanced Load }=2.652 \mathrm{klf} \\
& \mathrm{F}_{1}=\frac{\mathrm{w}_{\mathrm{b}} \mathrm{I}^{2}}{8 \delta_{1}}=597.6 \mathrm{k} \quad \text { Governs } \\
& \mathrm{F}_{2}=\frac{\left.\mathrm{w}_{\mathrm{b}}\right|^{2}}{8 \delta_{2}}=129.9 \mathrm{k}
\end{aligned}
$$

Strands Required

$$
\begin{aligned}
& \mathrm{N}=\frac{\mathrm{F}}{\mathrm{A}_{\mathrm{ps}} \mathrm{f}_{\mathrm{ps}}}=24.41111 \text { Use } 25 \text { Strands } \mathrm{F}=612 \mathrm{k} \\
& \longrightarrow \delta_{1}=4.394 \\
& \longrightarrow \delta_{2}=1.274
\end{aligned}
$$

Average Prestress

$$
\sigma_{s}=\frac{\mathrm{NA}_{p s} f_{p s}}{W d}=245.1923 \text { psi }
$$

\section{Tendon Distribution:}

Uniform, therefore need to check Moment Resistance within 1.5h of column 


\section{Stress Check}

Intials

$$
\begin{array}{ll}
\mathrm{Z}=\frac{\mathrm{Id}^{2}}{6}=3328 \mathrm{in}^{3} & \sigma_{\mathrm{t}}=\sigma_{\mathrm{g}}+\frac{\mathrm{M}}{\mathrm{Z}_{\mathrm{t}}} \\
\sigma_{\mathrm{g}}=255 \text { psi } & \sigma_{\mathrm{b}}=\sigma_{\mathrm{g}}-\frac{\mathrm{M}}{\mathrm{Z}_{\mathrm{b}}}
\end{array}
$$

\section{Checks}

Positive Moment: $\sigma<.45 \mathrm{f}_{\mathrm{c}}{ }^{\prime}=2250 \mathrm{psi}$ Negative Moment: $\sigma>-6 \mathrm{Vf}_{\mathrm{c}}{ }^{\prime}=-424 \mathrm{psi}$

\section{Reinforcing Check}

Needed if $\sigma>2 v_{\mathrm{c}}{ }^{\prime}=141 \mathrm{psi}$

\section{Stresses at Exterior Support}
$\sigma_{\mathrm{t}}=24.2$ psi $O K \quad$ No additional Reinforcing Needed
$\sigma_{\mathrm{b}}=485.8$ psi $\mathrm{OK}$

\section{Stresses at Midspan of Outside Span}

$$
\begin{aligned}
& \sigma_{\mathrm{t}}=744.0 \text { psi } \text { OK } \\
& \sigma_{\mathrm{b}}=-234.0 \text { psi } \text { OK Reinforcing Required } \\
& \text { Use \# } 7 \text { bars @ } 18 \text { "o.c }
\end{aligned}
$$

\section{Stresses at Critical Interior Support}

$$
\begin{array}{lllll}
\sigma_{\mathrm{t}}=-258.9 & \text { psi } & \text { OK } & \text { Reinforcing Required } \\
\text { Use } 7 \text { \# } & & \text { bars } \\
\sigma_{\mathrm{b}}=768.9 \text { psi } & \text { OK } & &
\end{array}
$$

\section{Stresses at Midspan of Inside Span}

$$
\begin{aligned}
& \sigma_{\mathrm{t}}=400.7 \text { psi } \text { OK } \\
& \sigma_{\mathrm{b}}=109.3 \text { psi OK No additional Reinforcing Needed }
\end{aligned}
$$




\section{Ultimate Flexural Strength}

$$
f_{p s}=f_{p e}+7.5=167 \mathrm{ksi}
$$

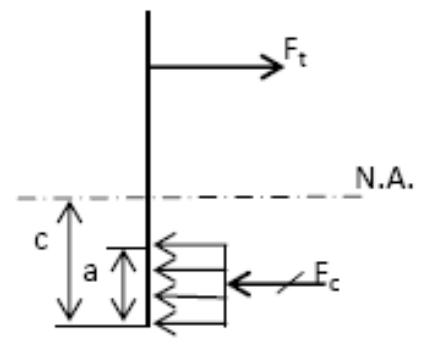

$$
\begin{aligned}
\phi M_{n} & =\phi\left(A_{p s} f_{p s}+A_{s} f_{y}\right)(d-a / 2) \\
a & =\frac{A_{p s} f_{p s}+A_{s} f_{y}}{.85^{*} f_{c}^{\prime} b} \\
c & =\frac{a}{\beta_{1}}
\end{aligned}
$$

\section{Check Interior Supports}

$$
\begin{aligned}
A_{p s}= & 3.825 \text { in }^{2} \quad f_{y}=60 \mathrm{ksi} \\
A_{s}= & 2.17 \text { in }^{2} \quad \beta_{1}=0.8 \\
a= & 0.57992 \mathrm{in} \\
c= & 0.7249 \text { in } \phi=0.9 \\
\phi M_{n}= & 5335.94 \mathrm{k}-\mathrm{in} \\
= & 444.662 \mathrm{k}-\mathrm{ft} \\
M_{\mathrm{u}}= & -355.25 \mathrm{k}-\mathrm{ft} \\
& <\phi M n \text {, therefore OK }
\end{aligned}
$$

\section{Check Within 1.5h of Columns}

$$
\begin{aligned}
A_{p s} & =0.918 \text { in }^{2} \quad f_{y}=60 \text { ksi } \\
A_{s} & =2.17 \text { in }^{2} \quad \beta_{1}=0.8 \\
a & =0.42761 \mathrm{in} \\
c & =0.53451 \text { in } \phi=0.9 \\
\phi M_{n} & =1963.01 \mathrm{k}-\mathrm{in} \\
& =163.584 \mathrm{k}-\mathrm{ft} \\
M_{u} & =-123.43 \mathrm{k}-\mathrm{ft} \\
& <\phi M n \text {, therefore OK }
\end{aligned}
$$

\section{Check Span}

$$
\begin{aligned}
A_{p s}= & 3.825 \text { in }^{2} \quad f_{y}=60 \mathrm{ksi} \\
A_{s}= & 10.4 \text { in }^{2} \quad \beta_{1}=0.8 \\
a= & 0.95232 \mathrm{in} \\
c= & 1.1904 \text { in } \phi=0.9 \\
\phi M_{n}= & 8550.83 \mathrm{k}-\mathrm{in} \\
= & 712.569 \mathrm{k}-\mathrm{ft} \\
\mathrm{M}_{\mathrm{u}}= & 344.497 \mathrm{k}-\mathrm{ft} \\
& <\phi \mathrm{Mn} \text {, therefore OK }
\end{aligned}
$$




\section{Punching Shear - Interior Columns}
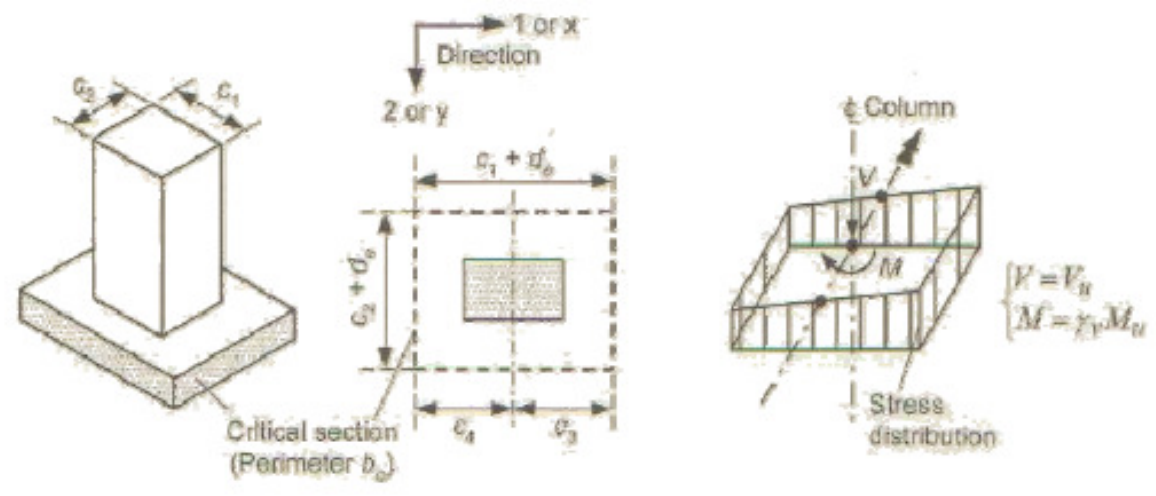

Definitions

$$
\begin{aligned}
& c_{3}=c_{4}=\frac{\left(c_{1}+d_{e}\right)}{2} \quad J_{c}=\frac{d_{e}\left(c_{1}+d_{e}\right)^{3}}{6}+\frac{\left(c_{1}+d_{e}\right) d_{e}^{3}}{6}+\frac{d_{e}\left(c_{2}+d_{e}\right)\left(c_{1}+d_{e}\right)^{2}}{2} \\
& b_{0}=2\left(c_{1}+c_{2}+2 d_{e}\right) \quad A_{c}=d_{e} b_{0} \\
& \gamma_{v}=1-\frac{1}{1+\frac{2}{3} \sqrt{\frac{c_{1}+d_{e}}{c_{2}+d_{e}}}} \\
& \begin{aligned}
v_{c} & =\beta_{p} \sqrt{f_{c}}+0.3 \sigma_{g}+\frac{v_{p}}{b_{0} d_{e}} \\
3.5 & \beta_{p}=\text { smaller of } \\
1.5 & +\frac{\alpha_{s} d_{e}}{b_{0}}
\end{aligned} \quad \alpha_{s}=40 \\
& v_{u}=\frac{v_{u}}{A_{c}}+\frac{\gamma_{v} M_{u} c_{3}}{J_{c}} \\
& \text { Check: } \phi v_{c}>v_{u} ?
\end{aligned}
$$

\section{Stud Rail Reinforcing:}

$$
\begin{aligned}
& V_{s}=\left(\frac{v_{u}}{\phi}-2 \sqrt{f_{c}{ }^{\prime}}\right) A_{c} \\
& \# \text { of Studs }=\frac{V_{s}}{f_{y} A_{s}}
\end{aligned}
$$

Note:

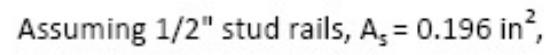
with $\mathrm{f}_{\mathrm{y}}=50 \mathrm{ksi}$. 


\section{Punching Shear - Interior Columns}

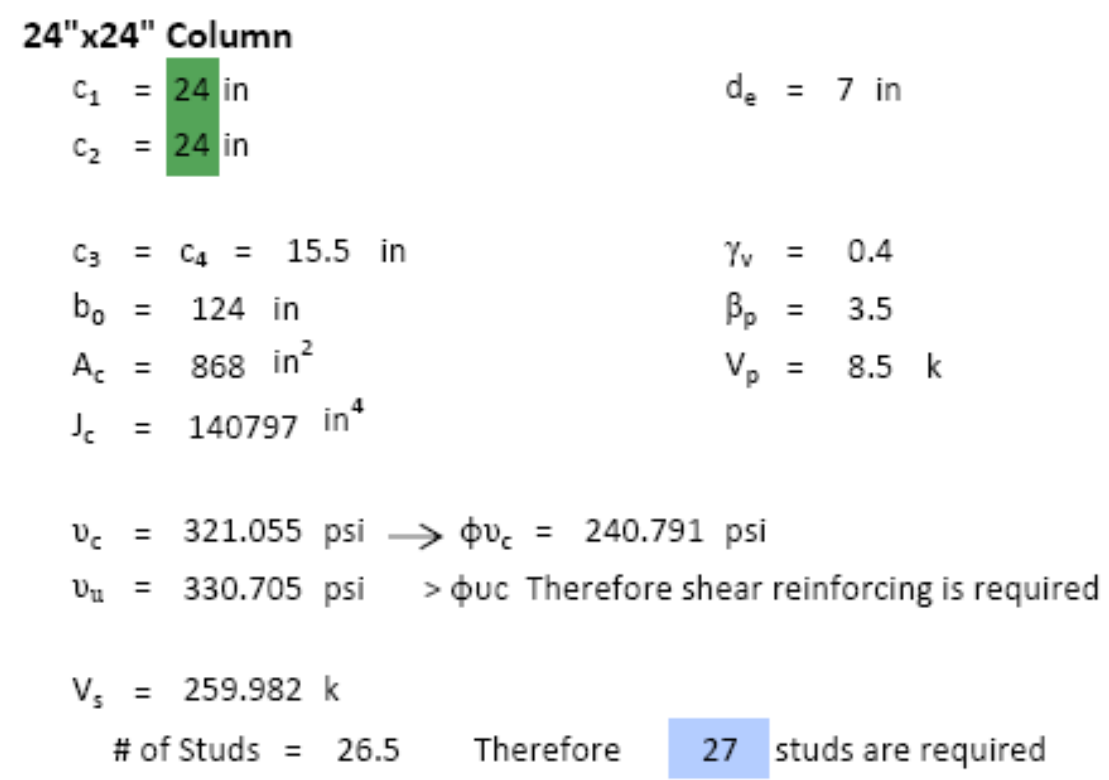


Punching Shear - Exterior Columns

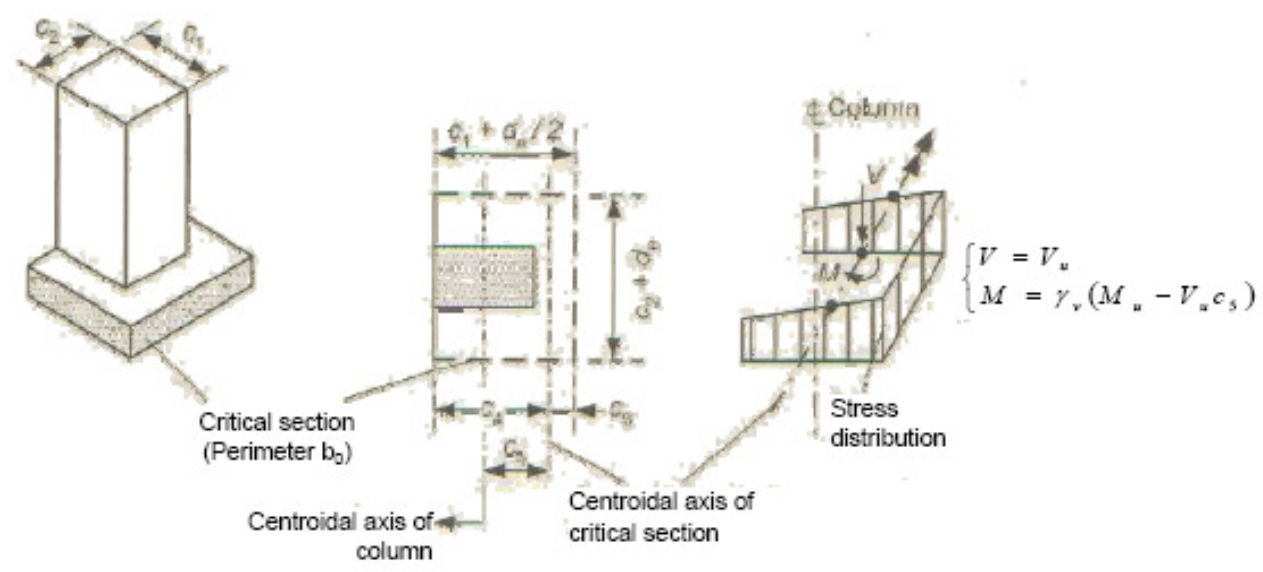

\section{Definitions}

$$
\begin{array}{ll}
b_{0}=\left(2 c_{1}+c_{2}+2 d_{e}\right) & c_{3}=\frac{d_{e}\left(c_{1}+1 / 2 d_{e}\right)^{2}}{A_{c}} \\
A_{c}=b_{0} d_{e} & \begin{array}{r}
c_{4}=\left(c_{1}+1 / 2 d_{e}\right)-c_{3} \\
c_{5}=c_{4}-1 / 2 c_{1}
\end{array} \\
J_{c}=\frac{\left(c_{1}+1 / 2 d_{e}\right) d_{e}{ }^{3}}{6}+\frac{2 d_{e}\left(c_{3}{ }^{3}+c_{4}{ }^{3}\right)}{3}+d_{e}\left(c_{2}+d_{e}\right) c_{3}{ }^{2}
\end{array}
$$

$v_{u}=$ larger of $\left\{\begin{array}{l}\frac{V_{u}}{A_{c}}+\frac{\gamma_{v}\left(M_{u}-V_{u} c_{5} c_{3}\right.}{J_{c}} \\ \frac{V_{u}}{A_{c}}-\frac{\gamma_{v}\left(M_{u}-V_{u} c_{5} c_{4}\right.}{J_{c}}\end{array}\right.$

Check: $\quad \phi v_{\mathrm{c}}>v_{\mathrm{u}}$ ?

\section{Stud Rail Reinforcing:}

$$
V_{s}=\left(\frac{v_{u}}{\phi}-2 \sqrt{f_{c}^{\prime}}\right) A_{c} \quad \text { \# of Studs }=\frac{V_{s}}{f_{y} A_{s}}
$$




\section{Punching Shear - Exterior Columns}

$$
\begin{aligned}
& \text { 18"x24" Column } \\
& c_{1}=18 \text { in } \\
& c_{2}=24 \text { in } \\
& b_{0}=74 \text { in } \\
& A_{c}=518 \mathrm{in}^{2} \\
& C_{3}=6.25 \mathrm{in} \\
& \mathrm{c}_{4}=15.25 \text { in } \\
& c_{5}=6.25 \mathrm{in} \\
& d_{e}=7 \text { in } \\
& J_{c}=27395.7 \mathrm{in}^{4} \\
& \gamma_{\mathrm{v}}=0.35699 \\
& \beta_{p}=3.5 \\
& V_{p}=8.5 \mathrm{k} \\
& v_{c}=321.061 \mathrm{psi} \rightarrow \phi v_{\mathrm{c}}=240.796 \mathrm{psi} \\
& v_{u}=361.246 \mathrm{psi}>\phi u c \text { Therefore shear reinforcing is required } \\
& V_{s}=176.245 \mathrm{k} \\
& \text { \# of Studs }=18 \quad \text { Therefore } 18 \text { studs are required }
\end{aligned}
$$




\section{Punching Shear-Corner Columns}

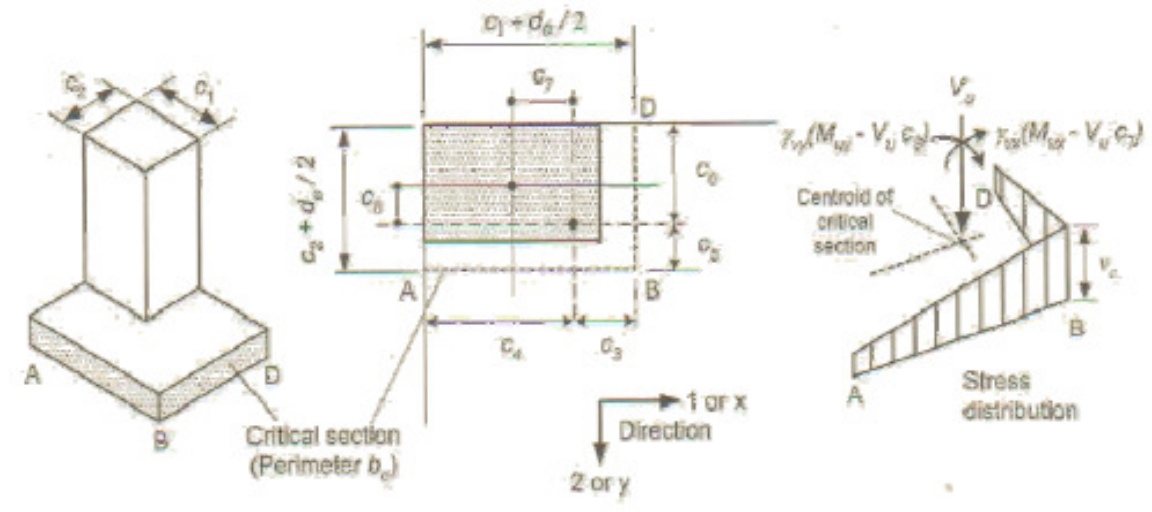

\section{Definitions}

$$
\begin{aligned}
& b_{0}=\left(c_{1}+c_{2}+d_{e}\right) \\
& A_{c}=b_{0} d_{e} \\
& c_{3}=\frac{\left(c_{1}+d_{e} / 2\right)^{2}}{2 A_{c}} \\
& c_{5}=\frac{\left(c_{2}+d_{e} / 2\right)^{2}}{2 A_{c}} \\
& c_{4}=c_{1}+\frac{d_{e}}{2}-c_{3} \\
& c_{6}=c_{2}+\frac{d_{e}}{2}-c_{5} \\
& c_{7}=\frac{\left(c_{1}+d_{e}\right)}{2}-c_{3} \\
& c_{8}=\frac{\left(c_{2}+d_{e}\right)}{2}-c_{5} \\
& J_{\mathrm{c} 1}=\frac{\mathrm{d}_{\mathrm{e}}\left(\mathrm{c}_{1}+\mathrm{d}_{\mathrm{e}} / 2\right)^{3}}{12}+\frac{\left(\mathrm{c}_{1}+\mathrm{d}_{\mathrm{e}} / 2\right) \mathrm{d}_{\mathrm{e}}{ }^{3}}{12}+\left(\mathrm{c}_{2}+\mathrm{d}_{\mathrm{e}} / 2\right) \mathrm{d}_{\mathrm{e}} \mathrm{c}_{3}{ }^{2}+\left(\mathrm{c}_{1}+\mathrm{d}_{\mathrm{e}} / 2\right) \mathrm{d}_{\mathrm{e}}\left(\frac{\mathrm{c}_{1}+\mathrm{d}_{\mathrm{e}} / 2}{2}-\mathrm{c}_{3}\right)^{2} \\
& J_{c 2}=\frac{d_{e}\left(c_{2}+d_{e} / 2\right)^{3}}{12}+\frac{\left(c_{2}+d_{e} / 2\right) d_{e}{ }^{3}}{12}+\left(c_{1}+d_{e} / 2\right) d_{e} c_{5}{ }^{2}+\left(c_{2}+d_{e} / 2\right) d_{e}\left(\frac{c_{2}+d_{e} / 2}{2}-c_{5}\right)^{2} \\
& v_{c}=\beta_{p} \sqrt{f_{c}^{\prime}}+0.3 \sigma_{g}+\frac{v_{p}}{b_{0} d_{e}} \\
& \beta_{p}=\text { smaller of }\left\{\begin{array}{l}
3.5 \\
1.5+\frac{\alpha_{s} d_{e}}{b_{0}}
\end{array} \quad \alpha_{s}=20\right.
\end{aligned}
$$

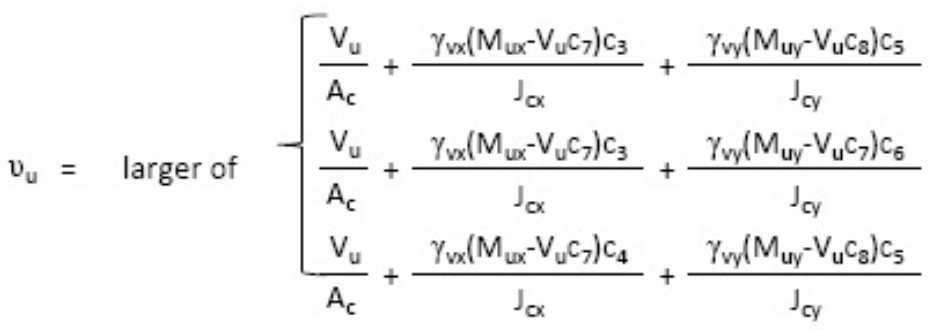




\section{Punching Shear - Corner Columns, cont.}

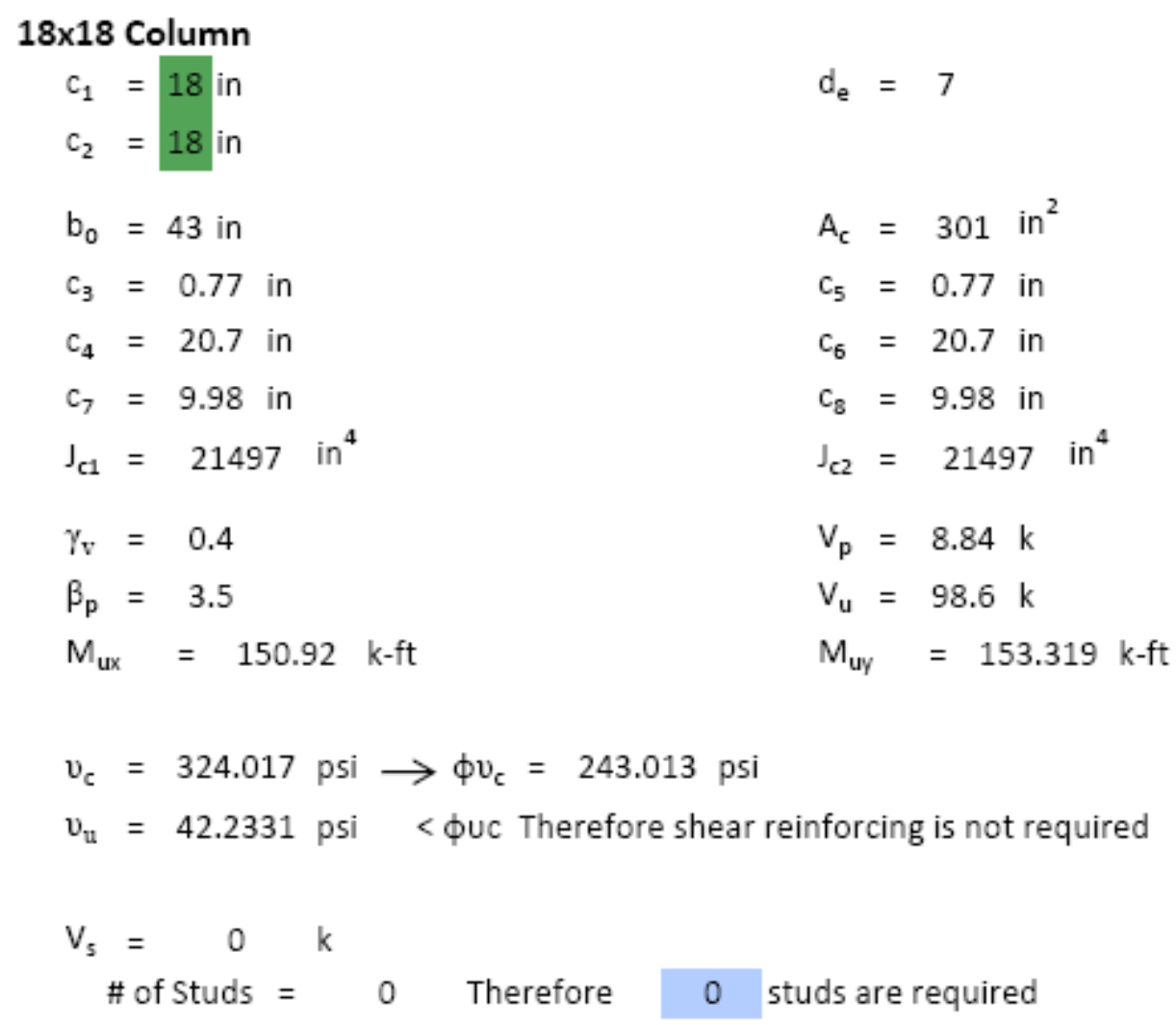


Appendix lxvii

\section{Deflection}

Largest deflection occurs in the edge, $26^{\prime} \times 26^{\prime}$, panels
$\mathrm{E}_{\mathrm{c}}=4030509 \mathrm{psi}$
$\%$ to Column
$=0.65$
$\%$ to Mid-Strip $\quad=0.35$

Long Direction (Grid $1 \& 2$ or $2 \& 3$ )

$\begin{array}{lll}\mathrm{w}_{\mathrm{b}}=102 & \mathrm{w}_{\mathrm{nb}}=118 \\ \mathrm{~L}=26 \mathrm{ft} & \mathrm{w}_{\mathrm{nb}-\mathrm{DL}}=18\end{array}$

$\mathrm{K}_{\text {ecA }}=625175524 \mathrm{k} / \mathrm{in} \mathrm{I}_{\text {tot }}=10240 \mathrm{in}^{4}$

$\mathrm{K}_{\text {ecE }}=1.278 \mathrm{E}+09 \mathrm{k} / \mathrm{in} \mathrm{I}_{\text {col }}=5120 \mathrm{in}^{4}$

$\mathrm{M}_{\mathrm{A}}=1091003.1$ \#-in $\mathrm{I}_{\text {mid }}=5120 \mathrm{in}^{4}$

$M_{B}=972271.38$ \#-in

$\delta^{\prime}=0.00588$

$\theta_{\mathrm{A}}=0.00175$

$\delta_{c}=0.00764$

$\delta_{s}=0.00412$

$\theta_{\mathrm{B}}=0.00076$

$\delta^{\prime \prime}=0.09773$

$\delta_{c y}=0.10537 \mathrm{in}$

$\delta_{s y}=0.10184 \mathrm{in}$
Short Direction (Grid B-H)

$\begin{array}{lll}\mathrm{w}_{\mathrm{b}}=102 & \mathrm{w}_{\mathrm{nb}}=118 \\ \mathrm{~L}=26 \mathrm{ft} & \mathrm{w}_{\mathrm{nb}-\mathrm{DL}}=18\end{array}$

$\mathrm{K}_{\text {ec } 1}=528855964 \mathrm{k} / \mathrm{in} \quad \mathrm{I}_{\text {tot }}=13312 \mathrm{in}^{4}$

$\mathrm{K}_{\text {ec1 }}=834812565 \mathrm{k} / \mathrm{in} \mathrm{I}_{\text {col }}=6656 \mathrm{in}^{4}$

$\mathrm{M}_{1}=1093601.6$ \#-in $\mathrm{I}_{\text {mid }}=6656 \mathrm{in}^{4}$

$\mathrm{M}_{2}=1106801.2$ \#-in

$\delta^{\prime}=0.00452$

$\theta_{1}=0.00207$

$\delta_{c}=0.00588$

$\theta_{2}=0.00133$

$\delta_{s}=0.00317$

$\delta^{\prime \prime}=0.13235$

$\delta_{c x}=0.13823$ in

$\delta_{\mathrm{sx}}=0.13552 \mathrm{in}$

Total Deflection
$\Delta_{i}=\delta_{c y}+\delta_{s x}=\delta_{c x}+\delta_{s y}=0.24048$ in
$\Delta_{\mathrm{LT}}=0.31385 \mathrm{in}$
$\Delta_{\text {All }}=L / 360=0.8667$ in $\quad$ OK 


\section{APPENDIX B - HAND ANALYSIS SUMMARIES}

\section{B.1 Slab 1}

\begin{tabular}{|c|c|c|c|c|c|}
\hline & \multicolumn{4}{|c|}{ Frames } \\
\hline & & $1 \& 4$ & $2 \& 3$ & $A \& I$ & B-H \\
\hline \multirow{3}{*}{$\underline{a}$} & Total PT & 15 & 23 & 15 & 29 \\
\hline & Over Columns & 15 & 23 & 4 & 4 \\
\hline & Uniform & & & $\begin{array}{l}24 \text {, @ } \\
22 \text { "o.c. }\end{array}$ & $\begin{array}{l}24, @ \\
22 \text { "o.c. }\end{array}$ \\
\hline \multirow{5}{*}{$\begin{array}{l}\stackrel{\Xi}{\pi} \\
\frac{0}{\mathscr{U}}\end{array}$} & & & & & \\
\hline & Outside Columns & & & $3 \# 5$ & $2 \# 3$ \\
\hline & Inside Columns & $3 \# 5$ & $5 \# 5$ & $3 \# 5$ & $2 \# 3$ \\
\hline & Outside Spans & & & & \\
\hline & Inside Spans & & & & \\
\hline \multirow{3}{*}{ 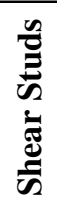 } & $\begin{array}{l}\text { Exterior } \\
\text { Columns }\end{array}$ & 0 & 16 & 0 & 18 \\
\hline & Interior Columns & & 24 & & 28 \\
\hline & Corner Columns & \multicolumn{4}{|c|}{0} \\
\hline
\end{tabular}




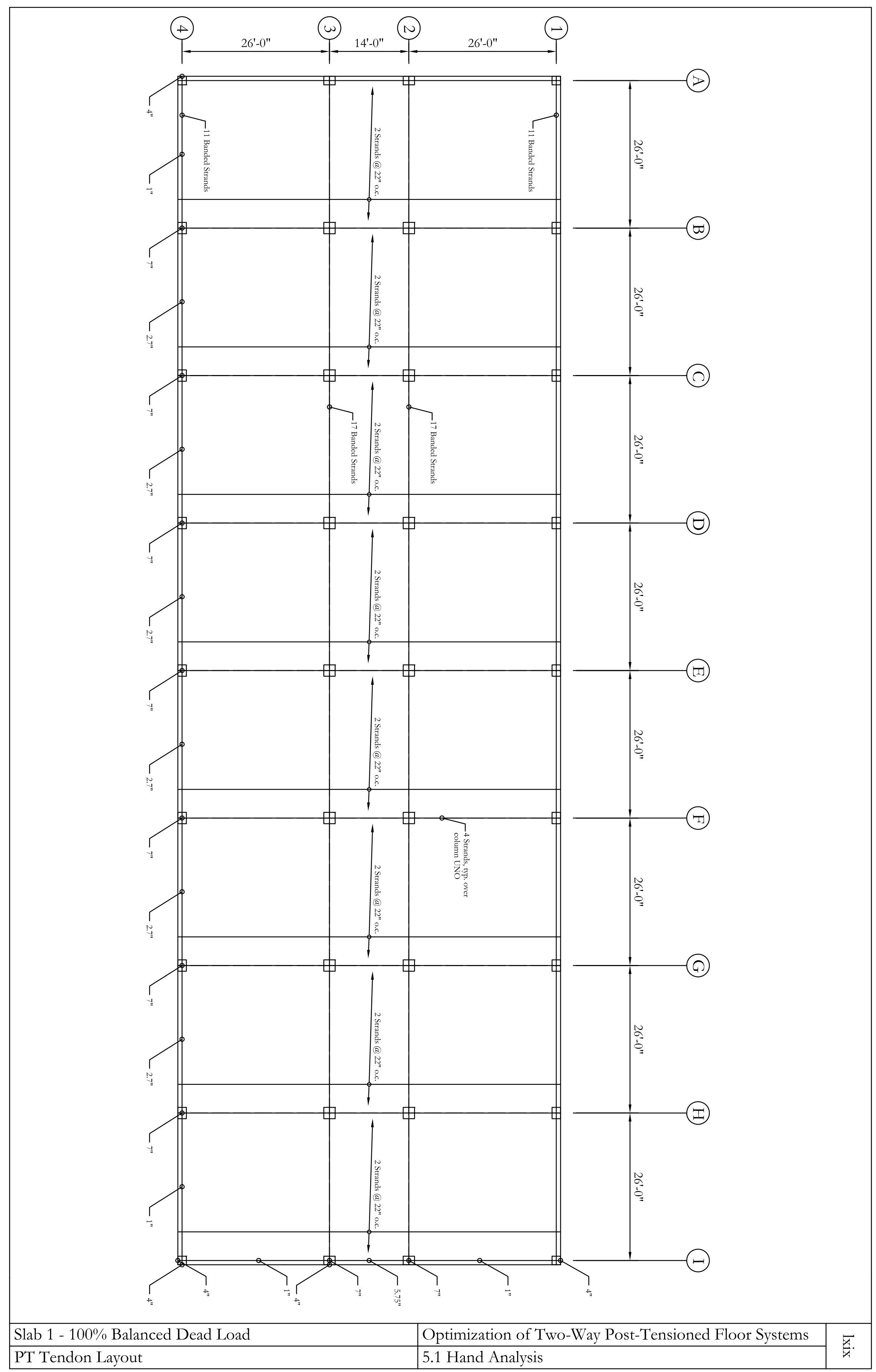




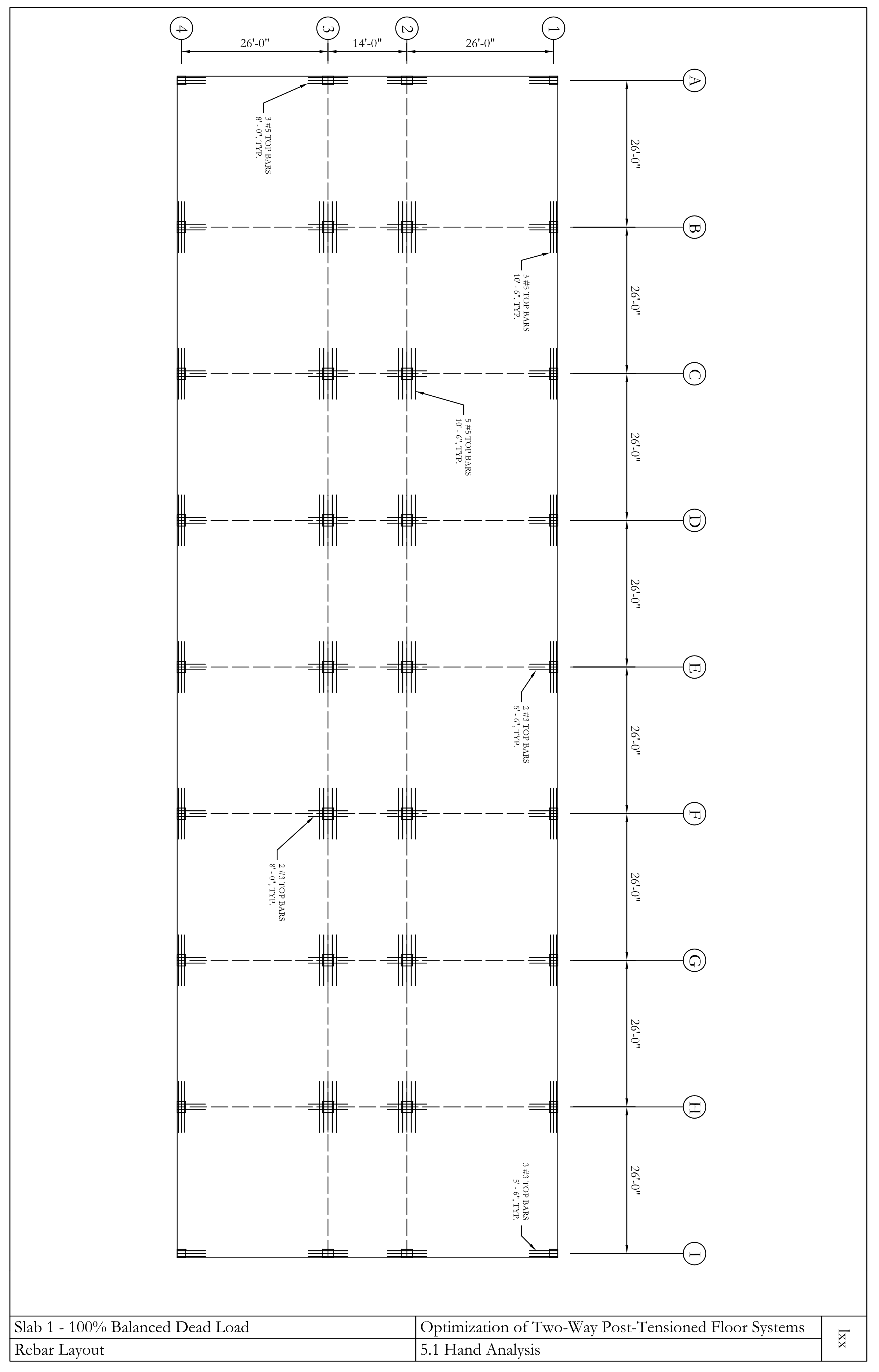




\section{B.2 Slab 2}

\begin{tabular}{|c|c|c|c|c|c|}
\hline & & $1 \& 4$ & $2 \& 3$ & A \& I & B-H \\
\hline \multirow{3}{*}{$E$} & Total PT & 13 & 20 & 13 & 26 \\
\hline & Over Columns & 13 & 20 & 4 & 4 \\
\hline & Uniform & & & $\begin{array}{l}20,2 @ \\
26 \text { "o.c. }\end{array}$ & $\begin{array}{l}22,2 @ \\
24 " \text { o.c. }\end{array}$ \\
\hline \multirow{5}{*}{ 苞 } & & & & & \\
\hline & Outside Columns & & & $2 \# 5$ & $3 \# 5$ \\
\hline & Inside Columns & 4 \#5 & $5 \# 5$ & $4 \# 5$ & $7 \# 5$ \\
\hline & Outside Spans & $\begin{array}{c}\# 7 \text { @ } \\
22 \text { "o.c }\end{array}$ & $\begin{array}{c}\text { \#7@ } \\
20 \text { "o.c }\end{array}$ & $\begin{array}{c}\text { \#7@ } \\
24 \text { "o.c. }\end{array}$ & $\begin{array}{c}\text { \#7@ } \\
18 \text { "o.c }\end{array}$ \\
\hline & Inside Spans & $\begin{array}{c}\text { \#7 @ } \\
\text { 26"o.c. }\end{array}$ & $\begin{array}{c}\text { \#7 @ } \\
\text { 24"o.c. }\end{array}$ & & \\
\hline \multirow{3}{*}{ 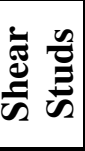 } & Eyteriir Clumnc & 0 & 16 & 0 & 18 \\
\hline & Interior Columns & 0 & 24 & 0 & 28 \\
\hline & Corner Columns & \multicolumn{4}{|c|}{0} \\
\hline
\end{tabular}




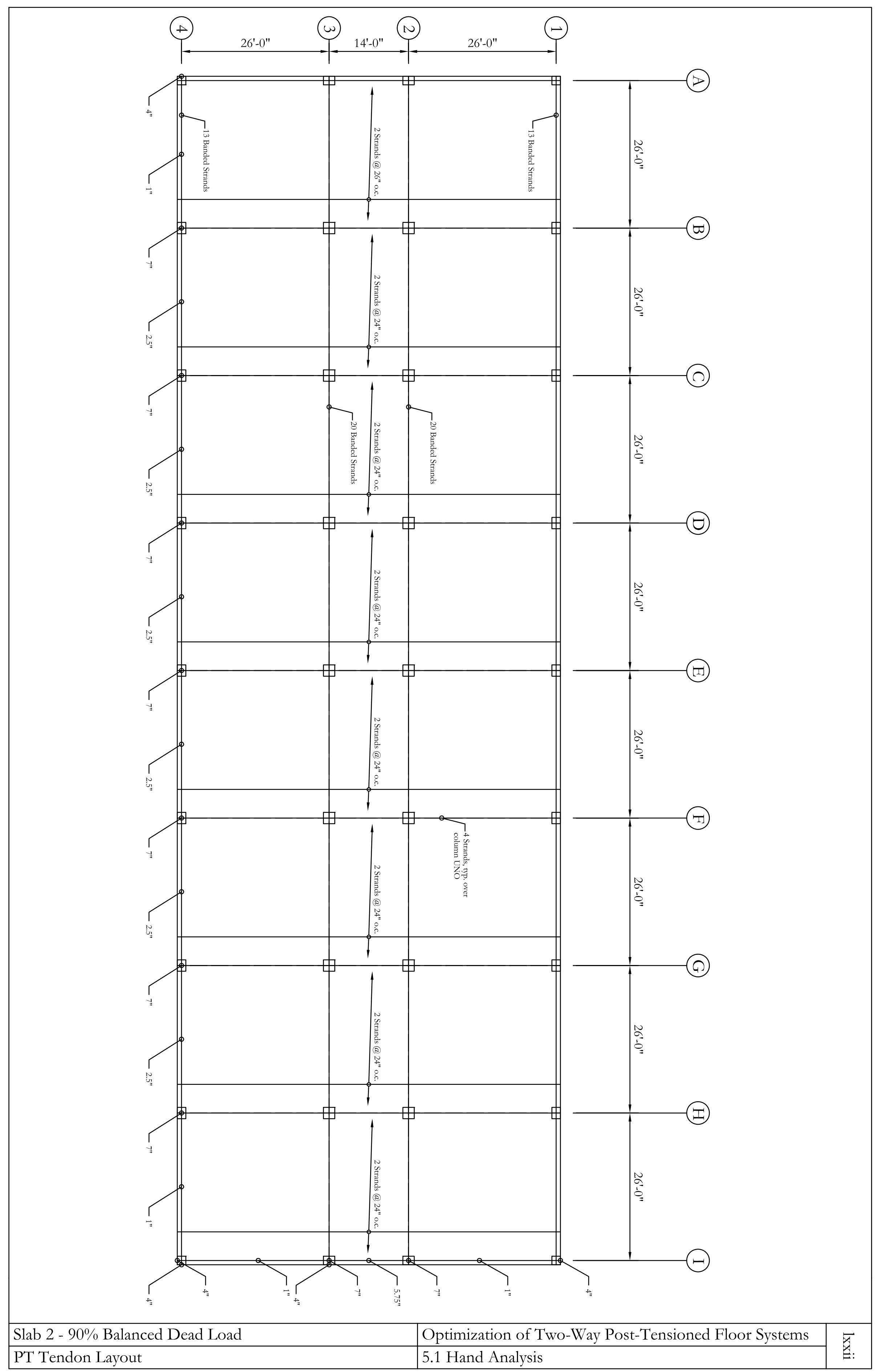




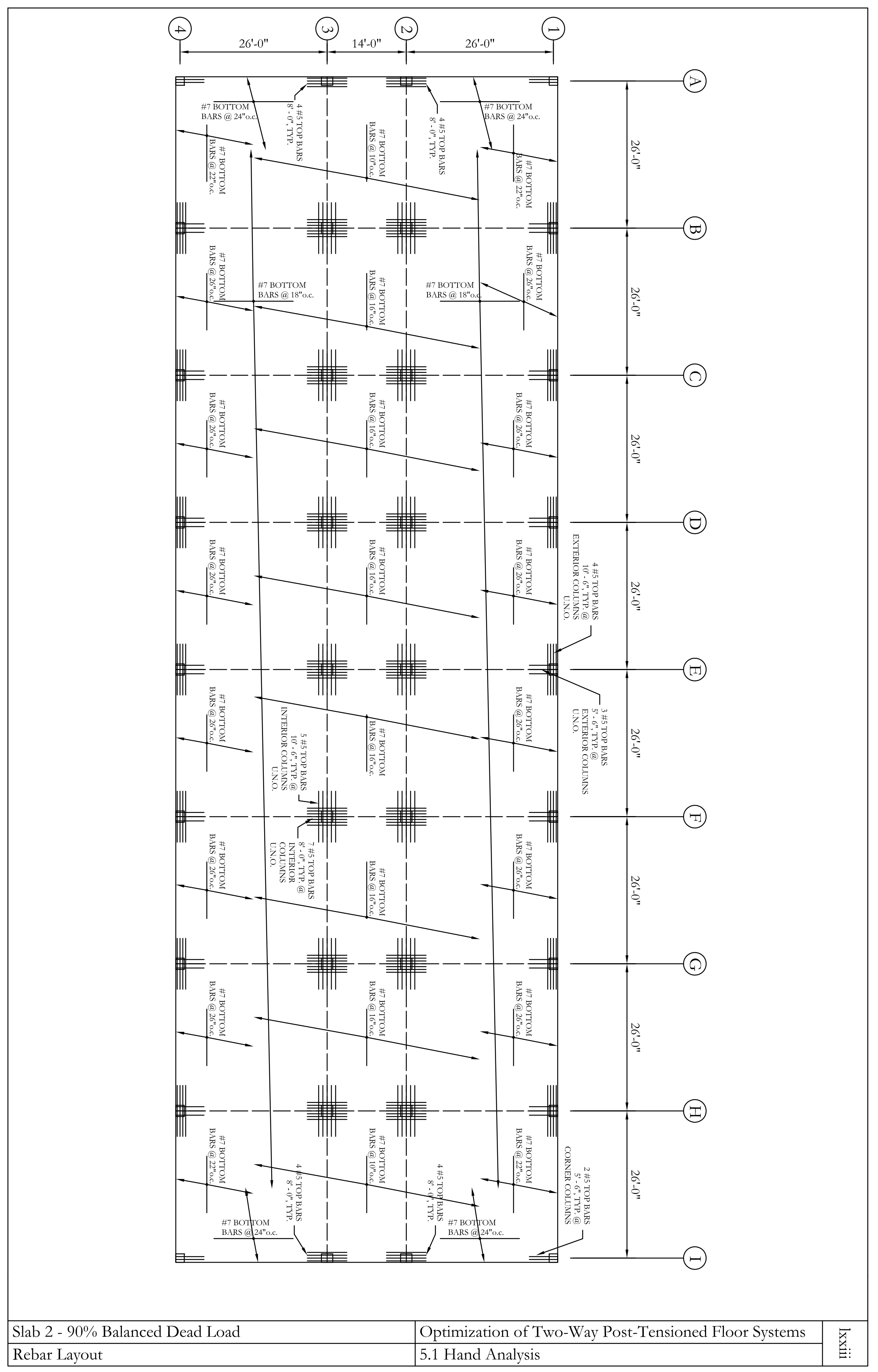




\section{B.2 Slab 3}

\begin{tabular}{|c|c|c|c|c|c|}
\hline & \multicolumn{4}{|c|}{ Frames } \\
\hline & & $1 \& 4$ & $2 \& 3$ & A \& I & B-H \\
\hline \multirow{3}{*}{ ta } & Total PT & 13 & 19 & 13 & 25 \\
\hline & Over Columns & 13 & 19 & 4 & 4 \\
\hline & Uniform & & & $\begin{array}{c}\text { 20,2 @ } \\
\text { 26"o.c. }\end{array}$ & $\begin{array}{c}\text { 20,2 @ } \\
\text { 26"o.c. }\end{array}$ \\
\hline & & & & & \\
\hline \multirow{4}{*}{ 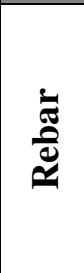 } & Outside Columns & & & $2 \# 5$ & 4 \#5 \\
\hline & Inside Columns & 4 \#5 & $5 \# 5$ & $4 \# 5$ & $7 \# 5$ \\
\hline & Outside Spans & $\begin{array}{c}\text { \#7 @ } \\
22 \text { "o.c. }\end{array}$ & $\begin{array}{c}\text { \#7 @ } \\
20 \text { "o.c. }\end{array}$ & $\begin{array}{c}\text { \#7 @ } \\
24 \text { "o.c. }\end{array}$ & $\begin{array}{c}\text { \#7 @ } \\
18 \text { "o.c. }\end{array}$ \\
\hline & Inside Spans & $\begin{array}{c}\# 7 @ \\
26 \text { "o.c. }\end{array}$ & $\begin{array}{c}\# 7 @ \\
22 \text { "o.c. }\end{array}$ & & \\
\hline \multirow{3}{*}{ 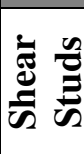 } & Exterior Columns & 0 & 16 & 0 & 18 \\
\hline & Interior Columns & & 24 & & 28 \\
\hline & Corner Columns & \multicolumn{4}{|c|}{0} \\
\hline
\end{tabular}




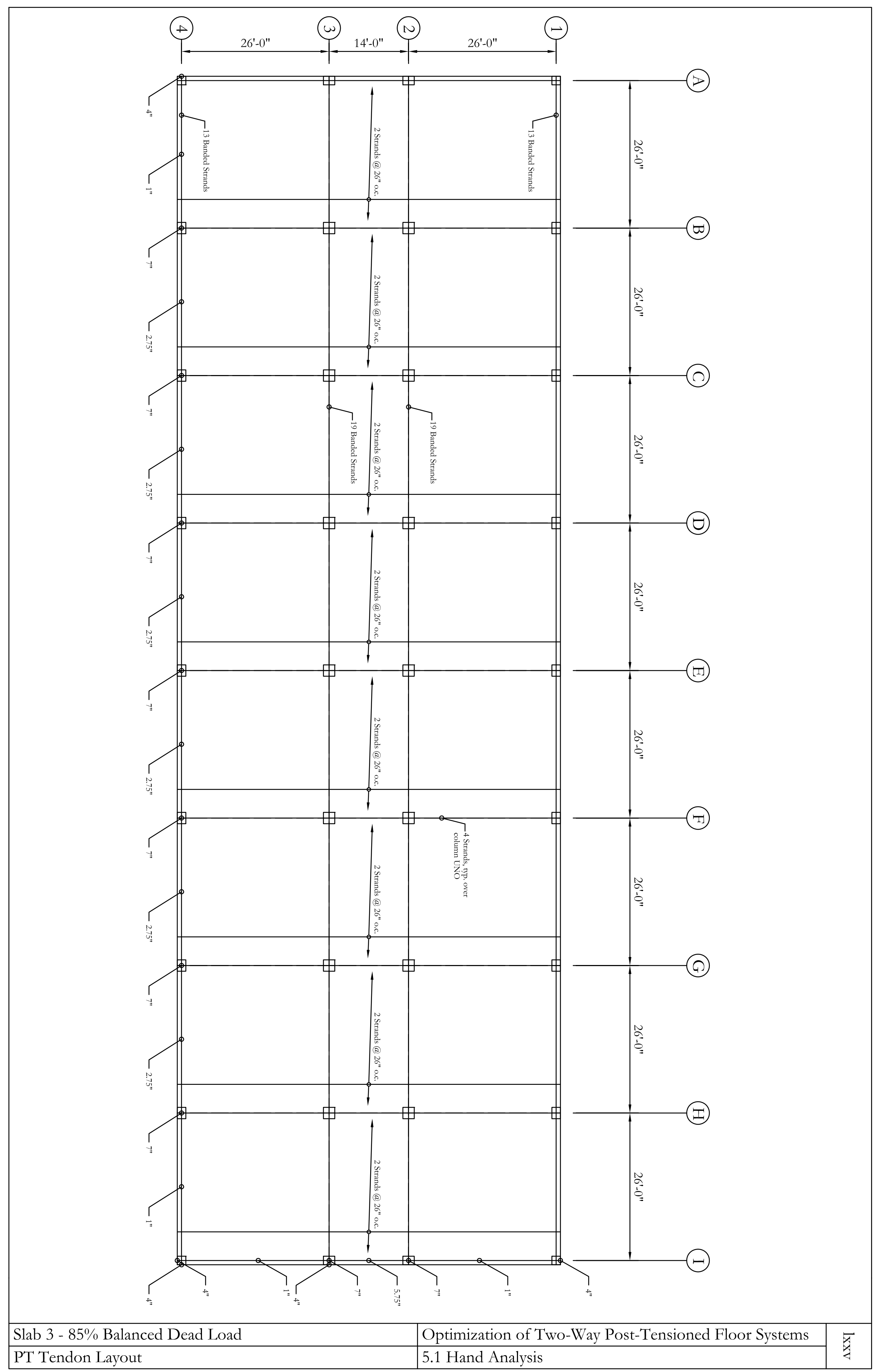




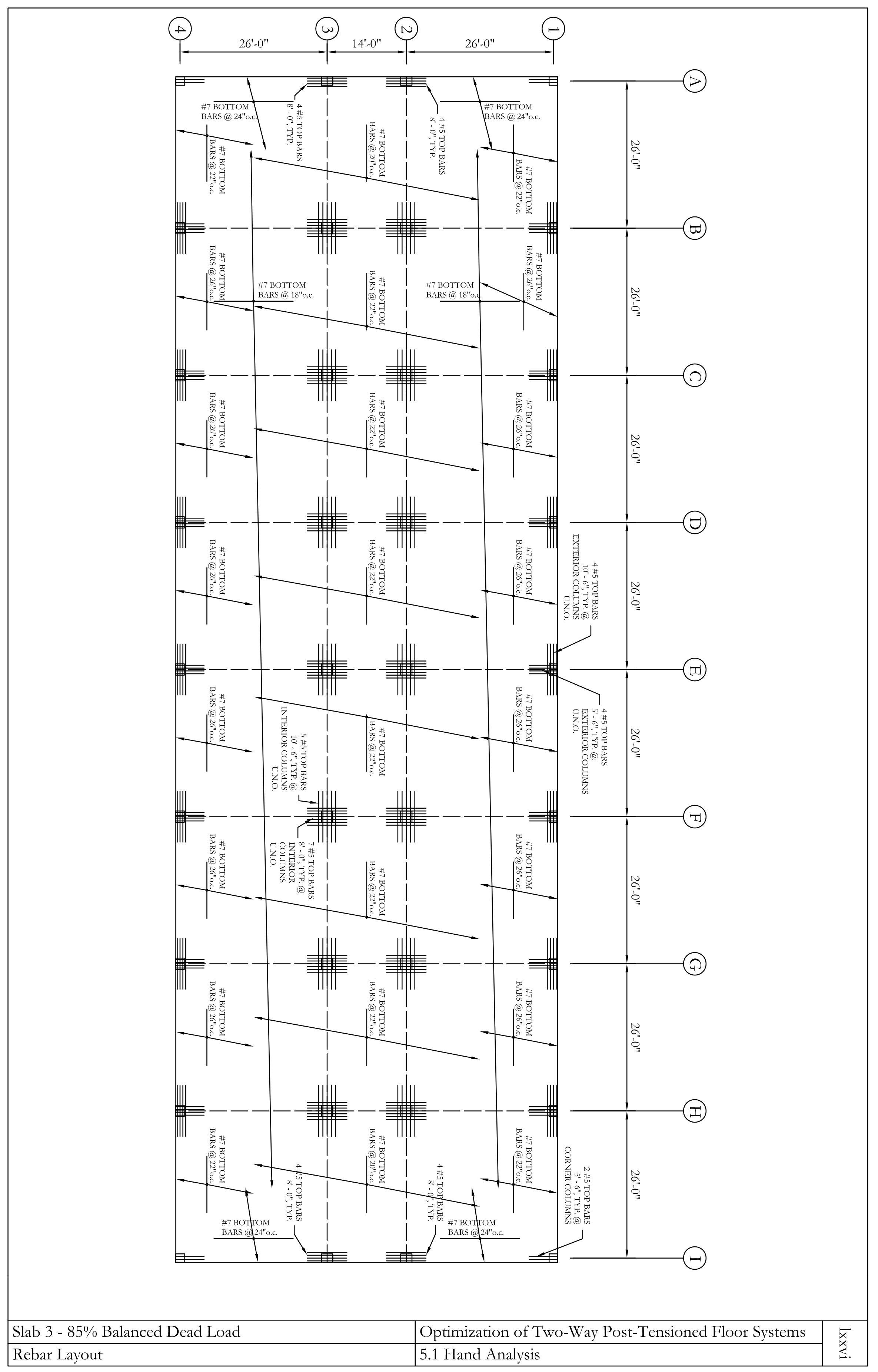




\section{B.4 Slab 4}

\begin{tabular}{|c|c|c|c|c|c|}
\hline & & \multicolumn{4}{|c|}{ Frames } \\
\hline & & $1 \& 4$ & $2 \& 3$ & A \& I & B-H \\
\hline \multirow{3}{*}{ 气́ } & Total PT & 12 & 18 & 12 & 23 \\
\hline & Over Columns & 12 & 18 & 4 & 4 \\
\hline & Uniform & & & $\begin{array}{l}18,2 @ \\
30 \text { "o.c. }\end{array}$ & $\begin{array}{c}18,2 \\
@ 30 \text { "o.c. }\end{array}$ \\
\hline \multirow{4}{*}{$\begin{array}{l}\overline{\bar{\pi}} \\
\stackrel{0}{0}\end{array}$} & Outside Columns & & & $2 * 5$ & 3 \\
\hline & Inside Columns & 4 \#5 & $6 \# 5$ & 4 \#5 & 7 \#5 \\
\hline & Outside Spans & $\begin{array}{l}\text { \#7 @ } \\
20 \text { "o.c. }\end{array}$ & $\begin{array}{c}\text { \#7 @ } \\
18 \text { "o.c. }\end{array}$ & $\begin{array}{c}\# 7 \text { @ } \\
22 \text { "o.c. }\end{array}$ & $\begin{array}{c}\text { \#7 @ } \\
18 \text { "o.c. }\end{array}$ \\
\hline & Inside Spans & $\begin{array}{l}\# 7 \text { @ } \\
24 \text { "o.c. }\end{array}$ & $\begin{array}{l}\# 7 \text { @ } \\
22 \text { "o.c. }\end{array}$ & & \\
\hline \multirow{3}{*}{ 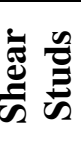 } & Exterior Columns & 0 & 16 & 0 & 20 \\
\hline & Interior Columns & & 24 & & 28 \\
\hline & Corner Columns & \multicolumn{4}{|c|}{0} \\
\hline
\end{tabular}




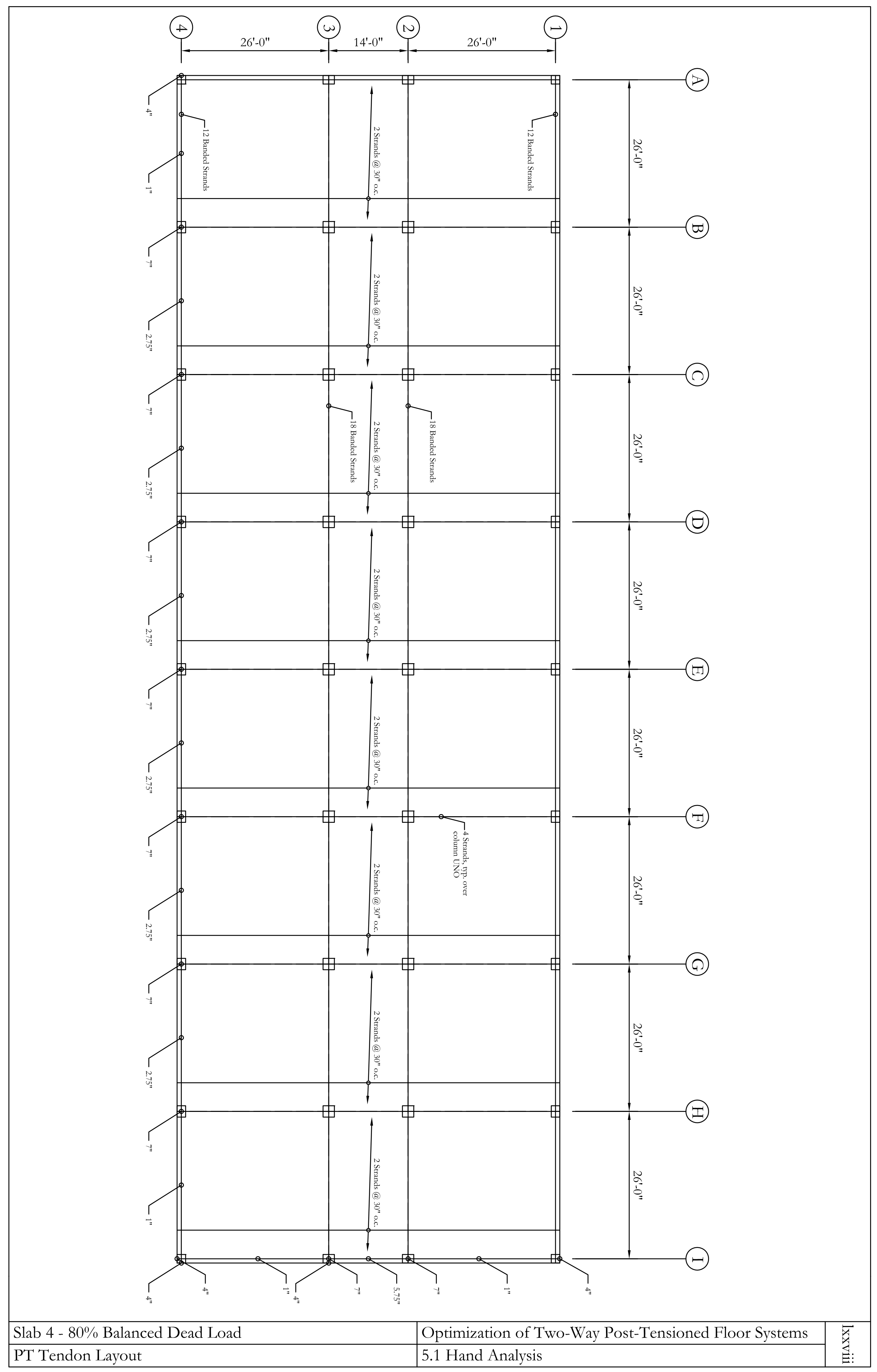




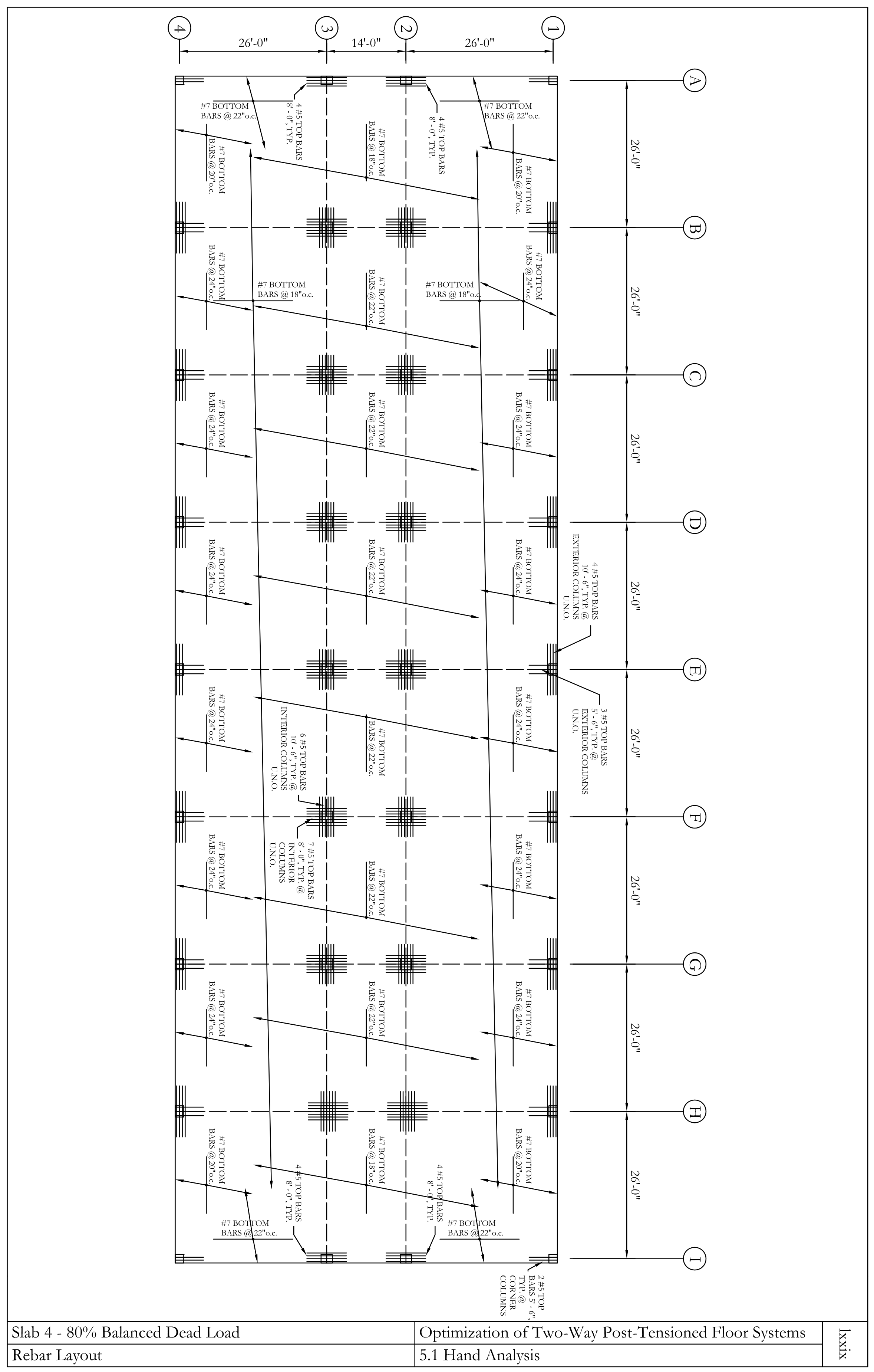




\section{B.5 Slab 5}

\begin{tabular}{|c|c|c|c|c|c|}
\hline & \multicolumn{4}{|c|}{ Frames } \\
\hline & & $1 \& 4$ & $2 \& 3$ & A \& I & B-H \\
\hline \multirow{3}{*}{ E } & Total PT & 11 & 17 & 11 & 22 \\
\hline & Over Columns & 11 & 17 & 4 & 4 \\
\hline & Uniform & & & $\begin{array}{l}16,2 \text { @ } \\
34 \text { "o.c. }\end{array}$ & $\begin{array}{l}\text { 18,2@ } \\
30 \text { "o.c. }\end{array}$ \\
\hline \multirow{4}{*}{$\begin{array}{l}\bar{\pi} \\
\frac{0}{0} \\
\simeq\end{array}$} & Outside Columns & 4 \#5 & & $4 \# 5$ & \\
\hline & Inside Columns & $5 \# 5$ & $7 \# 5$ & $4 \# 5$ & 7 \#5 \\
\hline & Outside Spans & $\begin{array}{c}\text { \#7 @ } \\
18 \text { "o.c. }\end{array}$ & $\begin{array}{c}\text { \#7 @ } \\
18 \text { "o.c. }\end{array}$ & $\begin{array}{c}\# 7 \text { @ } \\
22 " \text { o.c. }\end{array}$ & $\begin{array}{c}\text { \#7 @ } \\
16 \text { "o.c. }\end{array}$ \\
\hline & Inside Spans & $\begin{array}{c}\# 7 @ \\
22 \text { "o.c. }\end{array}$ & $\begin{array}{l}\# 7 @ \\
20 \text { "o.c. }\end{array}$ & & \\
\hline \multirow{3}{*}{ 离 } & Exterior Columns & 0 & 16 & 0 & 20 \\
\hline & Interior Columns & & 24 & & 28 \\
\hline & Corner Columns & \\
\hline
\end{tabular}




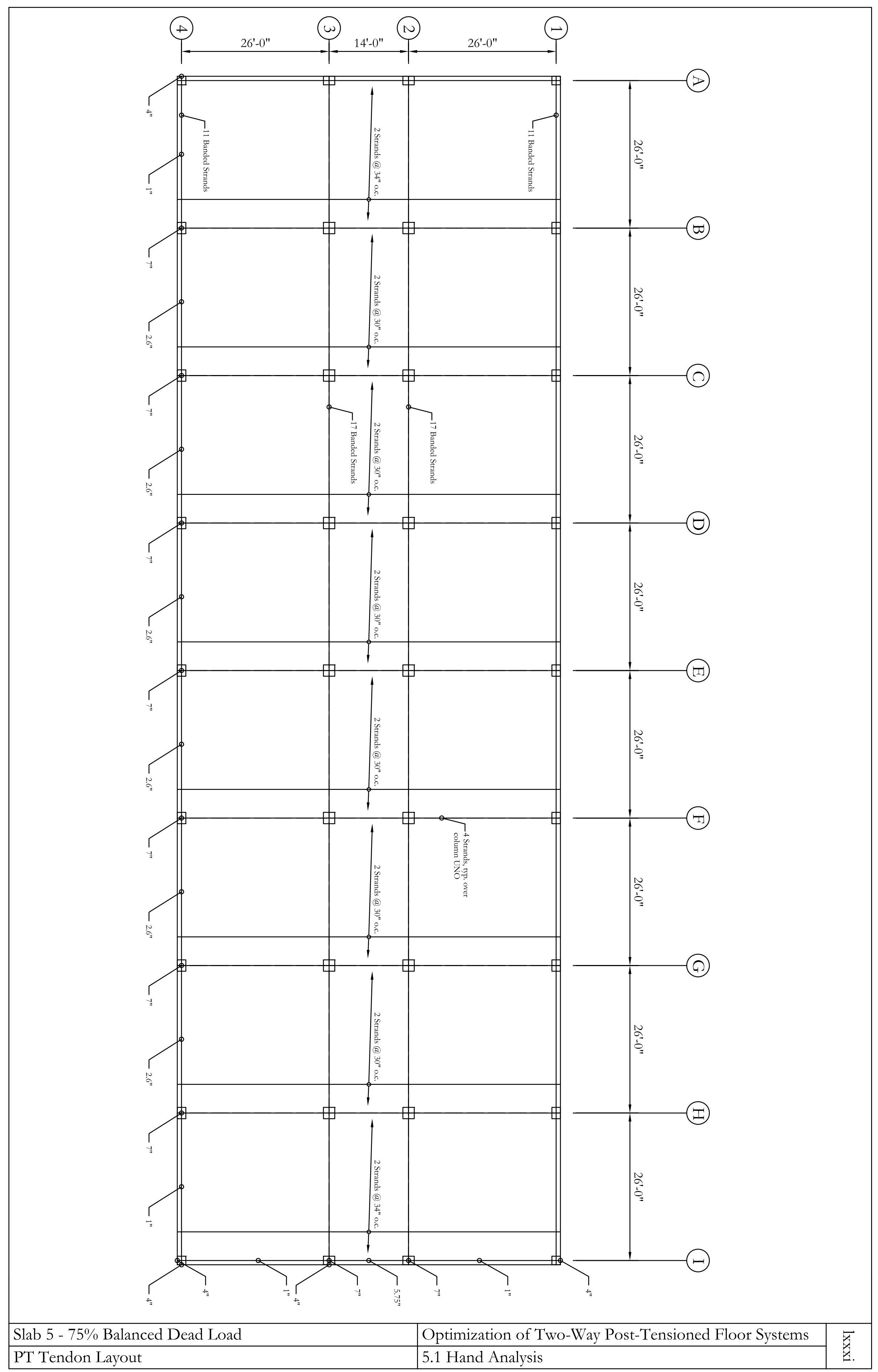




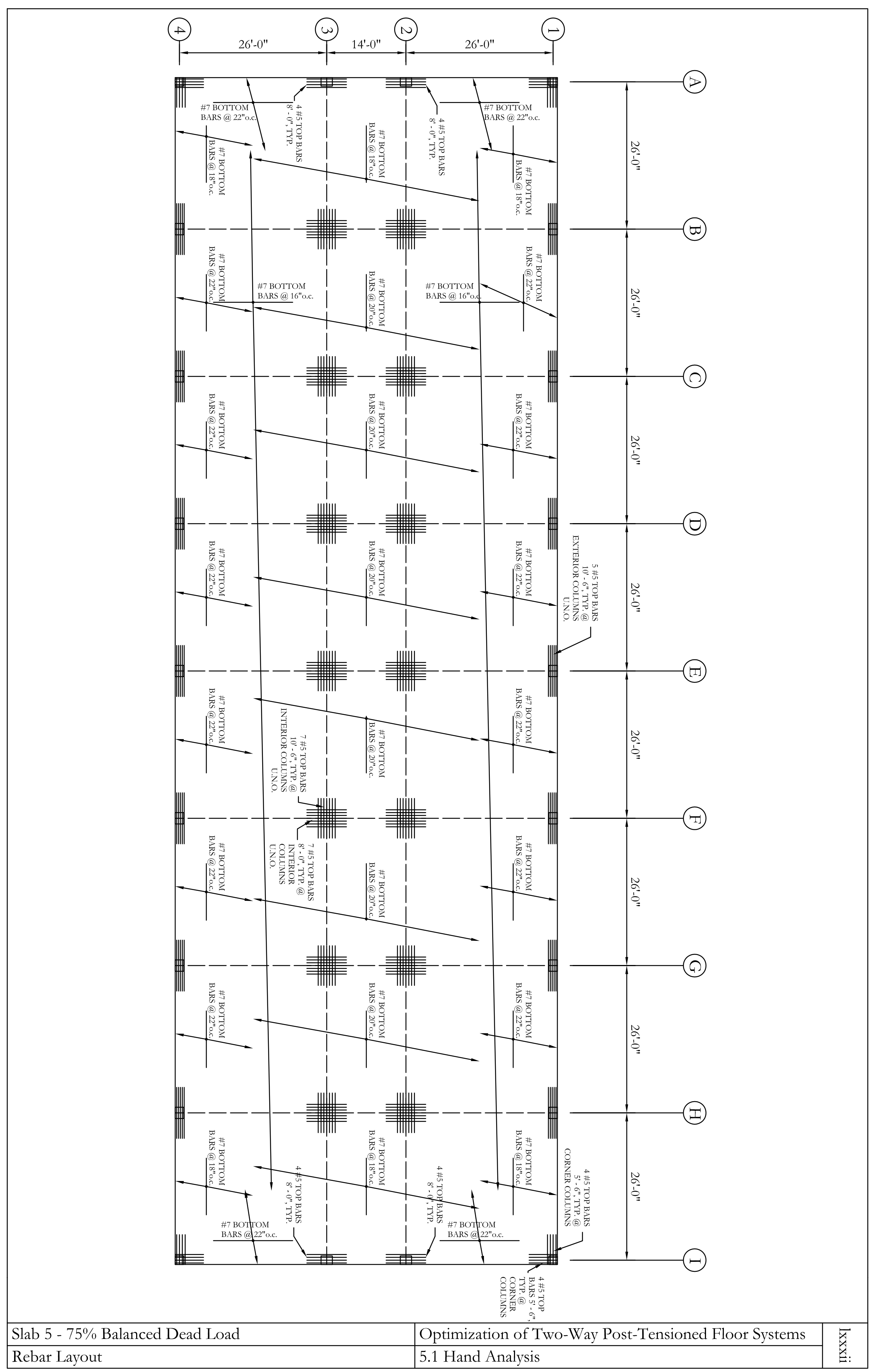




\section{B.6 Slab 6}

\begin{tabular}{|c|c|c|c|c|c|}
\hline & \multicolumn{4}{|c|}{ Frames } \\
\hline & & $1 \& 4$ & $2 \& 3$ & A \& I & $\mathrm{B}-\mathrm{H}$ \\
\hline \multirow{3}{*}{$\underline{E}$} & Total PT & 14 & 21 & 14 & 27 \\
\hline & Over Columns & 14 & 21 & 4 & 4 \\
\hline & Uniform & & & $\begin{array}{c}22,2 \text { @ 24" } \\
\text { o.c. }\end{array}$ & $\begin{array}{c}22,2 \text { @ 24" } \\
\text { o.c. }\end{array}$ \\
\hline \multirow{4}{*}{ 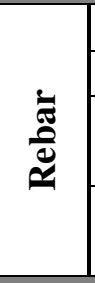 } & Outside Columns & & & & \\
\hline & Inside Columns & $3 \# 5$ & $5 \# 5$ & $3 \# 5$ & $6 \# 5$ \\
\hline & Outside Spans & $\begin{array}{l}\text { \#7 @ } \\
20 \text { "o.c. }\end{array}$ & $\begin{array}{l}\text { \#7 @ } \\
18 \text { "o.c. }\end{array}$ & $\begin{array}{c}\text { \#7 @ } \\
24 " \text { "o.c. }\end{array}$ & $\begin{array}{l}\text { \#7 @ } \\
18 \text { "o.c. }\end{array}$ \\
\hline & Inside Spans & $\begin{array}{l}\# 7 @ \\
24 \text { "o.c. }\end{array}$ & $\begin{array}{l}\# 7 @ \\
22 " \text { o.c. }\end{array}$ & & \\
\hline \multirow{3}{*}{$\begin{array}{l}\bar{\varpi} \\
\bar{\varpi} \\
\bar{E}\end{array}$} & Exterior Columns & 0 & 18 & 0 & 20 \\
\hline & Interior Columns & & 24 & & 28 \\
\hline & Corner Columns & \\
\hline
\end{tabular}




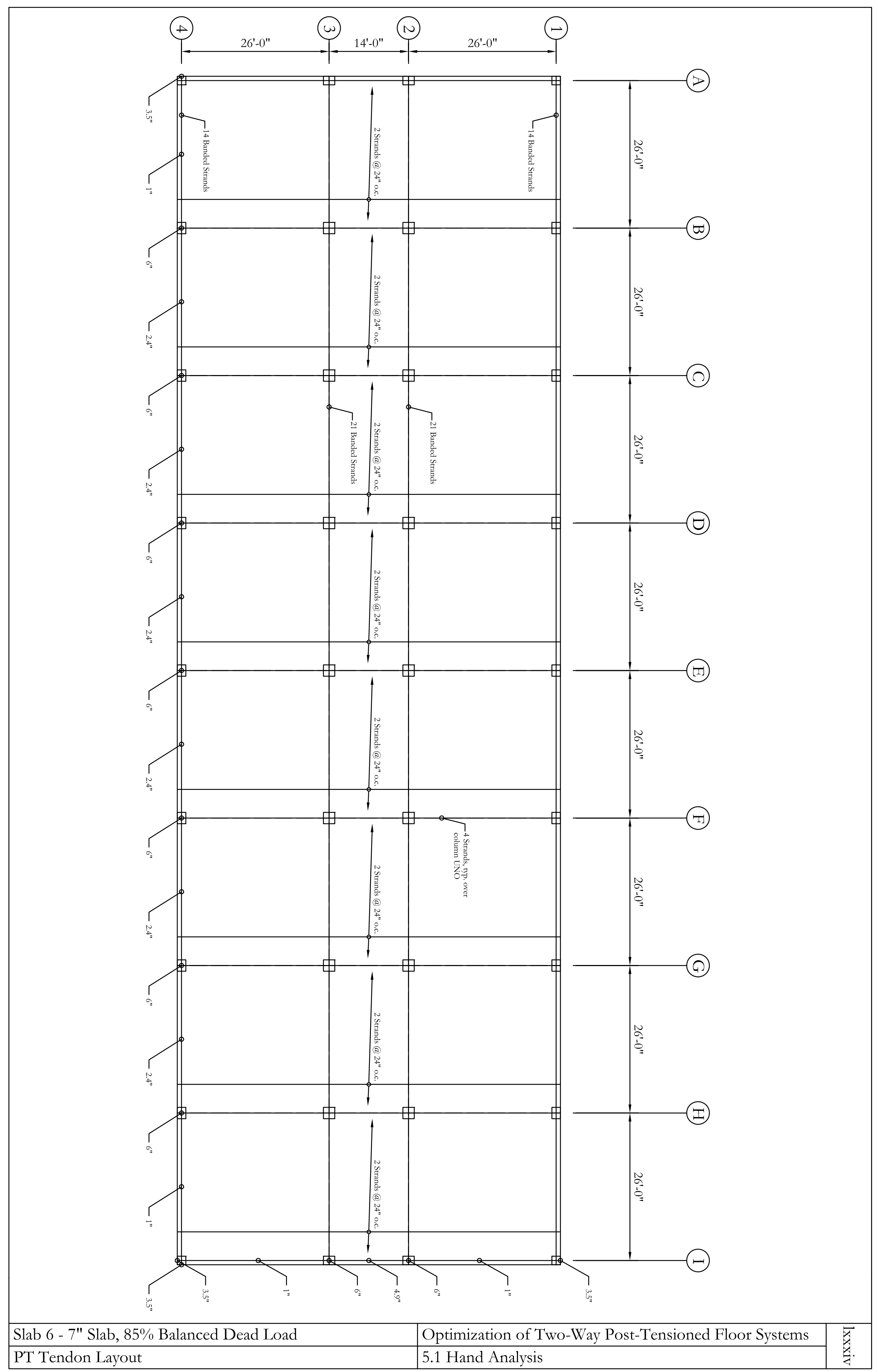




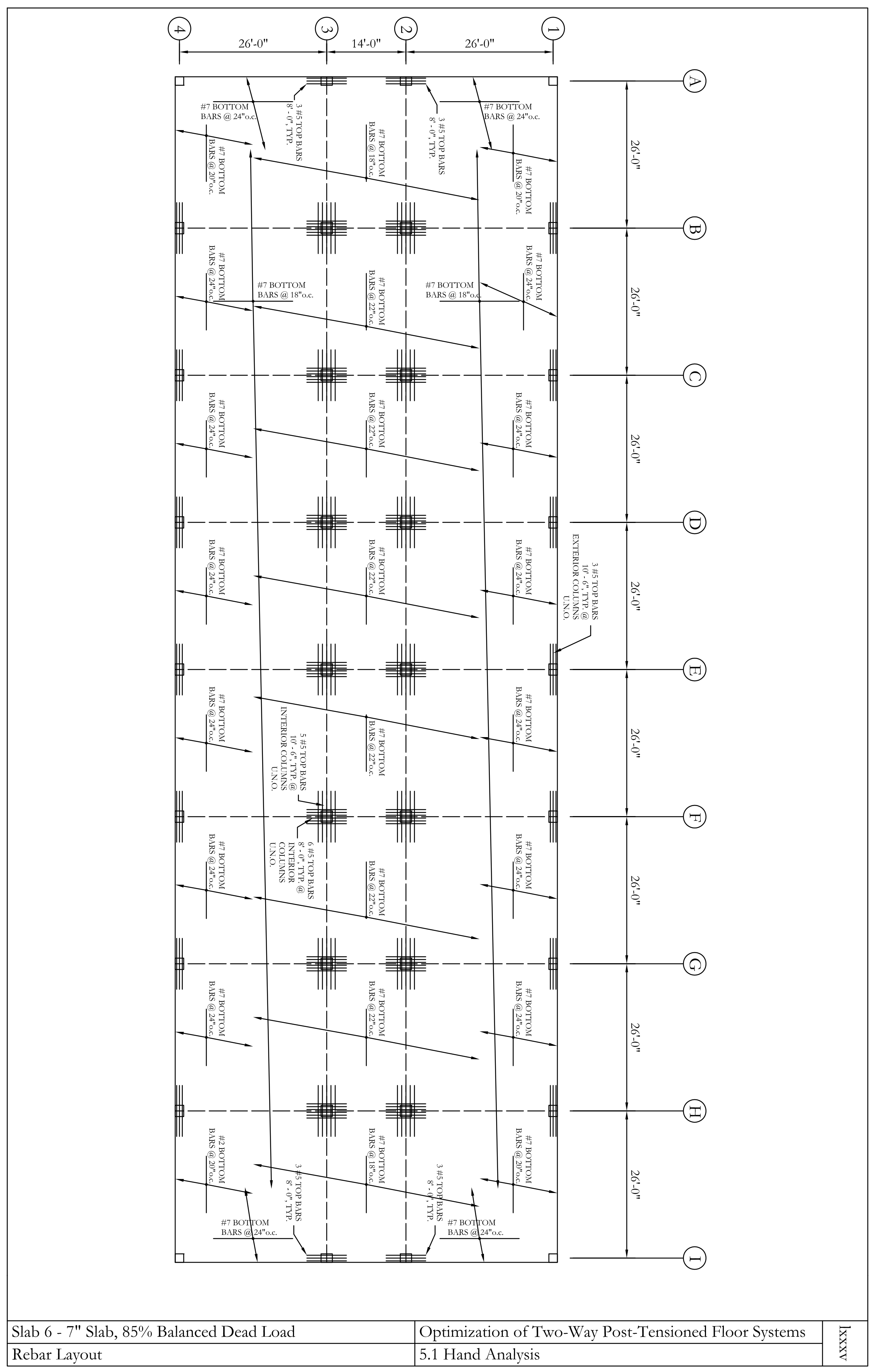




\section{B.7 Slab 7}

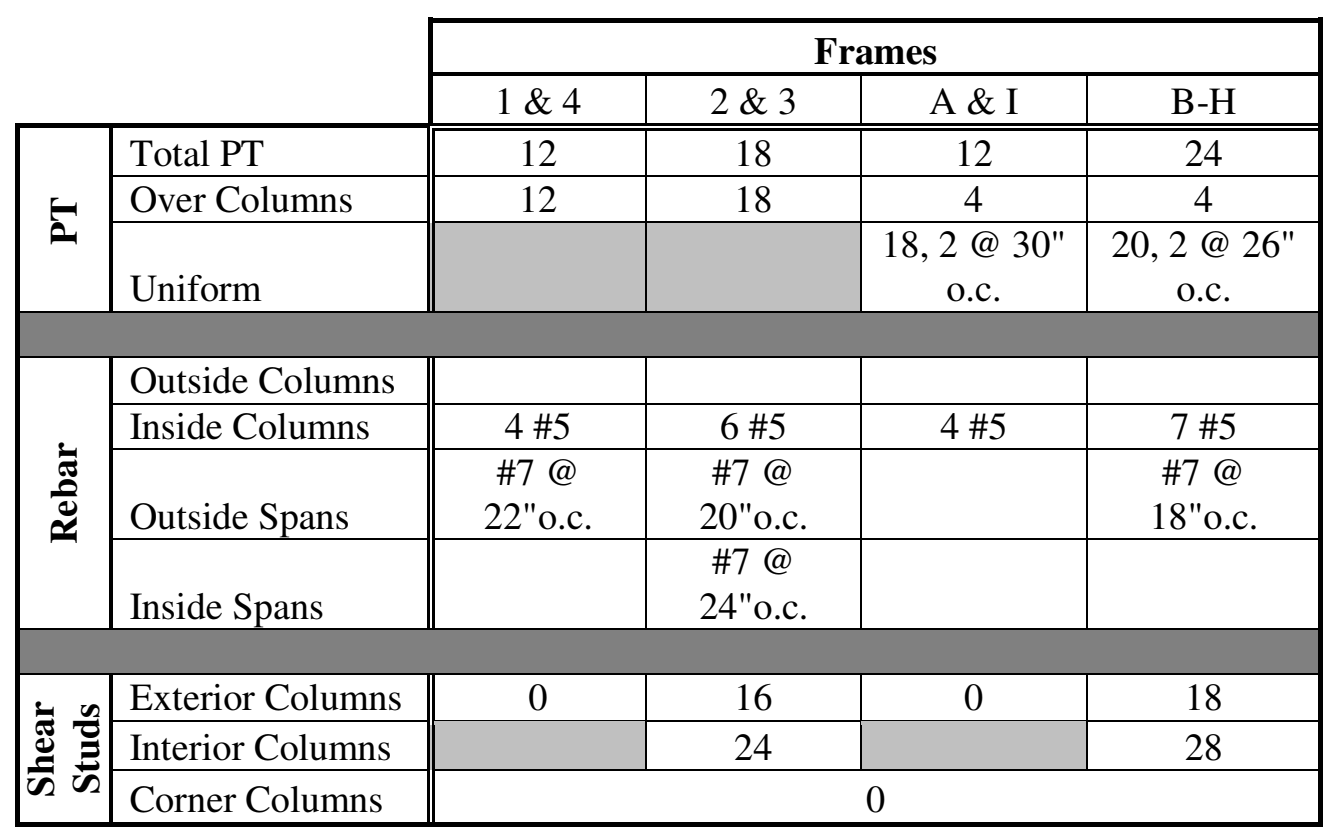




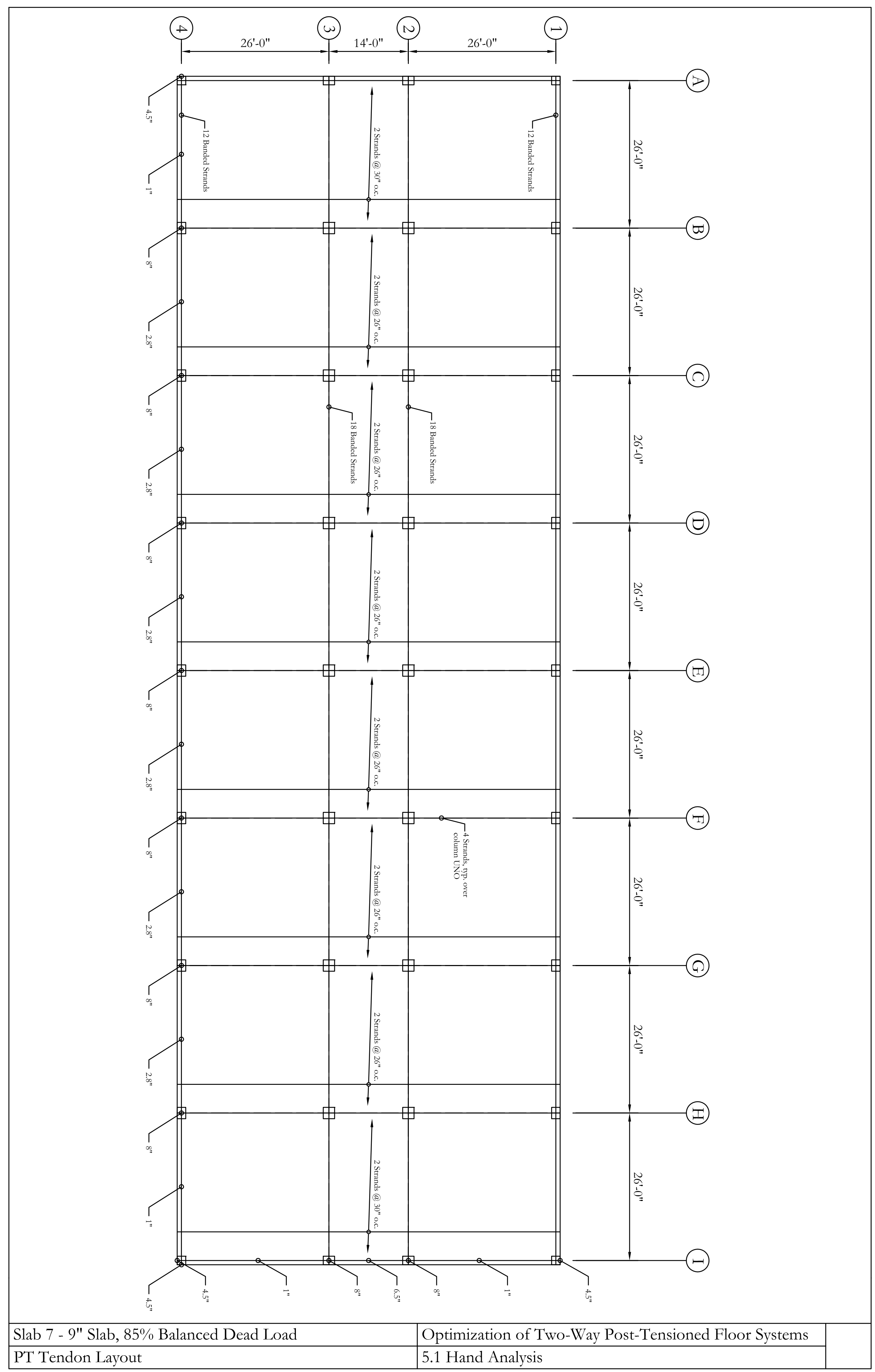




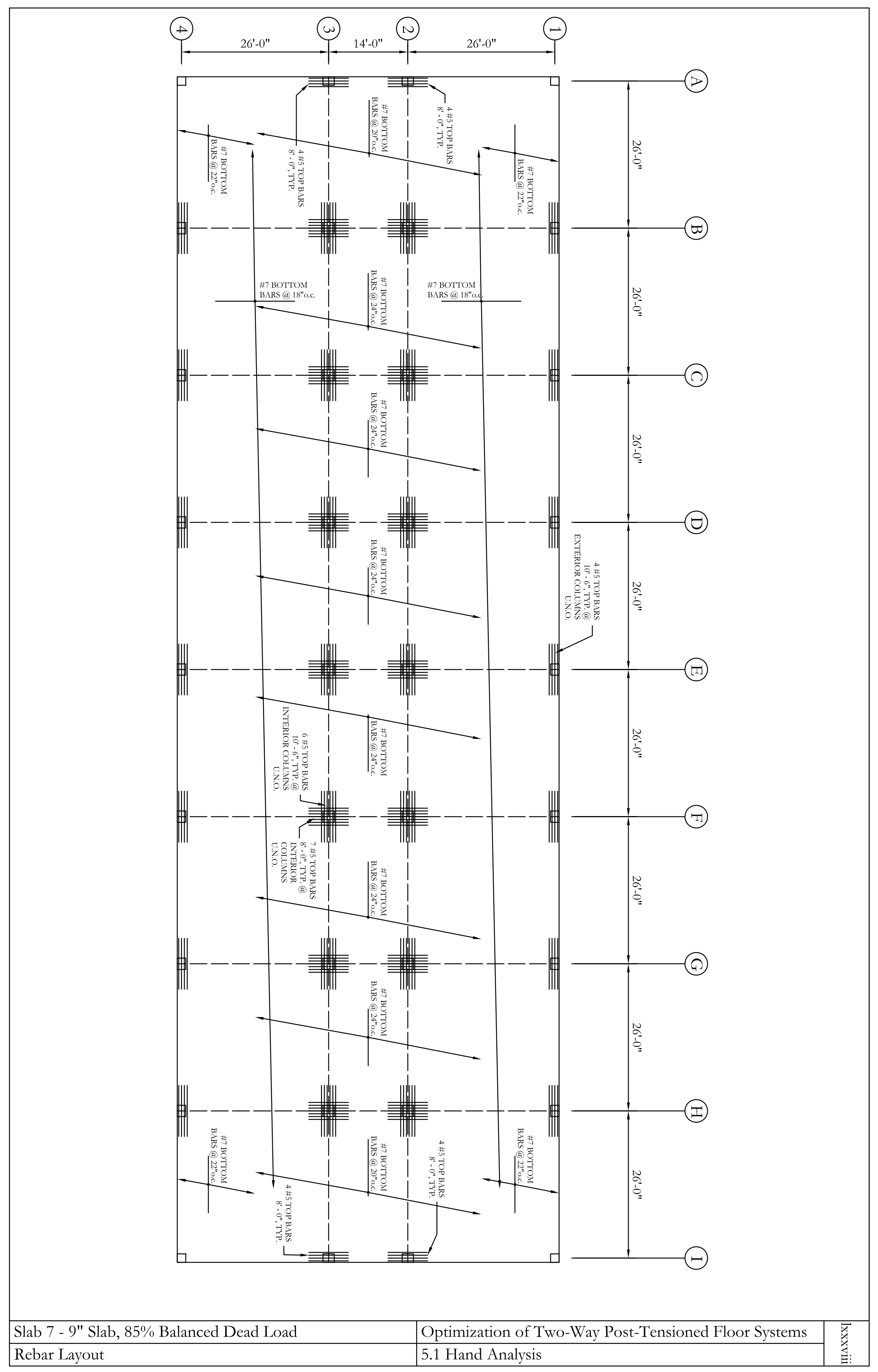




\section{B.8 Slab 8}

\begin{tabular}{|c|c|c|c|c|c|}
\hline & & \multicolumn{4}{|c|}{ Frames } \\
\hline & & $1 \& 4$ & $2 \& 3$ & A \& I & B-H \\
\hline \multirow{3}{*}{ E } & Total PT & 13 & 18 & 12 & 24 \\
\hline & Over Columns & 13 & 18 & 4 & 4 \\
\hline & Uniform & & & $\begin{array}{l}18,2 \text { @ } \\
30 \text { "o.c. }\end{array}$ & $\begin{array}{l}\text { 20,2@ } \\
26 \text { "o.c. }\end{array}$ \\
\hline \multirow{4}{*}{ 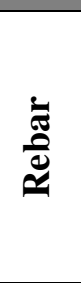 } & Outside Columns & & & $2 \# 5$ & $4 \# 5$ \\
\hline & Inside Columns & $4 \# 5$ & $5 \# 5$ & $4 \# 5$ & $7 \# 5$ \\
\hline & Outside Spans & $\begin{array}{c}\text { \#7 @ } \\
22 \text { "o.c. }\end{array}$ & $\begin{array}{c}\text { \#7 @ } \\
20 \text { "o.c. }\end{array}$ & $\begin{array}{c}\text { \#7 @ } \\
24 \text { "o.c. }\end{array}$ & $\begin{array}{c}\text { \#7 @ } \\
18 \text { "o.c. }\end{array}$ \\
\hline & Inside Spans & $\begin{array}{c}\# 7 @ \\
26 \text { "o.c. }\end{array}$ & $\begin{array}{l}\# 7 @ \\
22 \text { "o.c. }\end{array}$ & & \\
\hline \multirow{3}{*}{ 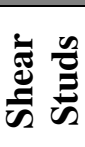 } & Exterior Columns & 0 & 14 & 0 & 16 \\
\hline & Interior Columns & & 20 & & 24 \\
\hline & Corner Columns & \multicolumn{4}{|c|}{0} \\
\hline
\end{tabular}




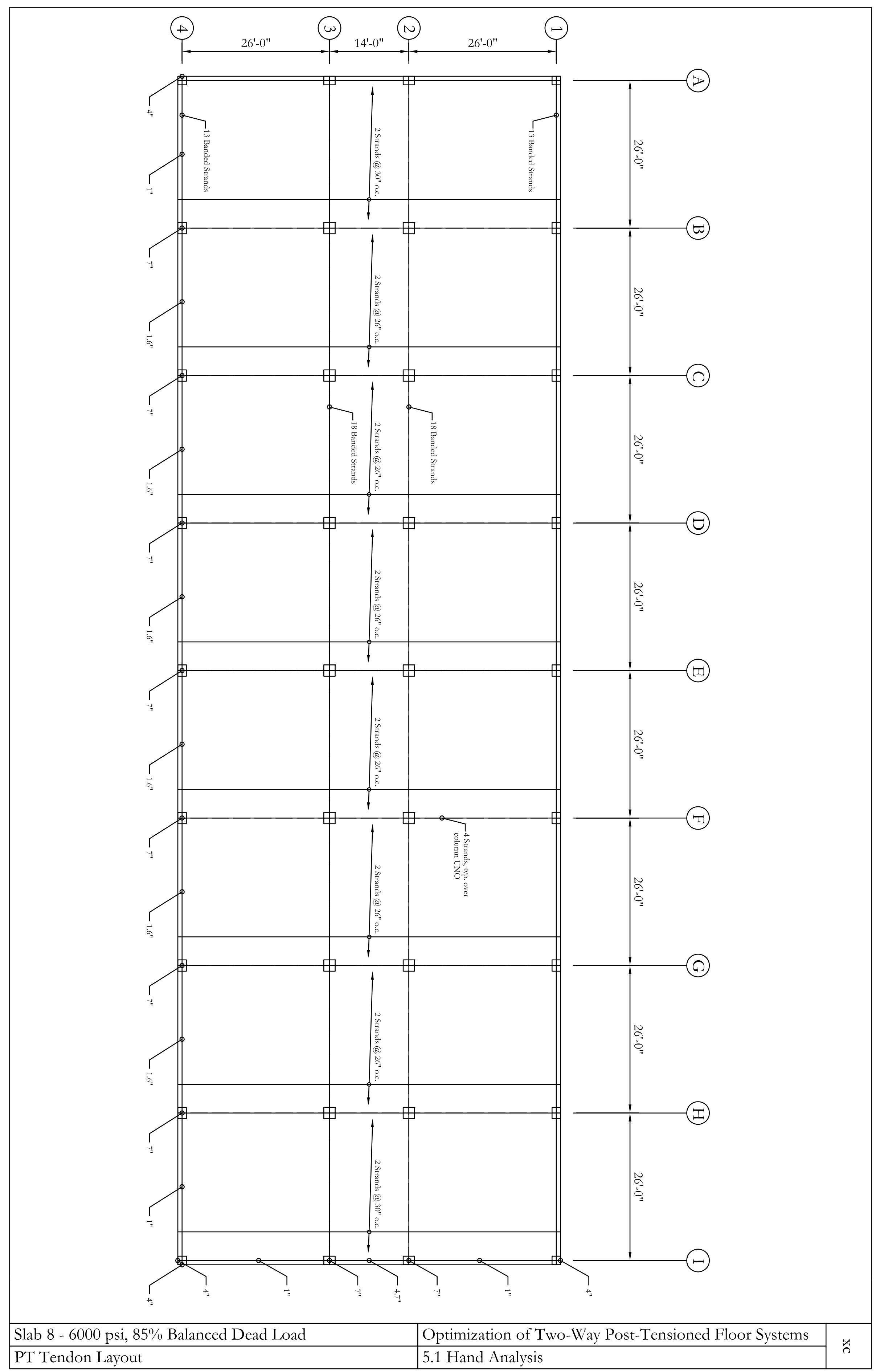




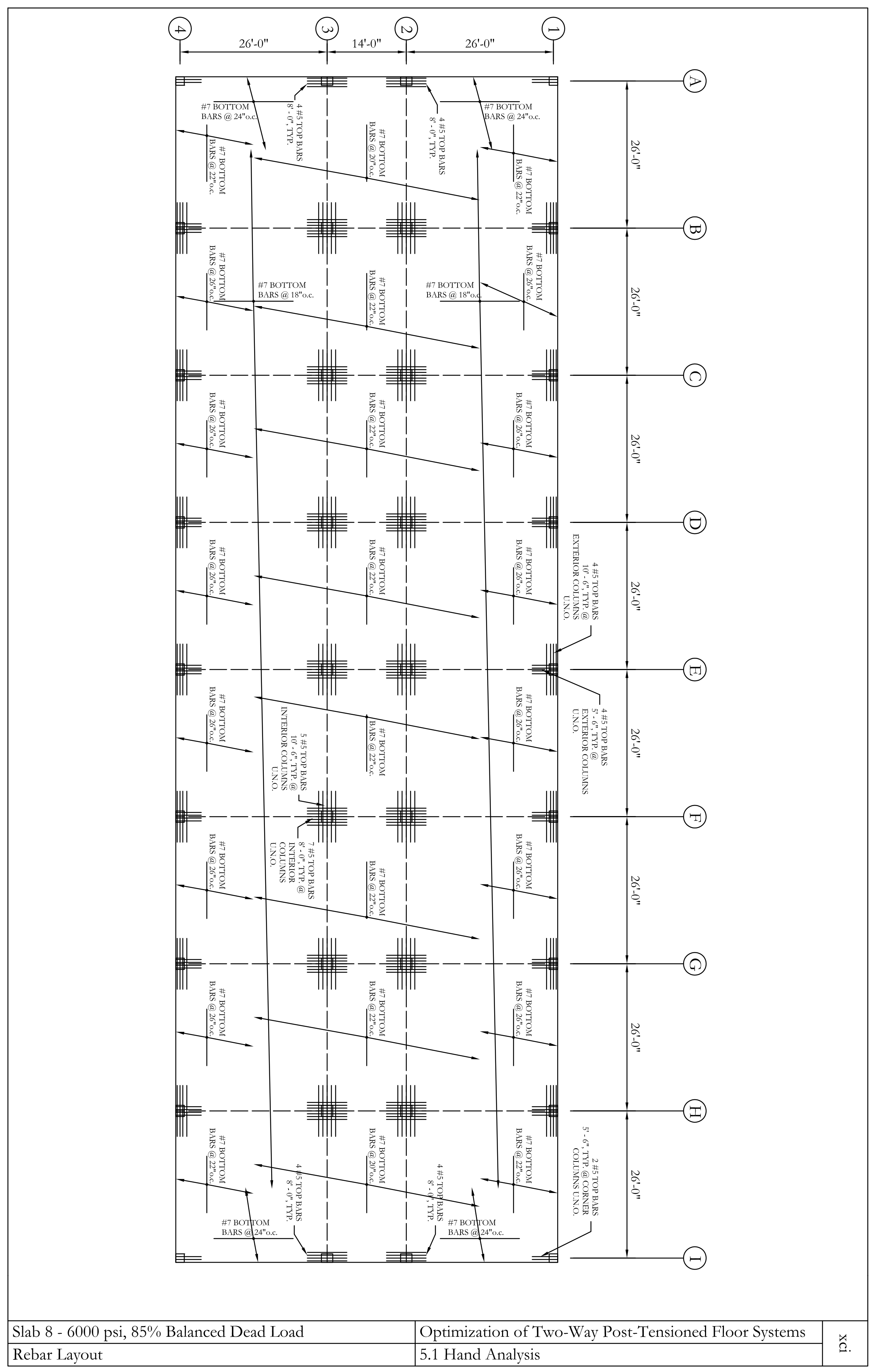




\section{APPENDIX C - COMPUTER ANALYSIS DOCUMENTATION}

\section{C.1 Slab 1 - Same Tendon Profile as Hand}

\section{C.1.1 Grids $2 \& 3$}
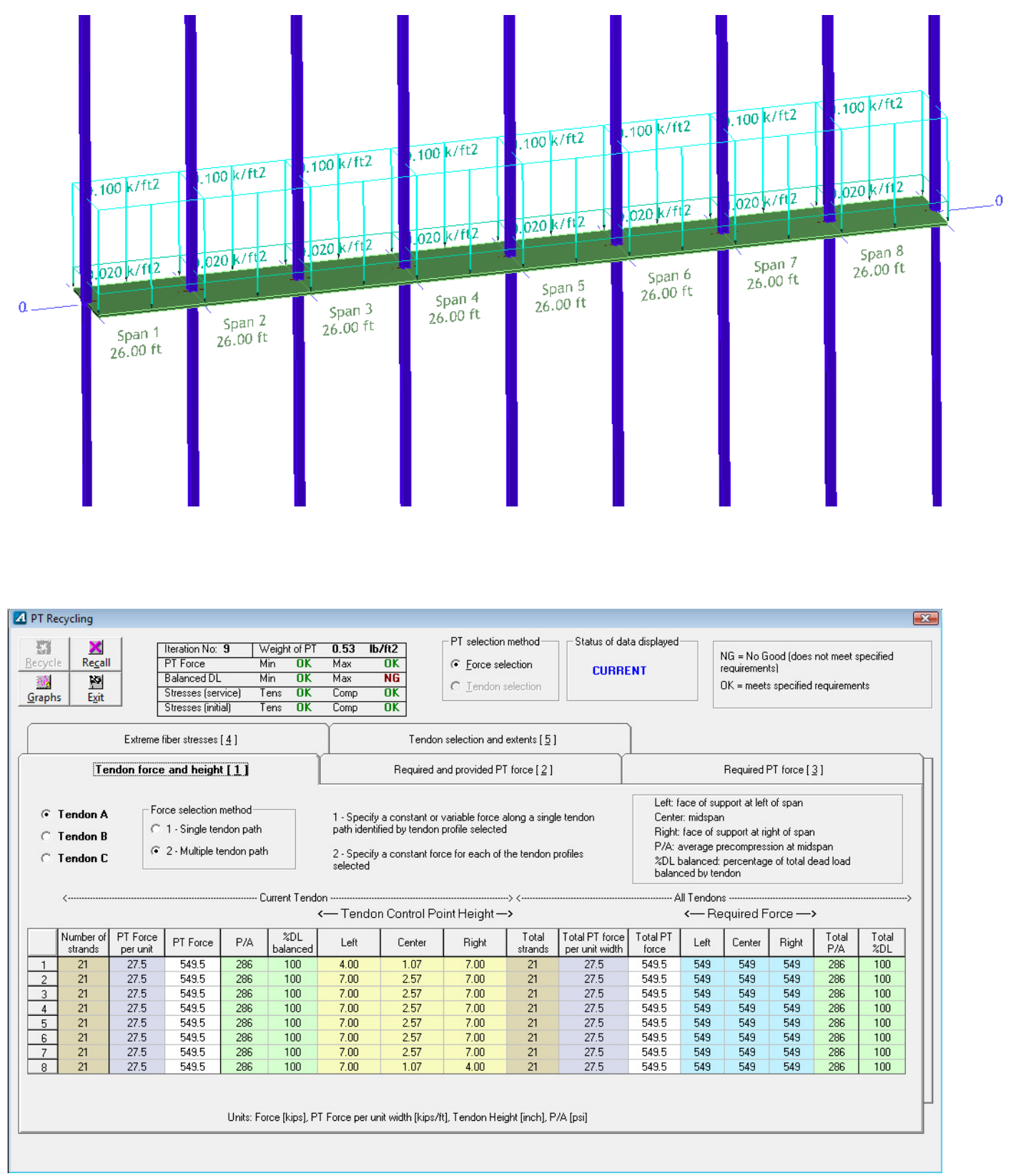

Optimization of Two-Way Post-Tensioned Concrete Floor Systems 
Appendix $\quad$ xciii

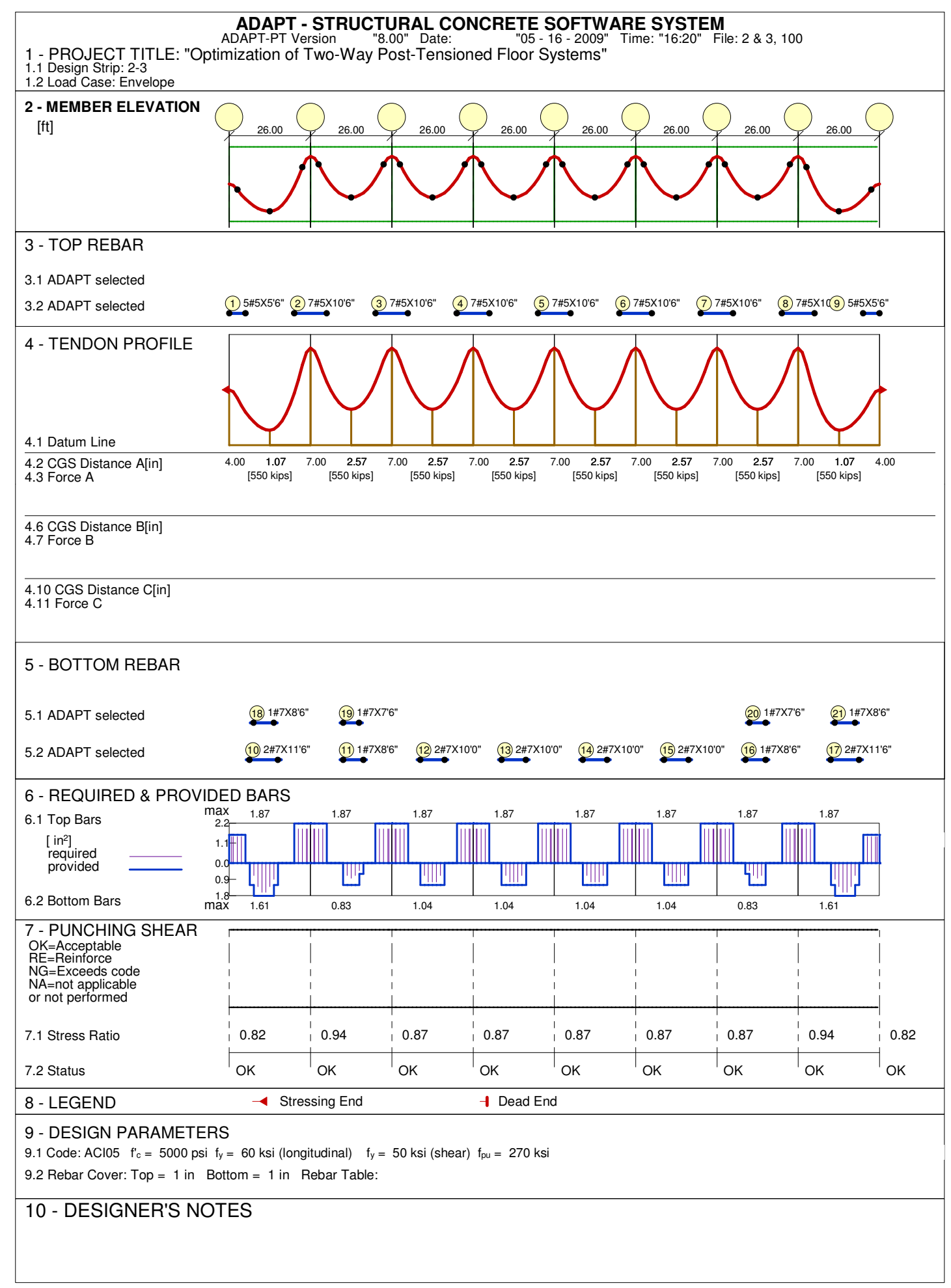

Optimization of Two-Way Post-Tensioned Concrete Floor Systems 


\section{C.1.2 Grids B-H}

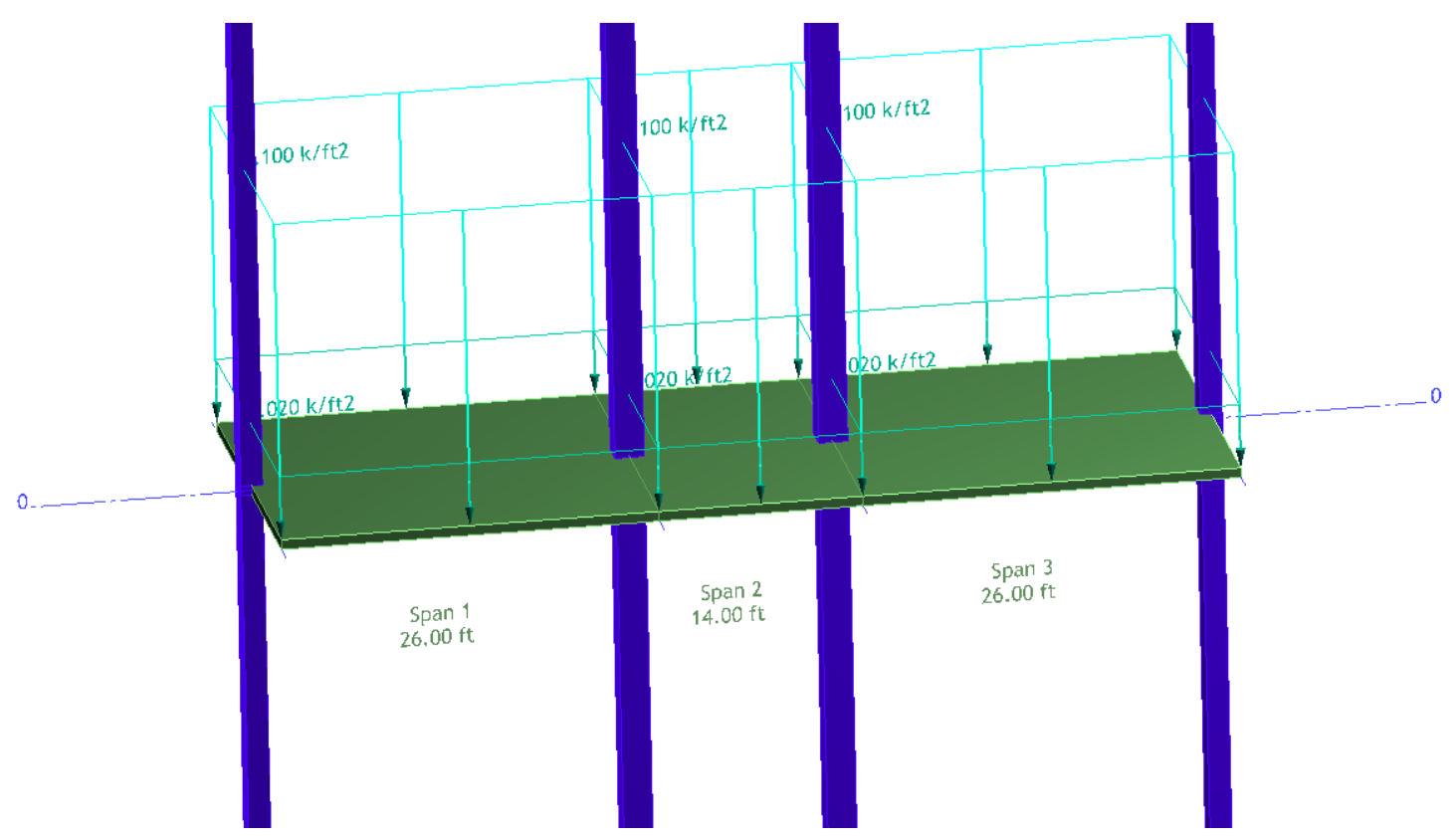

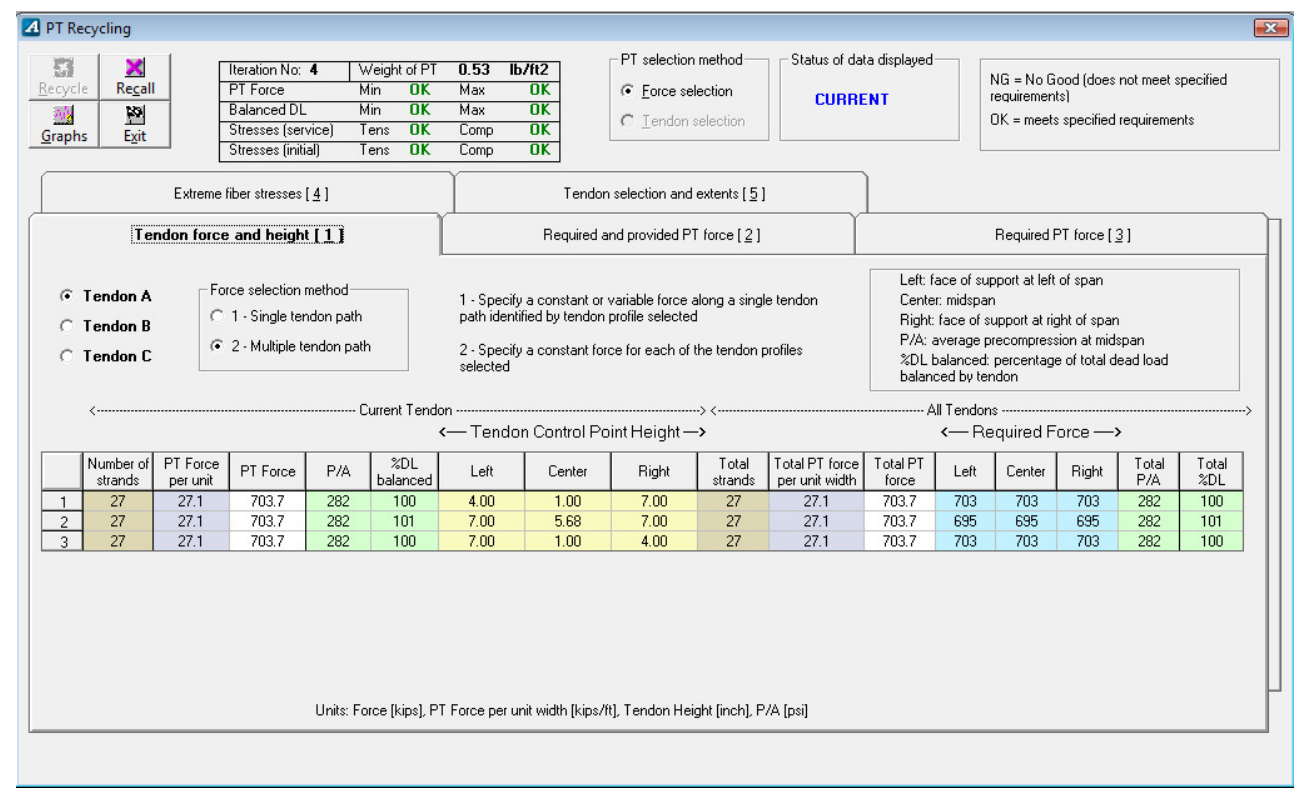

Optimization of Two-Way Post-Tensioned Concrete Floor Systems 


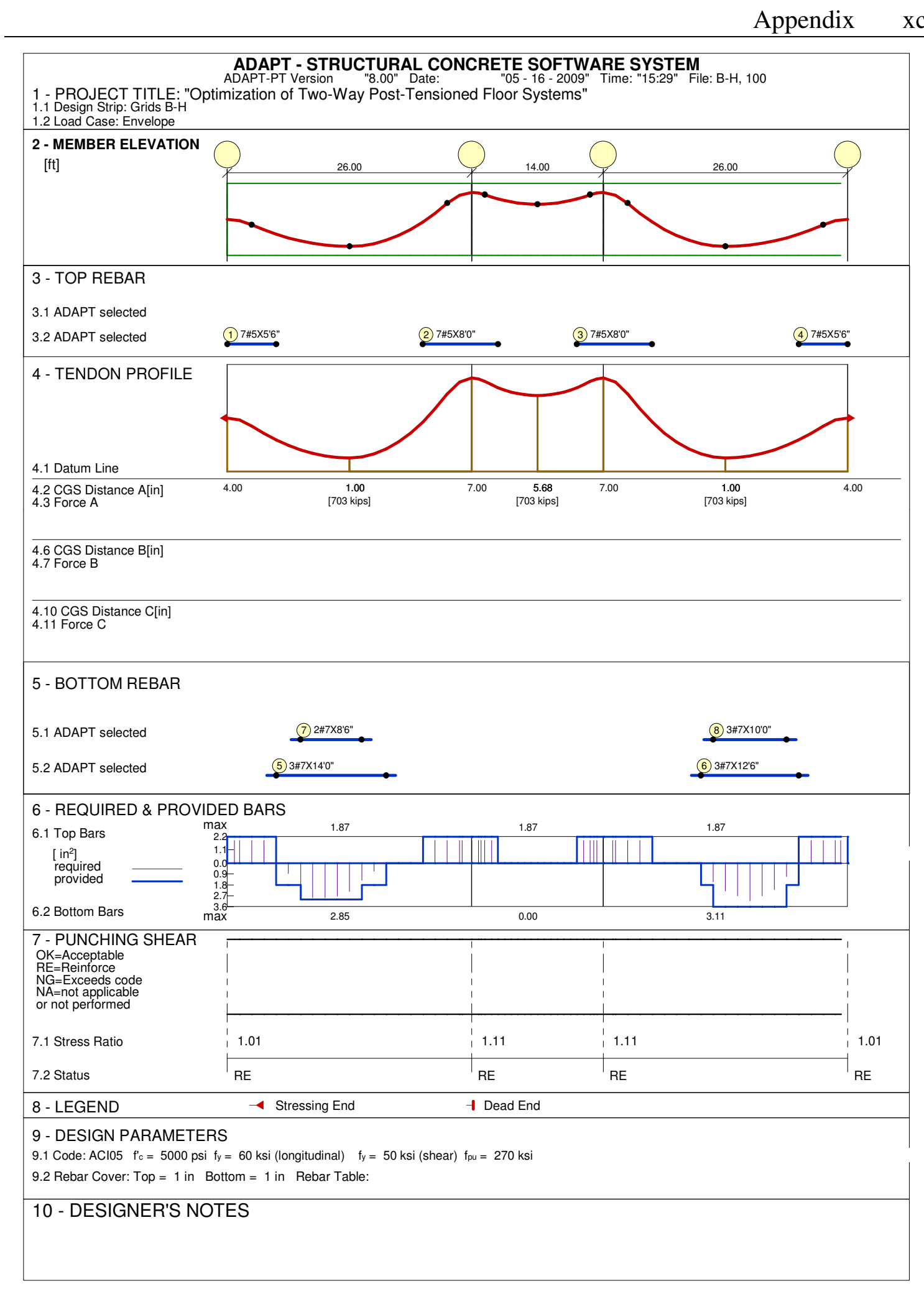




\section{C.2 Slab 1 - ADAPT Default Tendon Profile}

\section{C.2.1 Grids $2 \& 3$}

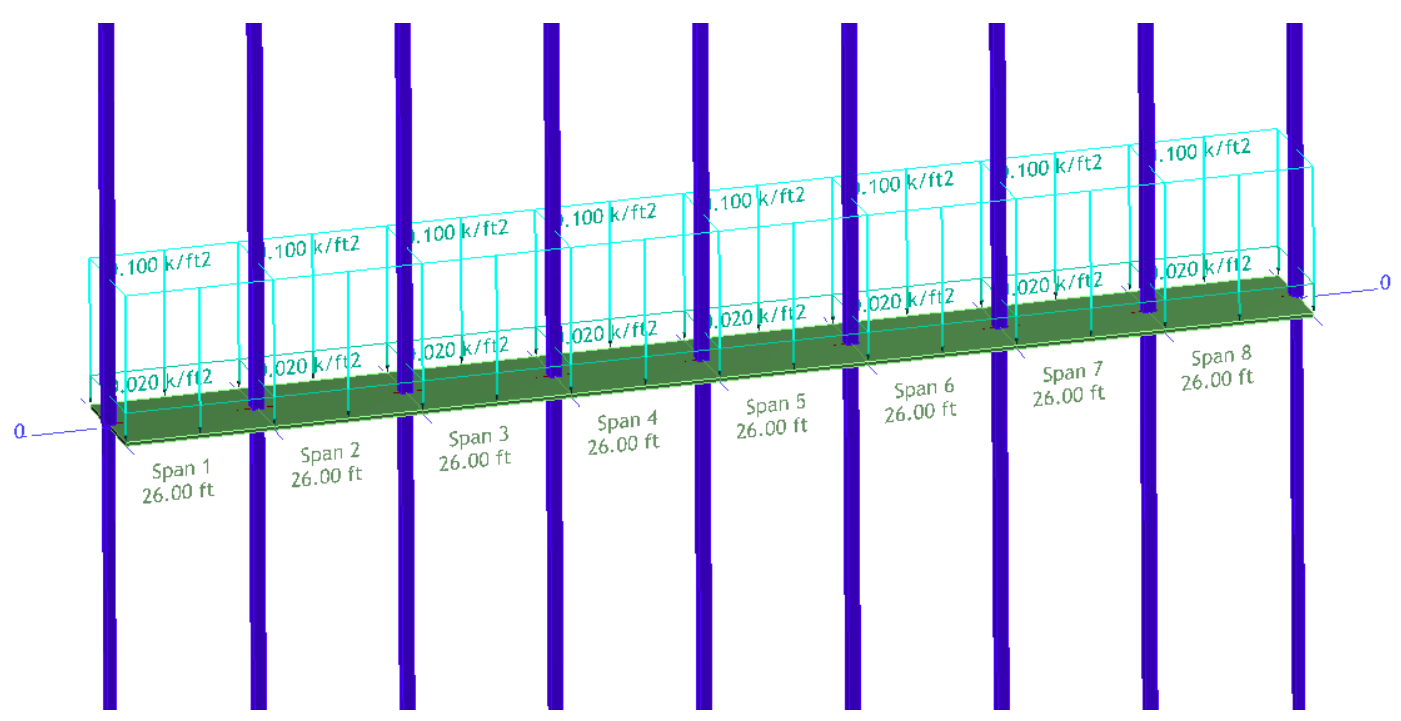

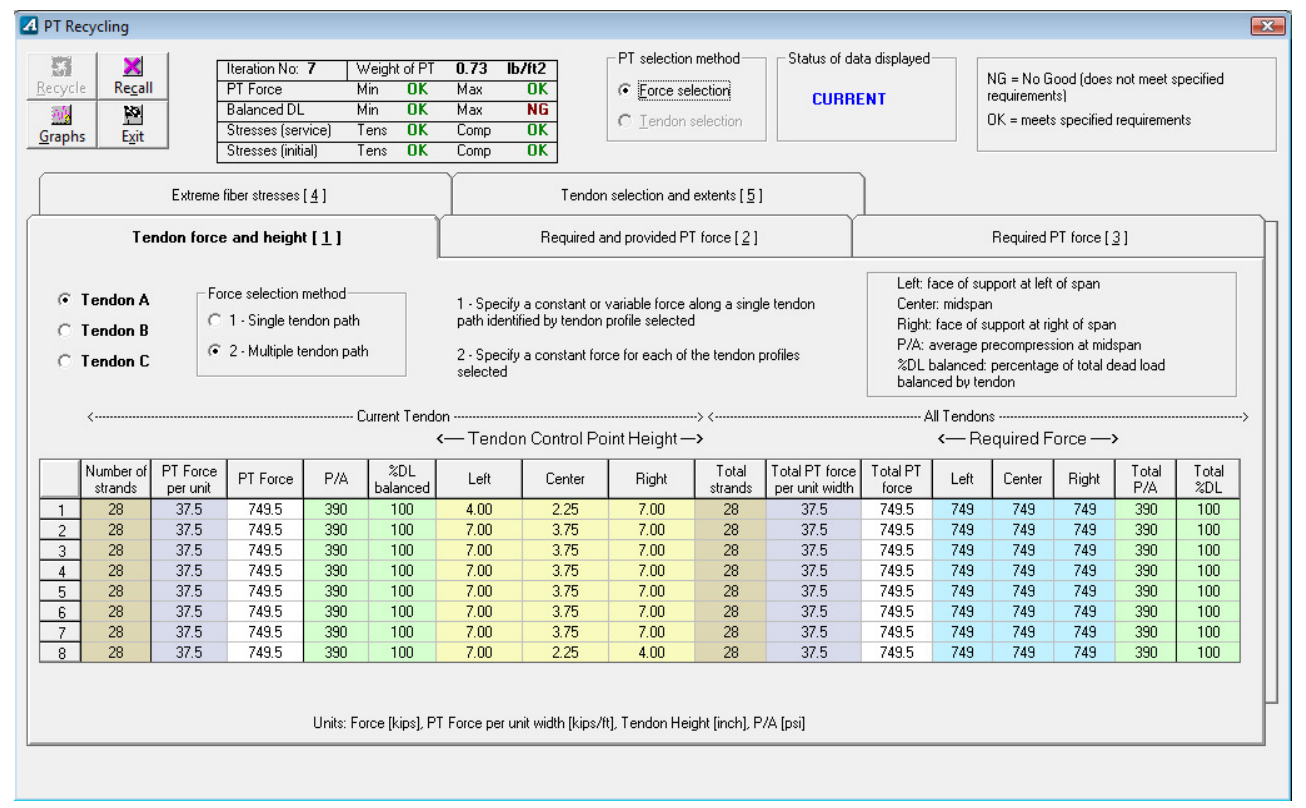

Optimization of Two-Way Post-Tensioned Concrete Floor Systems 
Appendix xcvii

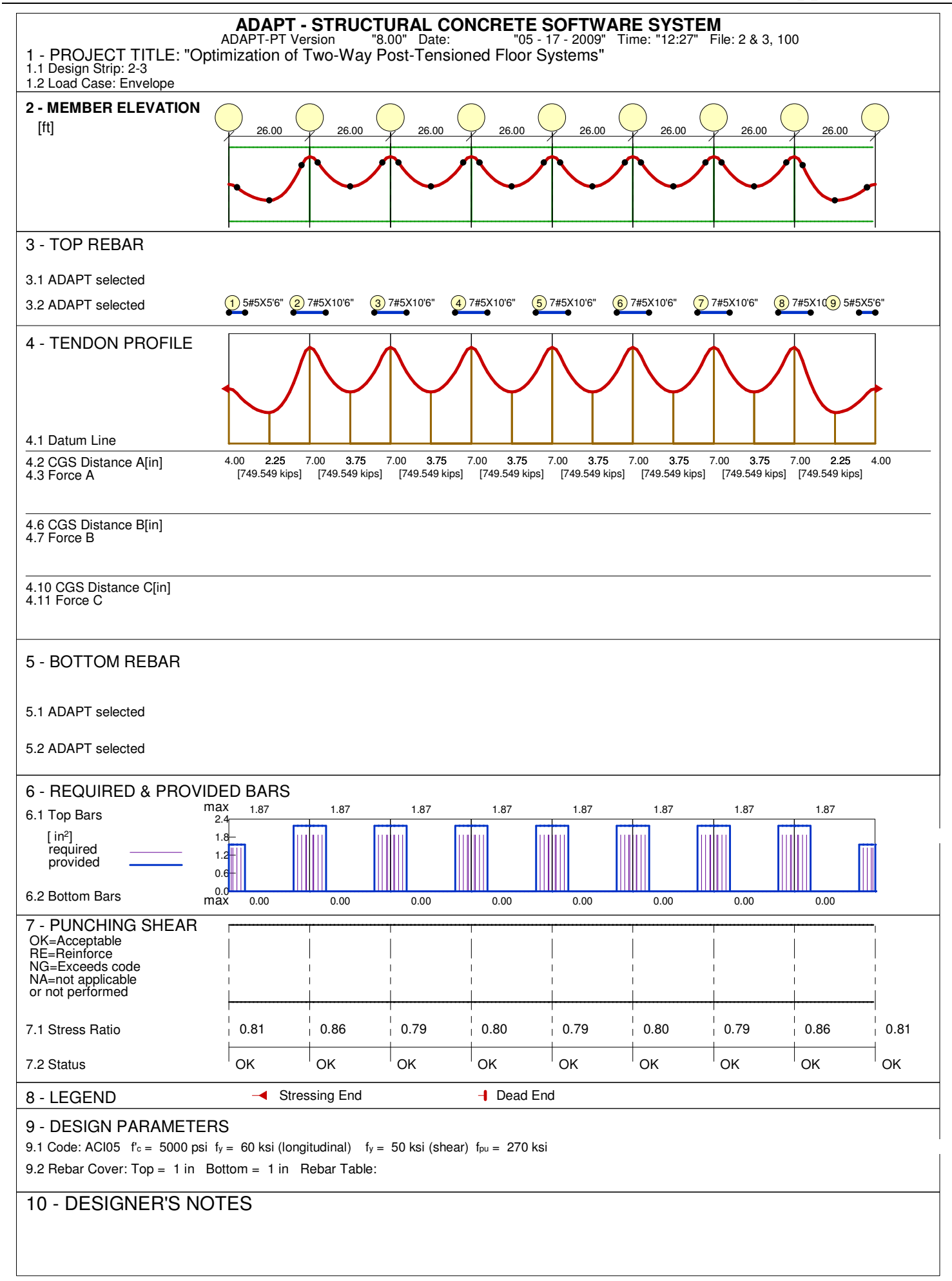

Optimization of Two-Way Post-Tensioned Concrete Floor Systems 


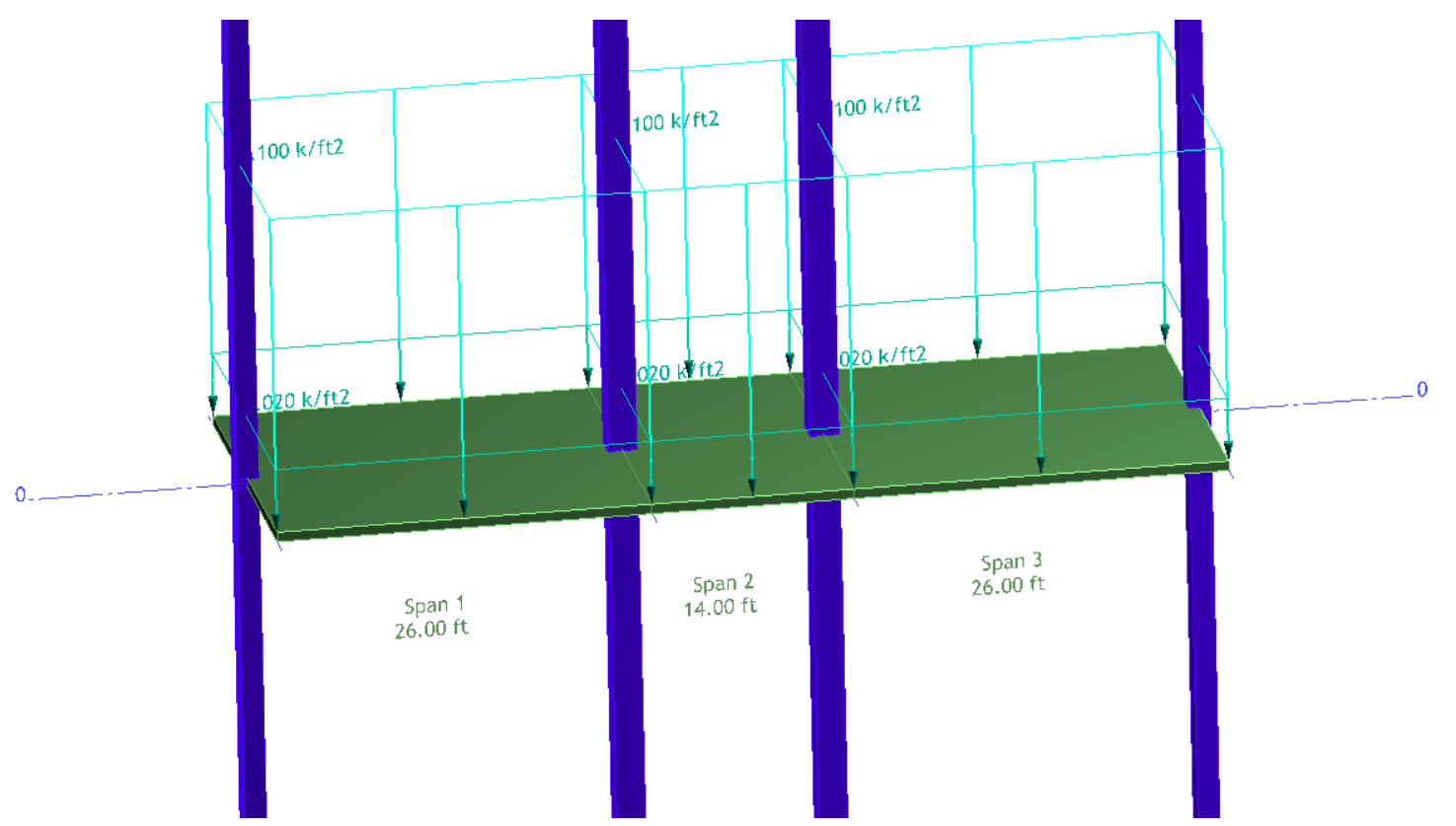

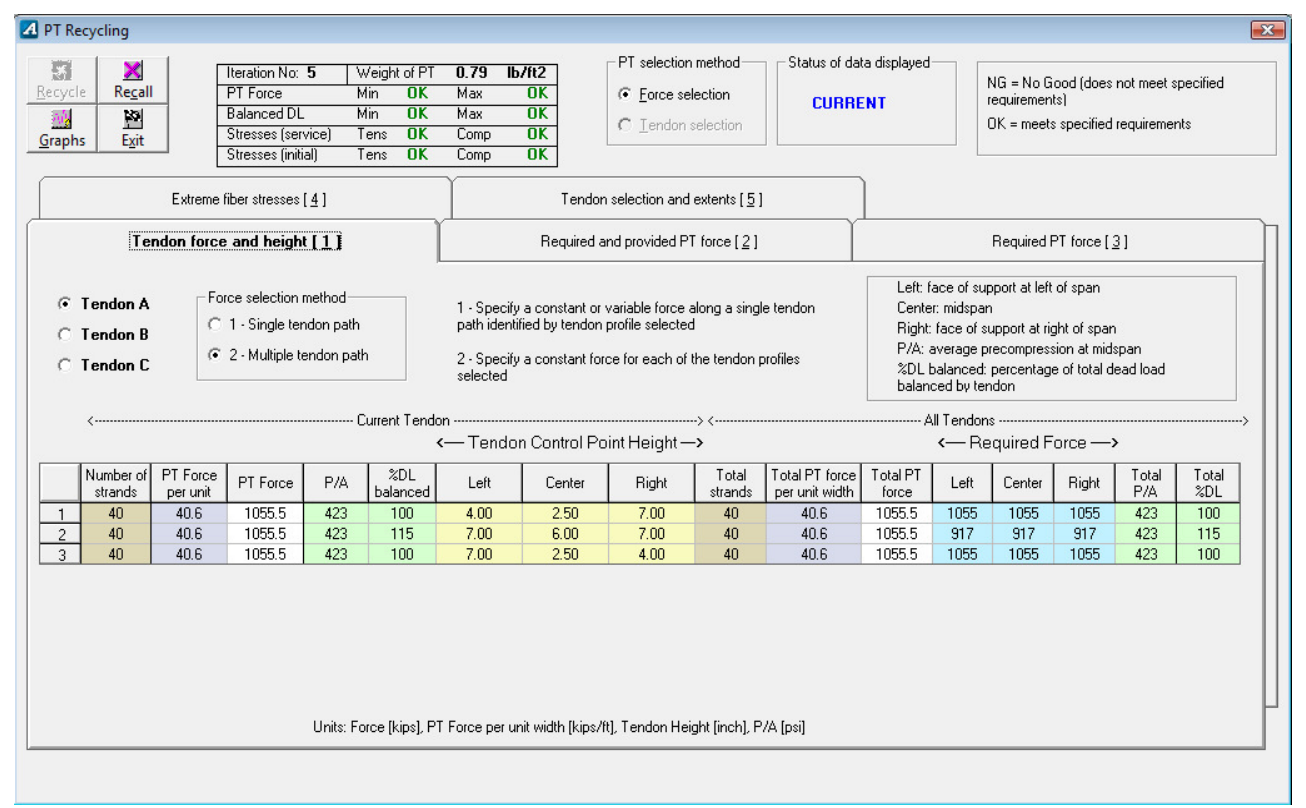


Appendix $\quad$ xcix

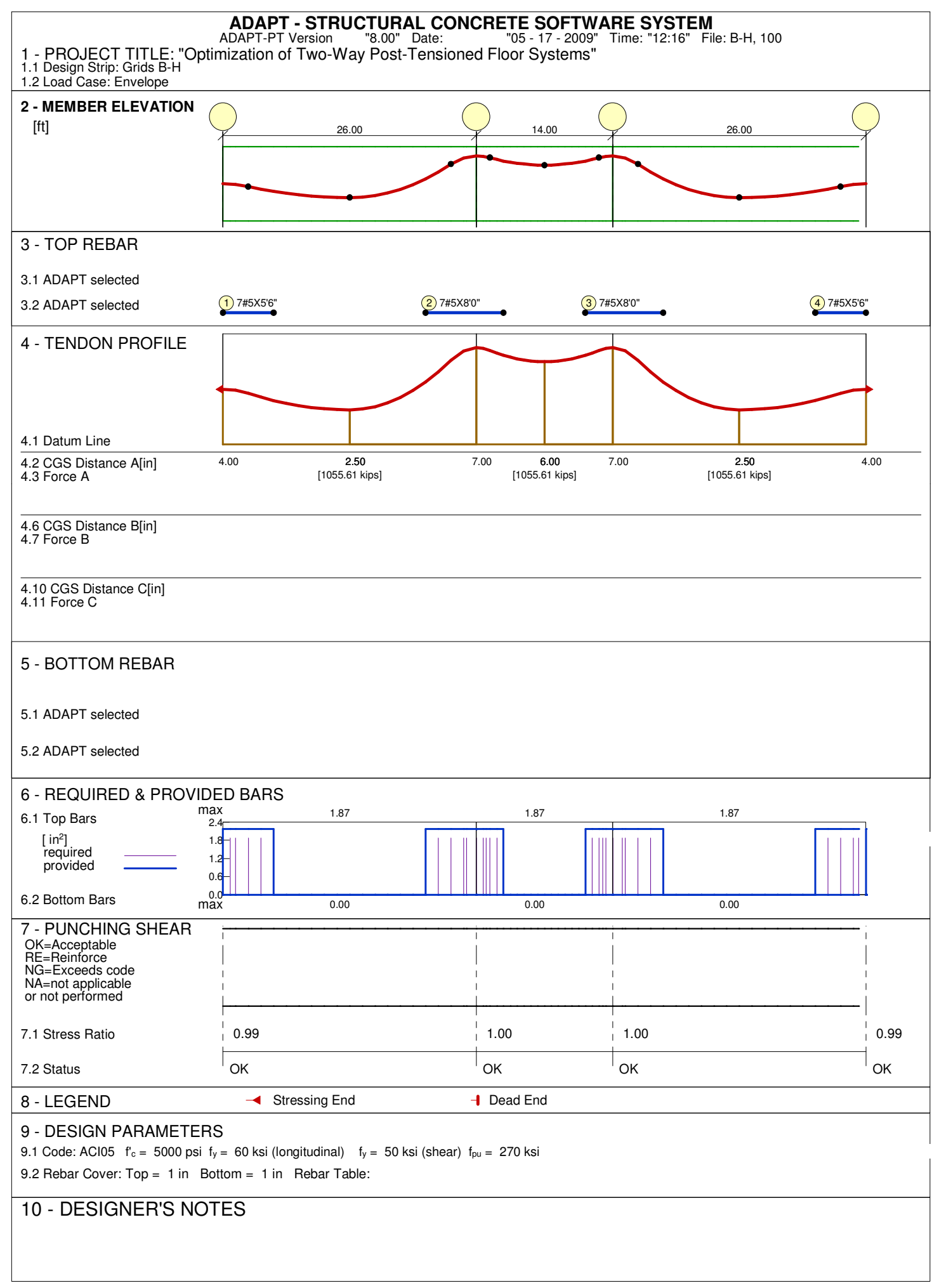




\section{C.3 Slab 2 - Same Tendon Profile as Hand}

\section{C.3.1 Grids $2 \& 3$}

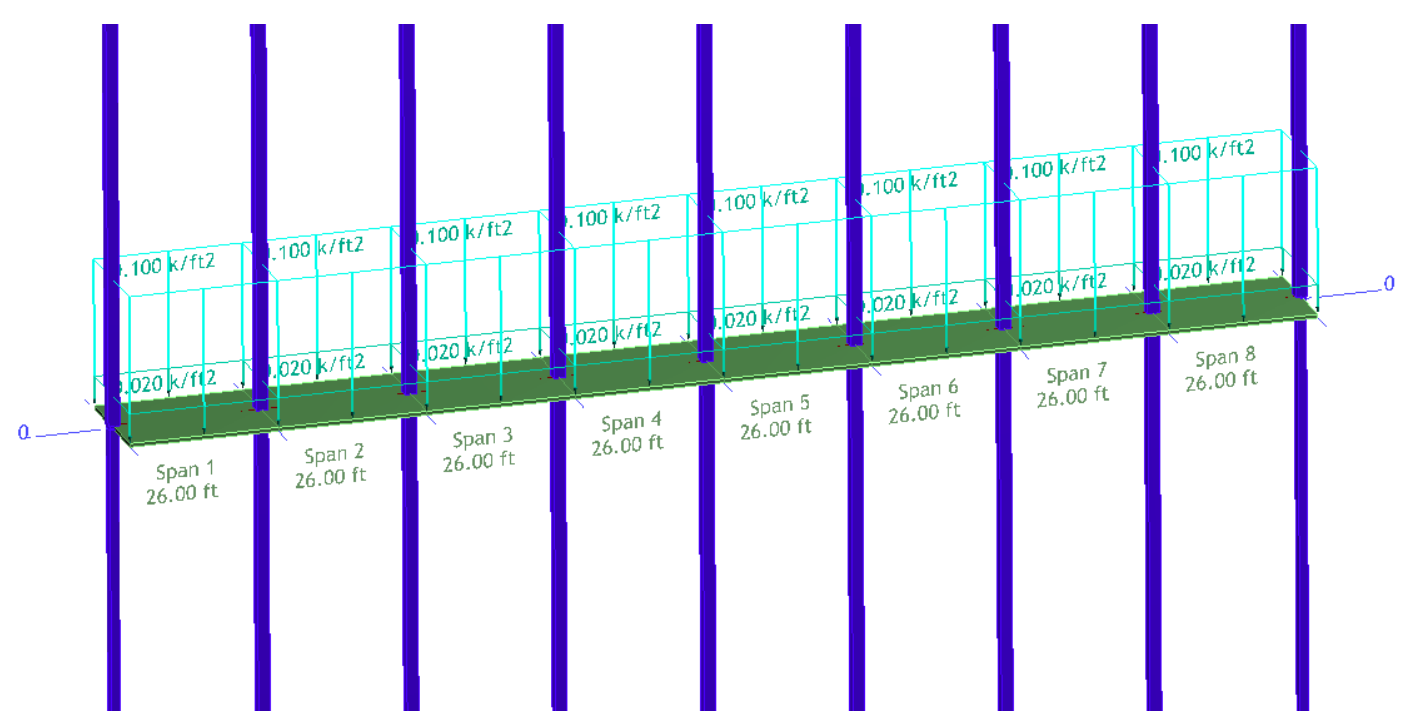

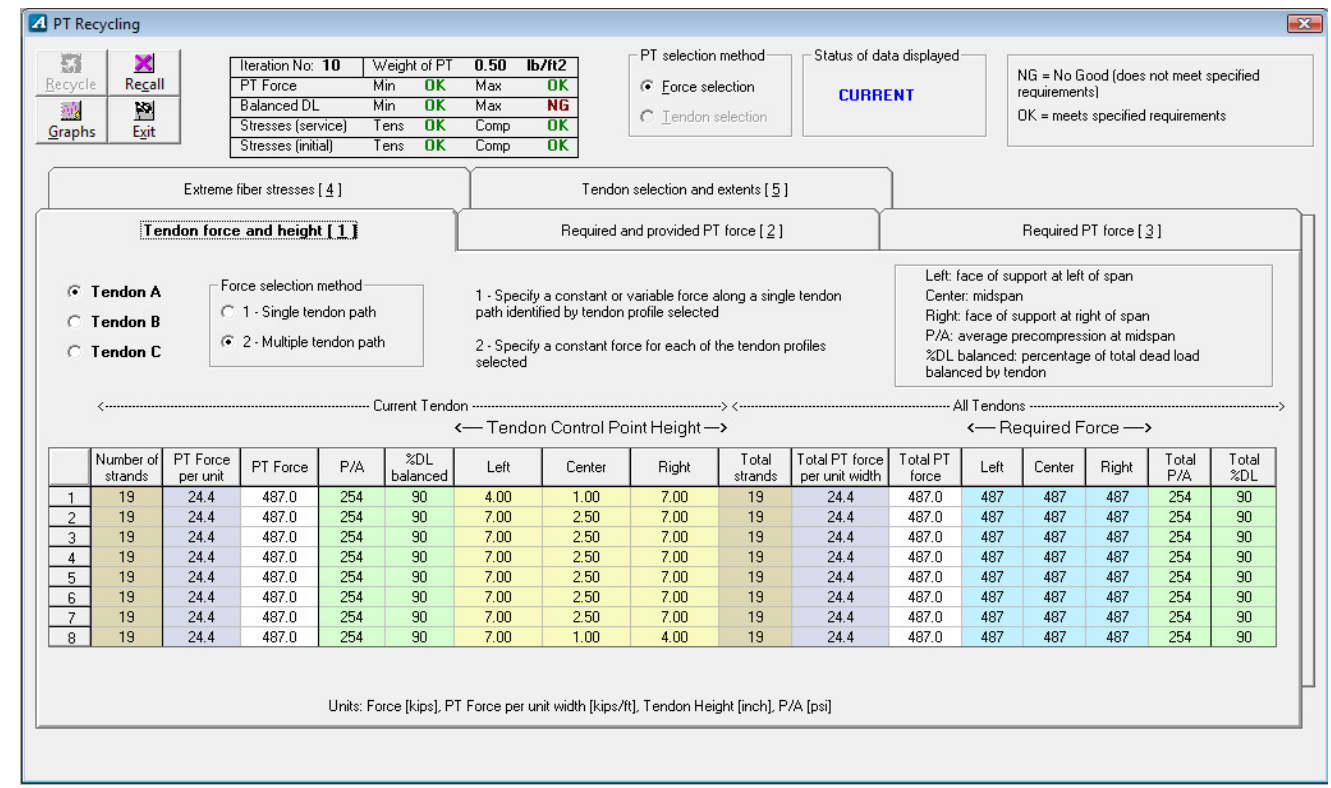


Appendix

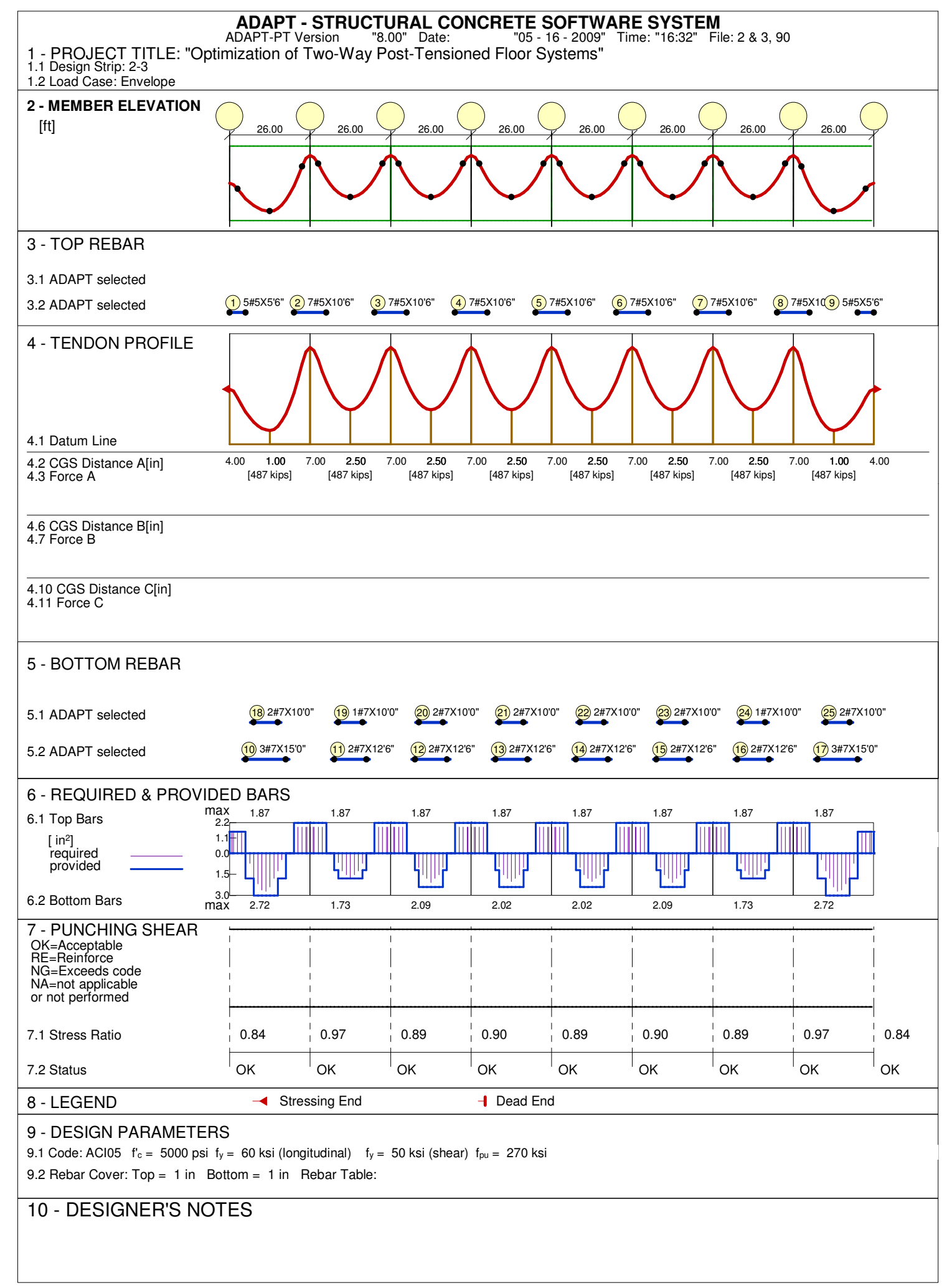




\section{C.3.2 Grids B-H}

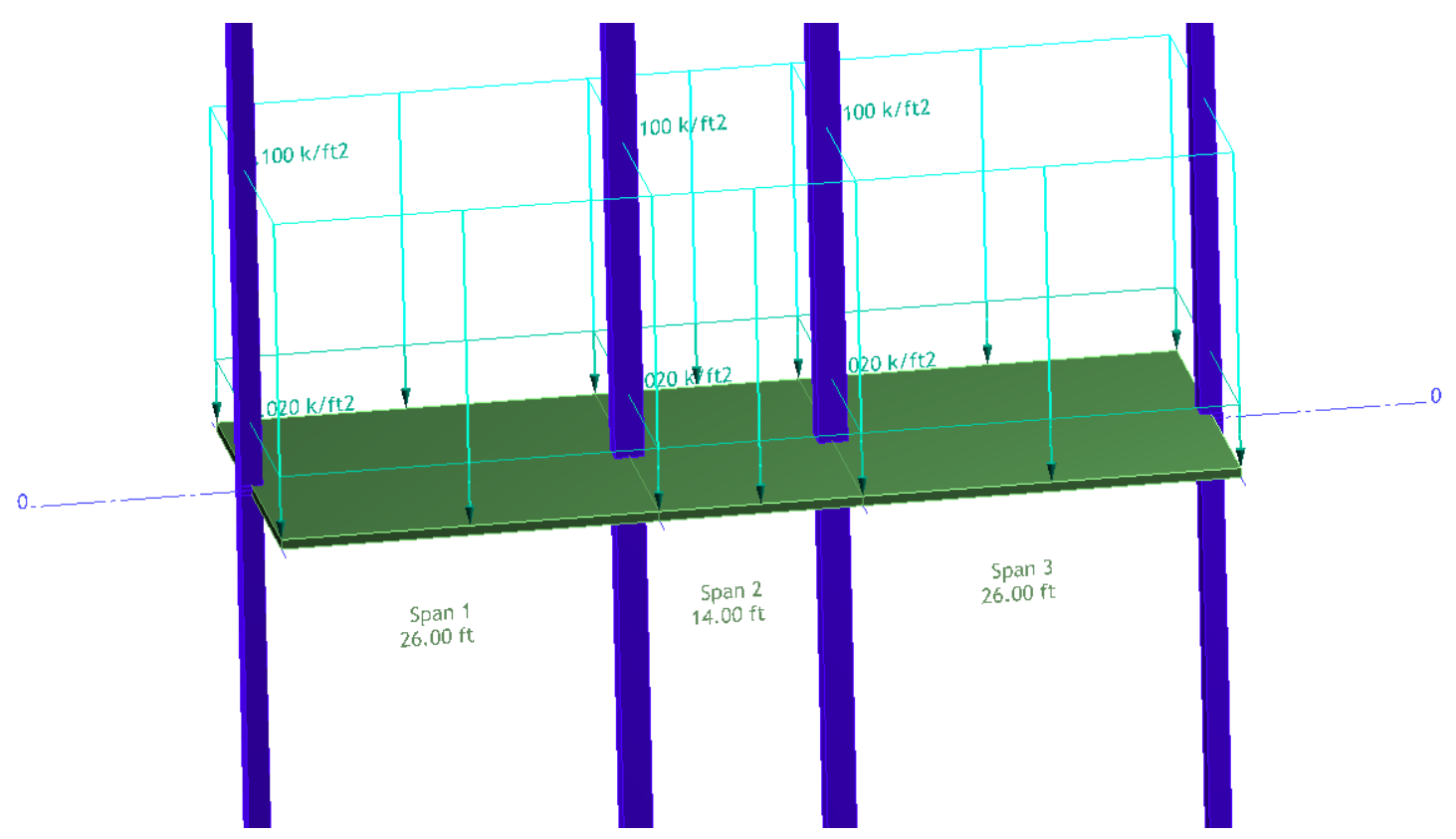

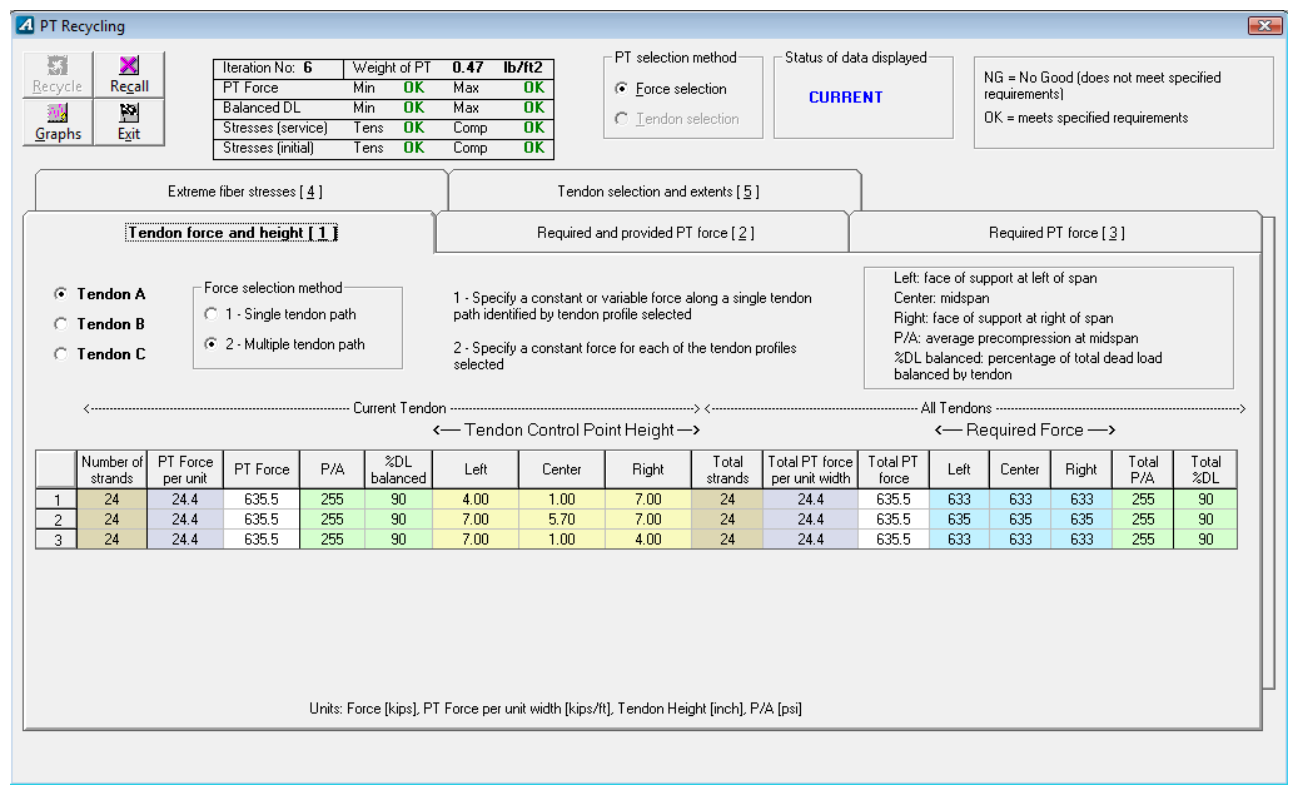


Appendix ciii

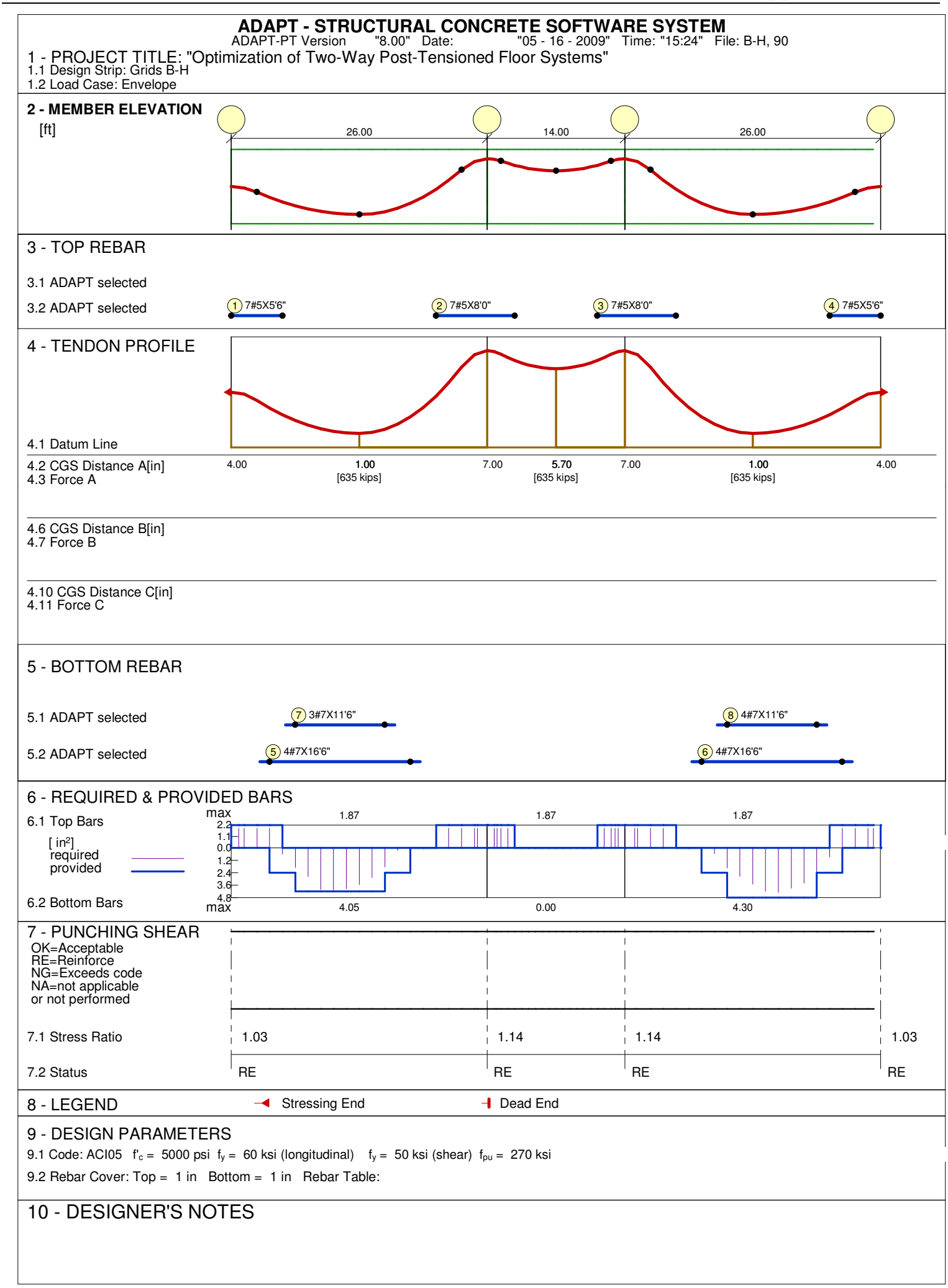


C.4 Slab 2 - ADAPT Default Tendon Profile

\section{C.4.1 Grids $2 \& 3$}

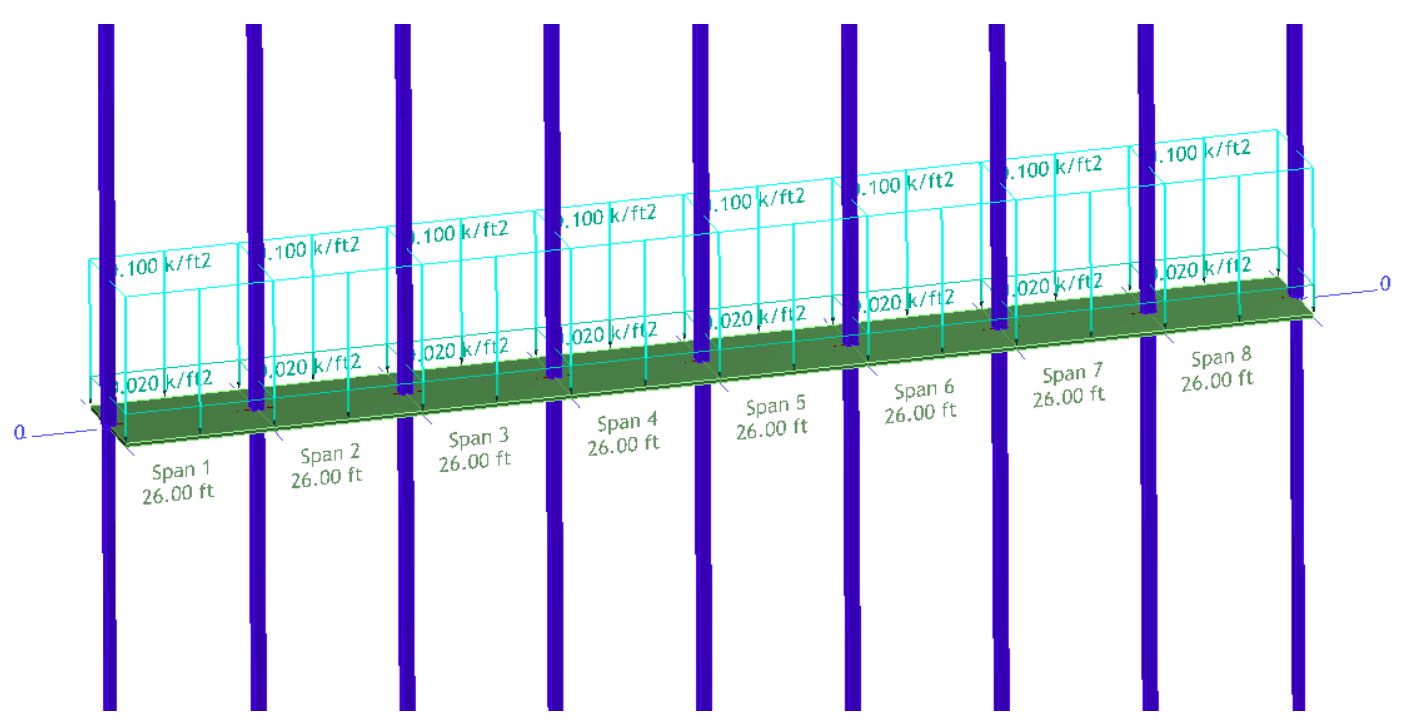

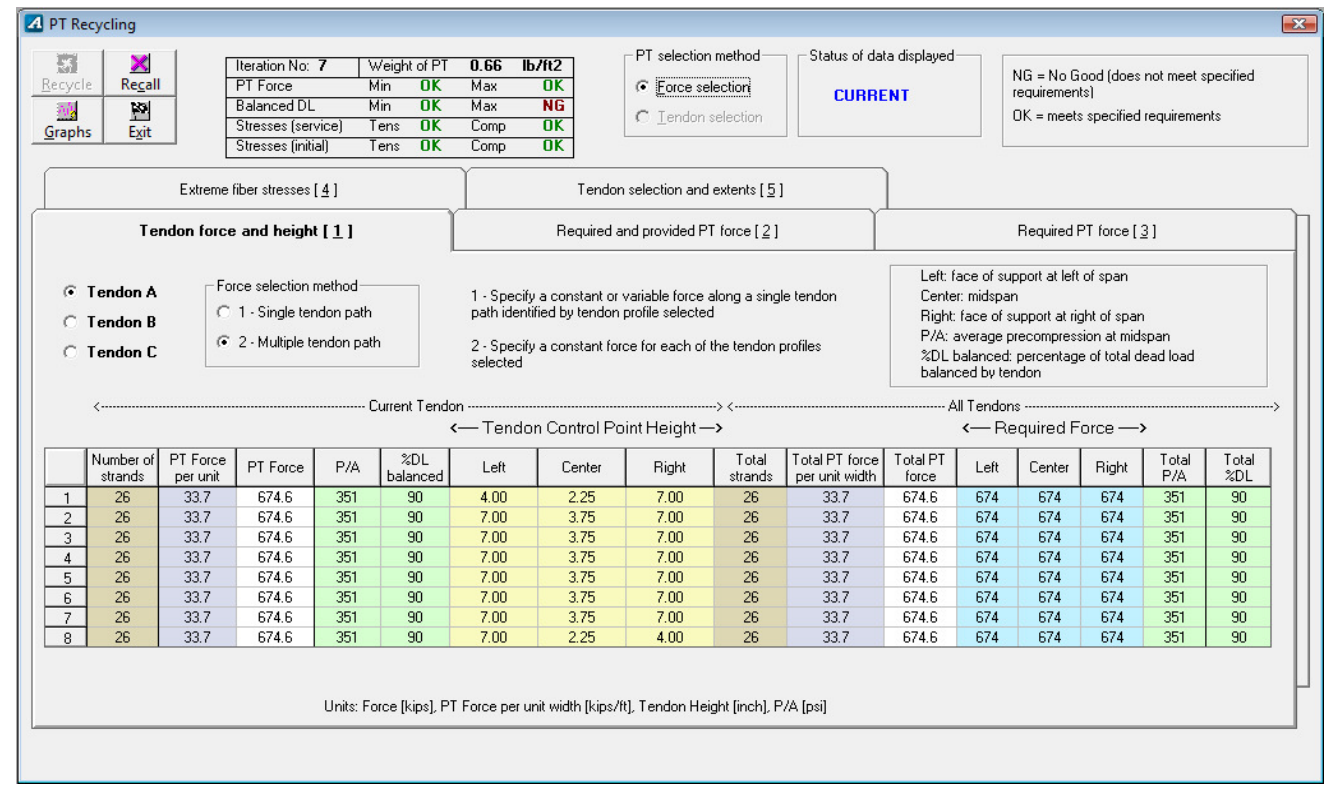


Appendix cV

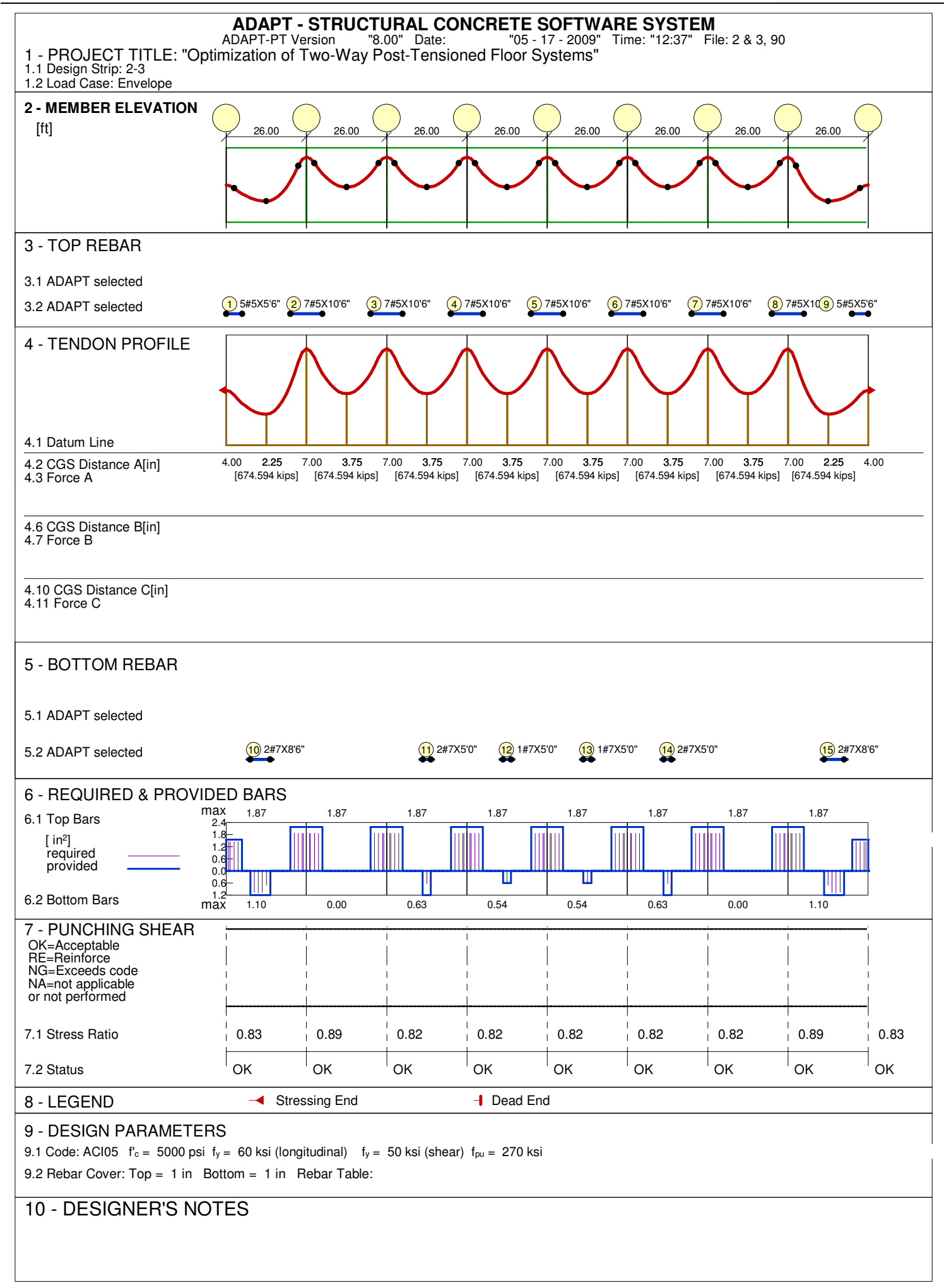




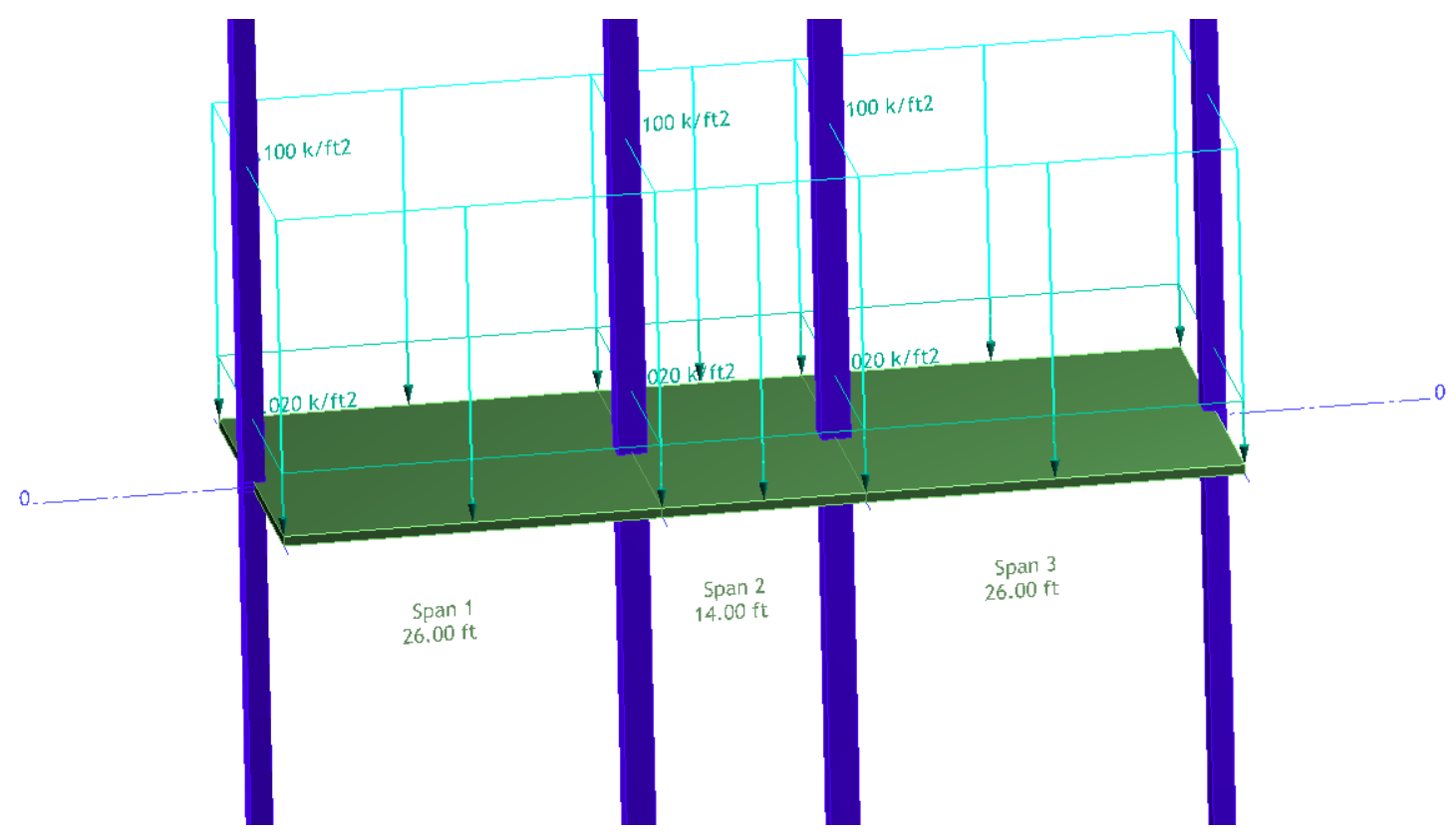

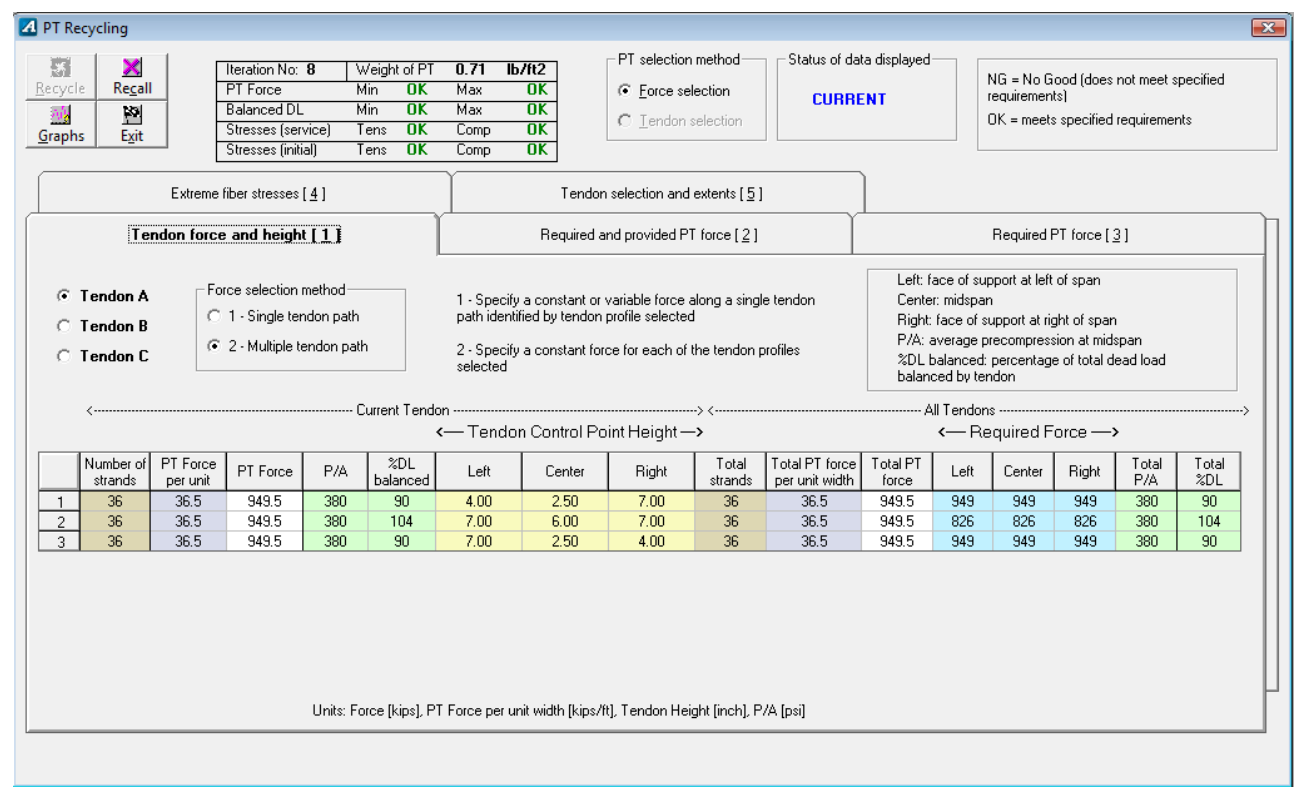


Appendix cvii

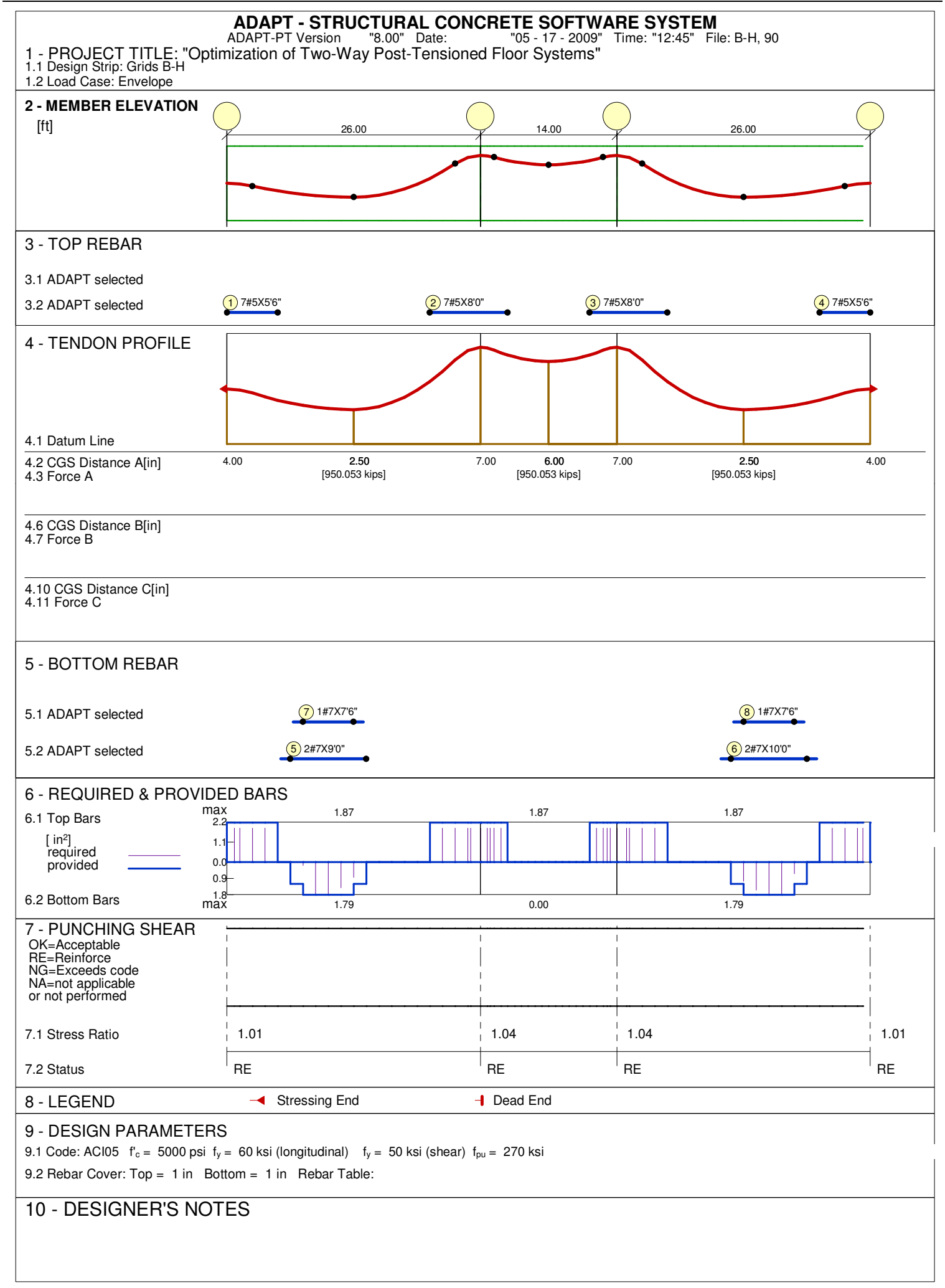




\section{C.5 Slab 3 - Same Tendon Profile as Hand}

\section{C.5.1 Grids $1 \& 4$}

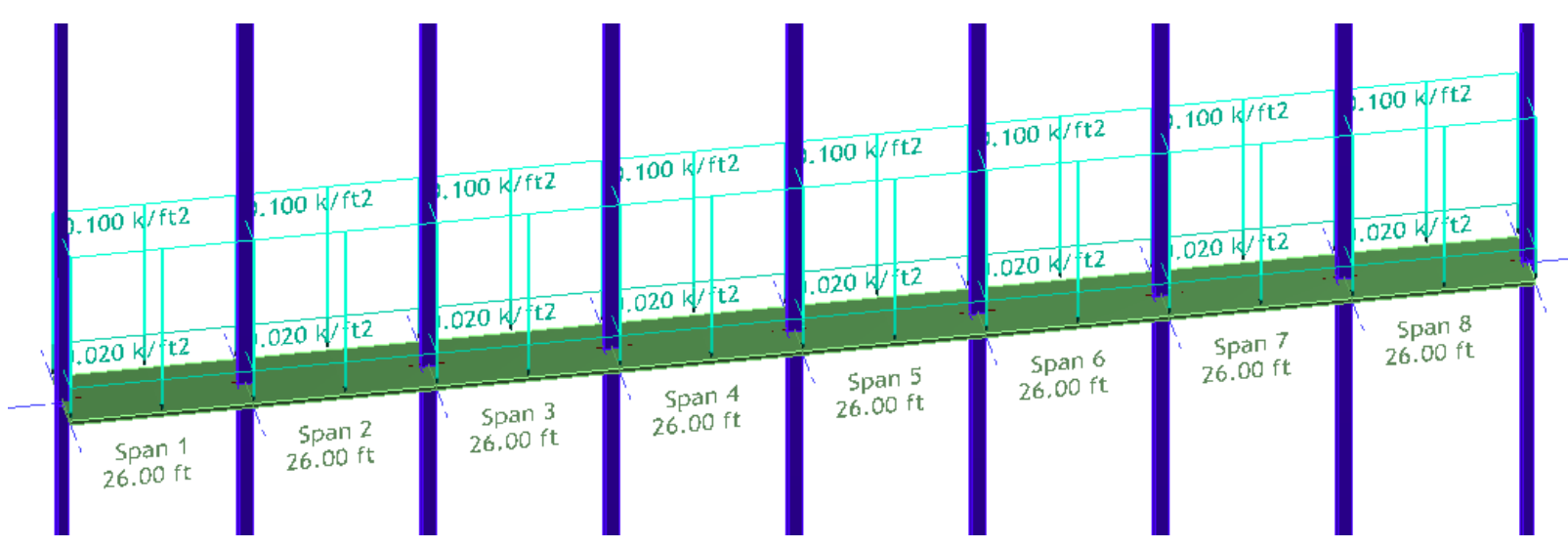

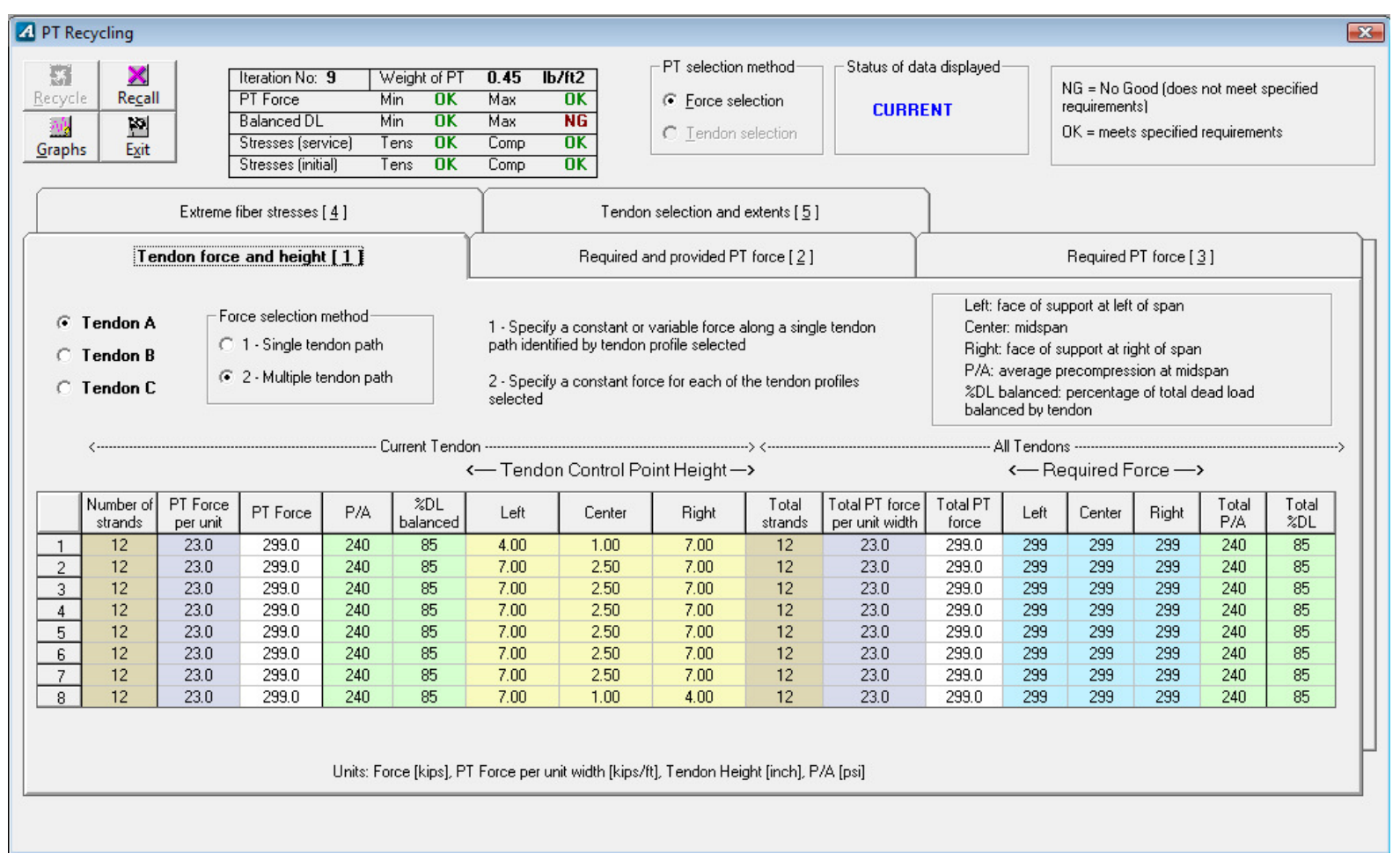


Appendix cix

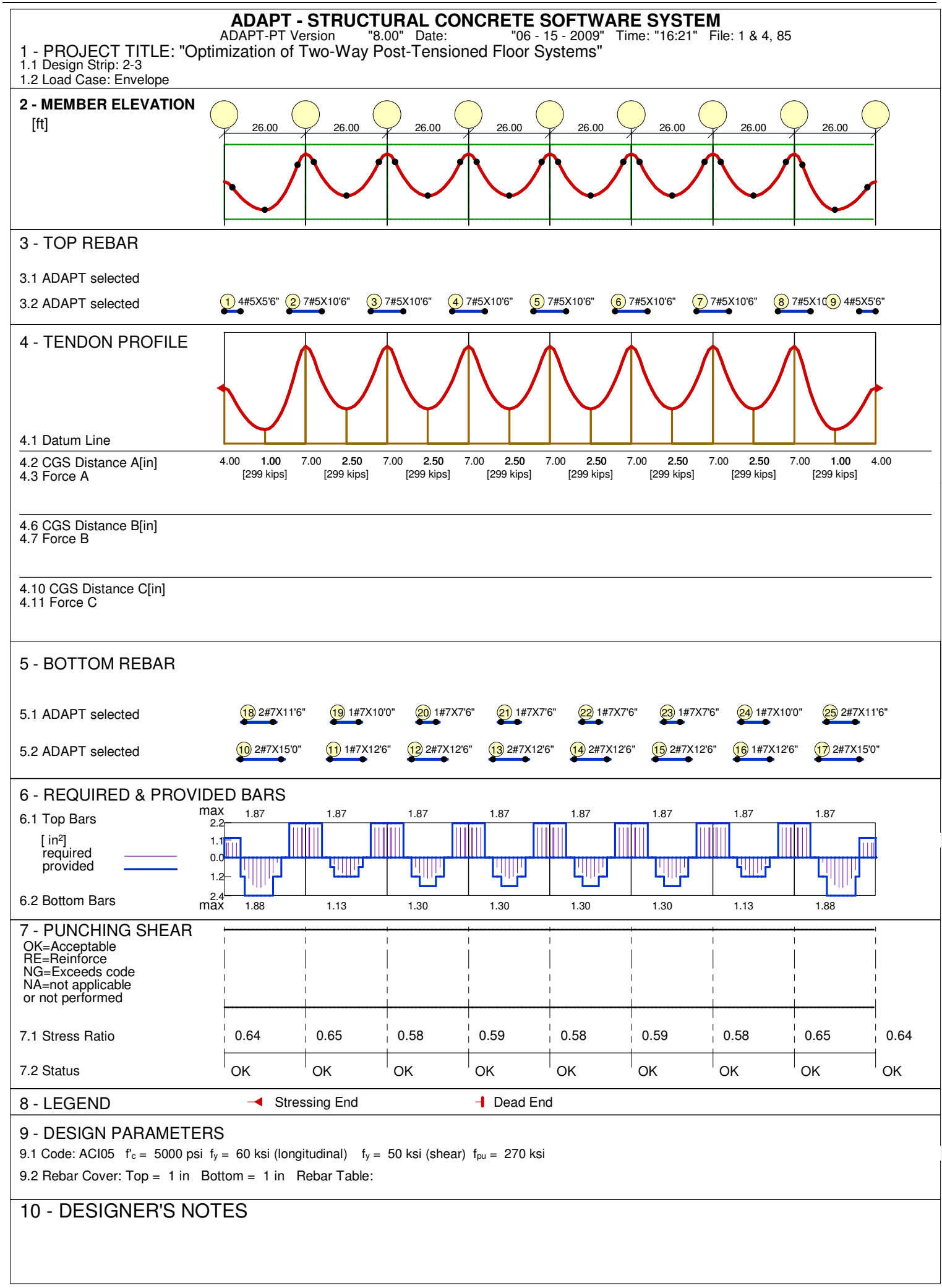




\section{C.5.2 Grids $2 \& 3$}

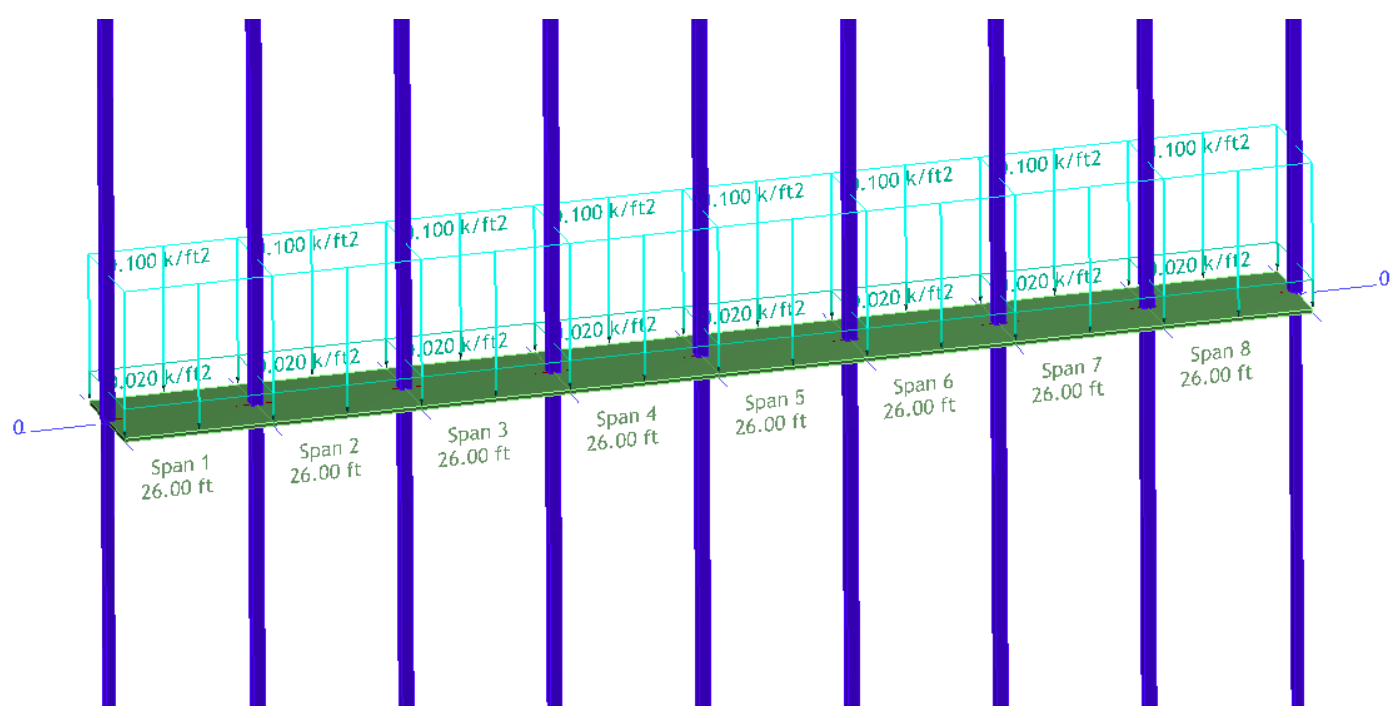

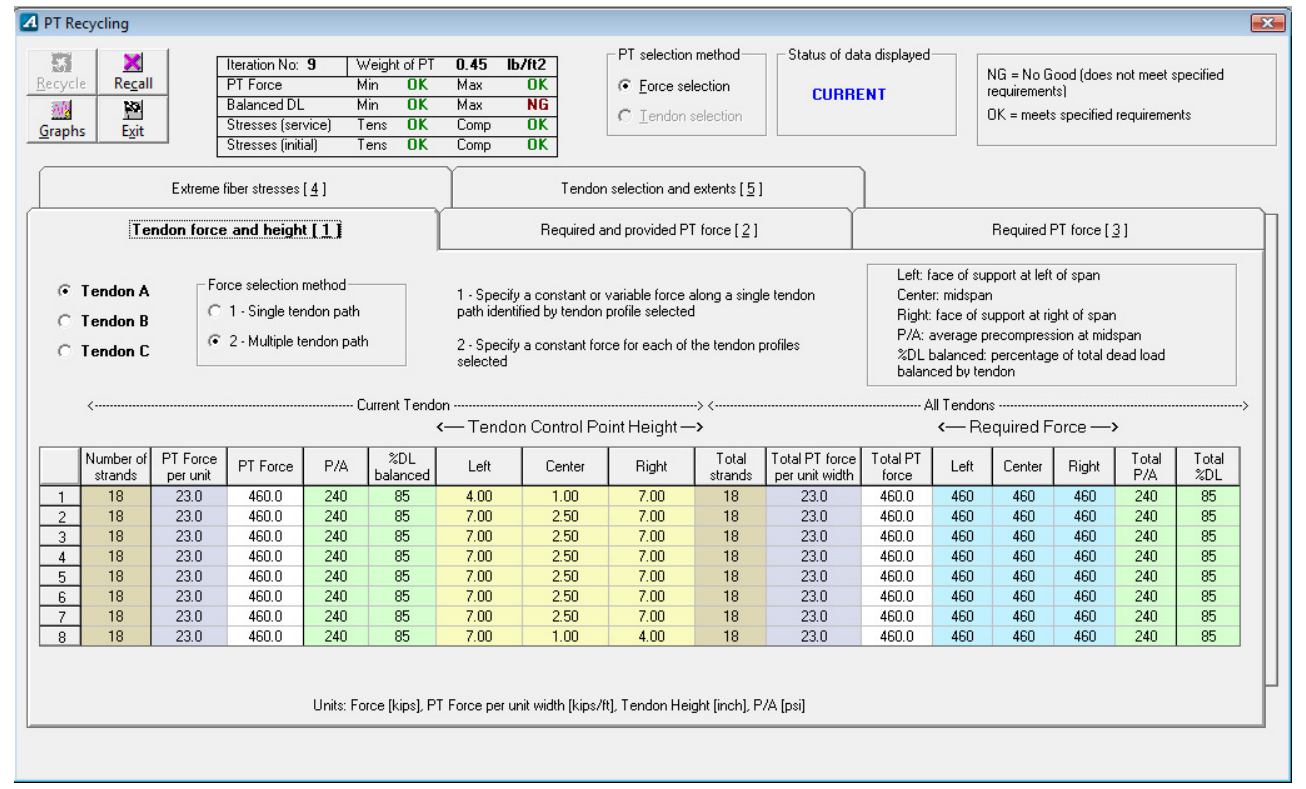


Appendix cxi

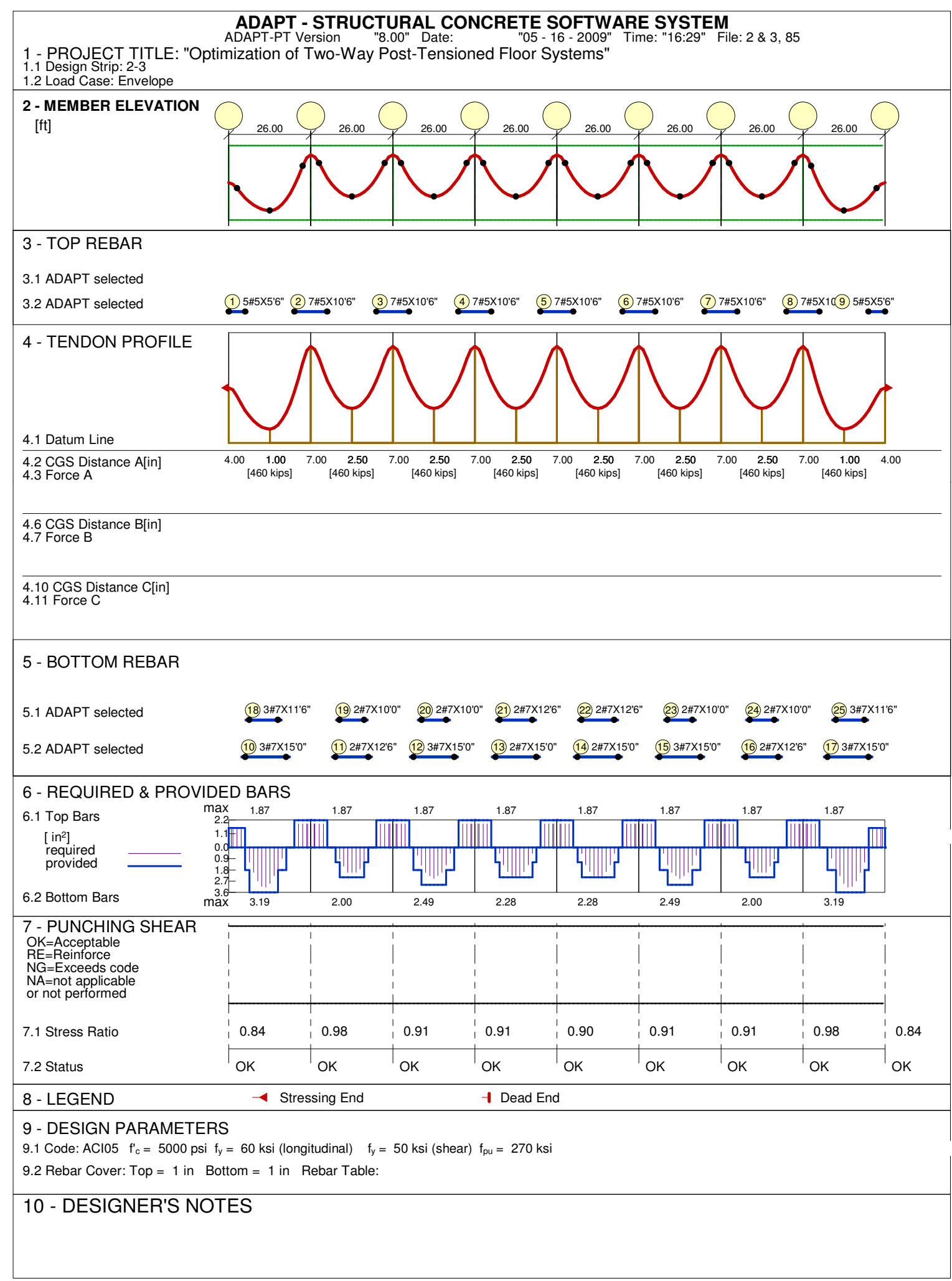




\section{C.5.3 Grids A \& I}

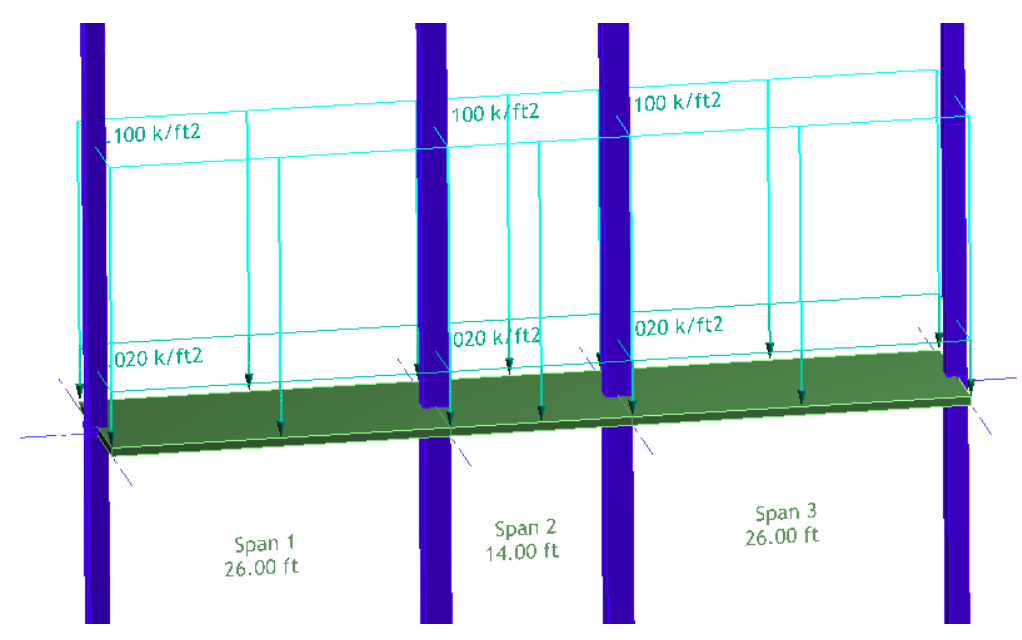

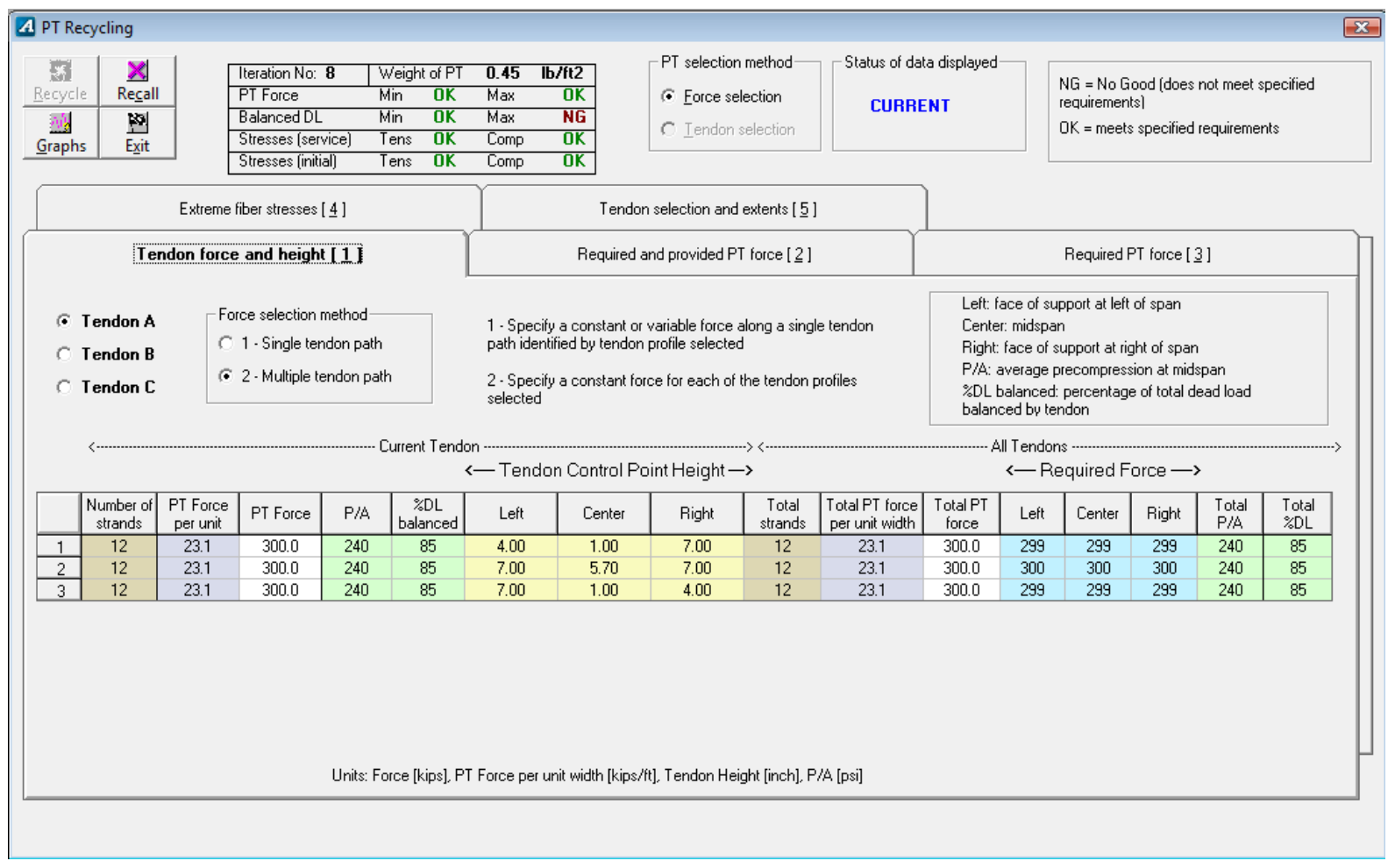

Optimization of Two-Way Post-Tensioned Concrete Floor Systems 
Appendix

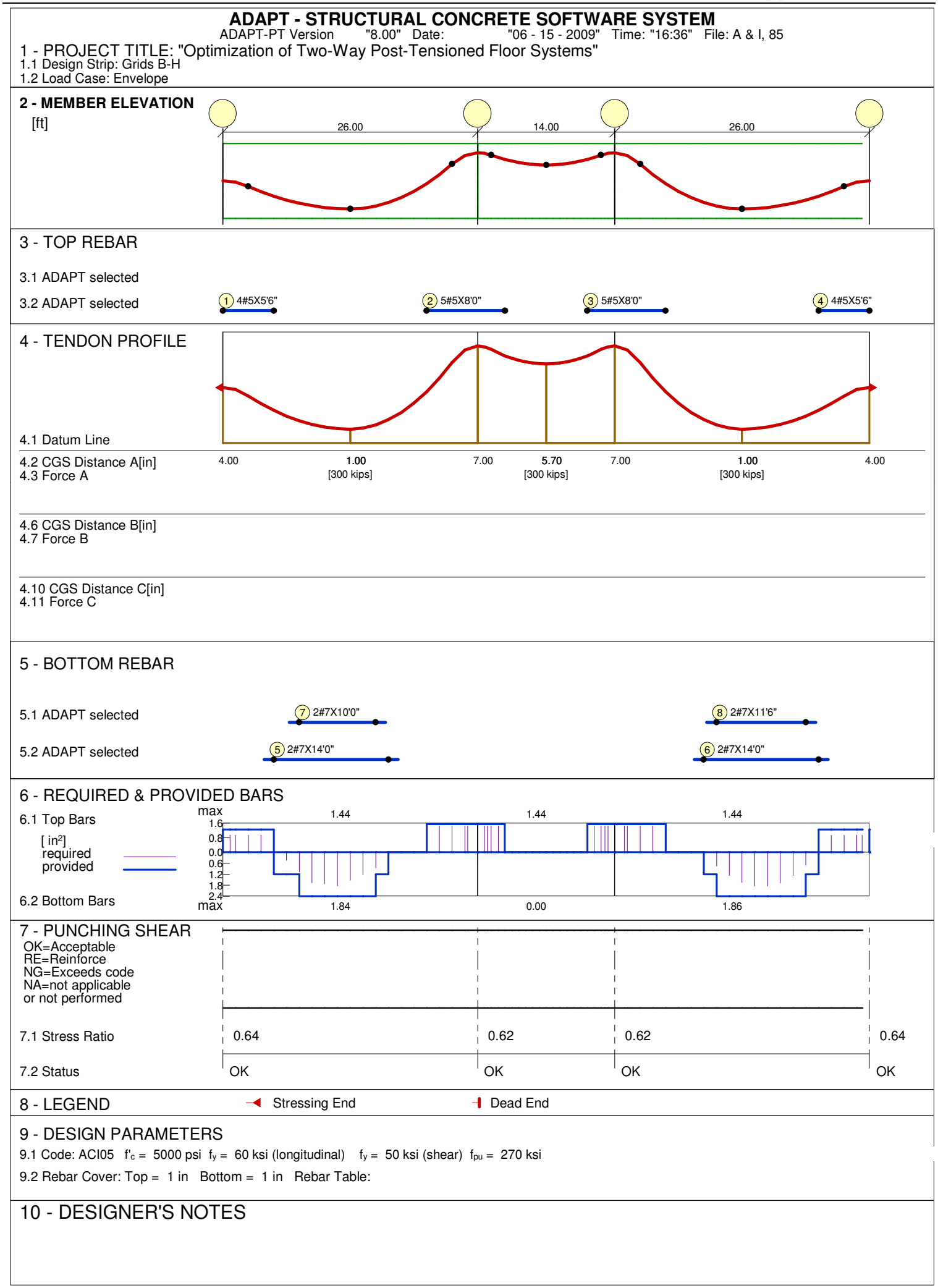




\section{C.5.4 Grids B-H}

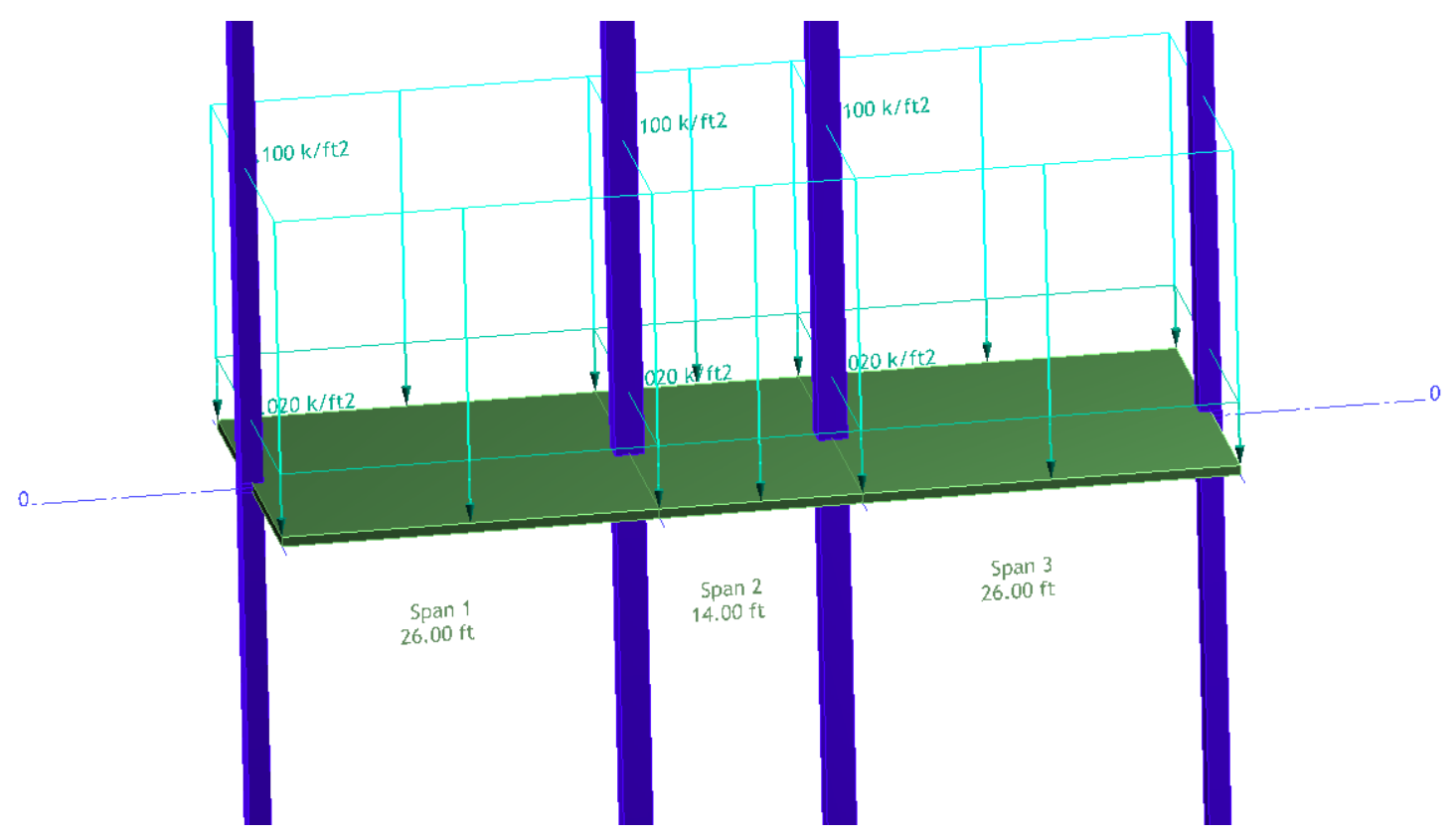

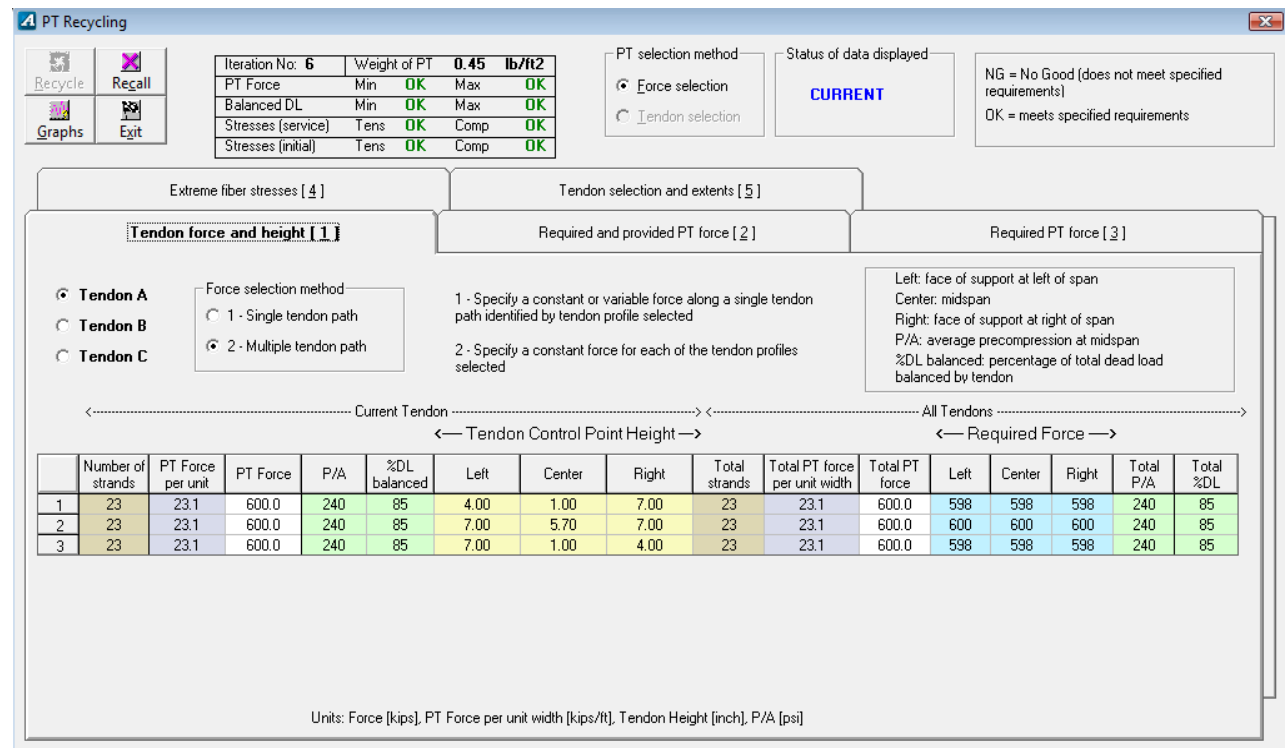




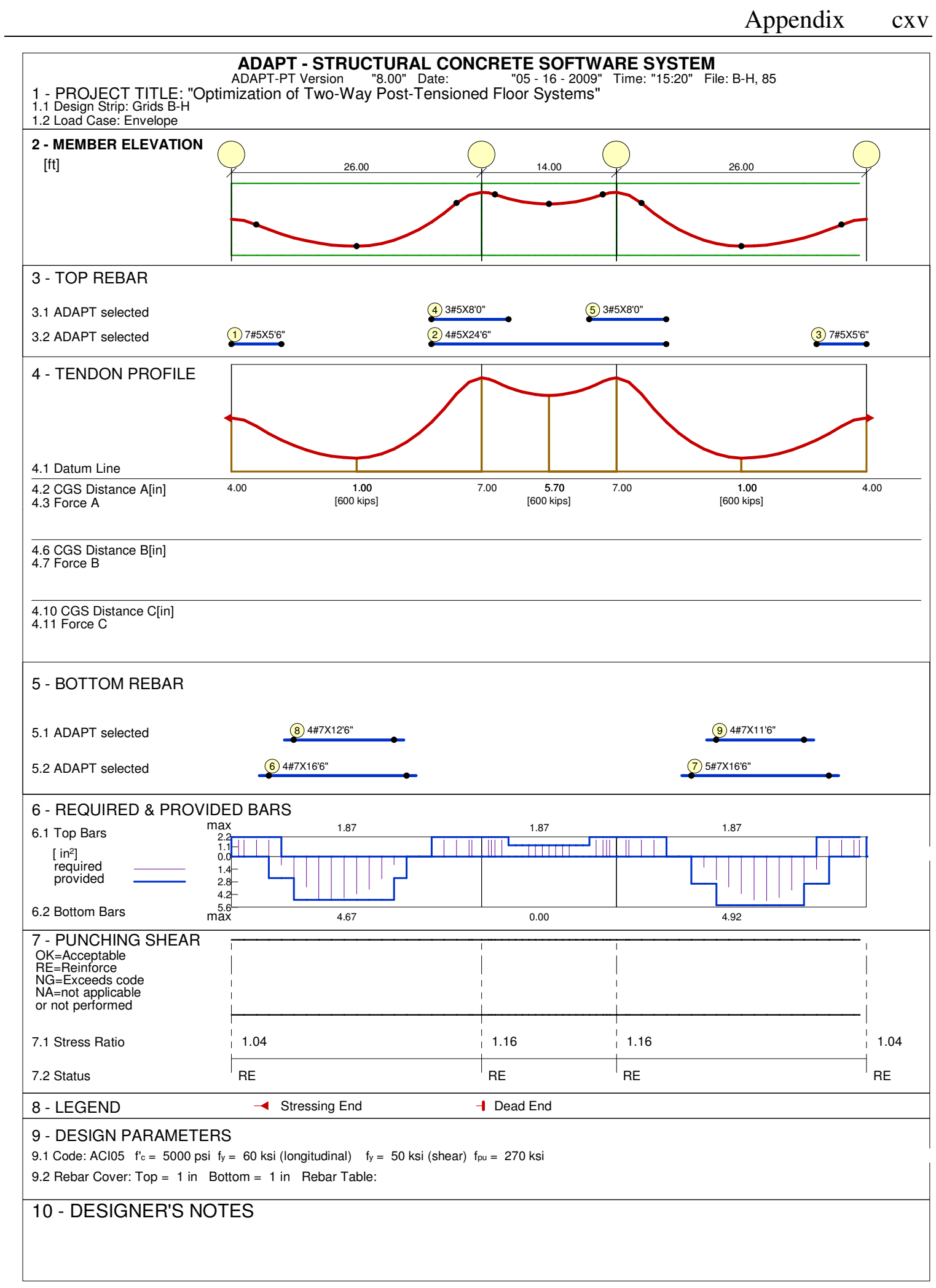


C.6 Slab 3 - ADAPT Default Tendon Profile

\section{C.6.1 Grids $2 \& 3$}

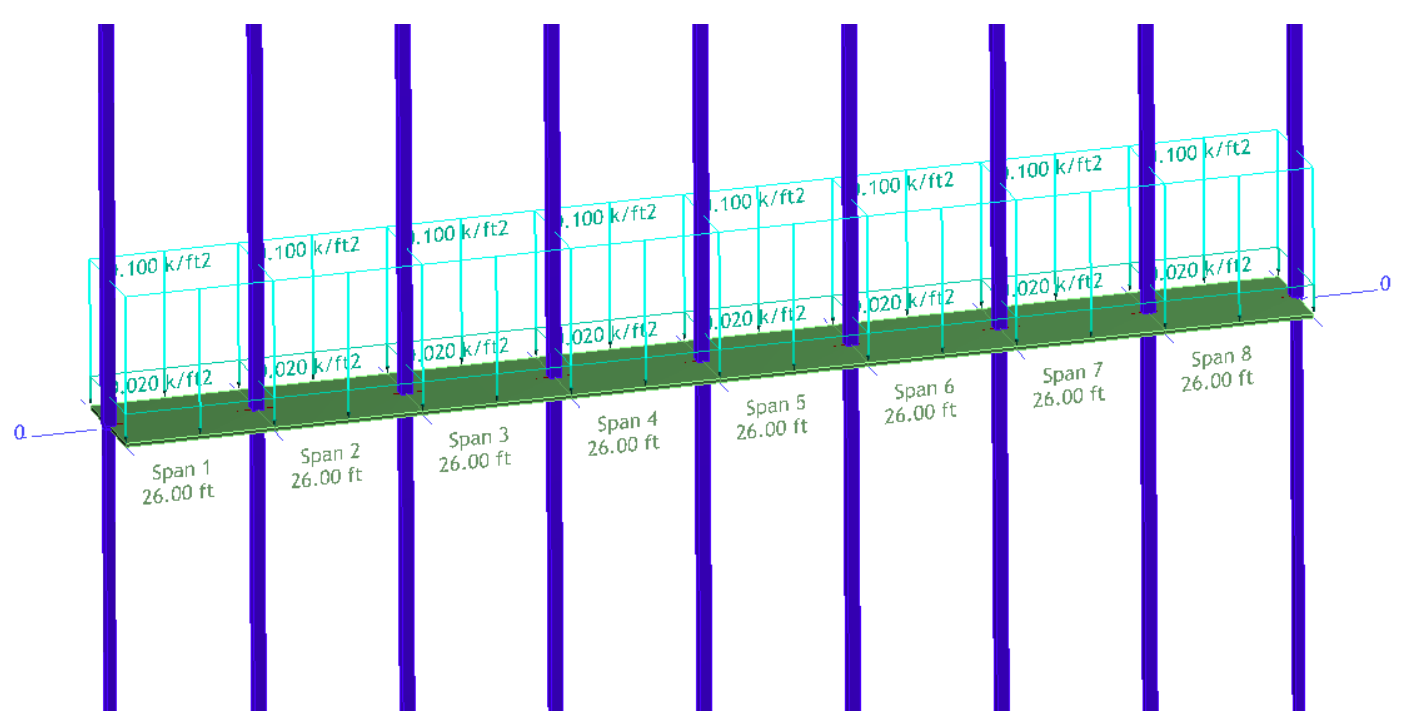

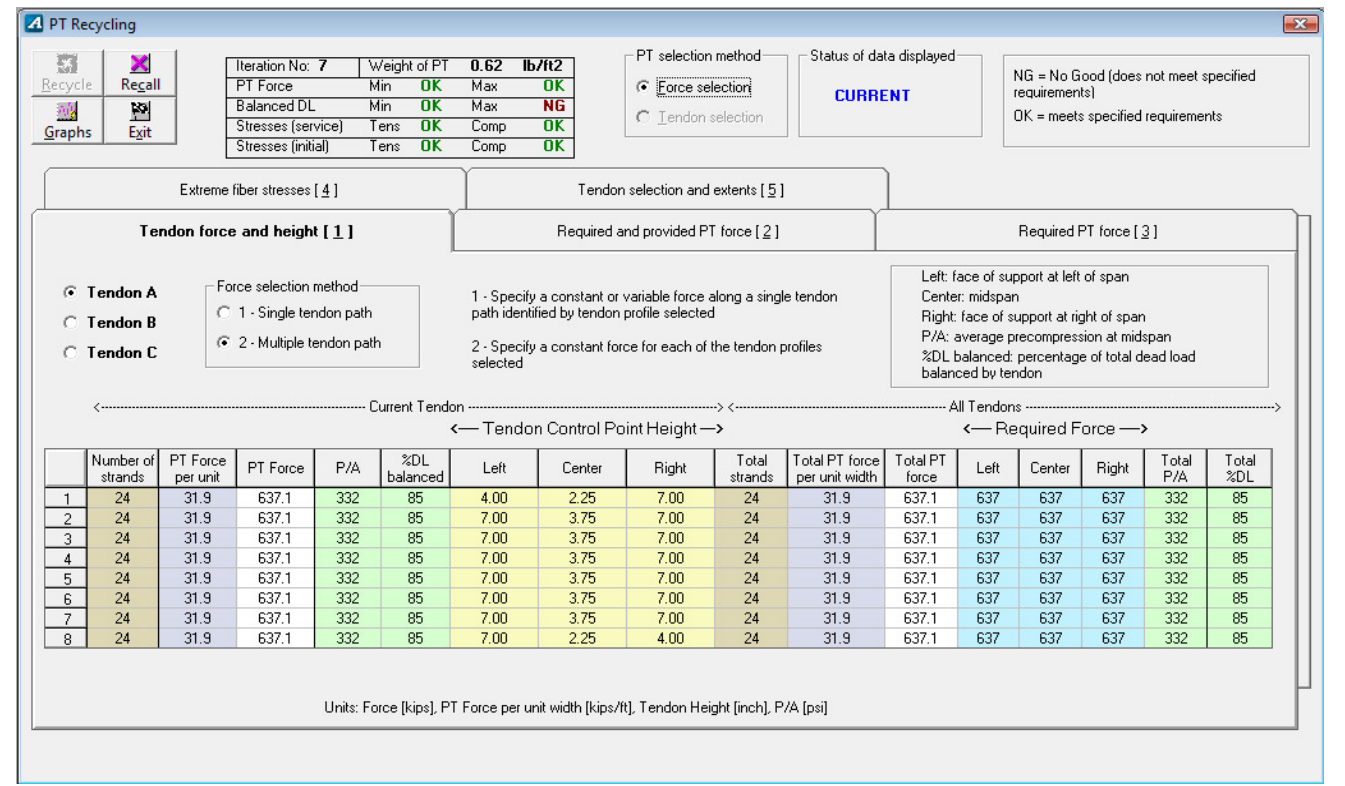


Appendix cxvii

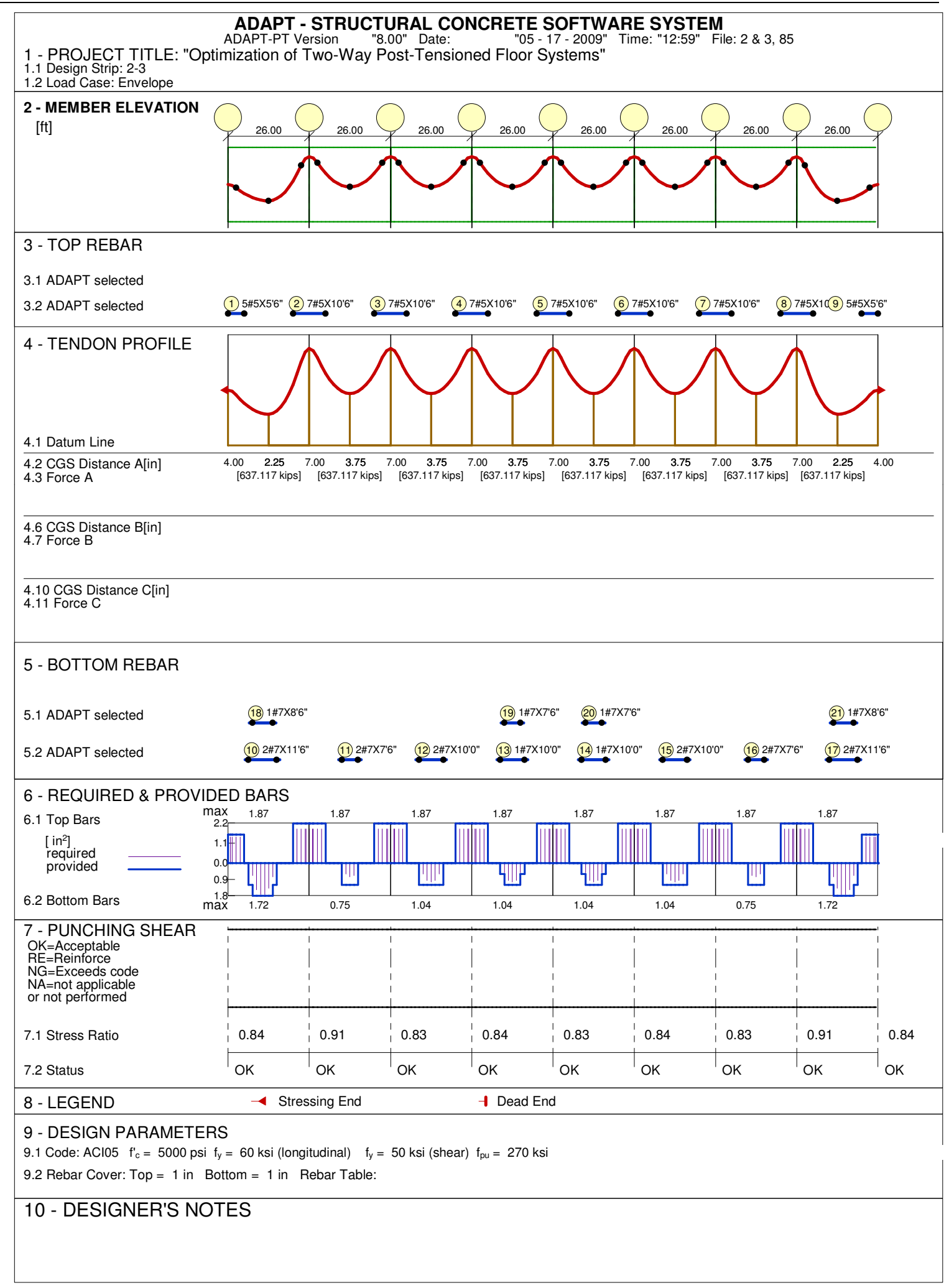




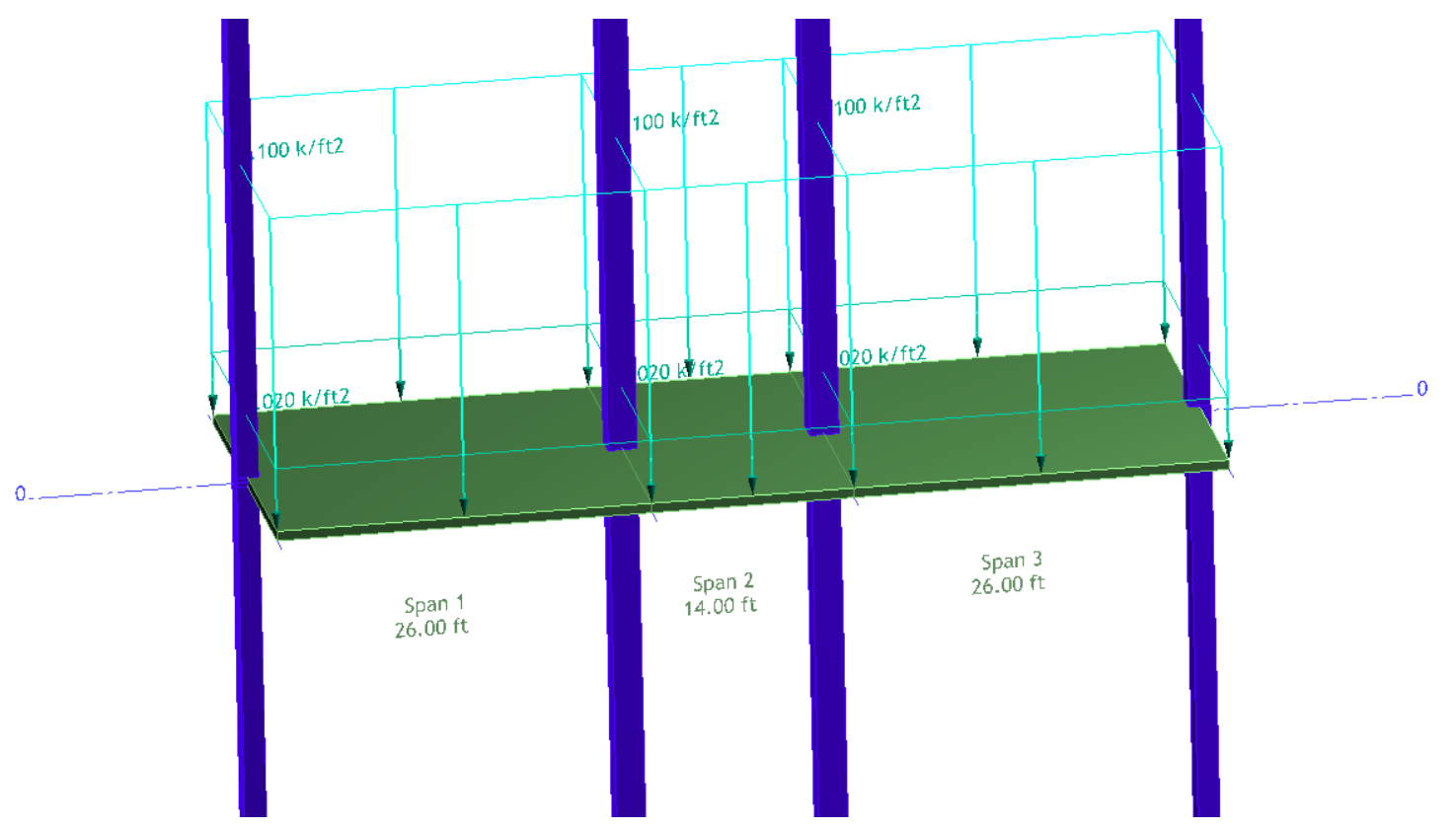

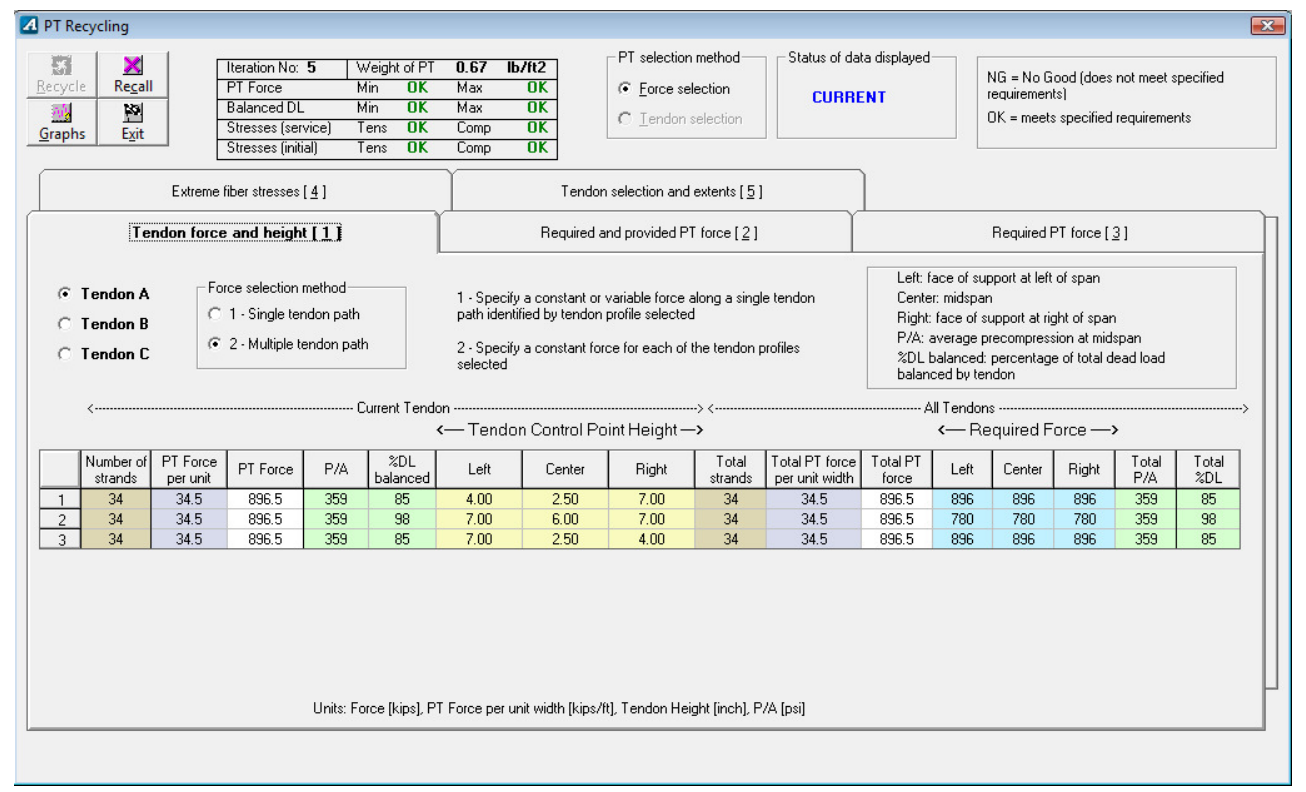


Appendix cxix

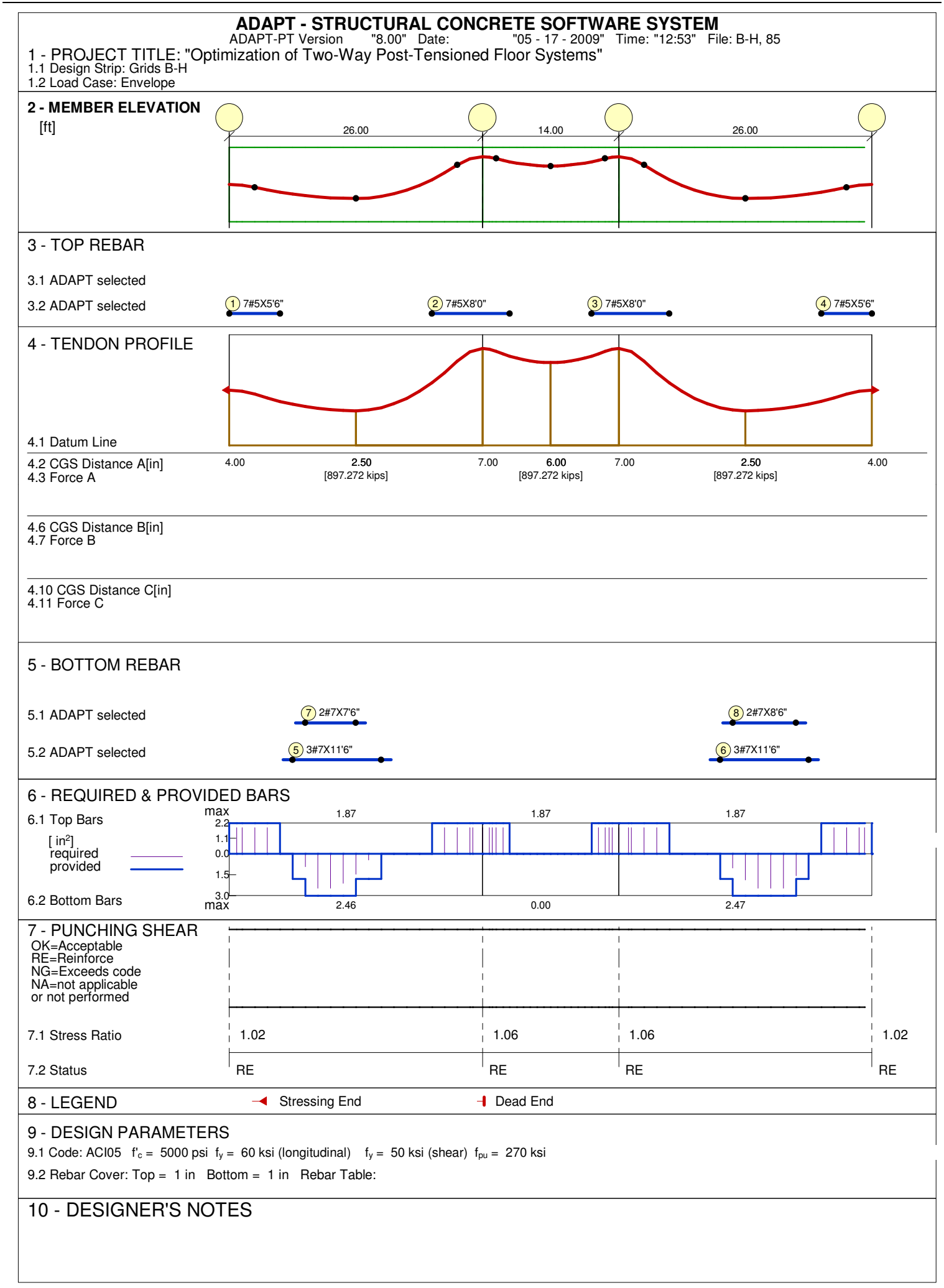




\section{C.7 Slab 4 - Same Tendon Profile as Hand}

\section{C.7.1 Grids $2 \& 3$}

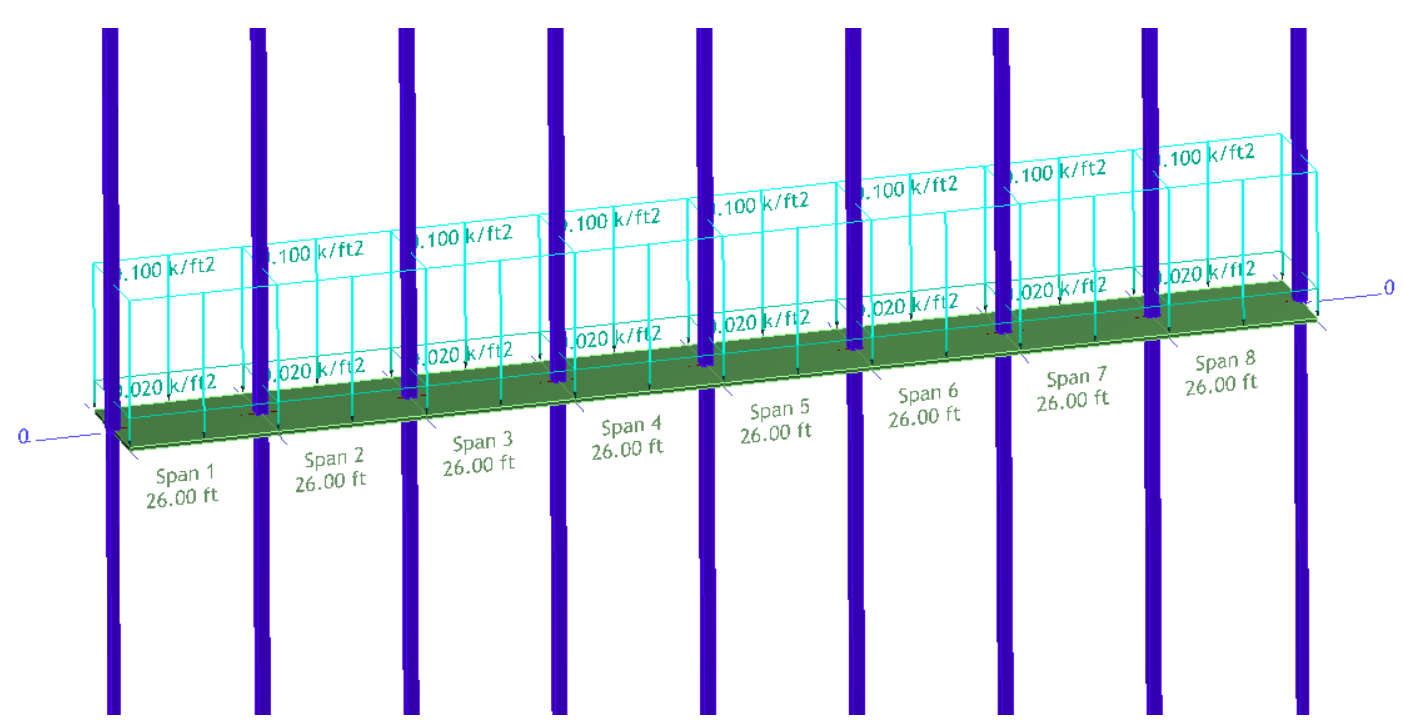

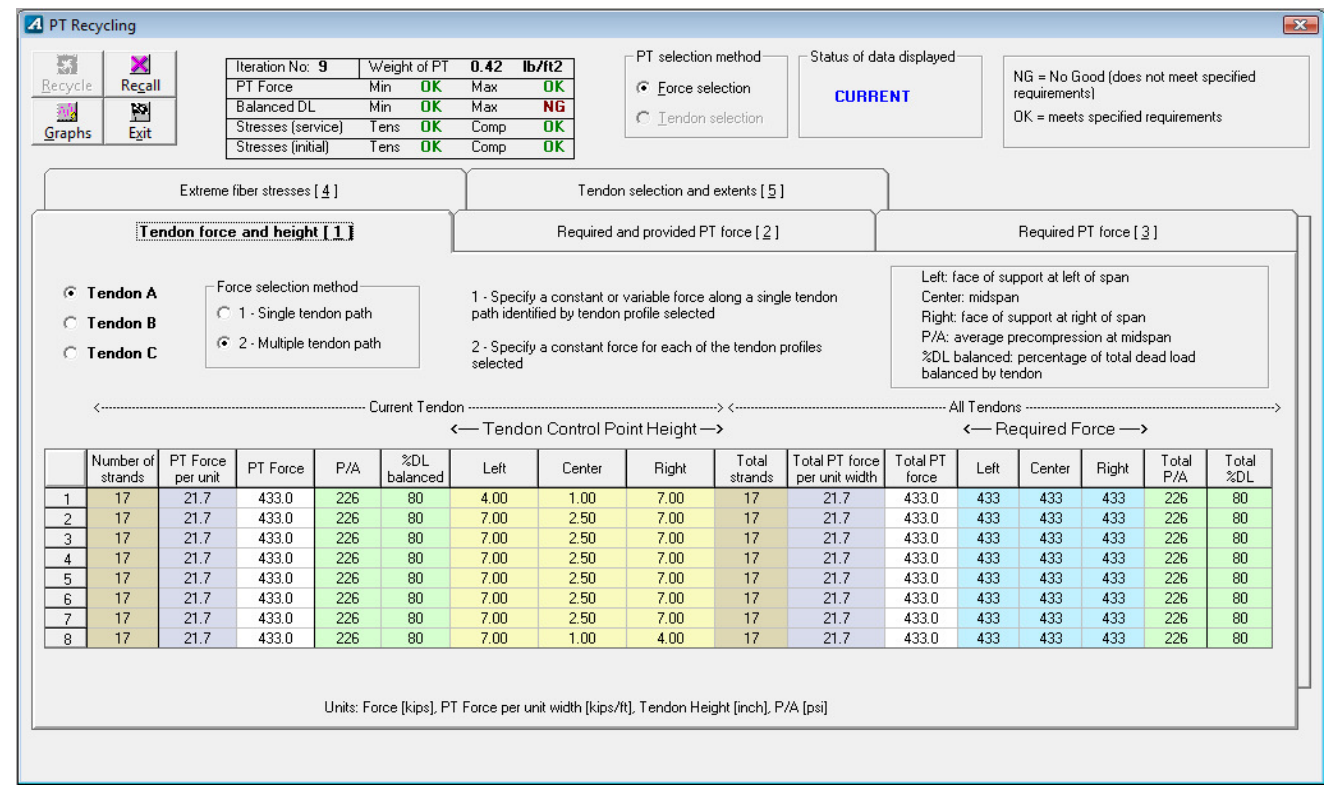


Appendix cxxi

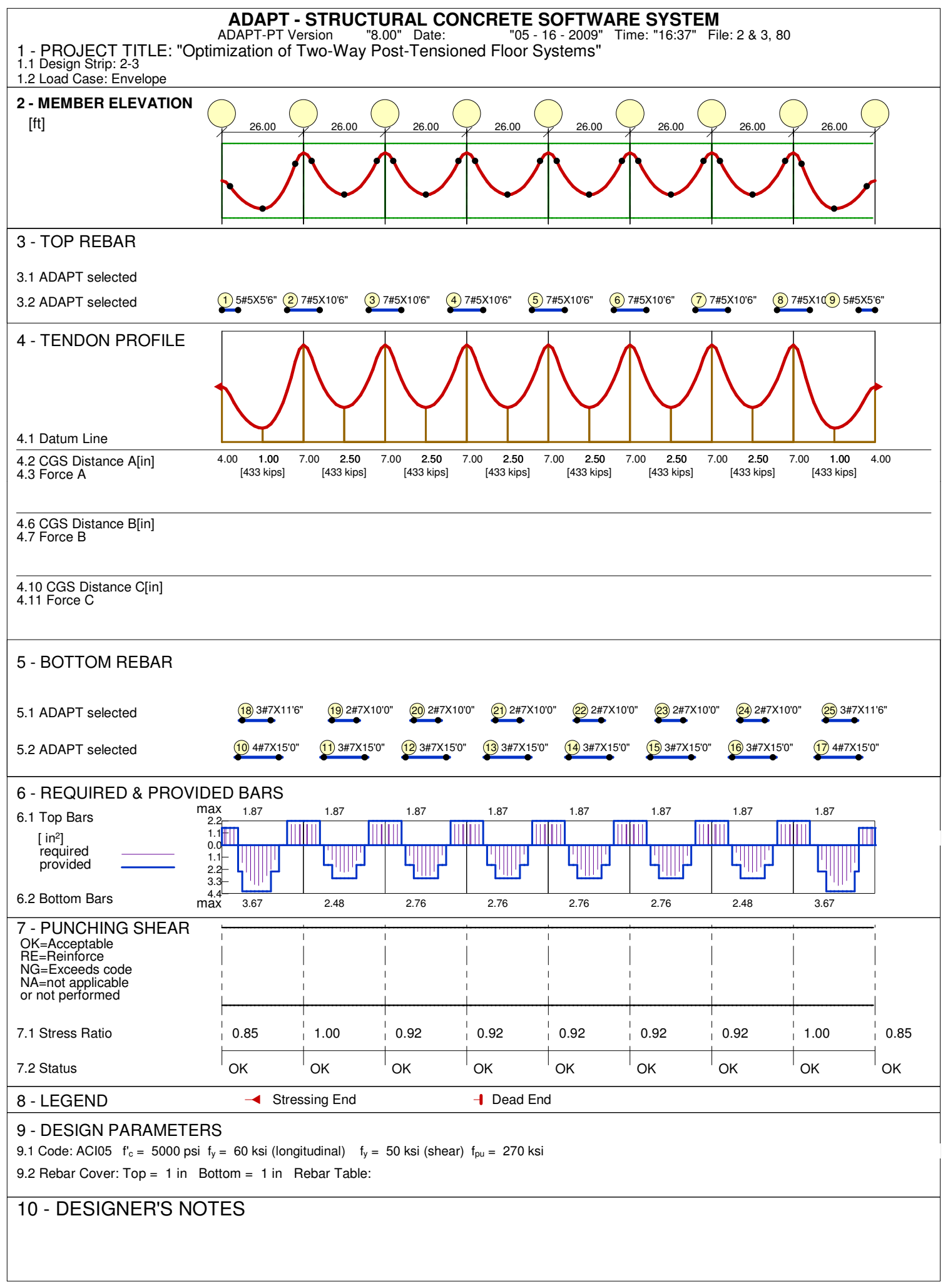




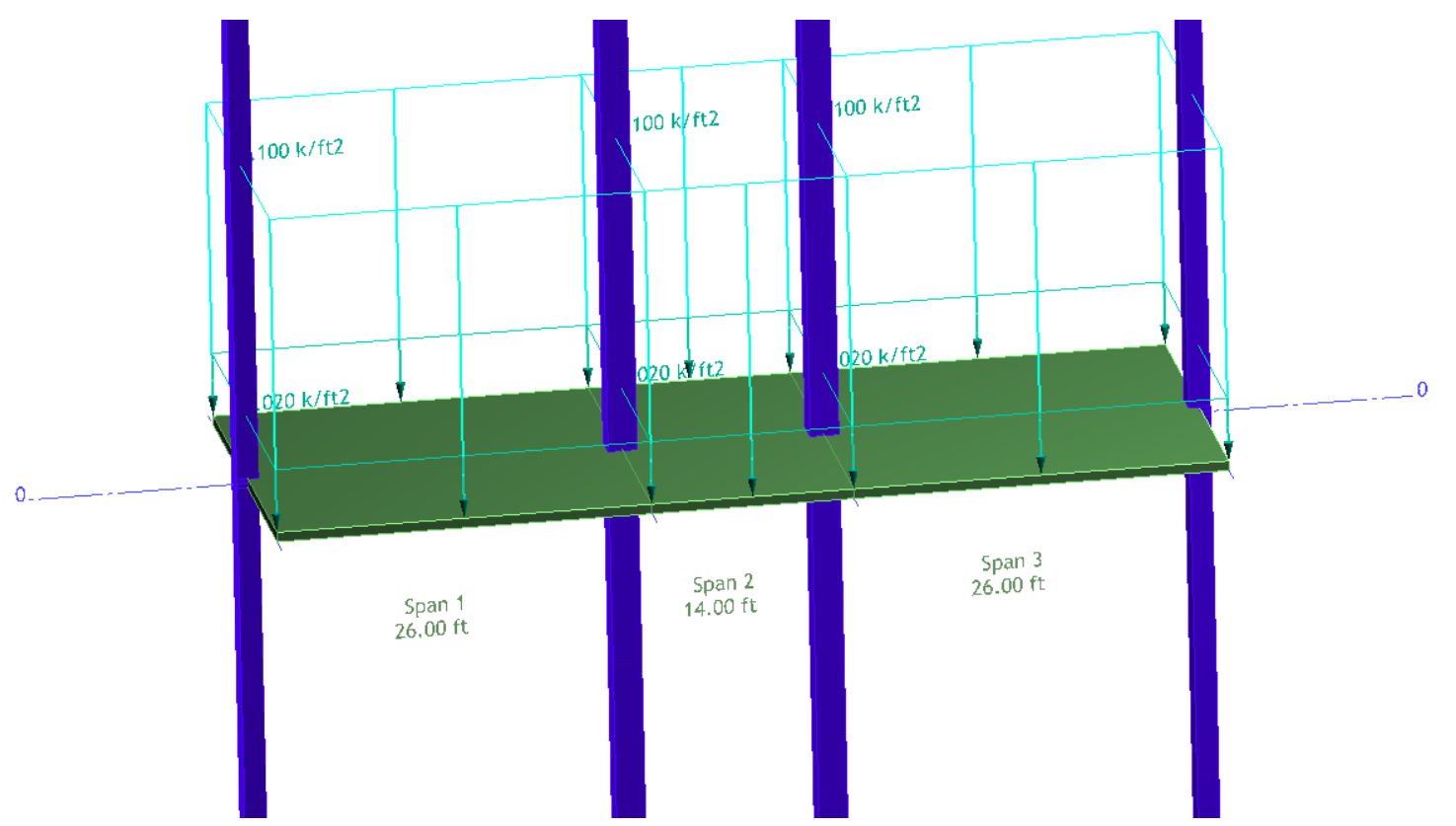

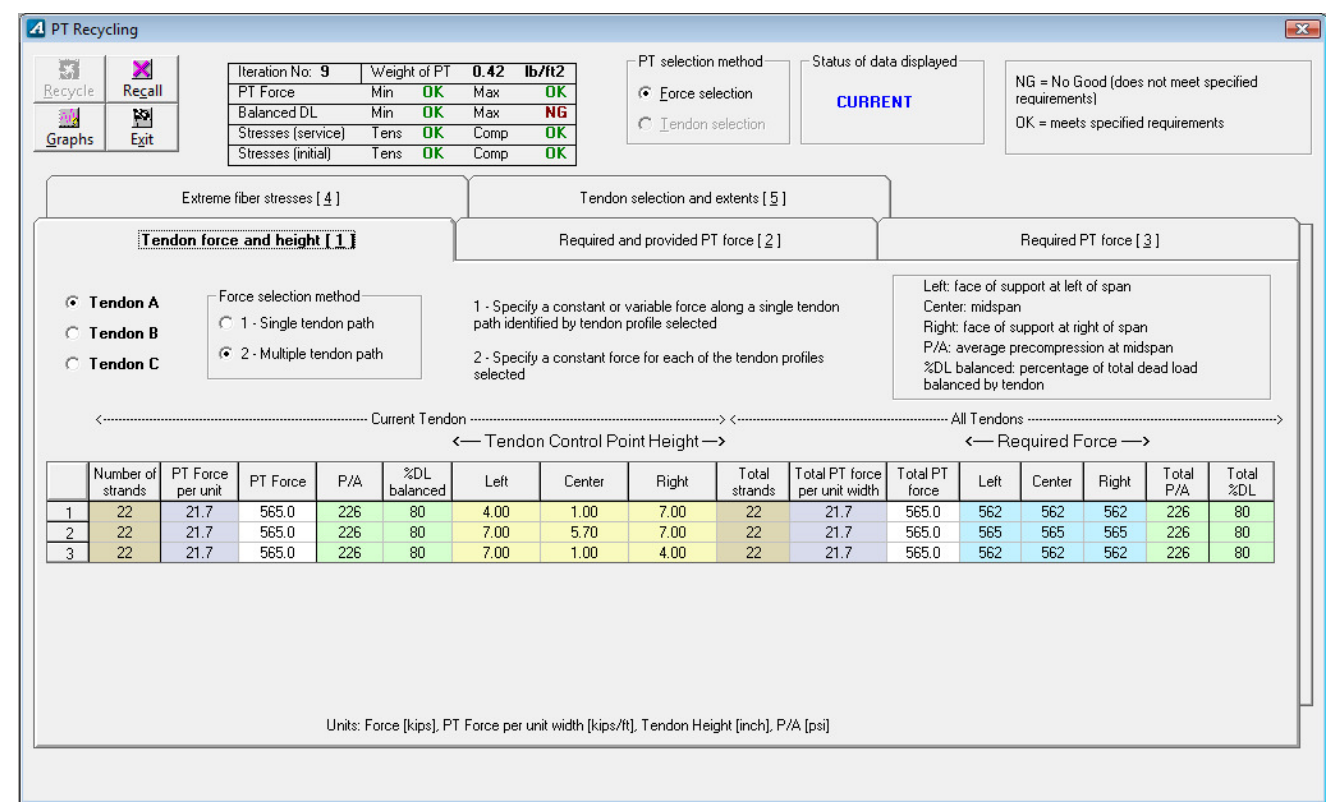


Appendix cxxiii

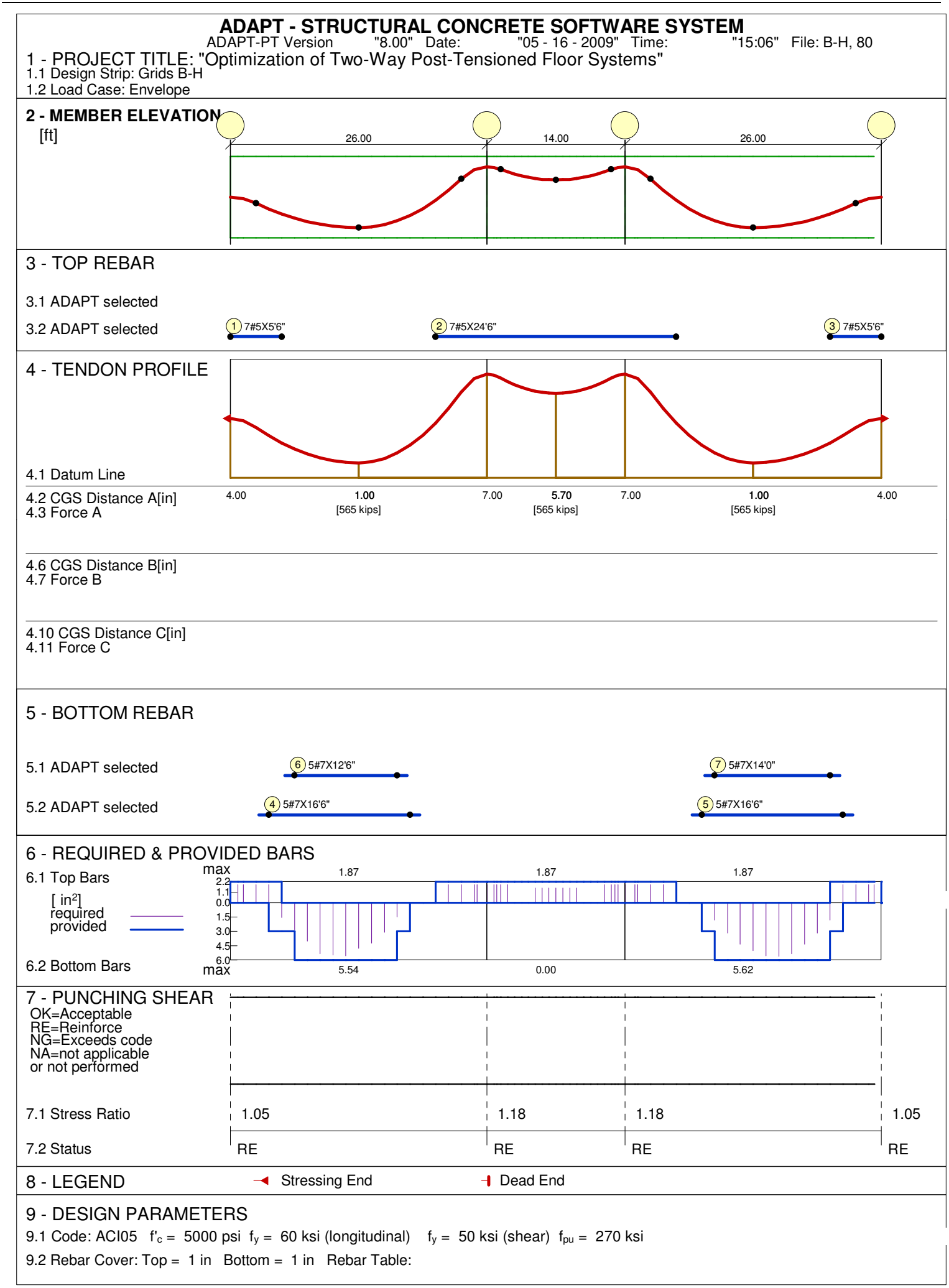

Optimization of Two-Way Post-Tensioned Concrete Floor Systems 
Appendix cxxiv

C.8 Slab 4 - ADAPT Default Tendon Profile

\section{C.8.1 Grids $2 \& 3$}

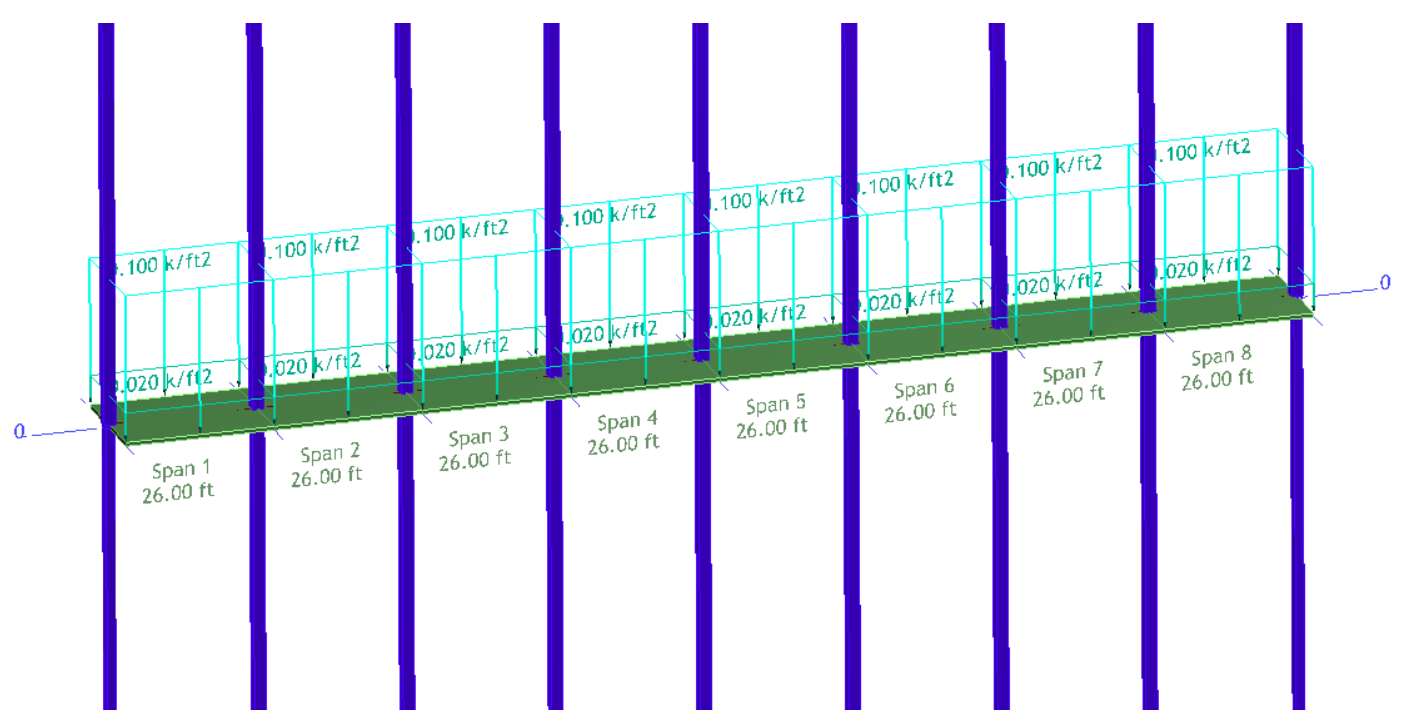

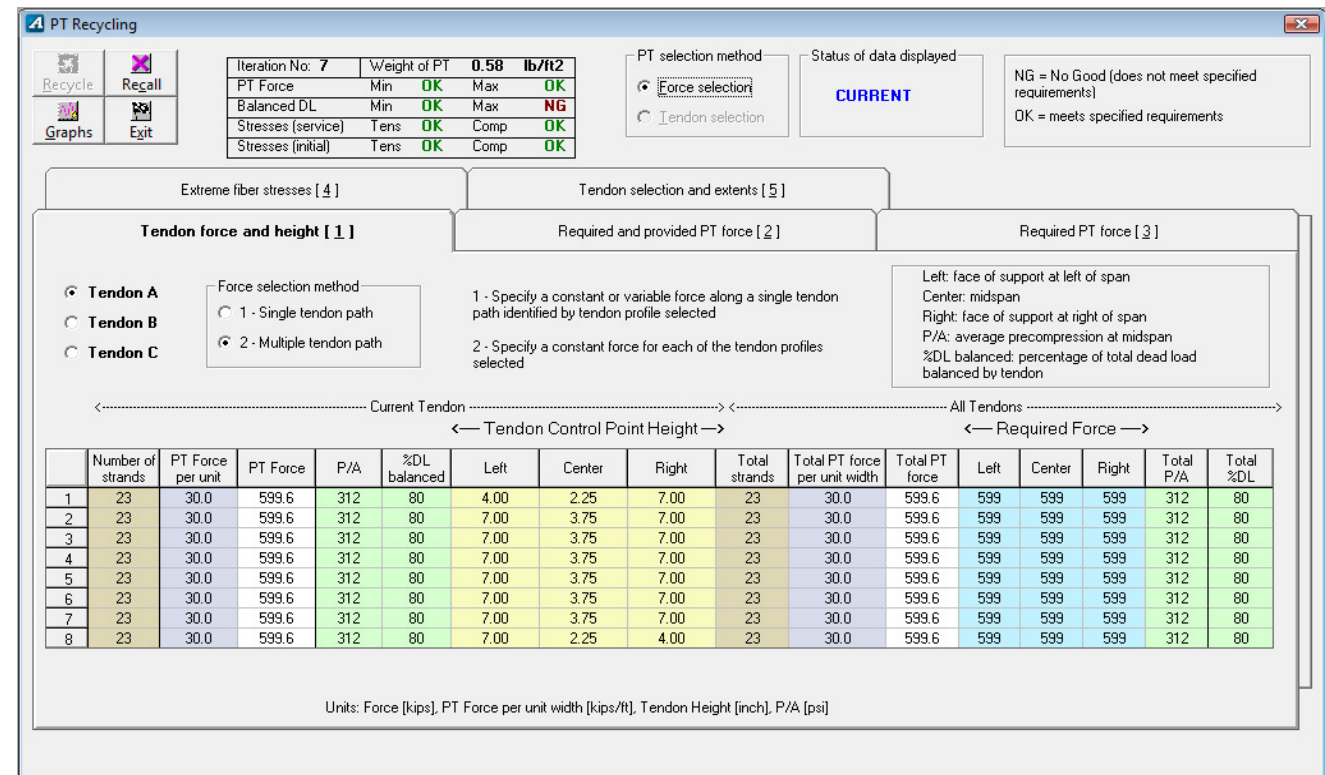

Optimization of Two-Way Post-Tensioned Concrete Floor Systems 
Appendix $\quad \operatorname{cxxv}$

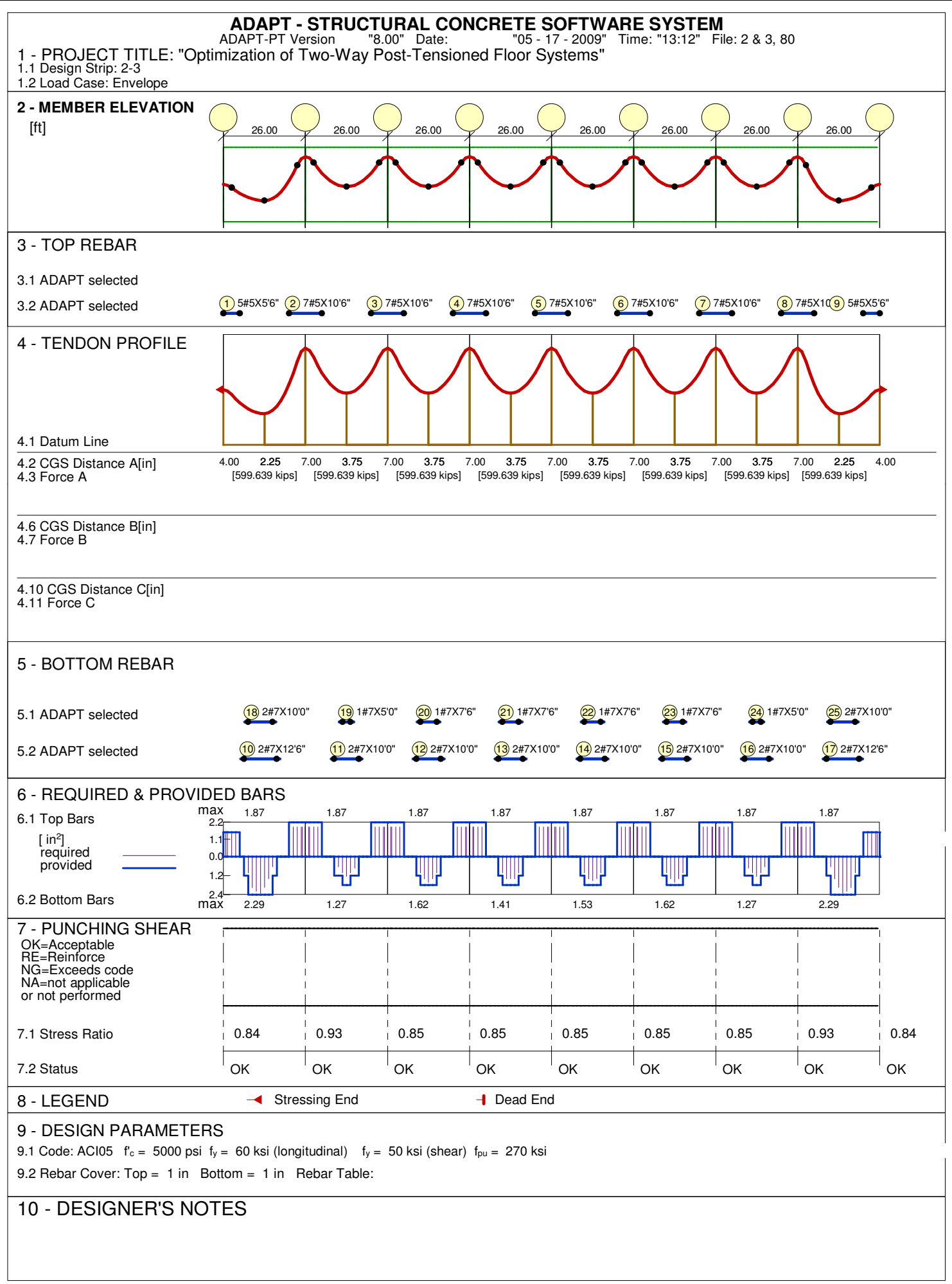




\section{C.8.2 Grids B-H}

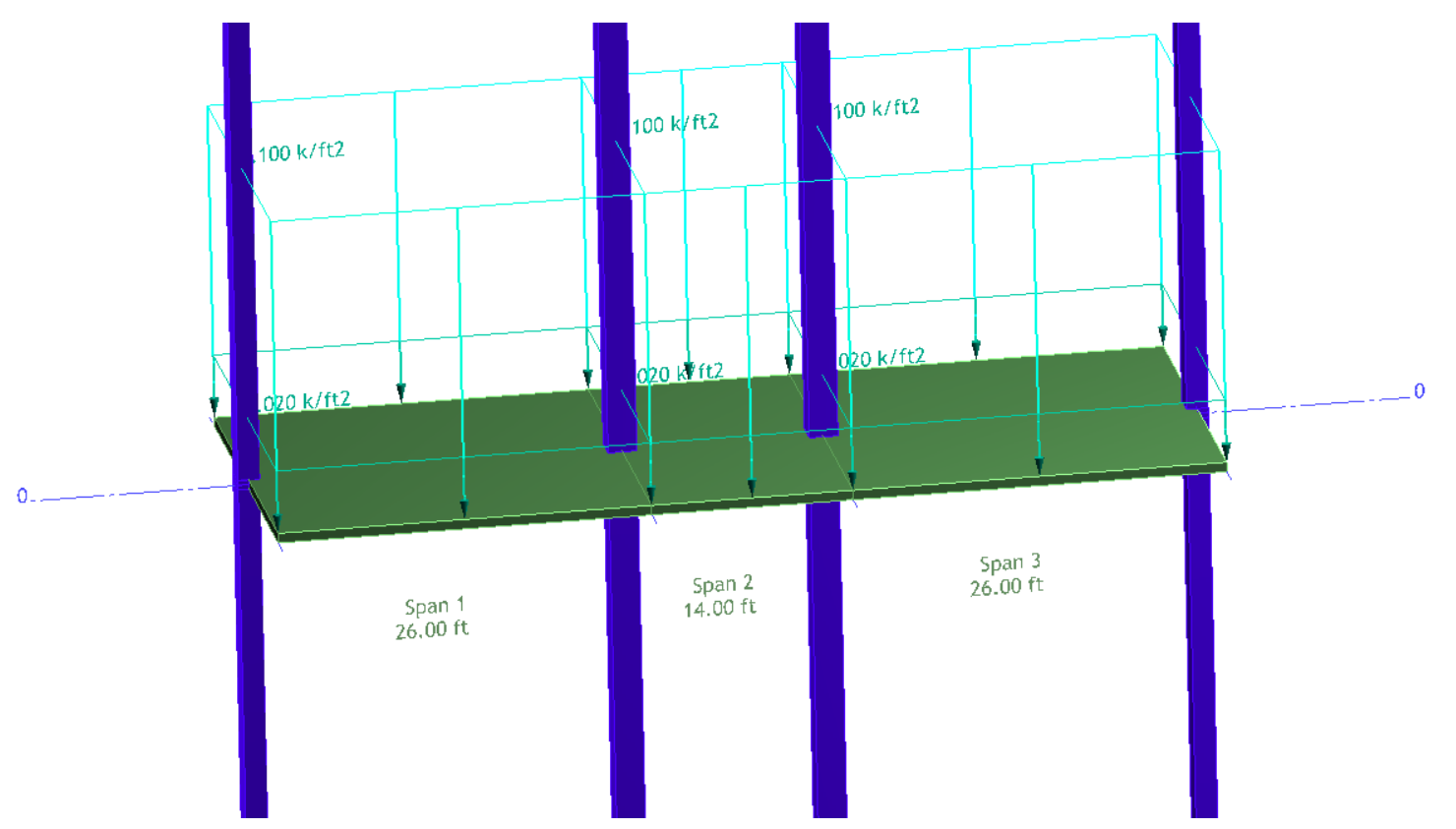

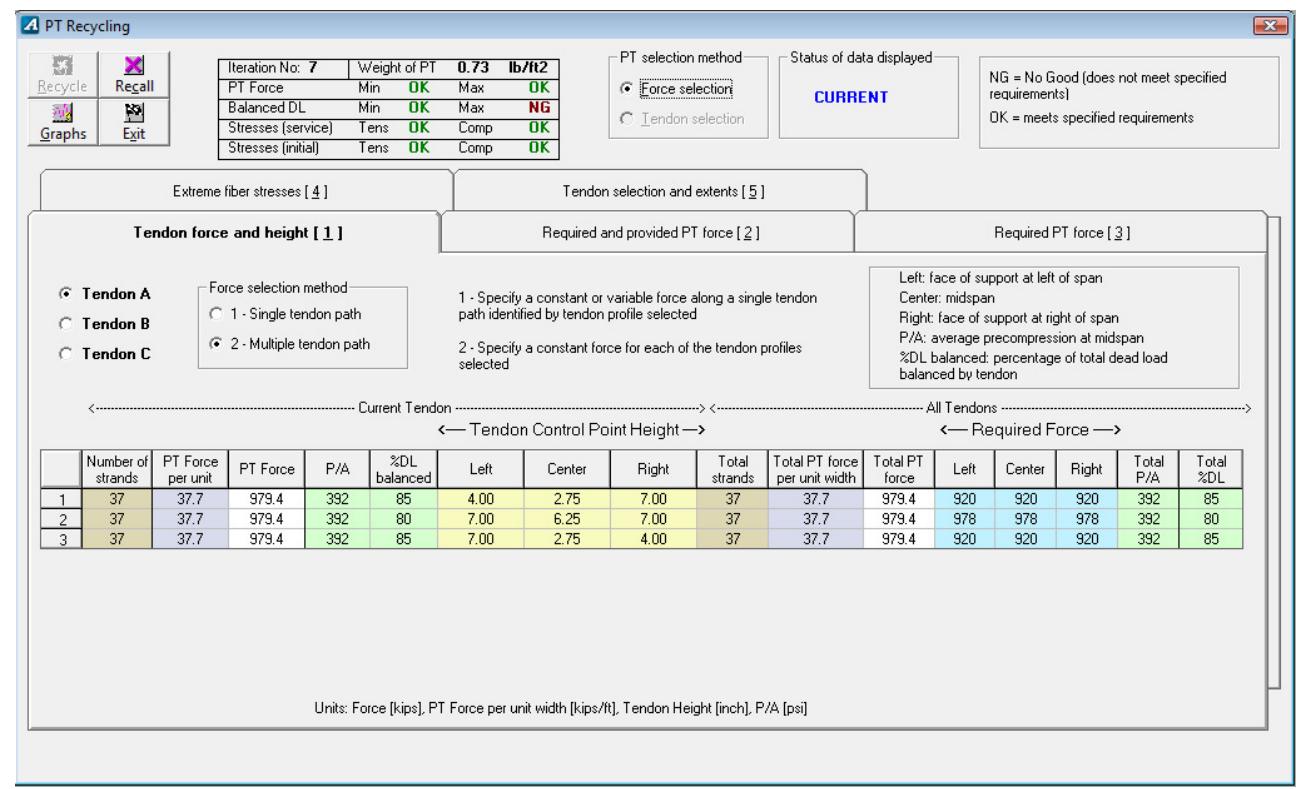


Appendix cxxvii

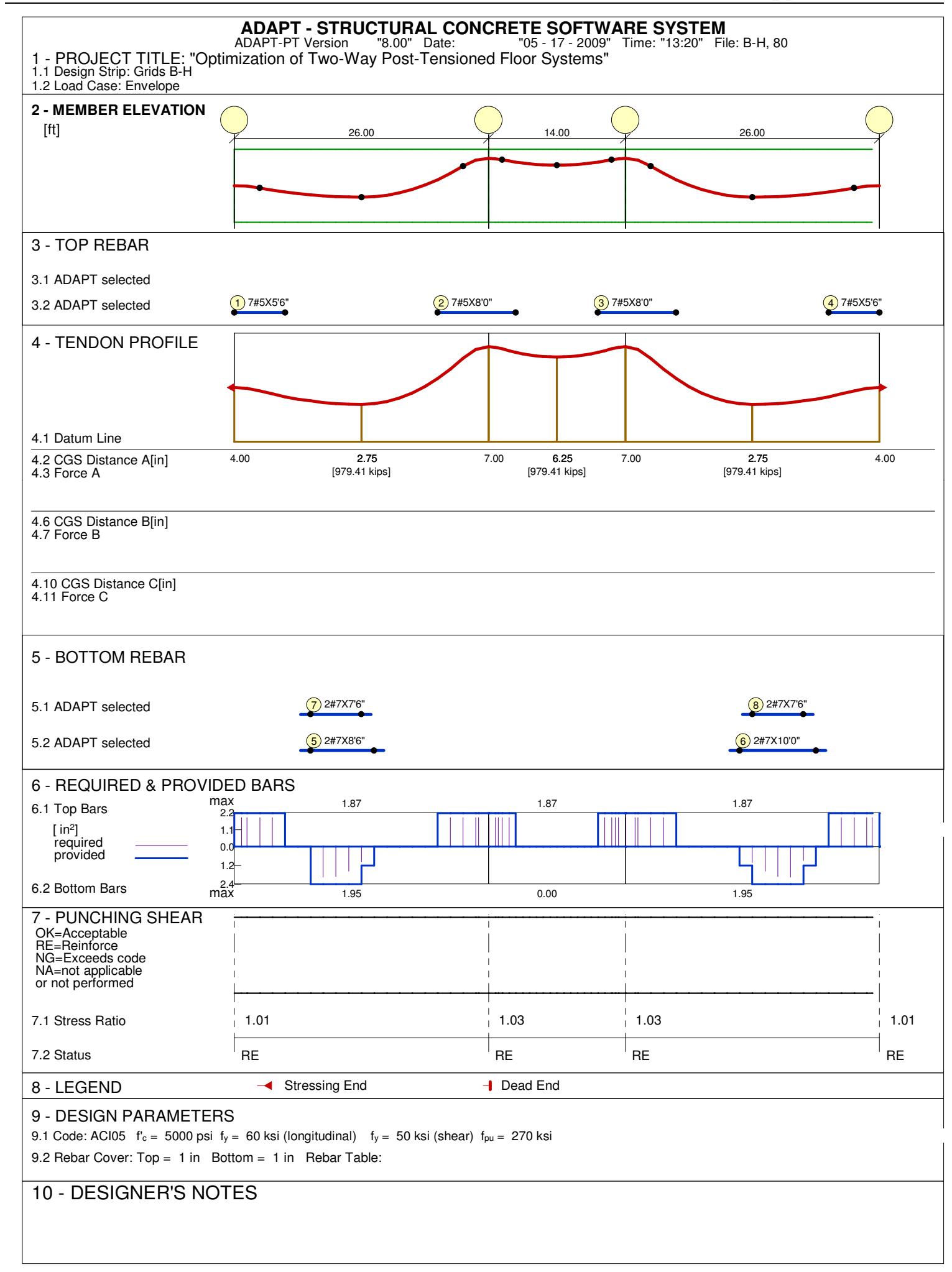

Optimization of Two-Way Post-Tensioned Concrete Floor Systems 


\section{C.9 Slab 5 - Same Tendon Profile as Hand}

\section{C.9.1 Grids 2 \& 3}
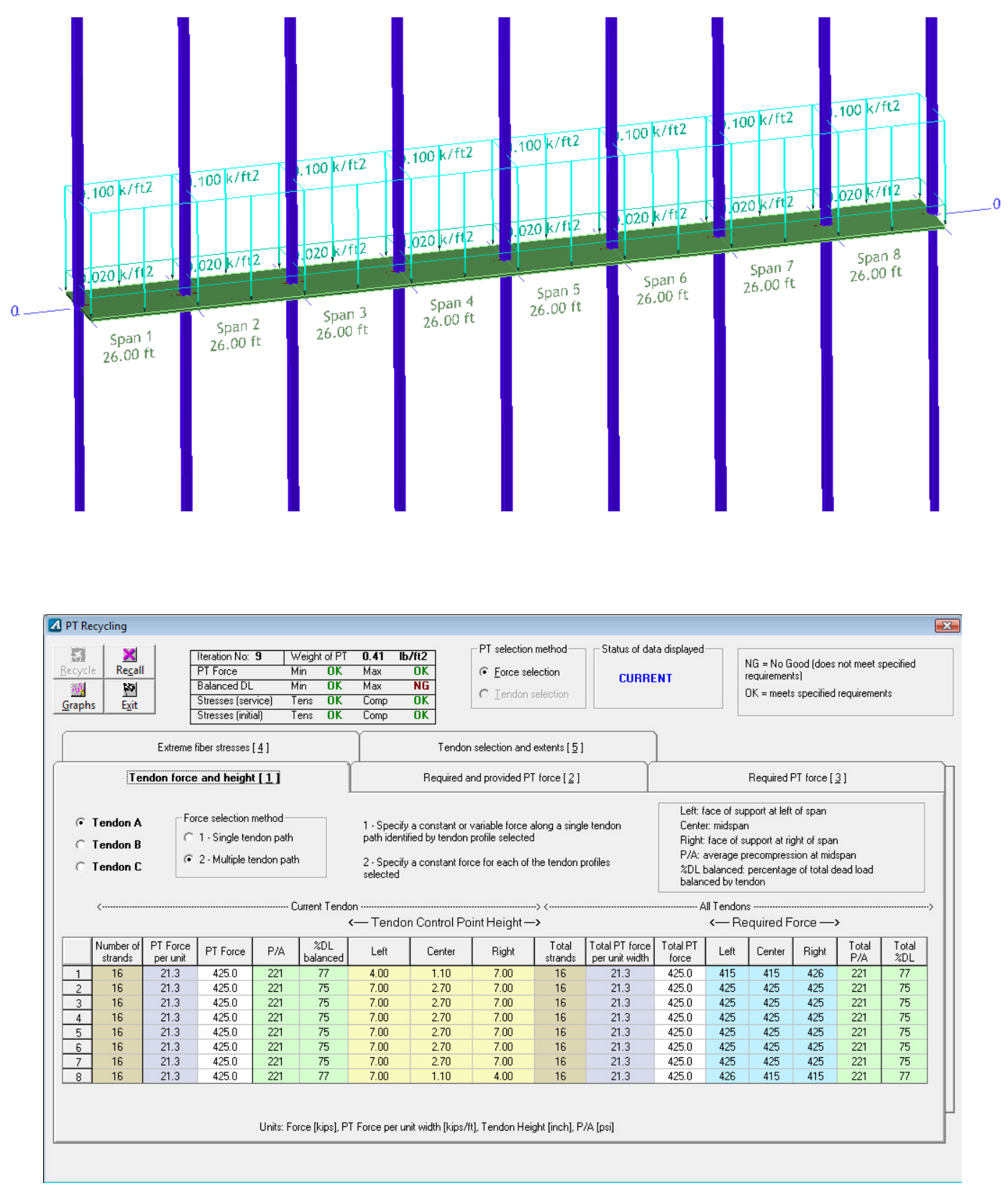

Optimization of Two-Way Post-Tensioned Concrete Floor Systems 
Appendix cxxix

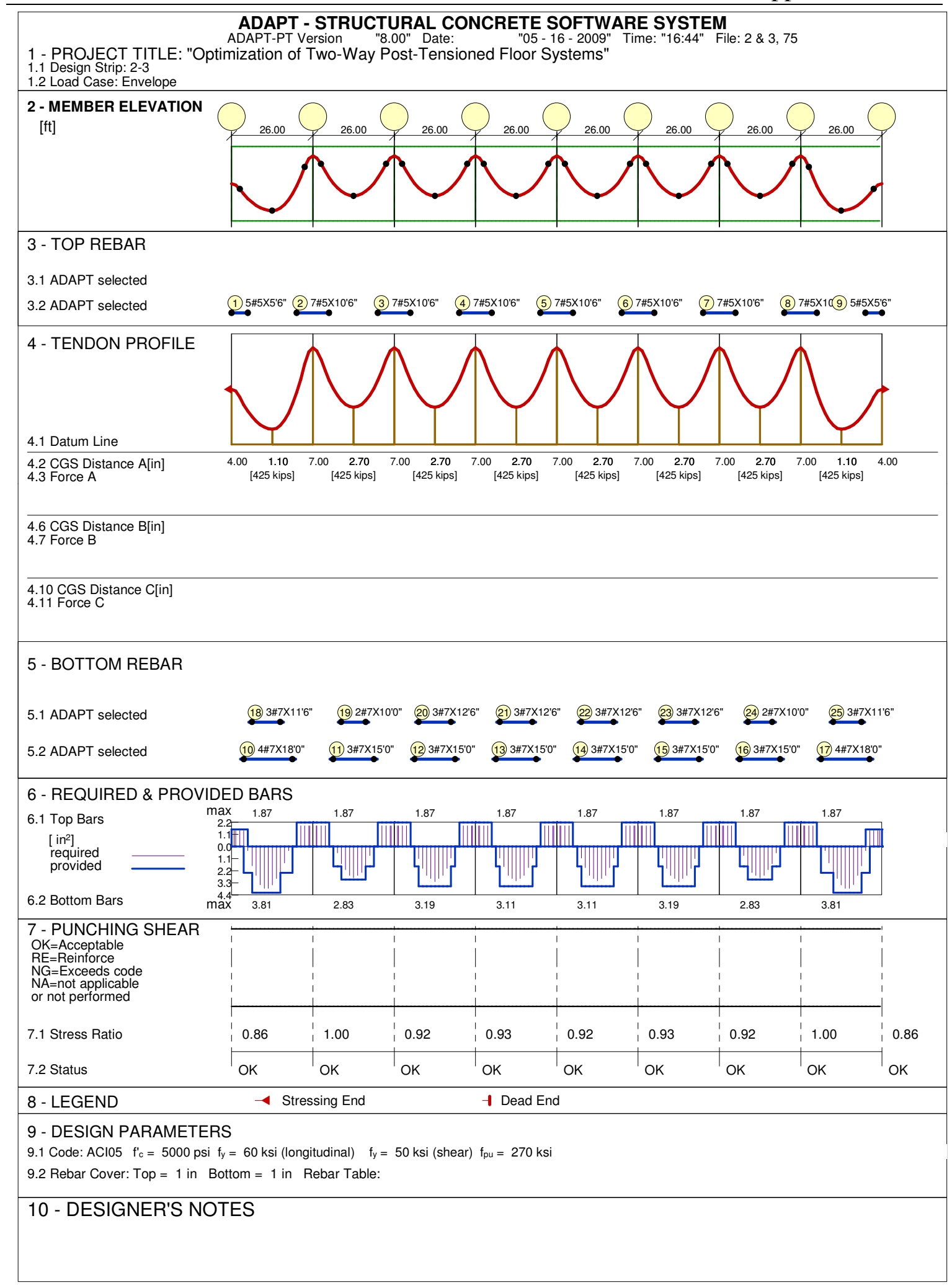




\section{C.9.2 Grids B-H}

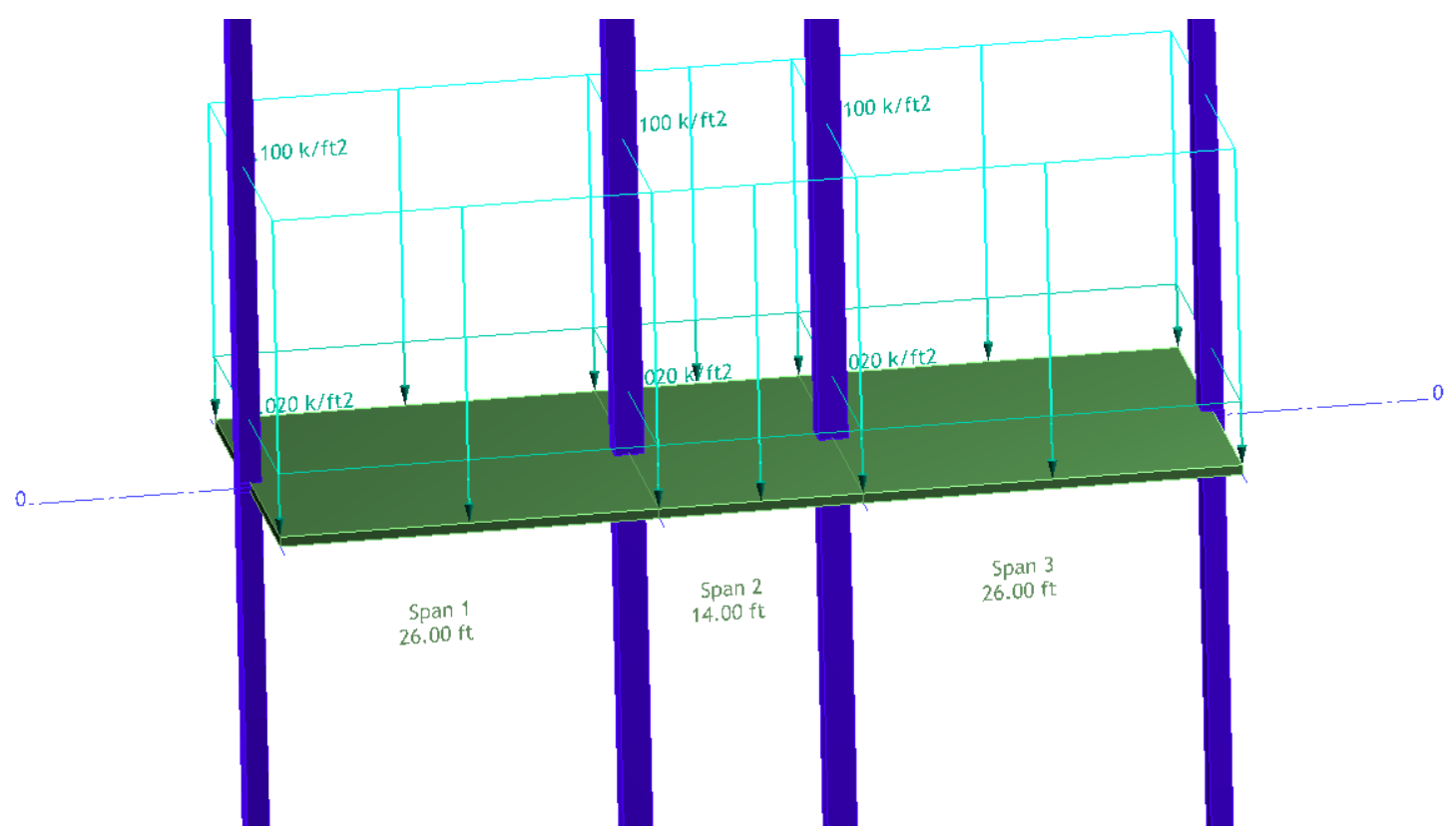

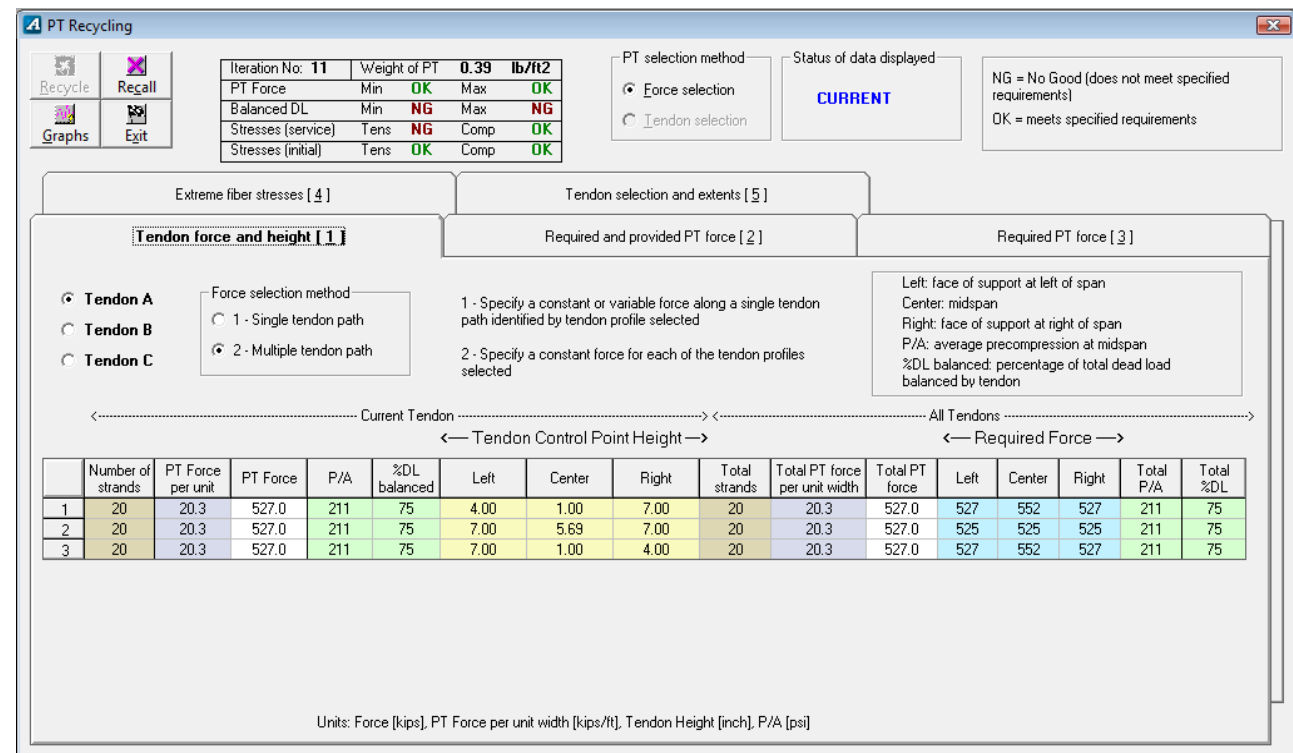


Appendix cxxxi

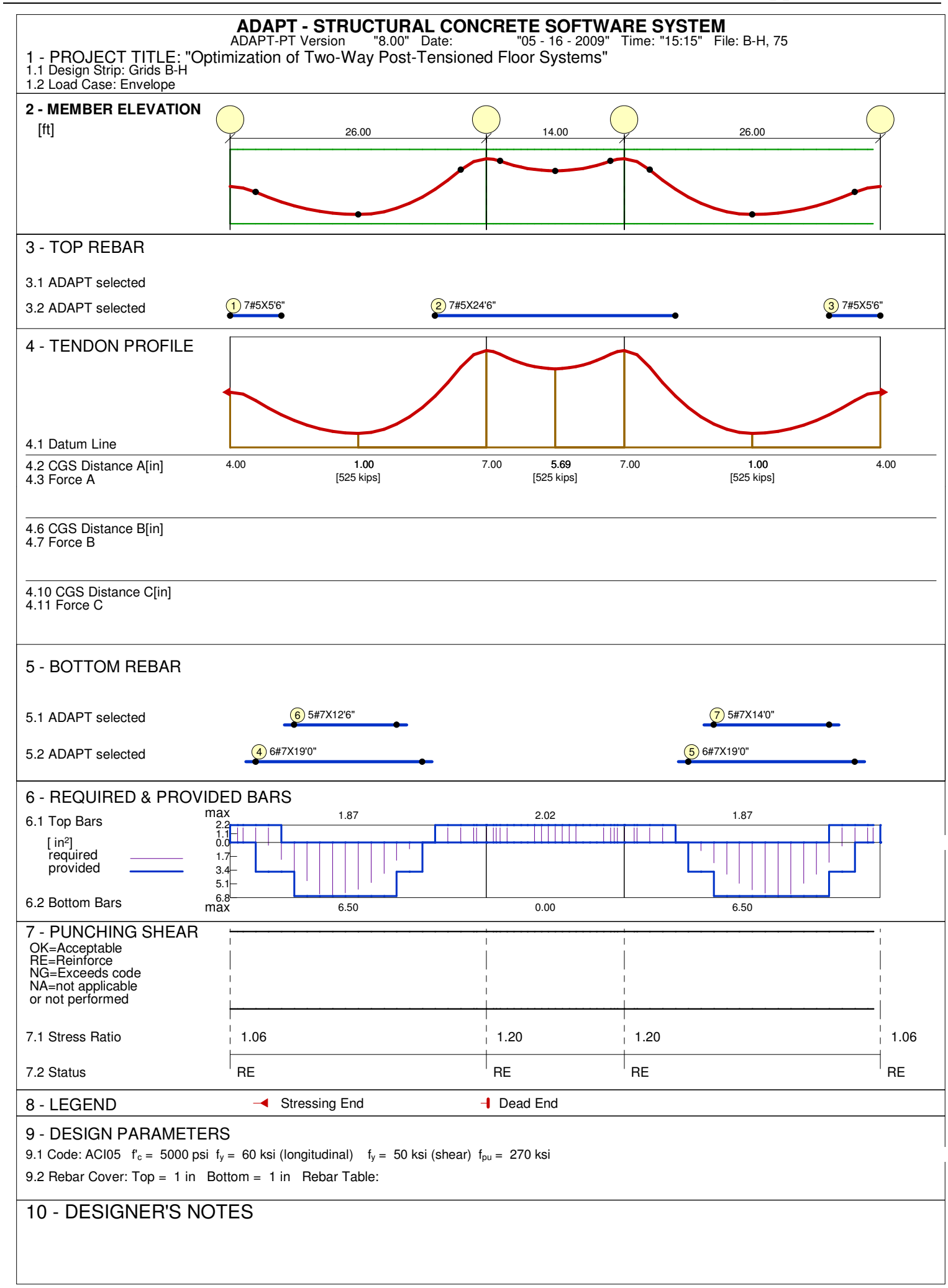




\section{C.10 Slab 5 - ADAPT Default Tendon Profile}

\section{C.10.1 Grids $2 \& 3$}

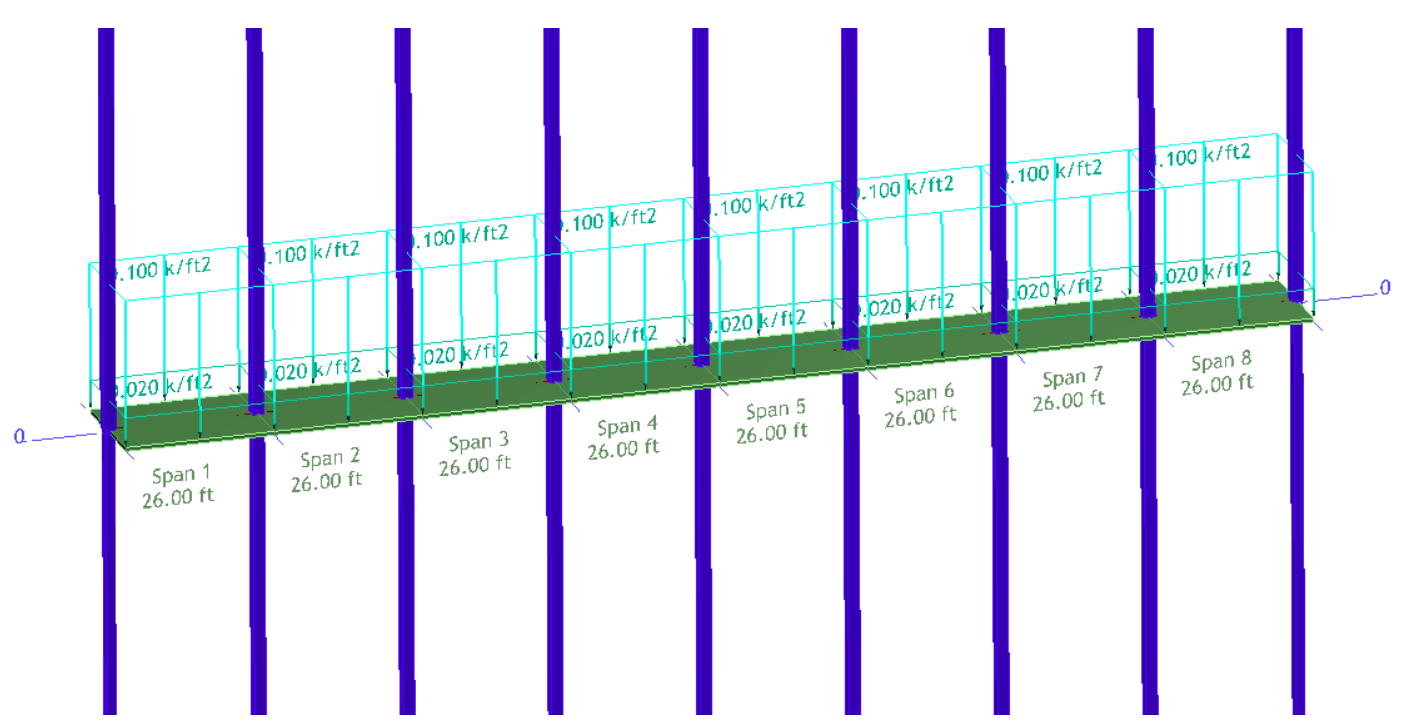

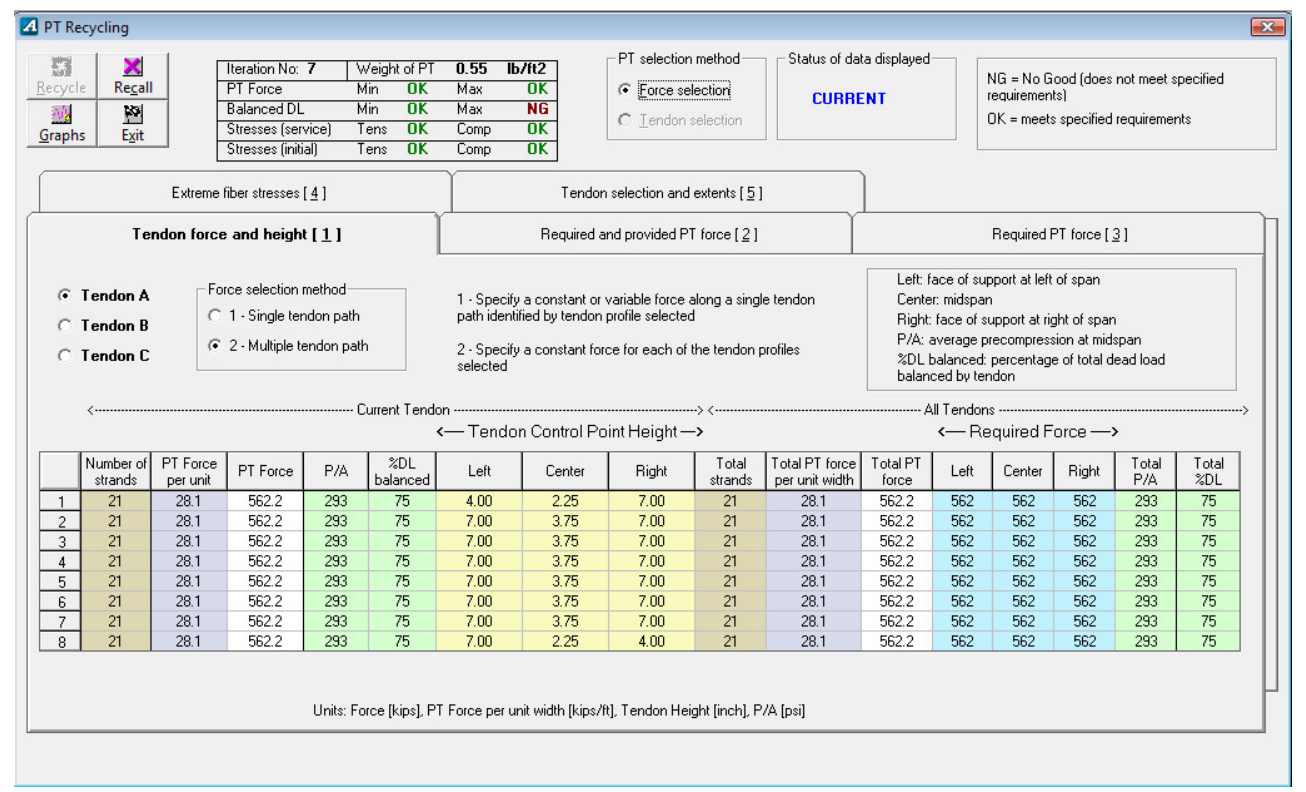

Optimization of Two-Way Post-Tensioned Concrete Floor Systems 
Appendix cxxxiii

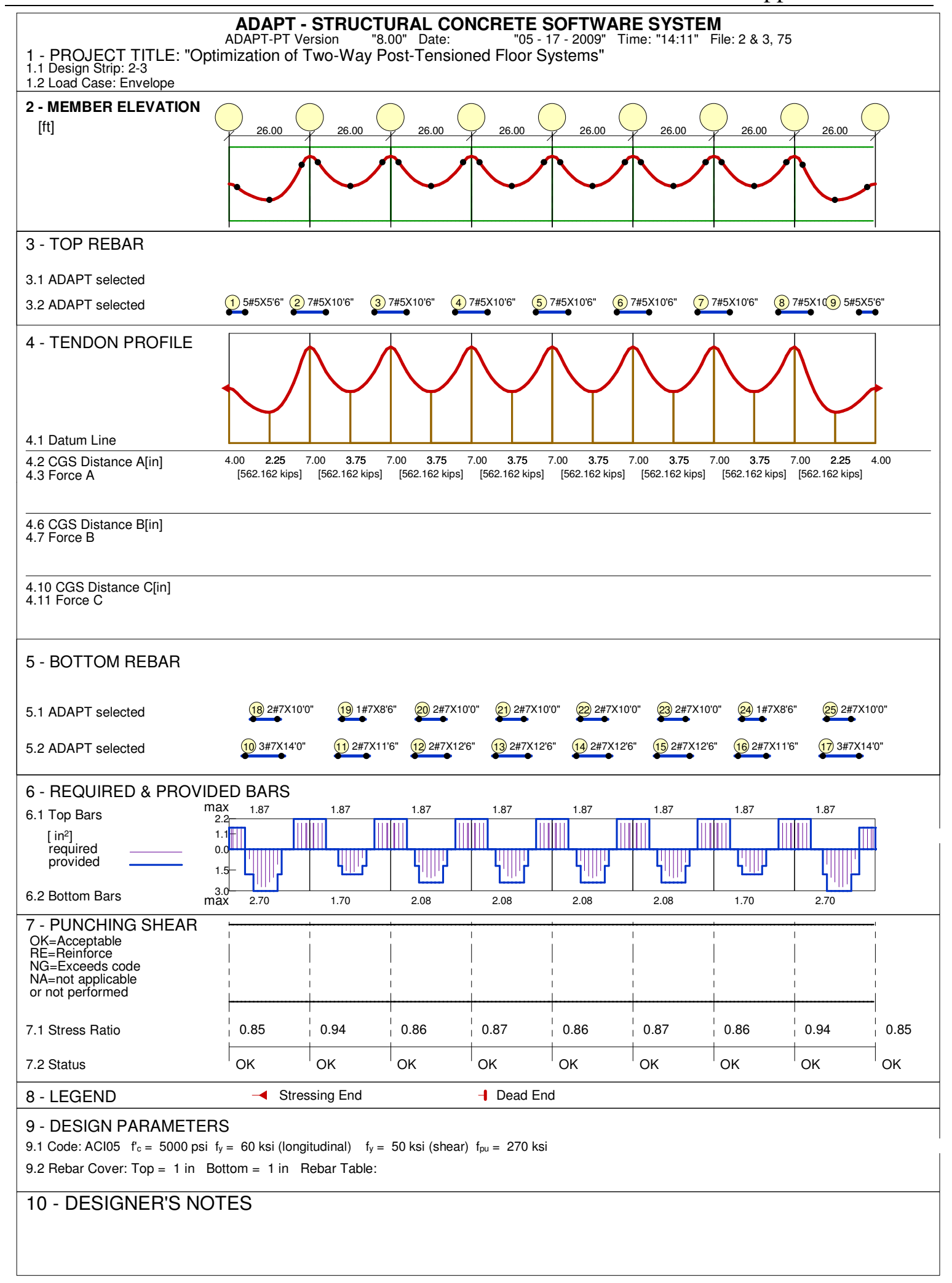




\section{C.10.2 Grids B-H}
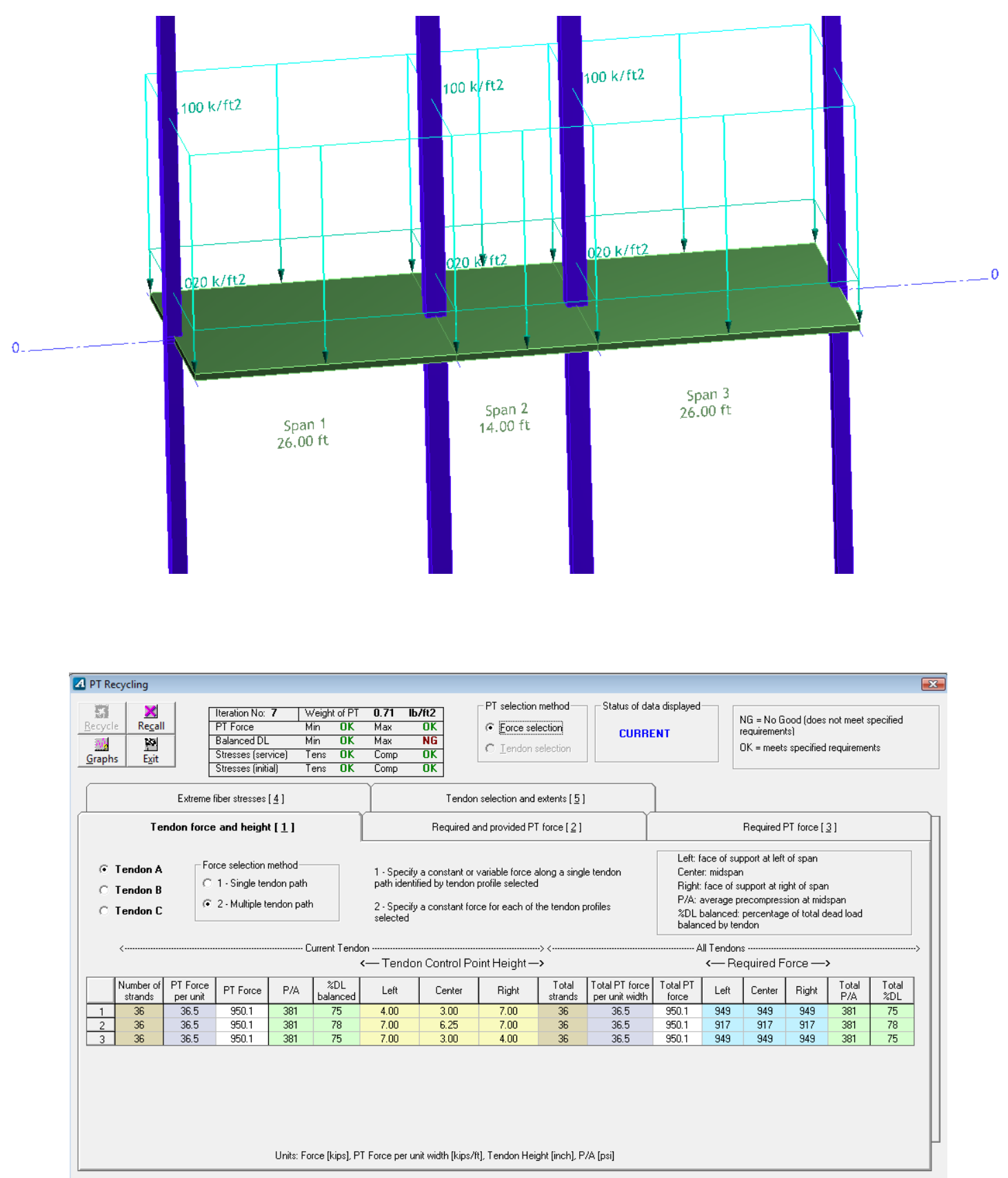

Optimization of Two-Way Post-Tensioned Concrete Floor Systems 
Appendix cxxxv

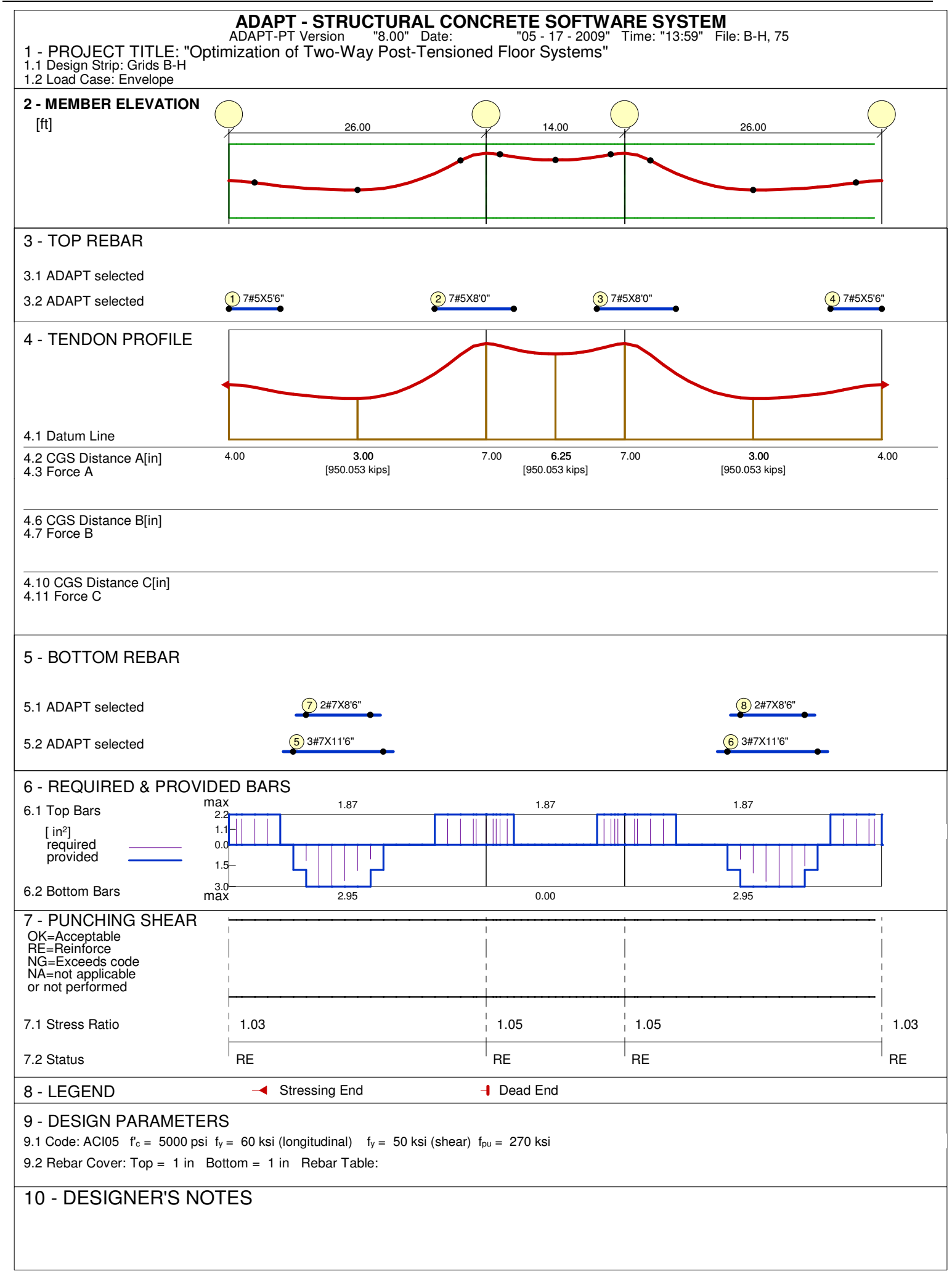

Optimization of Two-Way Post-Tensioned Concrete Floor Systems 


\section{C.11 Slab 6 - ADAPT Default Tendon Profile}

\section{C.11.1 Grids $2 \& 3$}

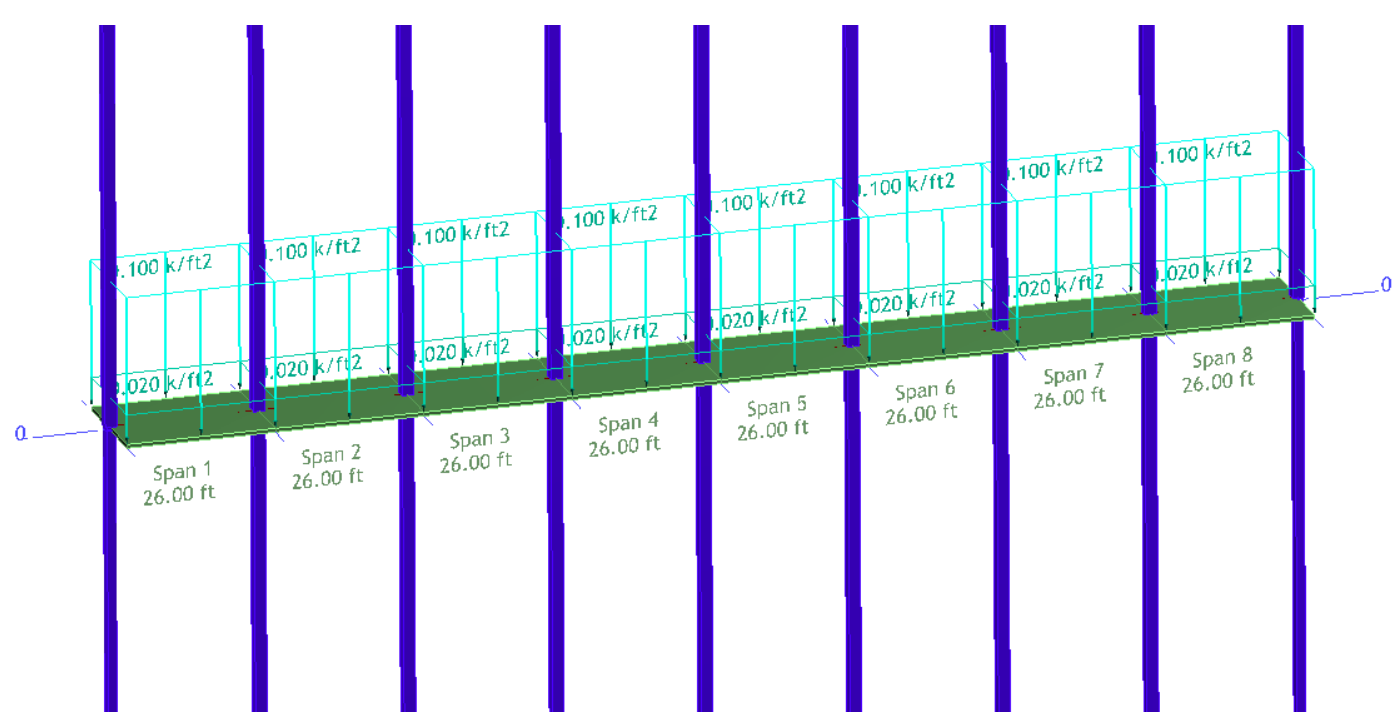

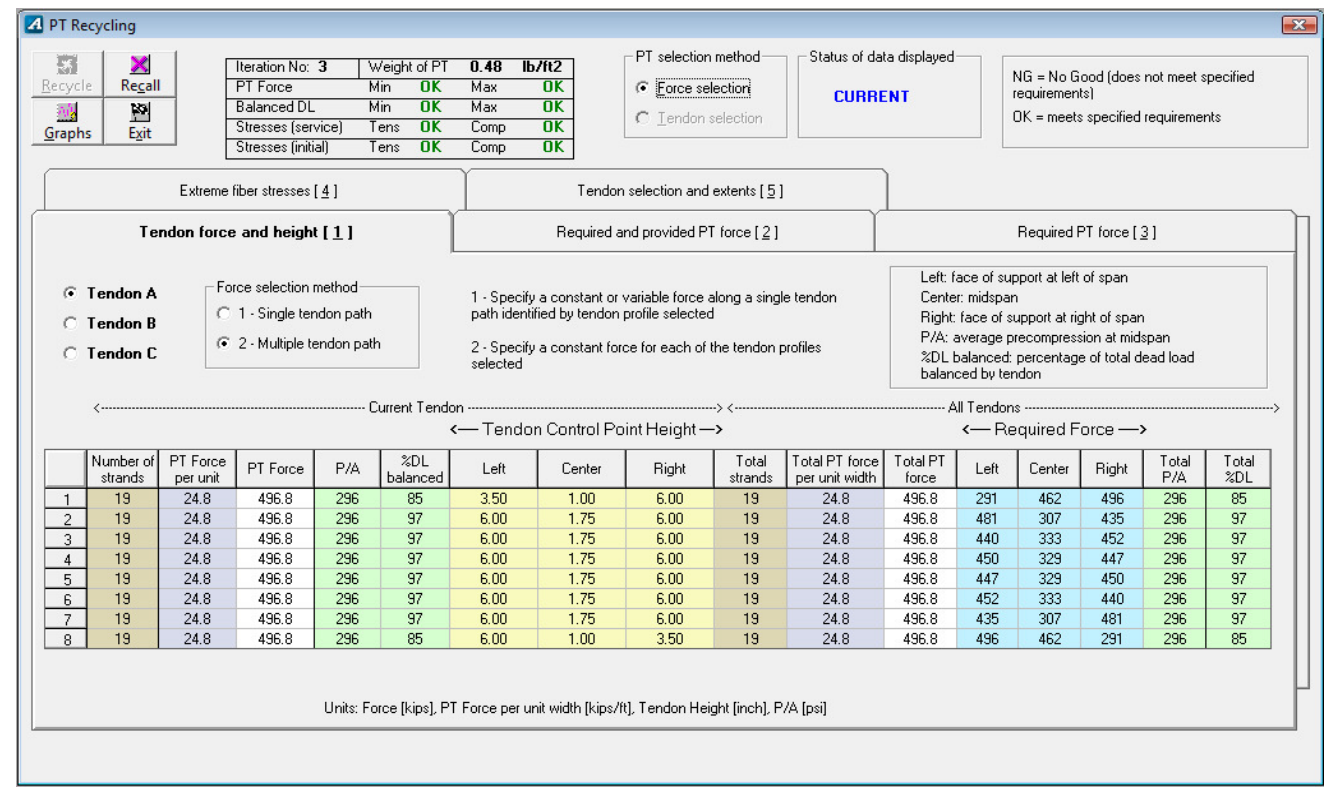


Appendix cxxxvii

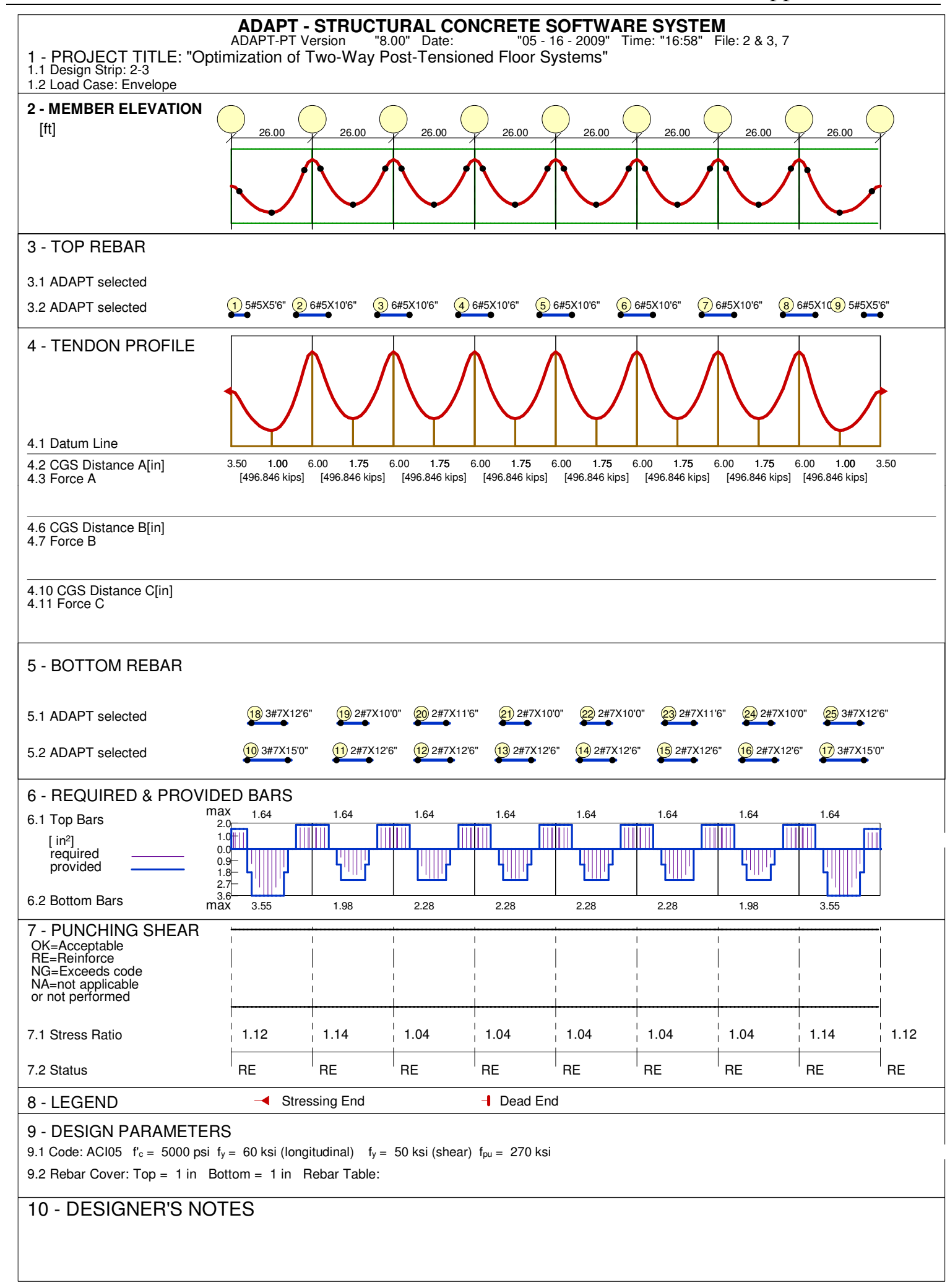




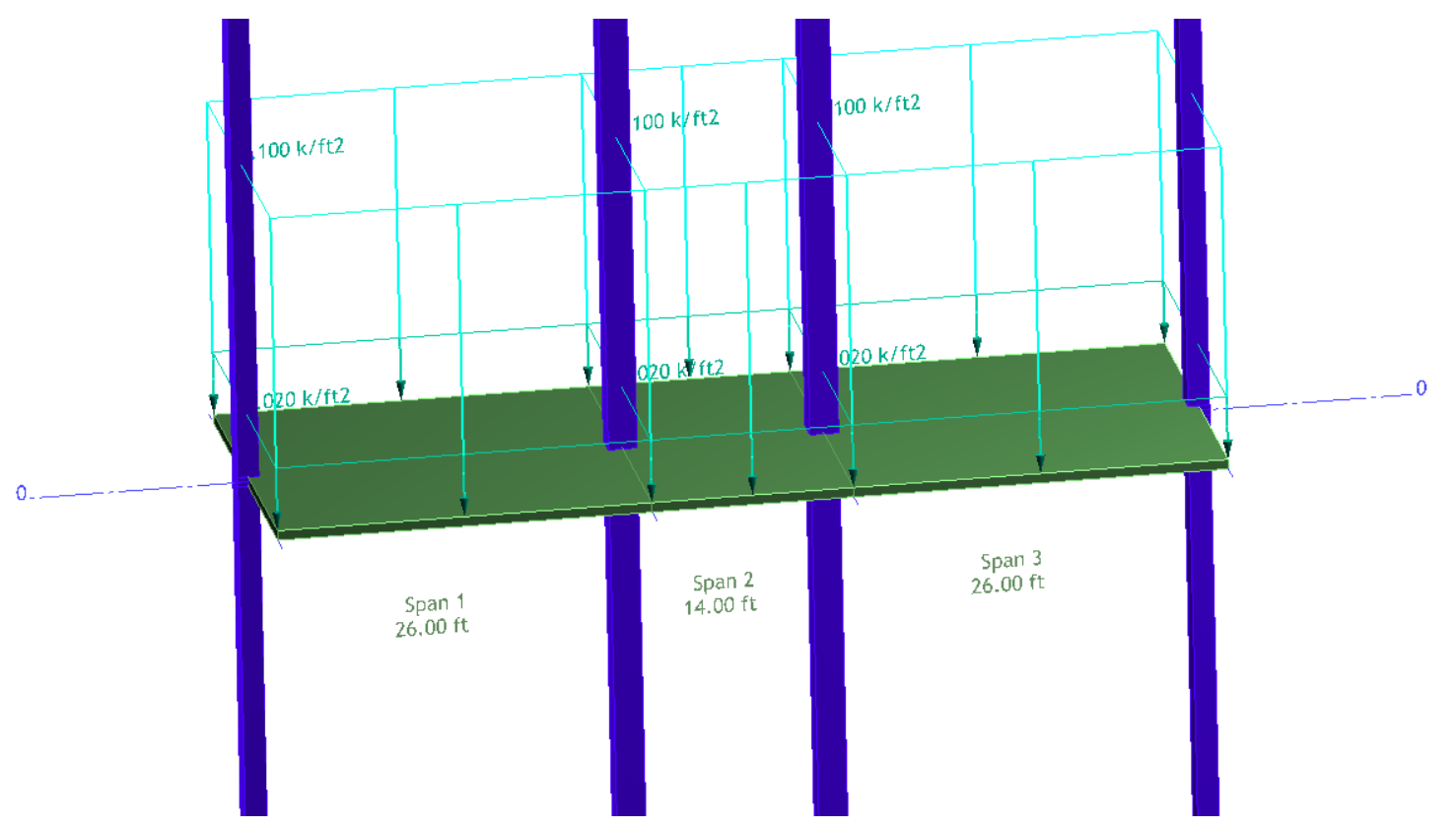

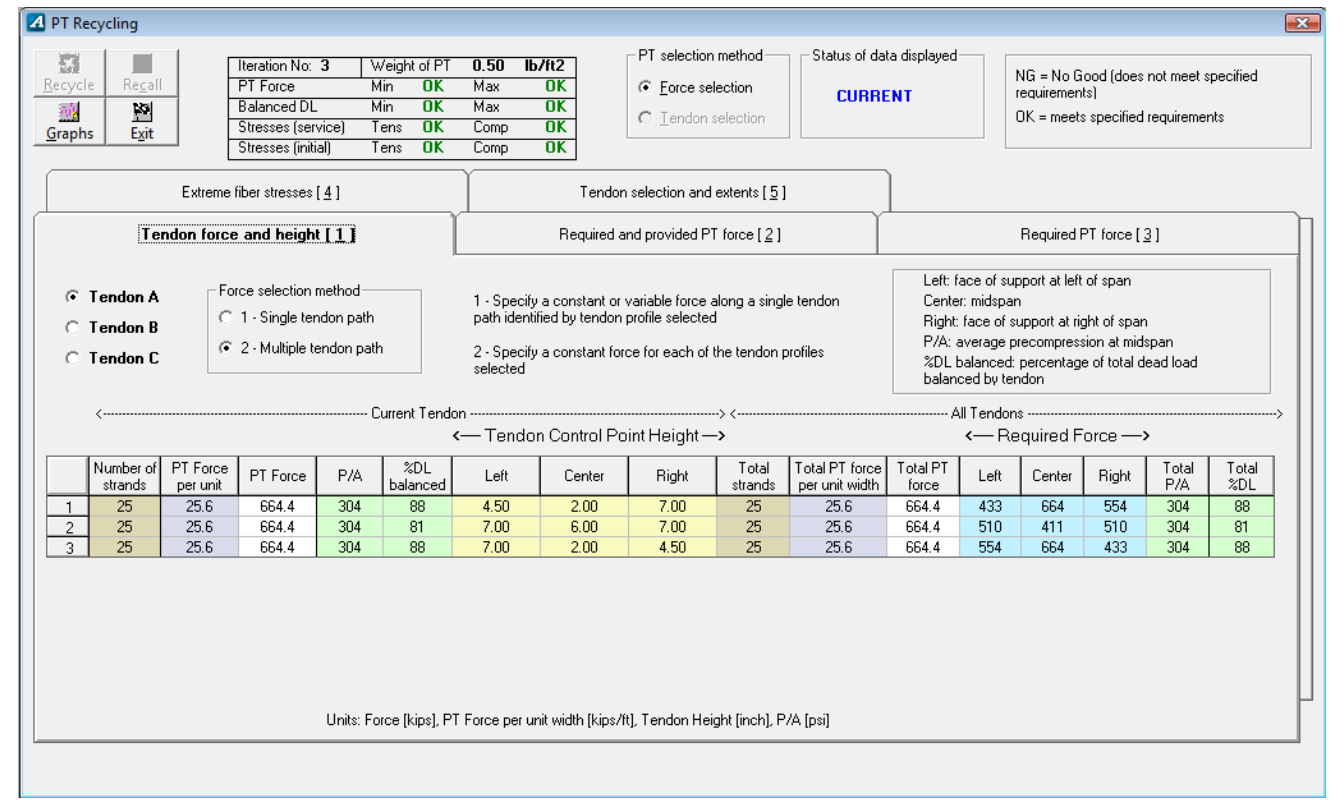


Appendix cxxxix

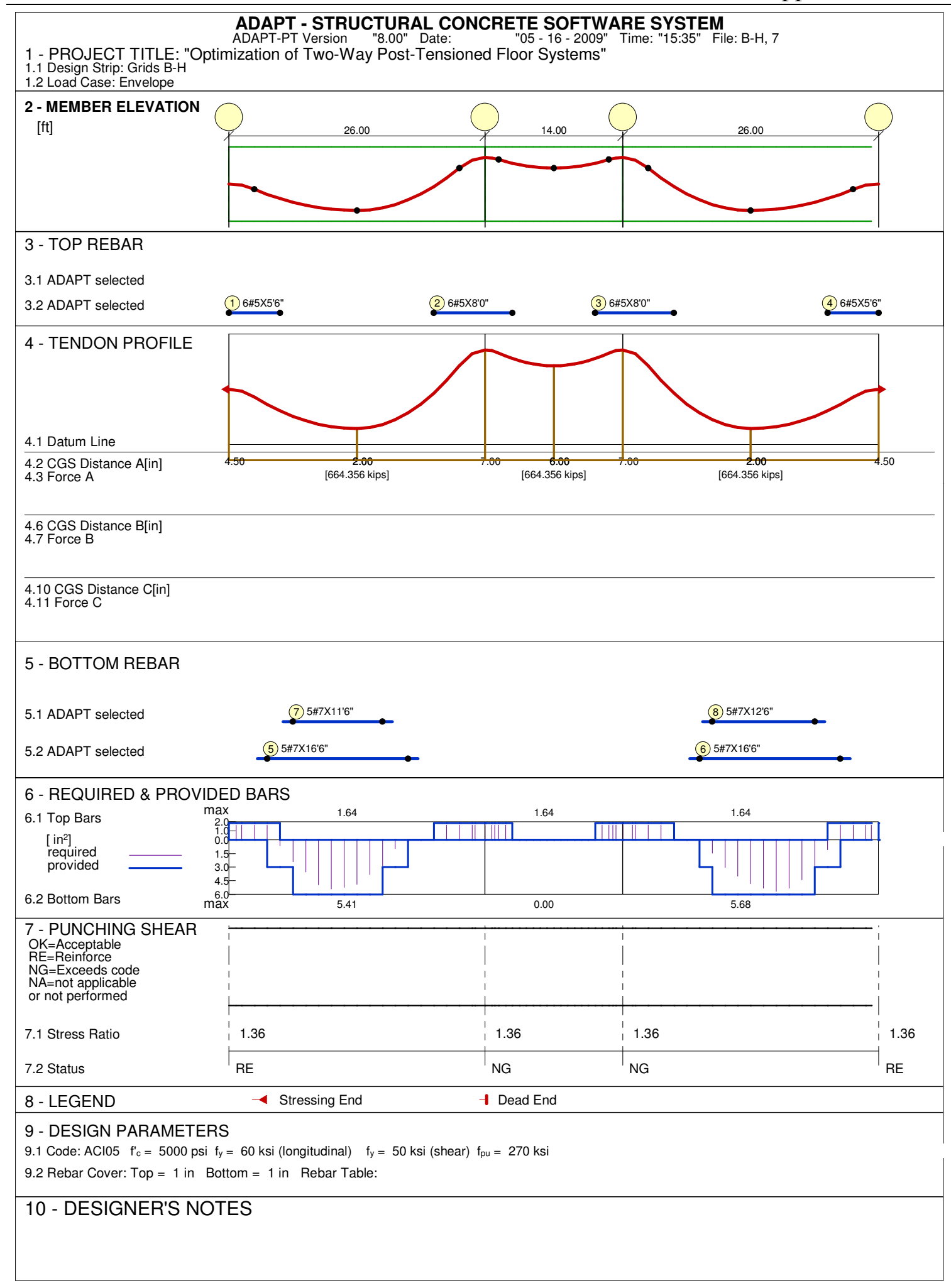




\section{C.12 Slab 7 - ADAPT Default Tendon Profile}

\section{C.12.1 Grids $2 \& 3$}

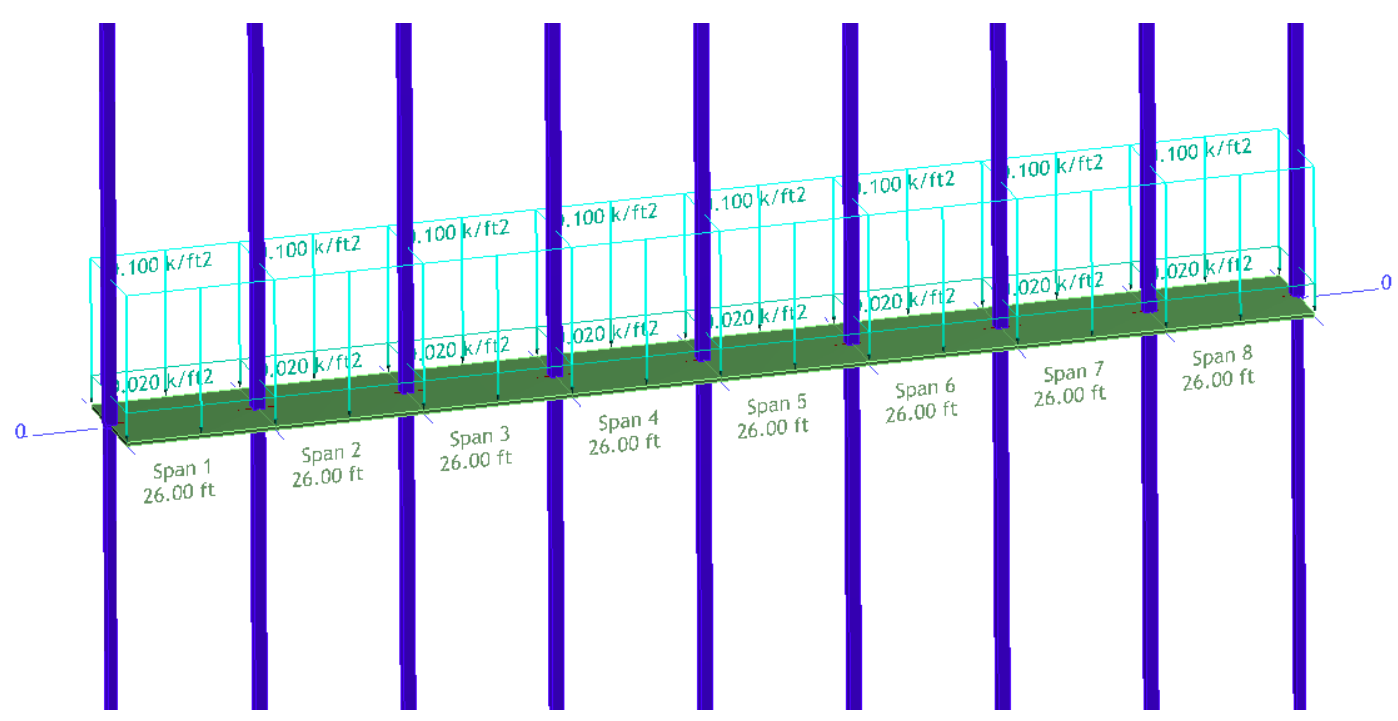

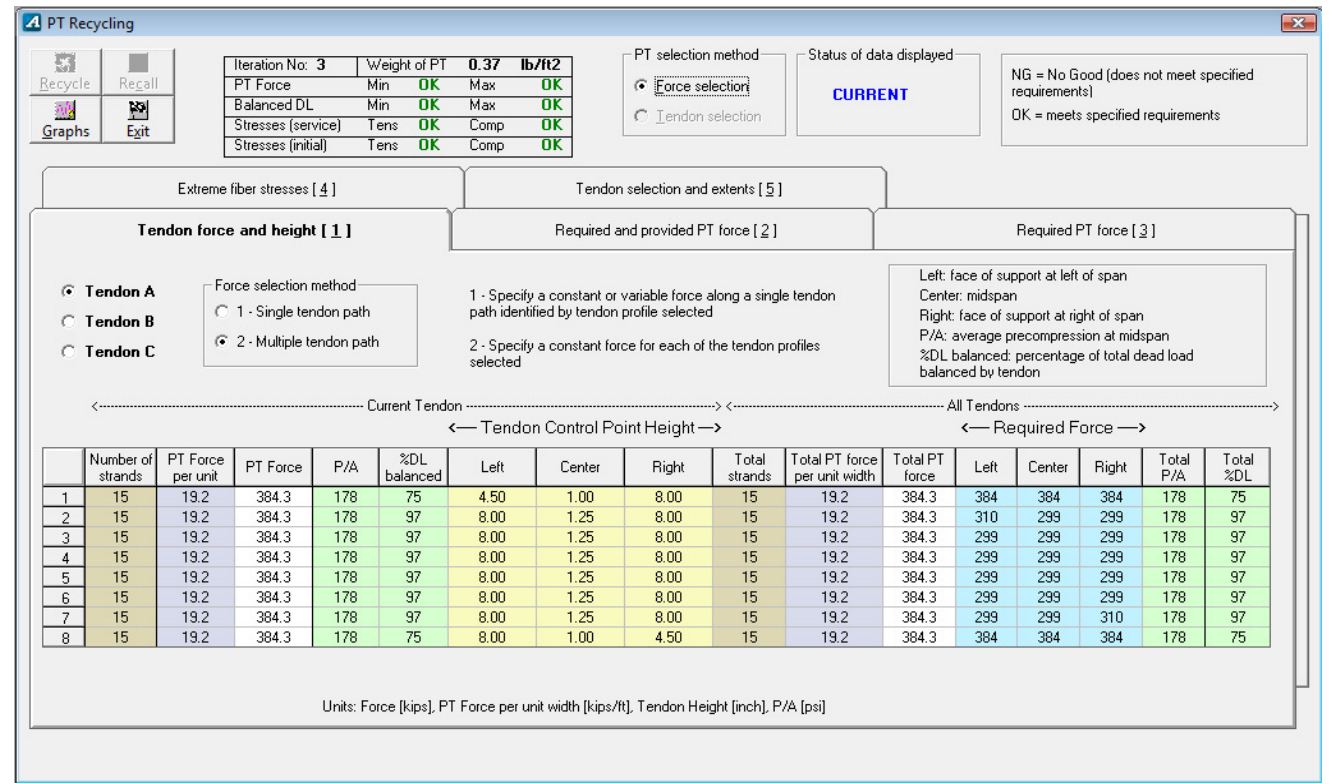


Appendix cxli

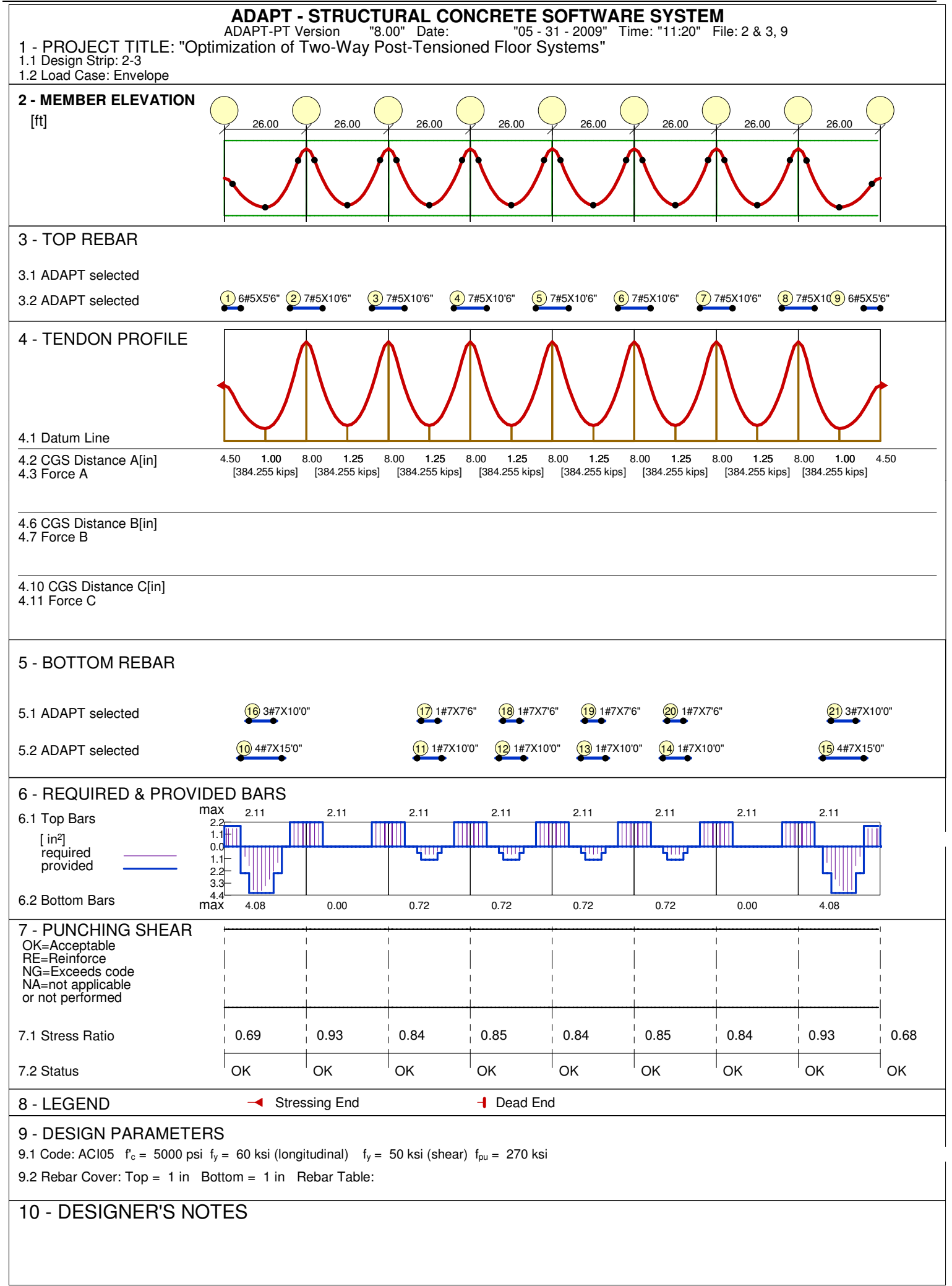




\section{C.12.2 Grids B-H}

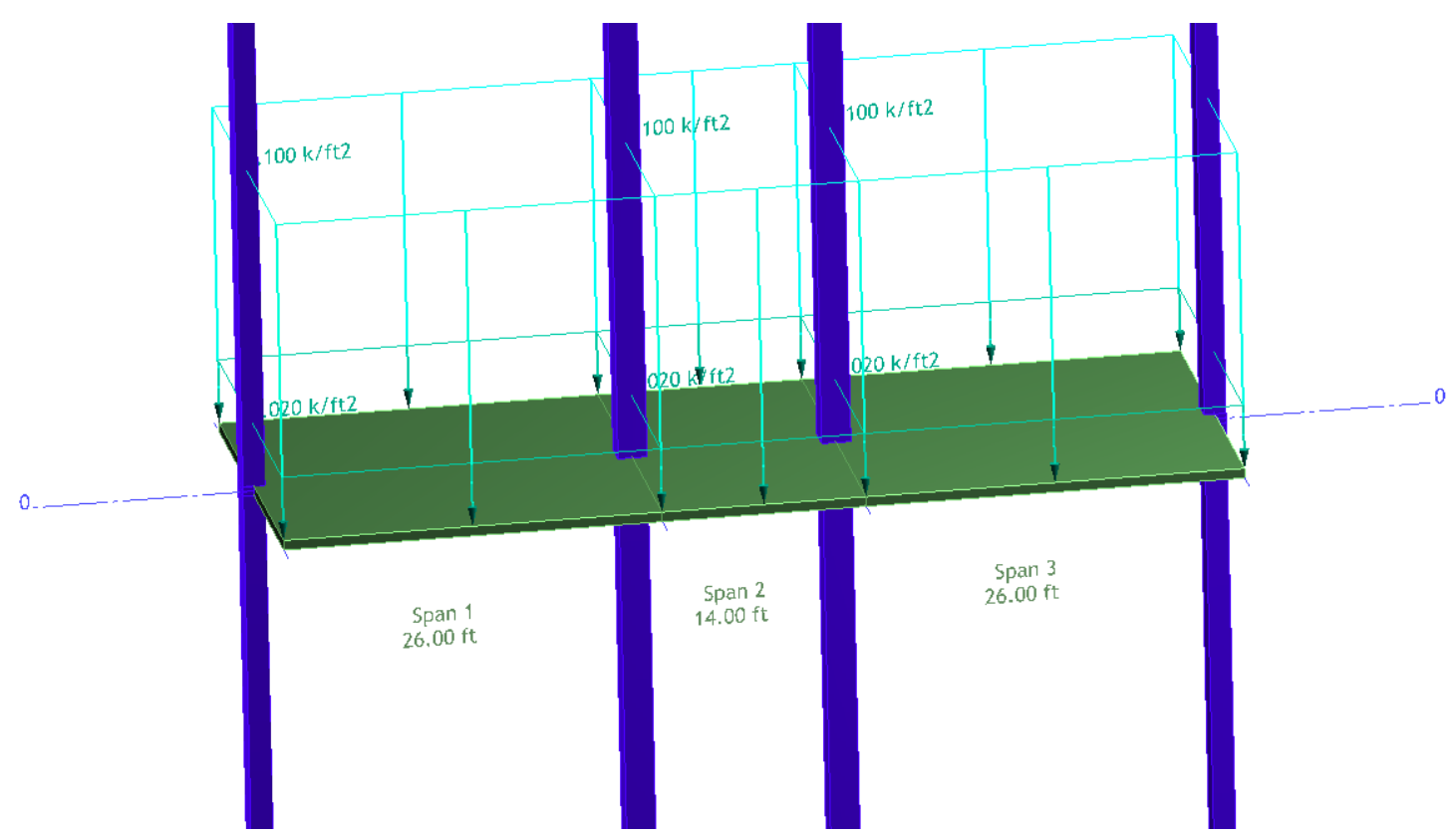

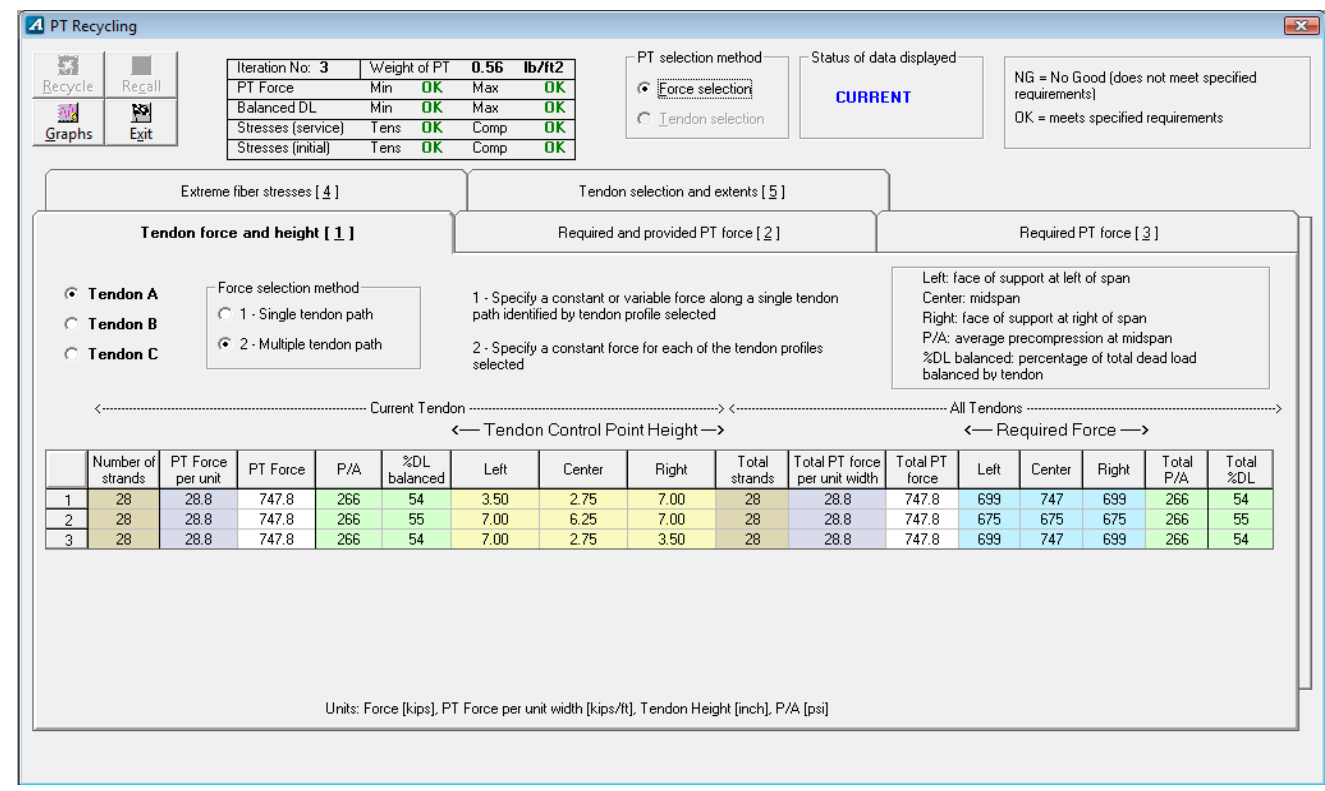


Appendix cxliii

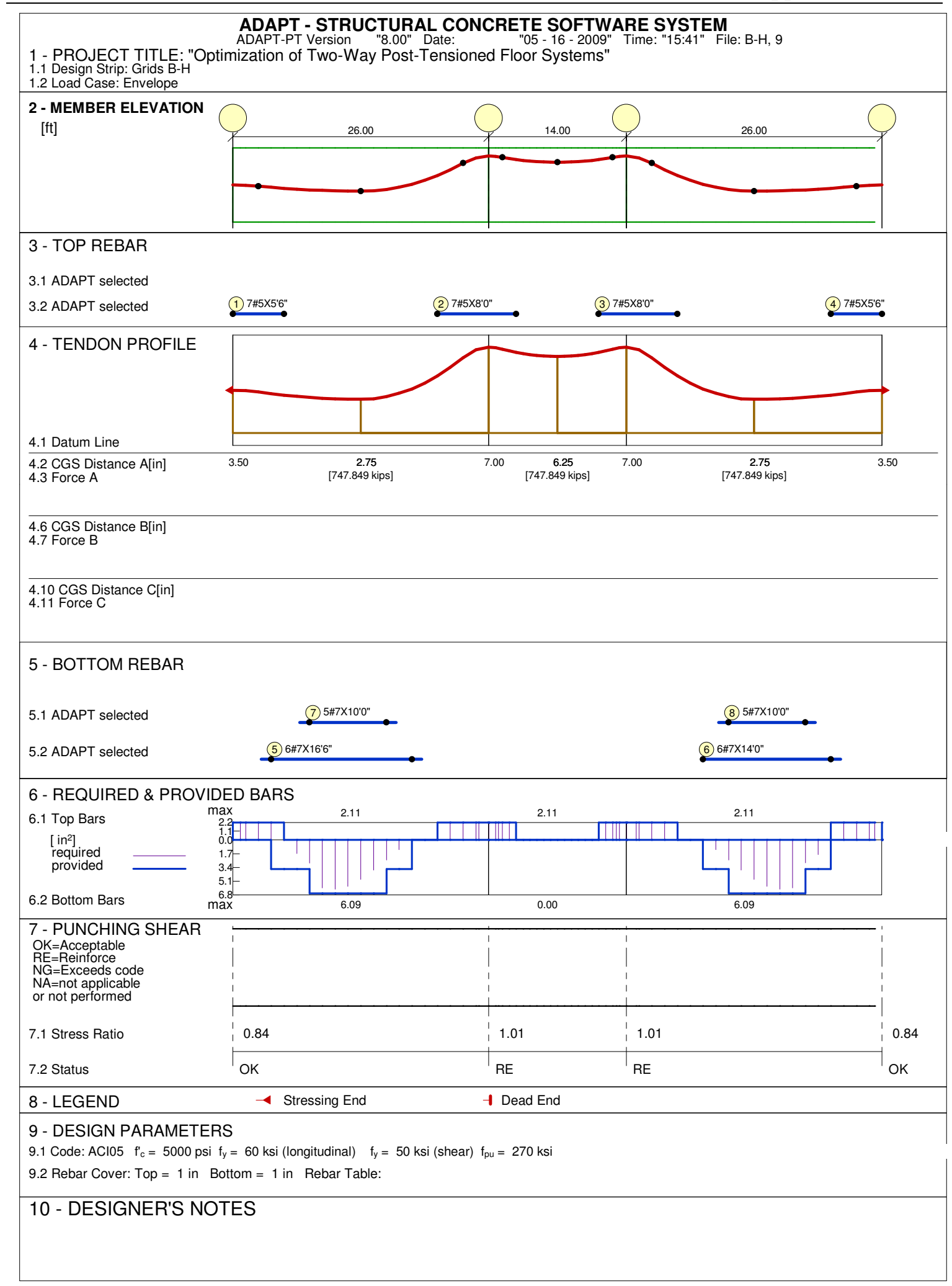

Optimization of Two-Way Post-Tensioned Concrete Floor Systems 
Appendix cxliv

\section{C.13 Slab 8 - ADAPT Default Tendon Profile}

\section{C.13.1 Grids $2 \& 3$}

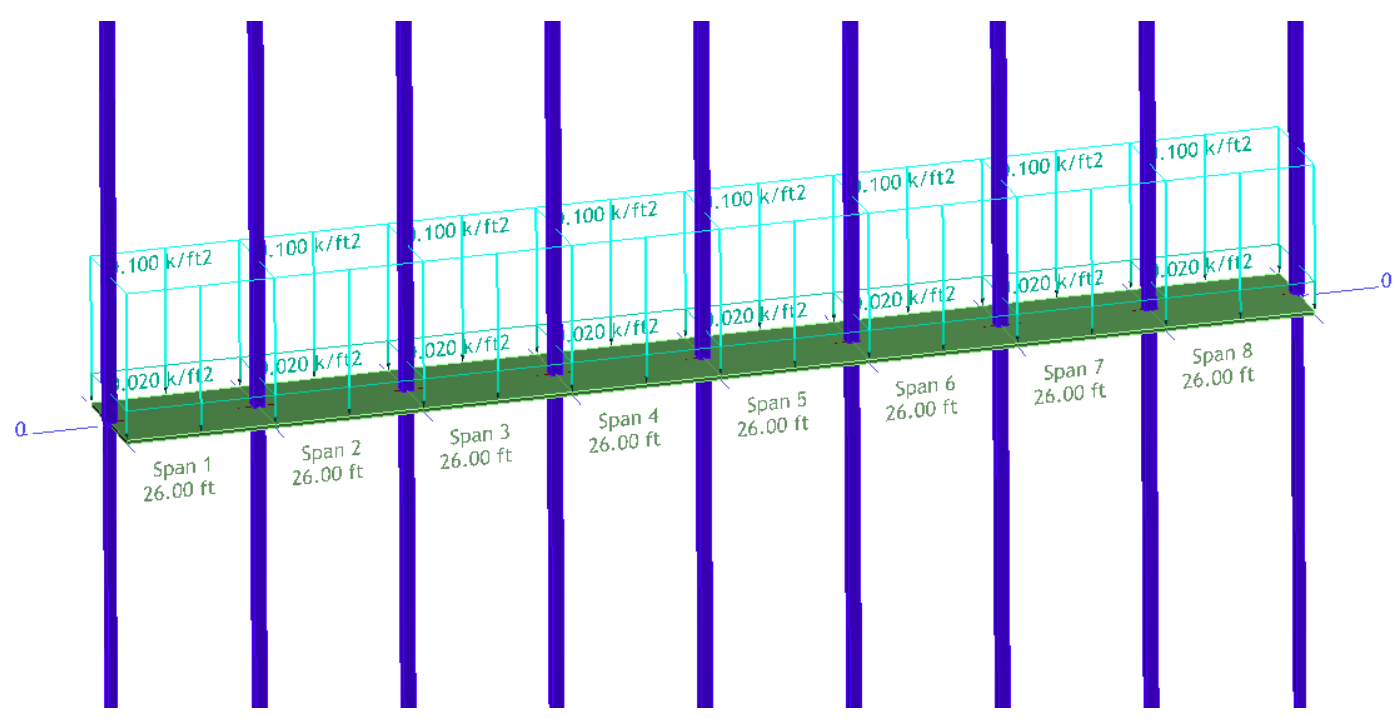

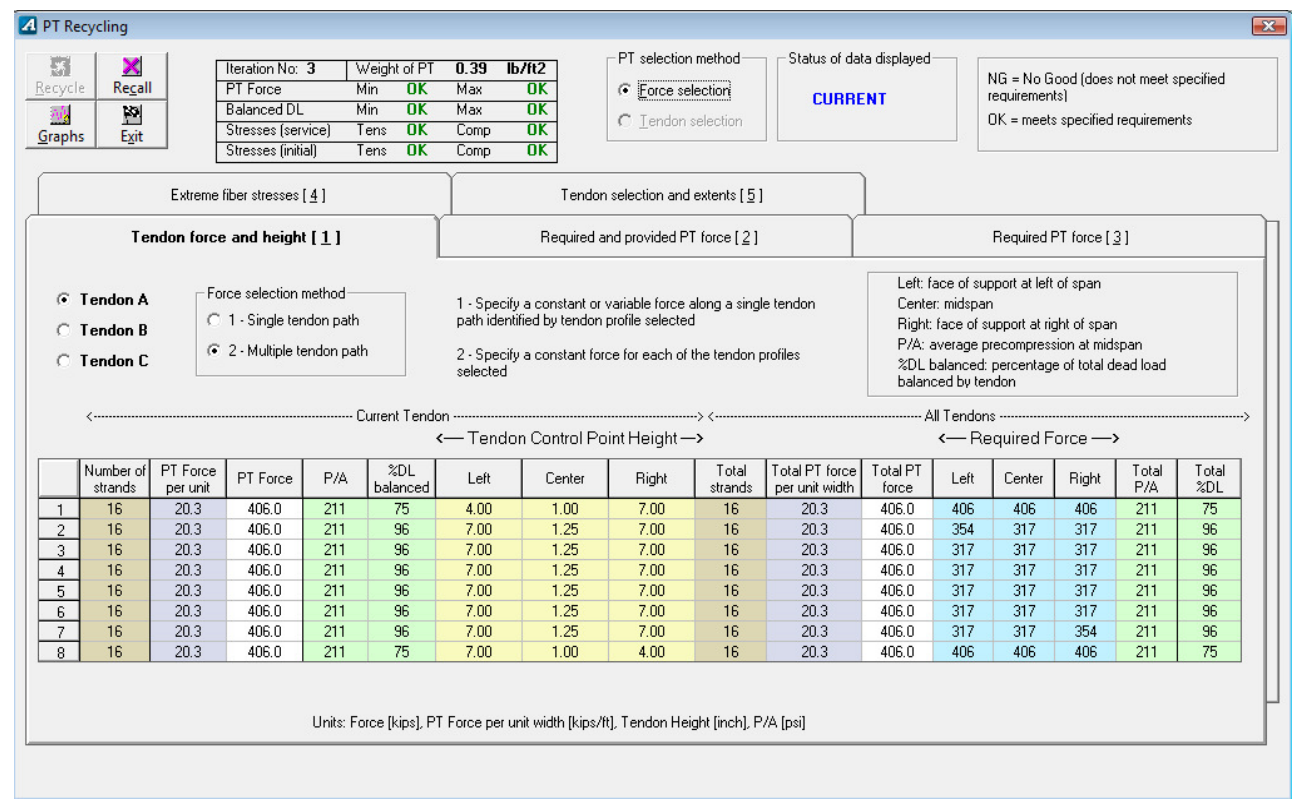

Optimization of Two-Way Post-Tensioned Concrete Floor Systems 
Appendix cxlv

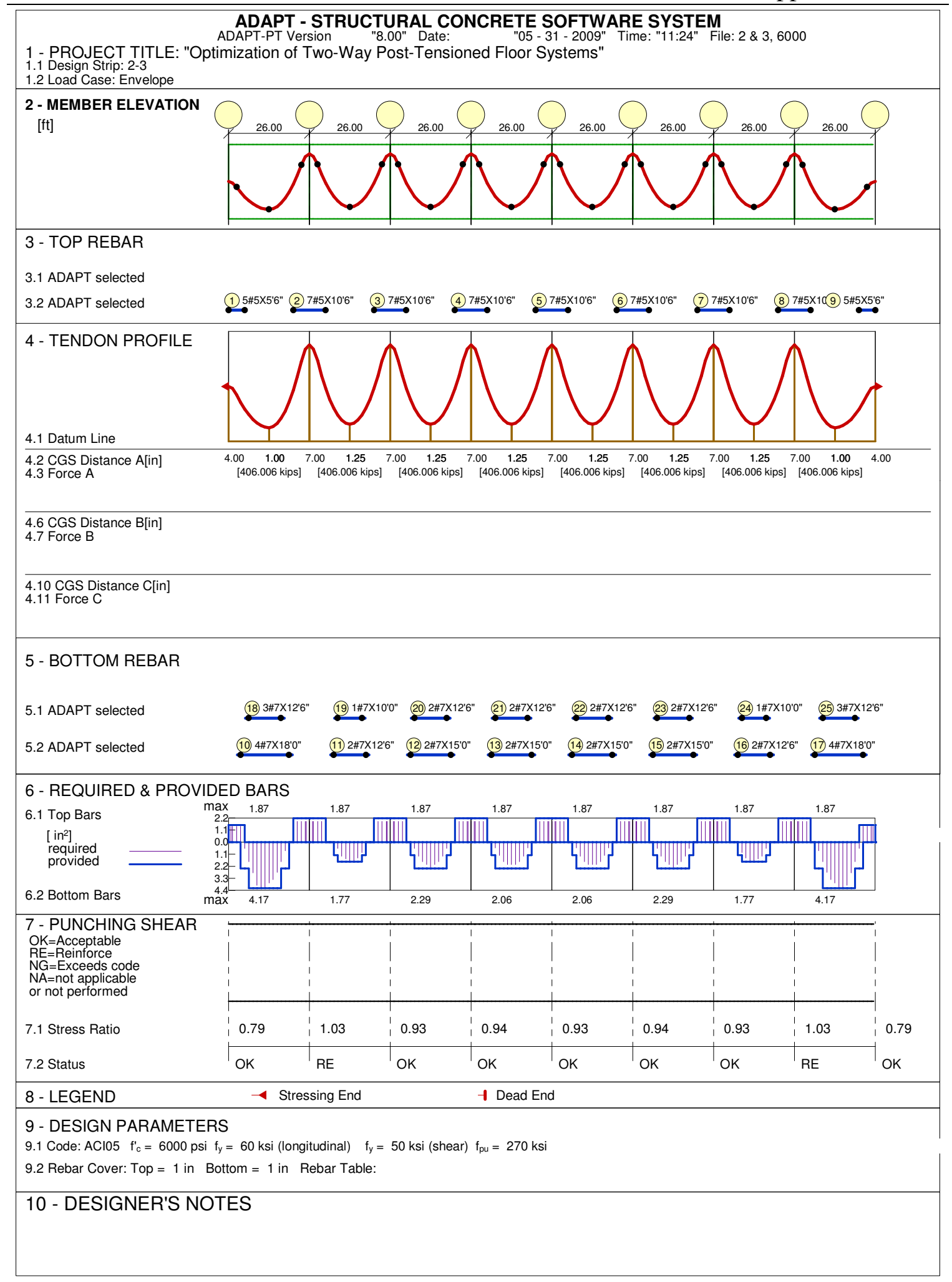




\section{C.13.2 Grids B-H}

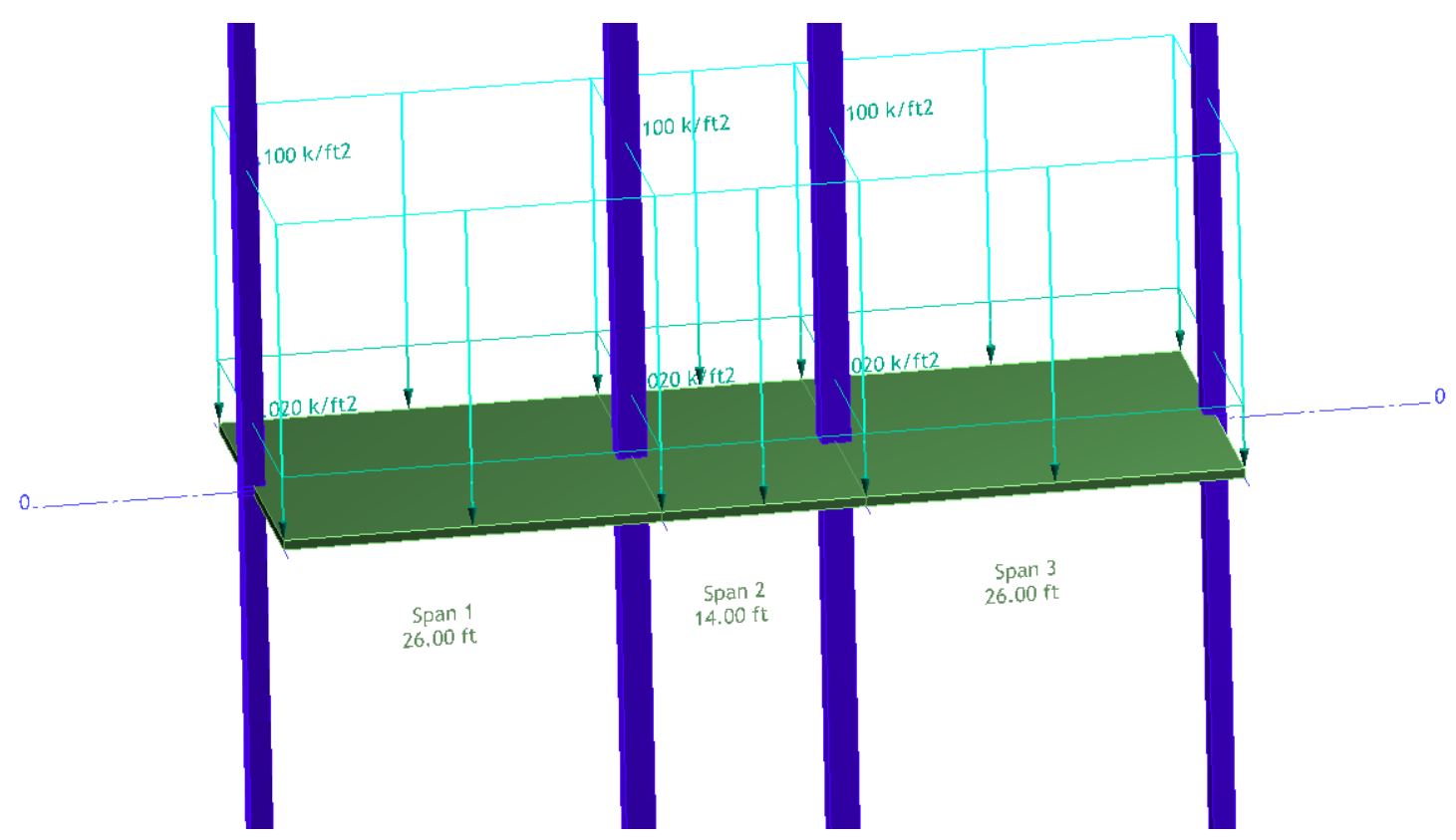

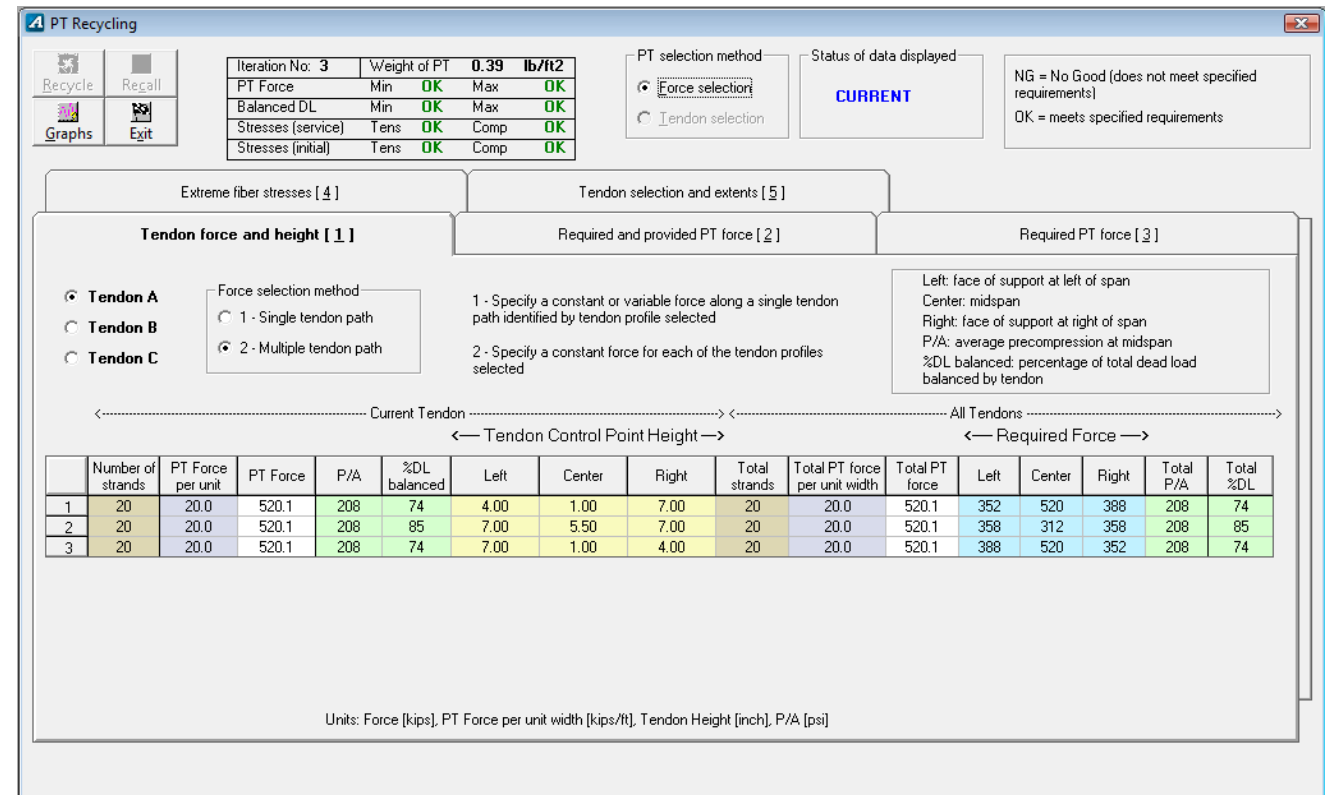


Appendix cxlvii

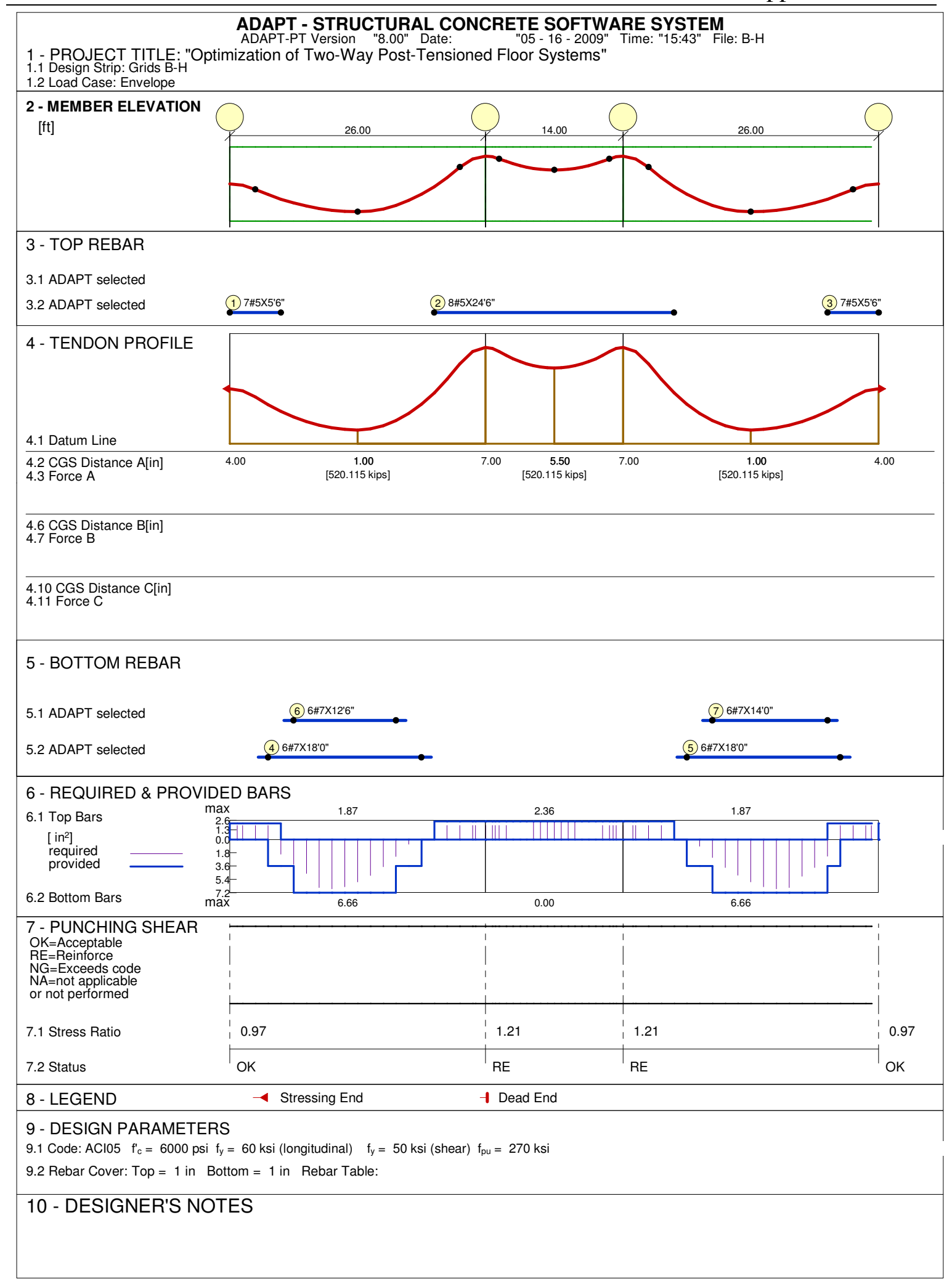

